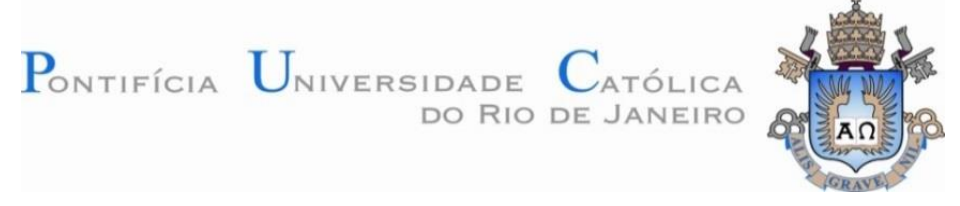

Rafael Magalhães Lyra

Monitoramento e avaliação de desempenho de parques tecnológicos: proposição de um modelo conceitual adaptativo

Dissertação de Mestrado

Dissertação apresentada como requisito parcial para obtenção do título de Mestre pelo Programa de Pós-Graduação em Metrologia (Área de concentração: Metrologia para Qualidade e Inovação) da PUC-Rio.

Orientadora: Prof ${ }^{\mathrm{a}}$ Maria Fatima Ludovico de Almeida 
Rafael Magalhães Lyra

\section{Monitoramento e avaliação de desempenho de parques tecnológicos: proposição de um modelo conceitual adaptativo}

Dissertação apresentada como requisito parcial para obtenção do título de Mestre pelo Programa de Pós-Graduação em Metrologia (Área de concentração: Metrologia para Qualidade e Inovação) da PUC-Rio. Aprovada pela Comissão Examinadora abaixo assinada.

Prof. a Maria Fatima Ludovico de Almeida Orientadora Programa de Pós-Graduação em Metrologia - PUC-Rio

Prof. Carlos Augusto Caldas de Moraes Universidade Candido Mendes - UCAM

Prof.. Maria Angela Campelo de Melo Departamento de Administração - PUC-Rio

Prof. Márcio da Silveira Carvalho Coordenador Setorial do Centro Técnico Científico - PUC-Rio 
Todos os direitos reservados. É proibida a reprodução total ou parcial do trabalho sem autorização da universidade, do autor e de seus orientadores.

\section{Rafael Magalhães Lyra}

Bacharel em Engenharia de Produção pela Universidade Federal Fluminense em 2013. Mestrando do Programa de Pós-Graduação em Metrologia para Qualidade e Inovação da PUC-Rio.

Ficha Catalográfica

Lyra, Rafael Magalhães

Monitoramento e avaliação de desempenho de parques tecnológicos: proposição de um modelo conceitual adaptativo / Rafael Magalhães Lyra; orientadora: Maria Fatima Ludovico de Almeida. - Rio de Janeiro: PUC, 2017.

171 f.: il.; $30 \mathrm{~cm}$

Dissertação (mestrado) - Pontifícia Universidade Católica do Rio de Janeiro, Centro Técnico Científico, Programa de PósGraduação em Metrologia para a Qualidade e Inovação, 2017.

Inclui referências bibliográficas

1. Metrologia - Teses. 2. Parques tecnológicos. 3 Monitoramento e avaliação. 4. Planejamento adaptativo. 5. Indicadores. 6. Métricas. I. Almeida, Maria Fatima Ludovico de. II. Pontifícia Universidade Católica do Rio de Janeiro. Centro Técnico Científico. Programa de Pós-Graduação em Metrologia para a Qualidade e Inovação. III. Título. 
Dedico esta dissertação à minha noiva, Sheila, meus pais, Maria Lucia e Evaldo e minha sogra, Matilde, pelo amor, apoio e confiança. 


\section{Agradecimentos}

À minha noiva, Sheila, que me incentivou, me deu muita força, carinho, amor e compreensão nesta etapa da minha vida. As várias noites em claro em que ela me acompanhava e incentivava até conseguir terminar cada capítulo, eu não teria conseguido se não fosse por ela.

Aos meus pais, Maria Lúcia e Evaldo, que me apoiaram e ajudaram da forma que podiam para que eu concluísse meus estudos e permitiram que eu estivesse aqui, neste momento, realizando um sonho.

À minha sogra, Matilde, que observava minhas dificuldades, estimulava e apoiava a vencê-las sempre. Serei sempre grato aos vários chás noturnos, aos quais ela me oferecia para que eu me acalmasse nos momentos de nervosismo e incertezas.

À minha orientadora, a professora Maria Fatima Ludovico, pela grande paciência que teve comigo, pela amizade, os ensinamentos, não só em sala de aula e orientação, como para toda a vida. E também, pela oportunidade e apoio em trabalhar com pessoas maravilhosas no Pós-MQI e junto ao Instituto Gênesis.

A Julia Zardo, Ruth Espinola e Maurício Guedes pela confiança e auxílio na realização da fase aplicada desta dissertação.

Aos gestores do $1^{\circ}$ Curso para Gestores de Parques Tecnológicos e Ambientes de Inovação (Uni-Anprotec/Instituto Gênesis), pelo comprometimento e espírito de equipe.

Aos professores da Comissão Examinadora, Carlos Augusto Caldas de Moraes e Maria Ângela Campelo de Melo, por disporem de seu tempo e contribuírem de forma significativa para melhoria da versão final desta dissertação.

Ao professor e coordenador do Pós-MQI Carlos Roberto Hall Barbosa, pelos ensinamentos e apoio para apresentações e trabalhos científicos de qualidade. 
Aos demais professores do Pós-MQI pela mais do que valiosa contribuição para a minha formação como Mestre em Metrologia pela Pontifícia Universidade Católica do Rio de Janeiro.

A Paula Molinari e Márcia Ribeiro, da Secretaria do Pós-MQI, pelos seus sorrisos e profissionalismo no atendimento às minhas dúvidas relacionadas ao regimento e normas do Programa de Mestrado.

Aos amigos mestrandos e aos já mestres do Programa Pós-MQI, pelos trabalhos e estudos em grupo, pelo companheirismo e pelas estórias compartilhadas durante nossa breve trajetória juntos.

À Coordenação de Aperfeiçoamento de Pessoal de Nível Superior (Capes) pela concessão da bolsa de estudos, que me permitiu realizar esta pesquisa. 


\section{Resumo}

Lyra, Rafael Magalhães. Almeida, Maria Fatima Ludovico de (Orientadora). Monitoramento e avaliação de desempenho de parques tecnológicos: proposição de um modelo conceitual adaptativo. Rio de Janeiro, 2017. 171 p. Dissertação de Mestrado - Programa de Pós-Graduação em Metrologia. Área de concentração: Metrologia para Qualidade e Inovação, Pontifícia Universidade Católica do Rio de Janeiro.

Destaca-se como um dos principais desafios da gestão de parques tecnológicos a criação de modelos e ferramentas de monitoramento e avaliação de desempenho, que considerem a diversidade de perfis estratégicos e de modelos de negócios desses ambientes de inovação. Na perspectiva de contribuir para o aprimoramento do processo de monitoramento e avaliação de desempenho de parques tecnológicos no Brasil e no exterior, o objetivo da dissertação é desenvolver e aplicar um modelo conceitual para o referido processo, baseado na abordagem de gestão adaptativa, que permita aos gestores definir indicadores e métricas em função de perfis estratégicos e modelos de negócios comuns a determinados agrupamentos de parques. A pesquisa pode ser considerada descritiva, metodológica e aplicada. A partir dos resultados da revisão bibliográfica e documental sobre os temas centrais da pesquisa, desenvolveu-se um modelo conceitual adaptativo para monitoramento e avaliação de desempenho de parques tecnológicos. Visando demonstrar a aplicabilidade desse modelo no contexto de diferentes parques tecnológicos no Brasil e explicitar seus diferenciais metodológicos em comparação a outros modelos reportados na literatura especializada, realizou-se um estudo empírico focalizando a fase de planejamento do modelo junto a 26 participantes do $1^{\circ}$ Curso para Gestores de Parques e Ambientes de Inovação, oferecido pela UniAnprotec, em parceria com o Instituto Gênesis, da PUC-Rio, em 2016. Destacam-se como principais contribuições da pesquisa um modelo conceitual adaptativo para mensuração e avaliação de desempenho de parques tecnológicos e conjuntos de indicadores e métricas associados a diferentes tipos de parques.

\section{Palavras-chave}

Metrologia; parques tecnológicos; monitoramento e avaliação; gestão adaptativa; indicadores e métricas. 


\section{Abstract}

Lyra, Rafael Magalhães; Almeida, Maria Fatima Ludovico de (Advisor). Monitoring and evaluating the performance of science and technology parks: proposal of a conceptual adaptive model. Rio de Janeiro, 2017. 171 p. Dissertação de Mestrado - Programa de Pós-Graduação em Metrologia. Área de concentração: Metrologia para Qualidade e Inovação, Pontifícia Universidade Católica do Rio de Janeiro.

One of the main challenges of managing science and technology parks is the creation of models and tools for monitoring and evaluating their performance, which consider the diversity of strategic profiles and business models of these innovation environments. Aiming to contribute to the improvement of the process of monitoring and evaluating the performance of science and technological parks in Brazil and abroad, the objective of this dissertation is to develop and apply a conceptual model for this process, based on adaptive management approach, which allows managers to establish indicators and metrics according to strategic profiles and business models common to certain groupings of parks. This research can be considered descriptive, methodological and applied. Based on the results provided by the bibliographic and documentary review on the central themes of the research, a conceptual adaptive model for monitoring and evaluating the performance of technology parks was developed. Aiming to demonstrate the applicability of this model in the context of different science and technology parks in Brazil and to explain its methodological differentials compared to other models reported in the specialized literature, an empirical study, focusing on the planning phase of the model, was carried out during 2016 with 26 participants of the 1st Course for Managers of Parks and Environments of Innovation, offered by Uni-Anprotec in partnership with Instituto Gênesis. The main contributions of the research are a flexible model for measuring and evaluating the performance of technological parks and sets of indicators and metrics associated with different types of parks.

\section{Keywords}

Metrology; technology parks; monitoring and evaluation; adaptive management; indicators and metrics. 


\section{Sumário}

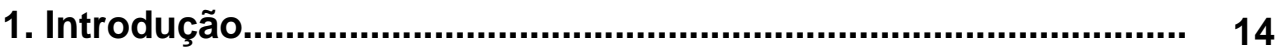

1.1 Definição do problema de pesquisa........................................... 17

1.2 Objetivos: geral e específicos................................................... 18

1.3 Motivação......................................................................... 18

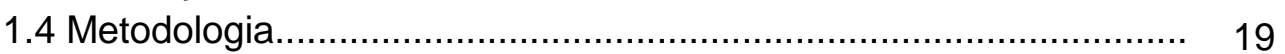

1.4.1 Fase exploratória e descritiva................................................. 20

1.4.2 Fase aplicada................................................................ 21

1.4.3 Fase conclusivo-propositiva..................................................... 21

1.5 Estrutura da dissertação........................................................ 22

2. Parques tecnológicos: conceituação e desafios......................... 23

2.1 Papel dos parques tecnológicos para o desenvolvimento regional.. 25

2.2 Experiências bem-sucedidas de parques tecnológicos no exterior

2.3 Experiências bem-sucedidas de parques tecnológicos nacionais.

2.4 Taxonomias de parques tecnológicos....................................... 33

2.4.1.Taxonomia de Escorsa e Valls................................................ 34

2.4.2. Taxonomia de gerações de parques tecnológicos .................... 35

2.4.3.Taxonomia da Anprotec....................................................... 37

2.4.4.Taxonomia de Kaczmarska e Gierulski................................... 40

2.5 Desafios atuais de gestão de parques tecnológicos....................... 41

2.6 Considerações finais sobre o capítulo........................................ 42

3. Monitoramento e avaliação de desempenho de parques tecnológicos..........................................................................

3.1 Conceitos básicos de monitoramento e avaliação de desempenho................................................................................. 43

3.2 Monitoramento e avaliação de desempenho como parte do ciclo de gestão de parques tecnológicos.

3.3 Modelos de monitoramento e avaliação de desempenho de parques tecnológicos: métodos e ferramentas adotadas.............. 47

3.4 Análise crítica dos modelos reportados nos estudos 53 empíricos.

4. Modelo conceitual adaptativo de monitoramento e avaliação do desempenho de parques tecnológicos.

4.1 A abordagem de gestão adaptativa aplicada a parques tecnológicos.

4.2 Descrição da fase de planejamento e de suas características adaptativas

4.2.1.Contextualização do parque tecnológico 
4.2.2. Caracterização das partes interessadas e seus objetivos em relação ao parque tecnológico

4.2.3 Análise do perfil estratégico do parque tecnológico: uso da ferramenta 'Estrategigrama' da IASP.

4.2.4. Modelo de negócio do parque tecnológico: uso da ferramenta Canvas.

4.2.5 Análise do estágio de desenvolvimento do parque tecnológico... 70

4.2.6 Classificação do parque tecnológico, segundo taxonomia de escolha

4.2.7 Definição do quadro lógico para definição de indicadores de desempenho de parques tecnológicos.

4.2.8 Proposição de indicadores e métricas de monitoramento e avaliação de desempenho do parque tecnológico

4.3 Fase de ação.

4.4 Fase de avaliação de resultados e impactos ................................ 72

4.5 Considerações finais sobre o capítulo.......................................... 73

5. Validação empírica do modelo conceitual adaptativo: foco na fase de planejamento.

5.1 Contexto de aplicação do modelo: Parques Tecnológicos do Brasil.

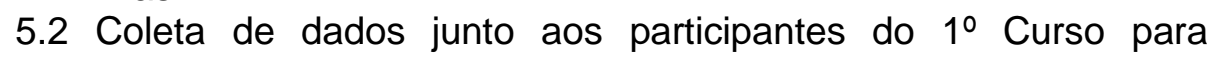
Gestores de Parques Tecnológicos e Ambientes de Inovação...

5.2.1 1 a Oficina de Trabalho - Rio de Janeiro

5.2.2 Tutorias a distância.

5.2.3 $2^{\text {a }}$ Oficina de Trabalho - Recife...

5.2.4 Coleta de dados nos sites institucionais dos parques tecnológicos.

5.3 Discussão dos resultados. 79

5.3.1 Parque Tecnológico Ulbratech.....

5.3.2 Parque Tecnológico de Santa Rita do Sapucaí......

5.3.3 Órion Parque Tecnológico da Serra Catarinense

5.3.4 Parque Tecnológico da Bahia..

5.3.5 ParqTec FB.

5.4 Discussão integrada dos resultados e conclusões do estudo empírico.

6. Conclusões e recomendações 


\section{Lista de Figuras}

Figura 1.1 - Desenho da pesquisa, seus componentes e métodos..... 19

Figura 2.1 - Padrões de parques tecnológicos segundo Escorsa e

Valls.

Figura 2.2 - Taxonomia Anprotec para classificação de parques tecnológicos no Brasil...

Figura 2.3 - Matriz de avaliação e classificação de parques

tecnológicos segundo taxonomia Kaczmarska e Gierulski.

Figura 3.1 - Modelo de avaliação de parques tecnológicos segundo

Guy.

Figura 4.1 - Aprendizagem organizacional segundo Argyris e Schön

Figura 4.2 - Modelo conceitual para monitoramento e avaliação de desempenho de parques tecnológicos, segundo a abordagem de gestão adaptativa.

Figura 4.3 - Estrutura da ferramenta "Estrategigrama" proposta pela IASP

Figura 4.4 - Ferramenta Canvas customizada para a modelagem de negócios de parques tecnológicos.

Figura 5.1 - Metodologia geral adotada na condução das Oficinas do 1 Curso para Gestores de Parques Tecnológicos e Ambientes de Inovação (Uni-Anrotec/instituto Gênesis).

Figura 5.2 - Perfil estratégico atual do Parque Tecnológico Ultratech....

Figura 5.3 - Evolução do perfil estratégico do Parque Tecnológico Ulbratech: curto, médio e longo prazo.

Figura 5.4 - Posicionamento atual do Parque Tecnológico Ulbratech segundo a taxonomia da Anprotec.

Figura 5.5 - Estratégia de crescimento do Parque Tecnológico

Ulbratech: curto, médio e longo prazo.

Figura 5.6 - Perfil estratégico atual do Parque Tecnológico de Santa Rita do Sapucaí.....

Figura 5.7 - Evolução do perfil estratégico do Parque Tecnológico de Santa Rita do Sapucaí: curto, médio e longo prazo.

Figura 5.8 - Posicionamento atual do Parque Tecnológico Santa Rita do Sapucaí.

Figura 5.9 - Estratégia de crescimento do Parque Tecnológico de

Santa Rita do Sapucaí: curto, médio e longo prazo.

Figura 5.10 - Perfil estratégico atual do Órion Parque Tecnológico.....

Figura 5.11 - Evolução do perfil estratégico do Órion Parque

Tecnológico: curto, médio e longo prazo.

Figura 5.12 - Posicionamento atual do Órion Parque Tecnológico......

Figura 5.13 - Estratégia de crescimento do Órion Parque Tecnológico: curto, médio e longo prazo. 
Figura 5.14 - Perfil estratégico atual do Parque Tecnológico da Bahia 123

Figura 5.15 - Evolução do perfil estratégico do Parque Tecnológico da

Bahia: curto, médio e longo prazo.....

Figura 5.16 - Posicionamento atual do Parque Tecnológico da Bahia

segundo a taxonomia da Anprotec....

Figura 5.17 - Estratégia de crescimento do Parque Tecnológico da

Bahia: curto, médio e longo prazo.....

Figura 5.18 - Perfil estratégico atual do ParqTec FB.

Figura 5.19 - Evolução do perfil estratégico do ParqTec FB: curto, médio e longo prazo

Figura 5.20 - Posicionamento atual do ParqTec FB na taxonomia Anprotec.

Figura 5.21 - Estratégia de crescimento do ParqTec FB: curto, médio e longo prazo

Figura 5.22 - Perfis estratégicos atuais dos Parques Tecnológicos:

visão comparativa.

Figura 5.23 - Estratégias de crescimento dos Parques Tecnológicos:

curto, médio e longo prazo

Figura 5.24 - Perfis estratégicos dos Parques Tecnológicos no longo prazo (10 anos).

\section{Lista de Tabelas}

Tabela 2.1 - Número de parques tecnológicos no Brasil: 2013

Tabela 2.2 - Número de empresas e empregados nos parques tecnológicos no Brasil: 2008 e 2013.

Tabela 2.3 - Evolução do número de parques tecnológicos no Brasil: período 2008 e 2013.

Tabela 2.4 - Investimento nos parques tecnológicos no Brasil: 2013 


\section{Lista de Quadros}

Quadro 2.1 - Principais definições de parques científicos e tecnológicos.

Quadro 2.2 - Principais stakeholders dos parques tecnológicos e

focos de interesse.

Quadro 2.3 - Melhores práticas de parques tecnológicos no

exterior.....

Quadro 2.4 - Avaliação de parques tecnológicos brasileiros segundo metodologia da Fundação Certi.

Quadro 2.5 - Categorias de parques tecnológicos e fatores de sucesso.

Quadro 3.1 - Esquema básico para construção do quadro lógico da atuação de um parque tecnológico

Quadro 3.2 - Variáveis e indicadores- chave de desempenho de parques tecnológicos, segundo Hogan

Quadro 3.3 - Quadro-síntese dos modelos adotados nos estudos empíricos.

Quadro 4.1 - Estrutura para a modelagem de parques tecnológicos:

definição dos componentes

Quadro 5.1 - Partes interessadas e seus objetivos em relação ao

Parque Tecnológico Ulbratech.

Quadro 5.2 - Quadro lógico para a proposição de indicadores e métricas de monitoramento e avaliação de desempenho do Parque Tecnológico Ulbratech....

Quadro 5.3 - Partes interessadas e seus objetivos em relação ao

Parque Tecnológico Aberto de Santa Rita do Sapucaí.

Quadro 5.4 - Quadro lógico para a proposição de indicadores e métricas de monitoramento e avaliação de desempenho do Parque Tecnológico de Santa Rita do Sapucaí.....

Quadro 5.5 - Partes interessadas do Órion Parque Tecnológico e seus interesses individuais.

Quadro 5.6 - Quadro lógico para a proposição de indicadores e métricas de monitoramento e avaliação de desempenho do Órion Parque Tecnológico.

Quadro 5.7 - Partes interessadas e seus objetivos em relação ao

Parque Tecnológico da Bahia.

Quadro 5.8 - Quadro lógico para a proposição de indicadores e métricas de monitoramento e avaliação de desempenho do Parque Tecnológico da Bahia.

Quadro 5.9 - Partes interessadas e seus objetivos em relação ao ParqTec FB.

Quadro 5.10 - Quadro lógico para a proposição de indicadores e métricas de monitoramento e avaliação de desempenho do ParqTec FB.

Quadro 5.11 - Estágio de desenvolvimento dos parques tecnológicos abordados no estudo empírico. 


\section{1 \\ Introdução}

Os parques tecnológicos são considerados empreendimentos de grande importância para o desenvolvimento tecnológico e econômico das regiões onde se localizam, por promoverem a geração de inovações, a transferência de tecnologia entre as instituições e empresas residentes e novos empregos, além de aumentar a competitividade de empresas locais frente às exigências do mercado global (Allen, 2007; European Commission, 2013; Magalhães e Zouain, 2009; Ratinho e Henriques, 2010; Steiner, Cassim e Robazzi, 2008).

A International Association of Science Parks and Areas of Innovation IASP, entidade mundial representativa dos parques científicos e tecnológicos, define um parque tecnológico da seguinte forma:

“Organização administrada por profissionais especializados, cujo principal objetivo é aumentar a riqueza da comunidade, através da promoção da cultura da inovação e da competitividade das empresas e instituições baseadas no conhecimento que lhe estão associadas. Para alcançar esse objetivo maior, um parque tecnológico deve estimular e gerenciar o fluxo de conhecimento e de tecnologias entre universidades, instituições de $\mathrm{P} \& \mathrm{D}$, empresas e mercados; facilitar a criação e o crescimento de empresas de base tecnológica, através de processos de incubação e de spin-offs e fornecer outros serviços de valor agregado, bem como espaços e instalações de alta qualidade" (IASP, 2016).

Neste sentido, os parques tecnológicos podem ser entendidos como complexos de desenvolvimento econômico e tecnológico, que visam fomentar economias baseadas no conhecimento, por meio da integração das atividades de pesquisa, desenvolvimento e inovação (PD\&I), de empresas e organizações governamentais em um local físico. Suas entidades gestoras dão suporte às interrelações entre estes grupos. Os parques são formalmente ligados (e usualmente fisicamente próximos) a centros de excelência tecnológica, universidades ou centros de pesquisa (IASP, 2016).

Ainda segundo a IASP, o principal objetivo de um parque científico e tecnológico é aumentar a riqueza da comunidade, através da promoção da cultura da inovação e da competitividade das empresas e instituições baseadas no 
conhecimento, que lhe estão associadas. Para alcançar esse objetivo maior, um Parque Tecnológico deve estimular e gerenciar o fluxo de conhecimento e de tecnologias entre universidades, instituições de P\&D, empresas e mercados; facilitar a criação e o crescimento de empresas de base tecnológica, através da incubação e de processos de spinoffs universitárias, e fornecer outros serviços de valor agregado, bem como espaços e instalações de elevada qualidade.

No Brasil, a Anprotec (2016) adota uma definição similar:

"Parque Tecnológico é um complexo produtivo industrial e de serviços de base científico-tecnológica, planejado, de caráter formal, concentrado e cooperativo, que agrega empresas, cuja produção se baseia em pesquisa tecnológica desenvolvida nos centros de $\mathrm{P} \& \mathrm{D}$ vinculados ao parque. Tratase de um empreendimento promotor da cultura da inovação, da competitividade, do aumento da capacitação empresarial, fundamentado na transferência de conhecimento e tecnologia, com o objetivo de incrementar a produção de riqueza de uma região" (Anprotec, 2016).

O novo marco legal da inovação, conhecido como Código de Ciência, Tecnologia e Inovação (CT\&I), aprovado em 11 de janeiro de 2016, também estabelece uma definição para Parques Tecnológicos. Segundo a Lei 13.243/2016:

"Parque Tecnológico é um complexo planejado de desenvolvimento empresarial e tecnológico, promotor da cultura de inovação, da competitividade industrial, da capacitação empresarial e da produção de sinergias em atividades de pesquisa científica, de desenvolvimento tecnológico e de inovação entre empresas e uma ou mais Instituições de Ciência e Tecnologia (ICTs), com ou sem vínculo entre si” (Brasil, 2016).

Complementando a definição acima, de acordo com a referida Lei, as ICTs são órgãos ou entidades da administração pública, direta ou indireta, ou pessoas jurídicas de direito privado sem fins lucrativos, legalmente constituídas sob as leis brasileiras, com sede e foro no país, que incluam em sua missão institucional os objetivos social ou estatutário, entre outros, a pesquisa básica ou aplicada de caráter científico ou tecnológico, ou o desenvolvimento de novos produtos, serviços ou processos (Brasil, 2016).

A Lei distingue os conceitos de parque tecnológico e polo tecnológico, sendo o último definido como um ambiente industrial e tecnológico caracterizado pela presença dominante de micro, pequenas e médias empresas com áreas correlatas de atuação em determinado espaço geográfico, com vínculos operacionais com ICTs, recursos humanos, laboratórios e equipamentos 
organizados e com predisposição ao intercâmbio entre os entes envolvidos para consolidação, marketing e comercialização de novas tecnologias (Brasil, 2016).

Wang, Wan e Zhao (2014) descrevem os parques tecnológicos como organizações em rede, tendo como um de seus objetivos aprimorar a competitividade das empresas residentes e que, para tanto, necessitam desenvolver modelos de avaliação eficientes para exercerem não só essa função, mas seus principais objetivos já estabelecidos em fase de projeto.

A partir dos trabalhos de Etzkowitz e Leydesdorff (1995; 2000), desenvolveu-se o conceito da hélice tríplice como um modelo de atuação da maioria dos parques tecnológicos abordados na presente pesquisa. Esse conceito associa-se a uma nova visão do papel desempenhado na sociedade pelas instituições científicas, tecnológicas e de inovação (ICTs), incluindo as universidades.

De acordo com Etzkowitz e Leydesdorff (1995; 2000), os processos de aprendizagem, aquisição e desenvolvimento de conhecimento nos parques tecnológicos são realizados segundo uma perspectiva dinâmica, em que as ICTs têm um papel proeminente. Assim, em ambientes que promovam a inovação, como os parques tecnológicos, empresas iniciantes de base tecnológica (startups), incubadoras, aceleradoras, Núcleos de Inovação Tecnológica - NIT, laboratórios e centros de PD\&I podem se articular em rede com agências de fomento, fundações de amparo à pesquisa e outras instituições públicas e privadas com o objetivo maior de transformar conhecimento em riqueza e promover o desenvolvimento regional sustentável.

A Anprotec destaca ainda que os parques tecnológicos beneficiam os empreendimentos neles localizados - além da região e da economia como um todo - por gerarem um ambiente de cooperação entre empresas inovadoras e instituições científicas, tecnológicas e de inovação. Oferecem serviços de alto valor agregado às empresas, facilitam o fluxo de conhecimento e tecnologia, possibilitam a geração de empregos qualificados e o aumento da cultura e da atividade empreendedora. Além disso, favorecem a formação de clusters de inovação e o aumento da competitividade das regiões onde estão localizados (Anprotec, 2016). 
Devido ao alto grau de complexidade e incerteza dos contextos institucionais em que atuam os parques, não existe um parque tecnológico similar a outro, sendo que cada empreendimento possui sua própria missão e prioridades relacionadas aos interesses de seus stakeholders. A partir da visão estratégica, definem-se metas e objetivos a serem alcançados, os serviços que prestarão a empresas e instituições residentes e áreas ou setores em que irão atuar (European Commission, 2013).

Nessa perspectiva, Phan, Siegel e Wright (2005) referem-se ao desafio de se estabelecer um modelo para monitoramento e avaliação do desempenho de parques tecnológicos, devido exatamente à diversidade de seus objetivos, modelos de negócio e perfis estratégicos.

Ao se levar em consideração esse problema e as diferentes perspectivas de sucesso entre os diversos parques tecnológicos no mundo, destaca-se como uma oportunidade de pesquisa neste campo a criação de ferramentas de monitoramento e avaliação de desempenho de parques, que considerem a diversidade de perfis estratégicos e de modelos de negócios desses ambientes de inovação.

\section{1}

\section{Definição do problema de pesquisa}

Considerando-se a complexidade (ou até a impossibilidade) de se definir um método único e generalizado para o monitoramento e avaliação de desempenho de parques tecnológicos, busca-se nesta dissertação contribuir para o aprimoramento desse processo no Brasil e no exterior. Como mencionado, cada parque tecnológico é diferente do outro, visto que possuem objetivos e metas particulares a serem alcançadas em função dos interesses de seus múltiplos stakeholders, de seus perfis estratégicos, modelos de negócio e estágios de desenvolvimento em que se encontram.

Identificou-se, já na fase exploratória desta pesquisa, a necessidade de se dispor de um ferramental desenvolvido segundo uma perspectiva que associasse os diferentes tipos de parque tecnológicos, gerando-se frameworks de medição personalizados para grupos de parques tecnológicos com características, objetivos estratégicos e metas similares. Outra característica a ser considerada no desenvolvimento desse ferramental é permitir que os gestores, com base nos resultados das atividades de monitoramento e avaliação, possam adotar uma 
postura proativa, adaptando-se a possíveis mudanças do ambiente externo e interno, tendo em vista o cumprimento da missão do parque.

A partir desse entendimento, definiu-se a seguinte questão de pesquisa:

"Como monitorar e mensurar o desempenho de parques tecnológicos, levando-se em conta a diversidade de seus perfis estratégicos e modelos de negócio e a complexidade e incerteza inerentes aos contextos institucionais em que atuam?"

\section{2 \\ Objetivos: geral e específicos}

Esta pesquisa tem por objetivo desenvolver e aplicar um modelo conceitual adaptativo para monitorar e mensurar o desempenho de parques tecnológicos, que permita aos gestores definir indicadores e métricas em função de perfis estratégicos e modelos de negócios comuns a determinados agrupamentos de parques e adaptar-se a possíveis mudanças do ambiente externo e interno. Em termos específicos, a presente dissertação busca:

- Apresentar e discutir os conceitos de parques tecnológicos, destacandose sua importância para o desenvolvimento regional;

- Discutir a importância de se monitorar e avaliar o desempenho de parques tecnológicos como parte fundamental do ciclo de gestão dessas instituições;

- Analisar modelos de monitoramento e avaliação de desempenho de parques tecnológicos, reportados em estudos empíricos;

- Propor um modelo conceitual adaptativo de monitoramento e mensuração do desempenho de parques tecnológicos, levando-se em conta perfis estratégicos e modelos de negócios comuns a determinados agrupamentos de parques;

- Demonstrar a aplicabilidade do referido modelo no contexto de diferentes parques tecnológicos no Brasil e explicitar seus diferenciais metodológicos em comparação a outros modelos reportados na literatura especializada.

\section{3}

\section{Motivação}

Os impactos técnicos e científicos desta pesquisa referem-se ao avanço do conhecimento sobre monitoramento e avaliação de parques tecnológicos, com o auxílio de um modelo adaptativo, que integra ferramentas de avaliação e gestão de ambientes de inovação e de programas. Com base no modelo proposto, sugeremse indicadores e métricas para os parques abordados na fase aplicada da pesquisa. 
Além do potencial de aproveitamento dos resultados desta dissertação por gestores de parques no Brasil e no exterior, um dos fatores que influenciaram positivamente a escolha deste tema foi a oportunidade oferecida pelo Instituto Genesis da Pontifícia Universidade Católica do Rio de Janeiro (PUC-Rio), de realizar o estudo empírico para validação do modelo conceitual junto a 26 participantes do $1^{\circ}$ Curso para Gestores de Parques e Ambientes de Inovação, oferecido pela Uni-Anprotec, em parceria com o Instituto Gênesis, da PUC-Rio.

\section{4 \\ Metodologia}

A Figura 1.1 representa graficamente as fases de desenvolvimento da pesquisa, a saber: (i) exploratória e descritiva; (ii) pesquisa aplicada; (iii) conclusivo-propositiva.
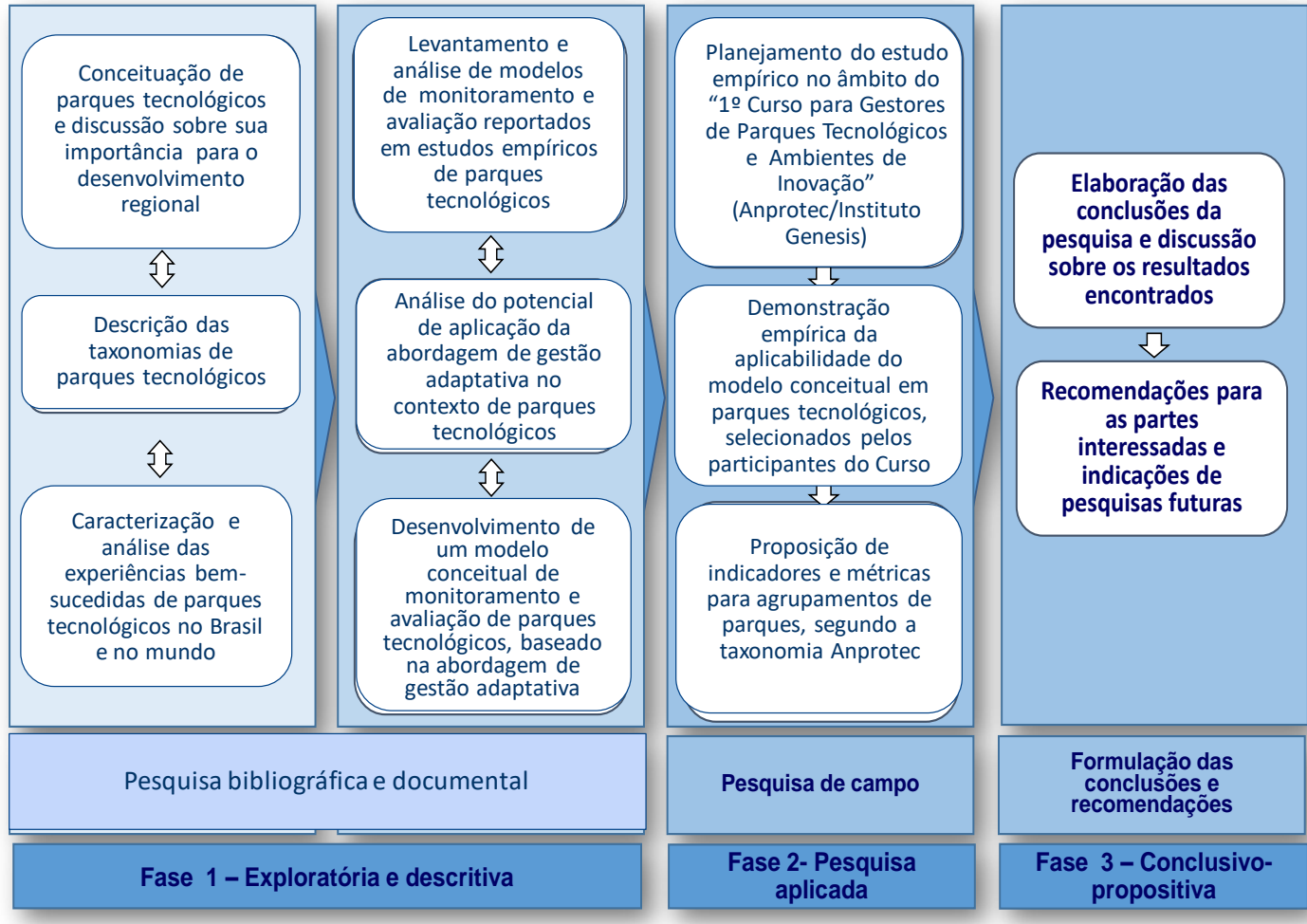

Figura 1.1 - Desenho da pesquisa, seus componentes e métodos Fonte: Elaboração própria.

A seguir, detalha-se o desenvolvimento e os resultados esperados de cada fase, em alinhamento com os objetivos enunciados na seção 1.2 deste capítulo. 


\subsection{1.}

\section{Fase exploratória e descritiva}

A fase exploratória e descritiva iniciou-se com uma pesquisa bibliográfica em bases de dados internacionais - Scopus, Web of Science, ScienceDirect, dentre outras - com o objetivo de identificar e selecionar trabalhos acadêmicos e documentos de referência para delimitar o escopo da pesquisa e definir seus objetivos específicos.

Em seguida, identificaram-se na literatura estudos empíricos realizados sobre monitoramento e avaliação de desempenho de parques tecnológicos nacionais e internacionais. Buscou-se, identificar e analisar as abordagens metodológicas utilizadas nesses estudos empíricos, particularmente os modelos e ferramentas reportadas nesses estudos.

A análise das abordagens metodológicas e ferramentas de monitoramento e avaliação do desempenho de parques tecnológicos, reportadas nos estudos empíricos, indicou a oportunidade de se desenvolver um modelo conceitual segundo uma perspectiva que associasse os diferentes tipos de parque tecnológicos, gerando-se frameworks de medição personalizados para grupos de parques tecnológicos com características, objetivos estratégicos e metas similares.

Avaliou-se então o potencial de aplicação da abordagem de gestão adaptativa na modelagem pretendida, tendo como ponto de partida a revisão bibliográfica sobre essa abordagem, com destaque para os trabalhos de Melo (1985; 1986; 2002); Almeida (2006); Melo e Agostinho (2007); e a tese de Alvarez (1997), intitulada "Processos de planejamento nos pólos tecnológicos: um enfoque adaptativo".

Ainda nesta fase, um modelo conceitual de monitoramento e avaliação de desempenho de parques tecnológicos foi proposto, baseando-se na abordagem de gestão adaptativa e levando-se em consideração perfis estratégicos e modelos de negócios comuns a determinados agrupamentos de parques e a complexidade e a incerteza inerentes aos contextos institucionais nos quais atuam. 


\subsection{2.}

\section{Fase aplicada}

A fase aplicada, cujos resultados são apresentados e discutidos no capítulo 5, foi desenvolvida a partir dos resultados da revisão bibliográfica e documental que nortearam o desenho do modelo conceitual adaptativo para o monitoramento e avaliação do desempenho de parques tecnológicos.

Esta fase compreendeu as seguintes etapas:

- Planejamento do estudo empírico junto a gestores participantes do ' 1 ' Curso para Gestores de Parques Tecnológicos e Ambientes de Inovação', oferecido pela Uni-Anprotec, em parceria com o Instituto Gênesis, da PUC-Rio, em 2016;

- Aplicação do modelo conceitual em cinco parques selecionados pelos participantes do referido Curso, focalizando a fase de planejamento do modelo e tendo como suporte as seguintes ferramentas de gestão:

- "Estrategigrama", ferramenta para definição de perfis estratégicos de parques tecnológicos, concebida e divulgado pela International Association of Science Parks and Innovation Areas (IASP);

- Business Model Generation (BMG), também denominado como Canvas, para definição de modelos de negócio de organizações;

- Taxonomia da Anprotec para classificação e posicionamento de parques tecnológicos;

- Ferramenta conhecida como quadro lógico para definição de indicadores e métricas de desempenho para determinados agrupamentos de parques, levando-se em conta perfis estratégicos e modelos de negócios comuns;

- Apresentação e discussão dos resultados do estudo empírico, demonstrando-se a aplicabilidade do modelo conceitual proposto.

\subsection{3.}

\section{Fase conclusivo-propositiva}

$\mathrm{Na}$ fase conclusiva-propositiva, elaboraram-se as conclusões gerais e as específicas, relacionando-as aos objetivos enunciados na seção 1.2. Enfatizaramse os benefícios desta pesquisa para os atores interessados na aplicação do modelo em seus contextos organizacionais. Encaminharam-se, ainda propostas de estudos futuros, como desdobramentos naturais da presente pesquisa. 


\section{5}

\section{Estrutura da dissertação}

Esta dissertação encontra-se estruturada em seis capítulos, incluindo esta introdução.

No capítulo 2, apresentam-se os conceitos básicos sobre parques tecnológicos, os desafios para sua implantação e contínuo funcionamento, além das experiências de sucesso em nível nacional e internacional. Complementa-se essa revisão com a descrição de taxonomias de parques tecnológicos relatadas na literatura.

O capítulo 3 aborda as atividades de monitoramento e avaliação de desempenho de parques tecnológicos e sua importância para o ciclo de gestão desses empreendimentos, além de uma análise crítica dos principais modelos reportados nos estudos empíricos selecionados na fase exploratória da pesquisa.

No capítulo 4, propõe-se o modelo conceitual para monitoramento e avaliação de parques tecnológicos, que foi desenvolvido segundo a abordagem de gestão adaptativa. Esse modelo foi validado empiricamente junto a 26 participantes a gestores participantes do $1^{\circ}$ Curso para Gestores de Parques Tecnológicos e Ambientes de Inovação, oferecido pela Uni-Anprotec, em parceria com o Instituto Gênesis, da PUC-Rio, em 2016.

No capítulo 5, descrevem-se os resultados da validação empírica referido modelo, focalizando sua fase de planejamento. Durante o estudo empírico, foram realizadas as seguintes etapas: (i) coleta de dados durante duas Oficinas de Trabalho, realizadas respectivamente no Rio de Janeiro e no Recife; (ii) tutorias a distância no intervalo entre as duas Oficinas de Trabalho, conduzidas pelo pesquisador e sua orientadora; (iii) aplicação do modelo adaptativo em cinco parques, incluindo a construção de indicadores e métricas de desempenho, conforme classificação dos parques segundo a taxonomia proposta pela Anprotec; e (iv) elaboração das conclusões do estudo empírico.

No capítulo 6, sintetizam-se as conclusões e propostas para estudos futuros, como desdobramentos naturais e aprofundamento de aspectos relevantes que emergiram da presente pesquisa. 


\section{2 \\ Parques tecnológicos: conceituação e desafios}

Abordam-se as atividades de monitoramento e avaliação de desempenho de parques tecnológicos, sua importância para o ciclo de gestão desses empreendimentos, além de uma análise crítica dos principais modelos reportados nos estudos empíricos selecionados na fase exploratória da pesquisa. Apresentamse os conceitos básicos sobre parques tecnológicos e os desafios para sua implantação e contínuo funcionamento, além da análise de experiências de sucesso no Brasil e no exterior. Complementa-se essa revisão com a descrição de taxonomias de parques tecnológicos relatadas na literatura.

A origem do conceito de parques tecnológicos deu-se na década de 1950 nos Estados Unidos, na Universidade de Stanford, Califórnia, no chamado Vale do Silício dos Estados Unidos. Juntamente com a Fundação Sophia Antipolis, na França, criada na década de 1960, e a Tsubasa Science City, no Japão, esses são os parques tecnológicos mais antigos e conhecidos do mundo (Collarino, 2014; United Nations Educational, Scientific and Cultural Organization, 2016; Vedovello, 2000).

Os arquétipos de parques tecnológicos desenvolvidos naquelas regiões foram responsáveis por influenciar outros modelos pelo mundo e tiveram como propósitos interligar centros de conhecimento e as empresas do setor público e privado em espaços com infraestrutura apropriada e promover a transferência de conhecimento e tecnologia entre as organizações e as universidades, visando atingir o objetivo de inserção no mercado altamente competitivo e globalizado. (Collarino, 2014; Jiminez-Zarco, Cerdan-Chiscano e Torren-Sellens, 2013; Zouain, 2003).

O Quadro 2.1, atualizado a partir do trabalho do trabalho de Zouain (2003), apresenta as definições de parques científicos e tecnológicos identificados em sites institucionais relacionados a essa temática. 
Quadro 2.1 - Principais definições de parques científicos e tecnológicos

\begin{tabular}{|c|c|}
\hline Fonte & Definição \\
\hline $\begin{array}{l}\text { Agência } \\
\text { Nacional de } \\
\text { Entidades } \\
\text { Promotoras de } \\
\text { Empreendimen } \\
\text { tos Inovadores - } \\
\text { (Anprotec) }\end{array}$ & $\begin{array}{l}\text { Parque tecnológico é um complexo produtivo industrial e de serviços de } \\
\text { base científico-tecnológica, planejado, de caráter formal, concentrado e } \\
\text { cooperativo, que agrega empresas, cuja produção se baseia em pesquisa } \\
\text { tecnológica desenvolvida nos centros de P\&D vinculados ao parque. Trata-se } \\
\text { de um empreendimento promotor da cultura da inovação, da } \\
\text { competitividade, do aumento da capacitação empresarial, fundamentado na } \\
\text { transferência de conhecimento e tecnologia, com o objetivo de incrementar } \\
\text { a produção de riqueza de uma região. }\end{array}$ \\
\hline $\begin{array}{l}\text { Código de } \\
\text { Ciência, } \\
\text { Tecnologia e } \\
\text { Inovação (CT\&l) } \\
\text { (Lei } \\
13.243 / 2016)\end{array}$ & $\begin{array}{l}\text { Parque tecnológico é um complexo planejado de desenvolvimento } \\
\text { empresarial e tecnológico, promotor da cultura de inovação, da } \\
\text { competitividade industrial, da capacitação empresarial e da produção de } \\
\text { sinergias em atividades de pesquisa científica, de desenvolvimento } \\
\text { tecnológico e de inovação entre empresas e uma ou mais Instituições de } \\
\text { Ciência e Tecnologia (ICTs), com ou sem vínculo entre si. }\end{array}$ \\
\hline $\begin{array}{l}\text { International } \\
\text { Association of } \\
\text { Science Parks - } \\
\text { (IASP) }\end{array}$ & $\begin{array}{l}\text { Parque tecnológico é uma organização administrada por profissionais } \\
\text { especializados, cujo principal objetivo é aumentar a riqueza da comunidade, } \\
\text { através da promoção da cultura da inovação e da competitividade das } \\
\text { empresas e instituições baseadas no conhecimento que lhe estão } \\
\text { associadas. Para alcançar esse objetivo maior, deve estimular e gerenciar o } \\
\text { fluxo de conhecimento e de tecnologias entre universidades, instituições de } \\
\text { P\&D, empresas e mercados; facilitar a criação e o crescimento de empresas } \\
\text { de base tecnológica, através de processos de incubação e de spin-offs e } \\
\text { fornecer outros serviços de valor agregado, bem como espaços e instalações } \\
\text { de alta qualidade. }\end{array}$ \\
\hline $\begin{array}{l}\text { Association of } \\
\text { University } \\
\text { Research Parks } \\
\text { - (AURP) }\end{array}$ & $\begin{array}{l}\text { Considera parques científicos e incubadoras tecnológicas: } \\
\text { - Áreas e prédios, existentes ou planejados, projetados principalmente } \\
\text { para instalações de pesquisa e desenvolvimento, públicas e privadas, } \\
\text { para empresas baseadas em ciência e alta tecnologia e para serviços de } \\
\text { apoio; } \\
\text { - Possuem contrato ou são de propriedade e mantém um relacionamento } \\
\text { operacional com uma ou mais universidades ou outras instituições de } \\
\text { educação superior e pesquisa científica; } \\
\text { - Têm função de promoção de pesquisa e desenvolvimento, por meio da } \\
\text { universidade em parceria com a indústria, assessorando no crescimento } \\
\text { de novos negócios e promovendo desenvolvimento econômico; } \\
\text { Têm função de auxiliar na transferência de tecnologia e práticas de } \\
\text { negócios entre universidades e arrendatários. O parque ou a incubadora } \\
\text { podem ser entidades para fins lucrativos ou sem fins lucrativos, de } \\
\text { propriedade, total ou parcial, da universidade ou de uma entidade } \\
\text { relacionada à universidade. Alternativamente, o parque ou a incubadora } \\
\text { podem ser de propriedade de uma entidade não universitária, mas que } \\
\text { tem contrato ou uma relação formal com a universidade, incluindo joint- } \\
\text { venture entre um parque científico privado e a universidade. }\end{array}$ \\
\hline $\begin{array}{l}\text { United } \\
\text { Kingdom } \\
\text { Science Parks } \\
\text { Association - } \\
\text { (UKSPA) }\end{array}$ & $\begin{array}{l}\text { Iniciativa de apoio aos negócios e transferência de tecnologia que: } \\
\text { - Encoraja e apoia os negócios baseados em conhecimento, promovendo } \\
\text { seu crescimento; } \\
\text { - Provê um ambiente em que os negócios grandes e internacionais podem } \\
\text { desenvolver interações específicas e próximas com um centro de criação } \\
\text { de conhecimento, para seu mútuo benefício; } \\
\text { - Têm uma ligação formal e operacional com centros de criação de } \\
\text { conhecimento, tais como universidades, institutos de educação superior } \\
\text { e organizações de pesquisa. }\end{array}$ \\
\hline
\end{tabular}

Fonte: Atualização a partir de Zouain (2003). 
Vedovello, Judice e Maculan (2006) argumentam que as várias definições de parques tecnológicos se tornaram 'nevrálgicas' para abranger as necessidades de todos os stakeholders envolvidos, sejam eles as universidades, centros de pesquisa, empresários e os chamados acadêmicos-empresários, além dos agentes financeiros e investidores, agências de desenvolvimento e autoridades ligadas ao governo em diferentes níveis (nacional, regional, estadual e municipal).

O Quadro 2.2 refere-se aos principais stakeholders envolvidos em empreendimentos de parques tecnológicos e seus focos de interesse, conforme a visão de Vedovello, Judice e Maculan (2006).

Quadro 2.2 - Principais stakeholders dos parques tecnológicos e focos de interesse

\begin{tabular}{|c|c|}
\hline Stakeholders & Foco principal de interesse \\
\hline $\begin{array}{l}\text { Universidades e institutos de } \\
\text { pesquisa }\end{array}$ & $\begin{array}{l}\text { - Comercializar resultados de pesquisa acadêmica } \\
\text { ampliando as fontes de recursos financeiros; } \\
\text { - Ampliar missão institucional; } \\
\text { - Ampliar mercado de trabalho para pesquisadores e } \\
\text { estudantes. }\end{array}$ \\
\hline $\begin{array}{l}\text { Empresários e acadêmicos- } \\
\text { empresários }\end{array}$ & $\begin{array}{l}\text { - Utilizar resultados das atividades acadêmicas e de } \\
\text { pesquisa de forma a potencializar as próprias } \\
\text { atividades de P\&D empresarial; } \\
\text { - Potencializar retornos financeiros; } \\
\text { - Acessar recursos humanos qualificados. }\end{array}$ \\
\hline $\begin{array}{l}\text { Agentes financeiros e investidores } \\
\text { (venture capital, investidores anjo } \\
\text { etc.) }\end{array}$ & $\begin{array}{l}\text { - Investir em novas empresas de base tecnológica com } \\
\text { alto e rápido potencial de crescimento econômico e } \\
\text { retornos financeiros }\end{array}$ \\
\hline $\begin{array}{l}\text { Governo e agências de } \\
\text { desenvolvimento }\end{array}$ & $\begin{array}{l}\text { - Apoiar atividades inovadoras nas empresas; } \\
\text { - Revitalizar regiões economicamente deprimidas; } \\
\text { - Gerar empregos }\end{array}$ \\
\hline
\end{tabular}

Fonte: Vedovello, Judice e Maculan (2006).

\section{1}

\section{Papel dos parques tecnológicos para o desenvolvimento regional}

Com relação às definições de parques tecnológicos apresentadas no Quadro 2.1, identifica-se que um dos principais papéis desses empreendimentos é a promoção do desenvolvimento da região em que estão localizados, criando novos empregos e riquezas.

Ratinho e Henriques (2010) ressaltam que, para a existência de um crescimento regional significativo, os parques tecnológicos precisam obter êxito em seu planejamento e operação. Nessa perspectiva, Nauwealaers, Kleibrink e Stancova (2014) discutem como parques tecnológicos constituem instrumentos 
utilizados por governos locais, regionais ou nacionais para o desenvolvimento regional, quando buscam crescimento e desenvolvimento de polos geradores de conhecimento e inovações.

Segundo a Anprotec (2008), as regiões Sudeste e Sul do Brasil apresentam a maior quantidade de parques em fase de operação, devido à concentração de produção científica e tecnológica e de instituições de CT\&I existentes nessas regiões.

Rodríguez-Pose e Hardy (2014) destacam que a existência de pesquisadores especializados e empresas com alto grau de conhecimento e tecnologia influenciam na concepção e localização dos projetos de projetos.

$\mathrm{Hu}$ (2006) comenta que, na China, todos os parques tecnológicos estão concentrados em grandes centros urbanos, próximos dos centros de conhecimento e P\&D e de indústrias.

No Brasil, entre 2008 e 2013, ocorreu um crescimento no número de parques tecnológicos em todas as regiões, porém ainda prevalece a maior quantidade de parques nas regiões Sul e Sudeste, conforme mostrado na Tabela 2.1 (Anprotec, 2008; Cdt/Unb, 2014).

Tabela 2.1 - Número de parques tecnológicos no Brasil: 2013

\begin{tabular}{|l|l|l|l|}
\hline \multirow{2}{*}{ Região } & \multicolumn{3}{|l|}{ Estágio de desenvolvimento } \\
\cline { 2 - 4 } & Fase de projeto & Fase de implantação & Fase de operação \\
\hline Norte & 04 & 01 & 0 \\
\hline Nordeste & 01 & 02 & 04 \\
\hline Centro-Oeste & 05 & 03 & 0 \\
\hline Sudeste & 17 & 11 & 11 \\
\hline Sul & 11 & 11 & 13 \\
\hline Total & 38 & 28 & 28 \\
\hline
\end{tabular}

Fonte: CDT/UnB ( 2014).

Conforme Fernandes (2014), os parques tecnológicos no Brasil são localizados próximos a grandes centros urbanos, sendo também essa característica um elemento chave de sua criação.

$\mathrm{Na}$ Tabela 2.2, apresenta-se a evolução do número de empresas e empregados nos parques tecnológicos, comparando-se os dados dos anos de 2008 e 2013. 
Tabela 2.2 - Número de empresas e empregados nos parques tecnológicos no Brasil: 2008 e 2013

\begin{tabular}{|l|l|l|}
\hline \multirow{2}{*}{ Item } & Anos \\
\cline { 2 - 3 } & $\mathbf{2 0 0 8}$ & $\mathbf{2 0 1 3}$ \\
\hline Número de empresas & 520 & 939 \\
\hline Total de empregados & 26233 & 32237 \\
\hline Empregados com pós-graduação & 7082 & 6412 \\
\hline Empregados com nível superior & 14338 & 17630 \\
\hline
\end{tabular}

Fontes: Anprotec (2008) e CDT/UnB (2014).

A Tabela 2.3 mostra a evolução do número de parques tecnológicos no Brasil, em função de seu estágio de desenvolvimento, comparando-se os anos de 2008 e 2013.

Tabela 2.3 - Evolução do número de parques tecnológicos no Brasil: 2008 e 2013

\begin{tabular}{|l|l|l|l|}
\hline \multirow{2}{*}{$\begin{array}{l}\text { Estágio de } \\
\text { desenvolvimento }\end{array}$} & \multicolumn{3}{|l|}{ Estágio de desenvolvimento } \\
\cline { 2 - 4 } & $\mathbf{2 0 0 8}$ & $\mathbf{2 0 1 3}$ & Evolução \\
\hline Projeto & 32 & 38 & $18,8 \%$ \\
\hline Implantação & 17 & 28 & $64,7 \%$ \\
\hline Operação & 25 & 28 & $12 \%$ \\
\hline Total & 74 & 94 & $27,0 \%$ \\
\hline
\end{tabular}

Fontes: Anprotec (2008) e CDT/UnB (2014).

Pelos dados apresentados, pode-se perceber um aumento significativo de parques tecnológicos e, consequentemente, de empregados e empresas residentes. É importante ressaltar que, segundo CDT/UnB (2014), o investimento nos parques tecnológicos por parte do governo municipal/estadual e federal tem sido fundamental para o fortalecimento das fases iniciais dos projetos. Já o investimento privado é mais forte em parques de maior porte e já consolidados.

Segundo Rodríguez-Pose e Hardy (2014), países com economia emergente, como o Brasil, possuem a maioria de seus parques tecnológicos em fase inicial de desenvolvimento, e colocam a importância da conexão entre os parques com o mercado regional e global para que possam aumentar sua competitividade.

A Tabela 2.4 mostra a distribuição dos investimentos nos parques tecnológicos no Brasil no ano de 2013. 
Tabela 2.4 - Investimento nos parques tecnológicos no Brasil: 2013

\begin{tabular}{|l|l|l|}
\hline Fase & Investimento & $\mathbf{2 0 1 3}$ \\
\hline \multirow{4}{*}{ Projeto } & Federal & $\mathrm{R} \$ 18,2$ milhões \\
\cline { 2 - 3 } & Municipal / Estadual & $\mathrm{R} \$ 11,5$ milhões \\
\cline { 2 - 3 } & Privado & $\mathrm{R} \$ 3,8$ milhões \\
\hline \multirow{3}{*}{ Implantação } & Federal & $\mathrm{R} \$ 133$ milhões \\
\cline { 2 - 3 } & Municipal / Estadual & $\mathrm{R}$ 1,8 bilhões \\
\cline { 2 - 3 } & Privado & $\mathrm{R} \$ 15,7$ milhões \\
\hline \multirow{3}{*}{ Operação } & Federal & $\mathrm{R}$ 1,1 bilhão \\
\cline { 2 - 3 } & Municipal / Estadual & $\mathrm{R}$ 1,8 bilhões \\
\cline { 2 - 3 } & Privado & $\mathrm{R}$ 15,7 milhões \\
\hline
\end{tabular}

Fonte: Adaptado de MCTI (2014).

\section{2}

\section{Experiências bem-sucedidas de parques tecnológicos no exterior}

Ressaltam-se as melhores práticas adotadas por parques tecnológicos no exterior. Um estudo do MCTI (2015) apresenta experiências bem sucedidas de parques tecnológicos localizados no Reino Unido, nos EUA, em Cingapura, Áustria, Suécia e China.

Matusiaka e Bakowskiego (2008, apud Zieliński, Rogala e Takemura, 2014) listam fatores chaves de sucesso de parques tecnológicos em vários países. São eles:

- Maior proximidade com as universidades locais, estimulando o empreendedorismo;

- Incentivo a programas de parceria entre os parques tecnológicos, empresas residentes, incubadoras, governo e universidades;

- Integração com a região, promovendo o desenvolvimento regional e empreendimentos inovadores;

- Gestores e funcionários especializados e envolvidos nas estratégias de longo prazo do parque tecnológico;

- Acesso a venture capital;

- Manter o desenvolvimento da área do parque tecnológico, com possibilidade de expansão, tendo em seus projetos áreas que incentivem a criatividade e inovação;

- Networking ativo e efetivo em diversos setores de serviços dos parques e colaboradores internos e externos;

- Incentivo à formação de clusters nos parques tecnológicos; 
- Seleção de empresas residentes com a finalidade de gerar sinergia entre elas, identificando suas necessidades e fornecendo acesso a redes e serviços;

- Alto padrão de infraestrutura para atividades de PD\&I e de transporte, propiciando um ambiente atrativo para se viver e trabalhar;

- Programas de incubação de empresas e conexão com as universidades, estimulando programas de "pré-incubação" e start-ups;

- Fortalecimento do marketing e da imagem institucional dos parques tecnológicos, estimulando a atração de possíveis novos colaboradores.

O Quadro 2.3 apresenta as melhores práticas de parques tecnológicos no exterior. Ao se comparar as melhores práticas adotadas pelos parques tecnológicos abordados, verifica-se que não existe um conjunto único de práticas para todos os parques, embora sejam constatadas algumas semelhanças em suas práticas.

Quadro 2.3 - Melhores práticas de parques tecnológicos no exterior

\begin{tabular}{|c|c|}
\hline $\begin{array}{l}\text { Parques Tecnológicos } \\
\text { Internacionais }\end{array}$ & Melhores Práticas \\
\hline $\begin{array}{l}\text { Reino Unido } \\
\text { (University of Warwick } \\
\text { Science Park, Surrey } \\
\text { Research }\end{array}$ & $\begin{array}{l}\text { - Desenvolvimento de serviços para melhorar a captação de } \\
\text { recursos iniciais ou para pesquisa e marketing. } \\
\text { - Desenvolvimento do capital intelectual junto aos parques } \\
\text { tecnológicos através de programas de apoio aos estudantes } \\
\text { universitários, com ênfase àqueles realizando pós-graduação. } \\
\text { - Forte interação entre o setor produtivo e o parque. } \\
\text { - Foco de incentivo aos pontos fortes de conhecimento das } \\
\text { - } \text { universidades, atraindo empresas. } \\
\text { - Gerenciamento das relações de patente entre pesquisadores e } \\
\text { - empresas. } \\
\text { - Apoio a spin-offs universitárias. } \\
\text { - Ancentivo ao empreendedorismo. }\end{array}$ \\
\hline $\begin{array}{l}\text { Suécia } \\
\text { (Ideon Science Park) }\end{array}$ & $\begin{array}{l}\text { - Programa estruturado e maduro de incubadoras para o } \\
\text { fortalecimento de possíveis empresas residentes ao parque. } \\
\text { - Forte interação entre universidade, governo municipal e } \\
\text { federal e empresas privadas. }\end{array}$ \\
\hline $\begin{array}{l}\text { China } \\
\text { (Zhangjiang High-Tech } \\
\text { Park) }\end{array}$ & $\begin{array}{l}\text { - Incentivo ao ingresso de empresas estrangeiras. } \\
\text { - Objetivo fortemente interligado com a missão do parque } \\
\text { (tornar-se referência mundial). }\end{array}$ \\
\hline $\begin{array}{l}\text { Áustria } \\
\text { (Softwarepark } \\
\text { Hagenberg) }\end{array}$ & $\begin{array}{l}\text { - Forte interação com parceiros externos e internos ao parque } \\
\text { industrial. } \\
\text { - Aproximação com empresas públicas e privadas. } \\
\text { - Incentivo ao capital intelectual. Programas de incentivo aos } \\
\text { estudantes de mestrado junto às empresas e institutos do } \\
\text { parque industrial. }\end{array}$ \\
\hline
\end{tabular}


Quadro 2.3 - Melhores práticas de parques tecnológicos no exterior (cont.)

\begin{tabular}{|l|l|}
\hline $\begin{array}{l}\text { Parques Tecnológicos } \\
\text { Internacionais }\end{array}$ & \multicolumn{3}{|c|}{ Melhores Práticas } \\
\hline $\begin{array}{l}\text { Estados Unidos } \\
\text { (Research Triangle Park) }\end{array}$ & $\begin{array}{l}\text { Forte interação com o governo estadual e federal e as } \\
\text { universidades. } \\
\text { - Incentivo ao desenvolvimento da economia local e educação. } \\
\text { - Auxílio à interação entre as universidades da região. }\end{array}$ \\
\hline $\begin{array}{l}\text { Cingapura } \\
\text { (Biopolis, Fusionopolis) }\end{array}$ & $\begin{array}{l}\text { Economia voltada para o desenvolvimento de novas } \\
\text { tecnologias. }\end{array}$ \\
& $\begin{array}{l}\text { Incentivo à propriedade intelectual e inovação. } \\
\text { - Este interligação com centros de pesquisa. } \\
\text { transferência de conhecimento. } \\
\text { - Forte interação com parceiros externos e internos ao parque } \\
\text { industrial. } \\
\text { Conexão com os centros de conhecimento e as empresas } \\
\text { residentes. }\end{array}$ \\
\hline
\end{tabular}

Fonte: MCTI (2015).

\section{3}

\section{Experiências bem-sucedidas de parques tecnológicos nacionais}

Focalizando as melhores práticas dos parques tecnológicos nacionais, o estudo do MCTI (2015) reporta e discute os resultados gerados pela equipe do Centro de Empreendedorismo Inovador da Fundação Centros de Referência em Tecnologias Inovadoras (Fundação Certi). A análise foi realizada em 15 parques tecnológicos no Brasil, sendo que essas práticas foram selecionadas pelos gestores dos parques tecnológicos, com base em suas visões e experiências de trabalho e das empresas residentes. O modelo gerou onze vertentes:

- Conceito: objetivo do parque tecnológico, motivação para sua criação e alinhamento com os modelos de negócio das empresas e instituições residentes;

- Infraestrutura: adequação da infraestrutura do parque para atender às necessidades das empresas e atrair novos empreendimentos. Proximidade a rodovias e aeroportos, facilidade de acesso aos residentes, entre outros aspectos;

- Capital: captação dos parques tecnológicos (públicos e privados) precisa ser desenvolvida para atender as empresas. Os parques tecnológicos precisam de estratégias fortes e adequadas para manter o parque em funcionamento;

- Inserção local: interação com a região em que se localiza o parque é um fator chave, pois contribui para o desenvolvimento do entorno, através da geração de novos empregos e aquisição de renda para a região. 
- Talentos: programas para atrair e manter empregados talentosos são de grande importância para o desenvolvimento das empresas residentes;

- Mercado: estratégias de marketing do parque tecnológico para atrair novas empresas, promover seus produtos e fortalecimento da marca.

- Clusters: é importante que os parques possuam capacidade de estruturar um networking entre as empresas e instituições de conhecimento ligadas a eles. Um programa de redes de cooperação adequado pode atrair novos clusters na região com a atração de novas empresas ao parque tecnológico;

- Parceiros: projetos e programas de parcerias entre colaboradores nacionais e internacionais e a manutenção dos mesmos é importante para o desenvolvimento do parque tecnológico;

- Governança e gestão: capacitação dos gestores, além do gerenciamento do parque, alinhado à sua missão e objetivos estratégicos;

- Mecanismos e serviços: proposições de negócios e programas que ampliem os serviços que agregam valor ao parque tecnológico, como serviços de transferência de tecnologia, propriedade intelectual e modelagem de novos negócios para empresas e instituições residentes;

- Conhecimento: fortalecimento do fluxo de conhecimento entre os centros de PD\&I e as empresas residentes.

O MCTI (2015) avaliou 15 parques tecnológicos, segundo as onze vertentes de análise, atribuindo notas em uma escala de 1 a 4 para o grau de adoção das respectivas práticas. Os parques tecnológicos brasileiros obtiveram um resultado acima da média, porém existe espaço e a necessidade de aperfeiçoar e fortalecer as boas práticas aplicadas. O Quadro 2.4 mostra a pontuação média alcançada pelos 15 parques tecnológicos avaliados.

Quadro 2.4 - Avaliação de parques tecnológicos brasileiros segundo metodologia da Fundação Crti

\begin{tabular}{|l|l|}
\hline Vertente & Nota \\
\hline Conceito & 3,6 \\
\hline Infraestrutura & 3,5 \\
\hline Capital & 3,1 \\
\hline Inserção local & 2,2 \\
\hline Talentos & 2,8 \\
\hline Mercado & 2,5 \\
\hline Clusters & 2,3 \\
\hline Parceiros & 2,3 \\
\hline Governança e gestão & 3,3 \\
\hline Mecanismos e serviços & 2,9 \\
\hline Conhecimento & 2,6 \\
\hline
\end{tabular}

Fonte: MCTI (2015).

Vale destacar a contribuição de Telechea (2011), que identificou os fatores chave de sucesso dos parques tecnológicos nacionais. Segundo Telechea (2011), 
tais fatores podem relacionar-se às competências organizacionais, que por sua vez, associam-se à adoção das melhores práticas para as atividades e gerenciamento dos parques tecnológicos nacionais.

O Quadro 2.5 apresenta os fatores de sucesso, segundo a visão de Telechea (2011).

Quadro 2.5 - Categorias de parques tecnológicos e fatores de sucesso

\begin{tabular}{|c|c|}
\hline Categorias & Fatores de sucesso \\
\hline Infraestrutura & $\begin{array}{l}\text { - Infraestrutura adequada para as empresas de base } \\
\text { tecnológica incluindo edificações, utilidades, infra de TI, áreas de } \\
\text { preservação ambiental, saneamento básico, etc.; } \\
\text { - Fácil acesso e proximidade de rodovias, aeroportos e centros urbanos, } \\
\text { facilidade de transporte; } \\
\text { - Disponibilidade de infraestrutura de segurança; } \\
\text { - Infraestrutura de comunicação; } \\
\text { - Localização física do parque: diversidade industrial da região, oferta de } \\
\text { serviços com valor agregado, existência de empresas de base tecnológica, } \\
\text { etc. }\end{array}$ \\
\hline $\begin{array}{l}\text { Serviços } \\
\text { especializados }\end{array}$ & $\begin{array}{l}\text { - Presença de núcleos especializados em tecnologia e } \\
\text { inovação; } \\
\text { - Treinamento e qualificação de mão-de-obra; } \\
\text { - Treinamento empresarial e gerencial; } \\
\text { - Disponibilidade de acesso a novas tecnologias; } \\
\text { - Disponibilidade de serviço e suporte técnico de apoio à indústria; } \\
\text { - Presença de pessoal especializado em estruturação de projetos de } \\
\text { desenvolvimento tecnológico via agências de fomentos e fundos setoriais. }\end{array}$ \\
\hline $\begin{array}{l}\text { Gestão do } \\
\text { parque }\end{array}$ & $\begin{array}{l}\text { - Mecanismos de governança próprios com autonomia para decisões; } \\
\text { - Modelos de gestão profissional do parque com o uso de indicadores de } \\
\text { qualidade de prestação dos serviços do parque; } \\
\text { - As propriedades pertencentes ao parque devem possuir condições } \\
\text { fundiárias favoráveis a instalação do parque. }\end{array}$ \\
\hline $\begin{array}{l}\text { Fatores } \\
\text { econômicos e } \\
\text { financeiros }\end{array}$ & $\begin{array}{l}\text { - Preços competitivos cobrados pela infraestrutura do parque, gerando } \\
\text { - Vconomia de escala no seu uso; } \\
\text { - Cabilidade econômica e financeira do parque, gerando o retorno esperado } \\
\text { - Captação de recursos financeiros via agências de fomentos e fundos } \\
\text { - Actoriais governamentais; } \\
\text { - Existência de políticas públicas favoráveis ao desenvolvimento empresarial; } \\
\text { - Baixo custo de transação da região; } \\
\text { - Custo da mão-de-obra; } \\
\text { - Acessibilidade à instituições de capital de risco; } \\
\text { - Estabilidade econômica. }\end{array}$ \\
\hline
\end{tabular}


Quadro 2.5 - Categorias de parques tecnológicos e fatores de sucesso (cont.)

\begin{tabular}{|c|c|}
\hline Categorias & Fatores de sucesso \\
\hline $\begin{array}{l}\text { Interação universidade - } \\
\text { empresa }\end{array}$ & $\begin{array}{l}\text { - Internacionalização do parque tecnológico com a presença de } \\
\text { empresas transnacionais com centros de P\&D; } \\
\text { - Acesso aos pesquisadores, professores e mão-de-obra } \\
\text { proveniente da universidade; } \\
\text { - Acesso a uma ampla base de conhecimento; } \\
\text { - Políticas formais de interação universidade - empresa. }\end{array}$ \\
\hline Fatores mercadológicos & $\begin{array}{l}\text { - Oportunidades de negócio; } \\
\text { - Presença do mercado consumidor e ferramentas de interação } \\
\text { entre empresa e consumidor; } \\
\text { - Proximidade a fornecedores. }\end{array}$ \\
\hline
\end{tabular}

Fonte: Telechea (2011).

Steiner, Cassim e Robazzi (2008), apesar de se limitarem aos parques tecnológicos privados, confirmam a adoção das práticas apresentadas e fatoreschave de sucesso, discutindo a importância de interligar a geração de conhecimento com políticas públicas e a gestão dos parques tecnológicos.

Esses autores mostram a importância do governo como indutor e articulador da implantação de parques tecnológicos, ressaltando que o setor empresarial precisa trabalhar em conjunto com o setor público e perceber a importância dos parques para o estímulo econômico. Os autores reforçam ainda que, apesar dos parques tecnológicos serem fortes empreendimentos imobiliários, não devem ficar limitados a isso, uma vez que sua função primordial é a promoção de projetos de CT\&I e transferência de tecnologia entre ICTs locais e empresas/instituições residentes.

\section{4}

\section{Taxonomias de parques tecnológicos}

Diferentes taxonomias ${ }^{1}$ foram desenvolvidas para os parques tecnológicos de para melhor classificá-los em grupos com características comuns (Escorsa e Valls, 1996; Haselmayer, 2004; Annerstedt, 2006; Anprotec, 2008; Kaczmarska e Gierulski, 2012; Luger e Goldstein, 1991).

1 O conceito de taxonomia, conforme explicitado por Miranda (2014): “(...) é uma classificação de acordo com um sistema de critérios pré-determinados, que almeja separar elementos de um grupo (taxon) em subgrupos (taxa), que são mutuamente excludentes e não ambíguos" (Miranda, 2014, p. 219). 
2.4.1.

\section{Taxonomia de Escorsa e Valls}

Escorsa e Valls (1996) realizaram uma análise de doze parques científicos e tecnológicos pela Europa, a saber:

- França - Zirst-Meylan, Savoie Technolac-Chambéry, HelioParc-Pau e Bordeaux;

- Portugal - Almada-Uninova, Taguspark e Lispolis;

- Espanha - Zamudio-Bilbao, Seville, Valladolid e Barcelona;

- Itália-Bari.

A partir dessa pesquisa, os autores identificaram pontos em comum entre esses parques tecnológicos, sendo os principais:

- Coordenação e promoção do desenvolvimento regional;

- Localização empresarial;

- Centros de P\&D e universidades em parceria com os parques tecnológicos.

Os autores estabeleceram sete padrões para parques tecnológicos, que representam combinações geradas pelos pontos em comum entre os parques analisados. A Figura 2.1 representa graficamente a formação dos padrões de parques tecnológicos, segundo a visão de Escorsa e Valls (1996).

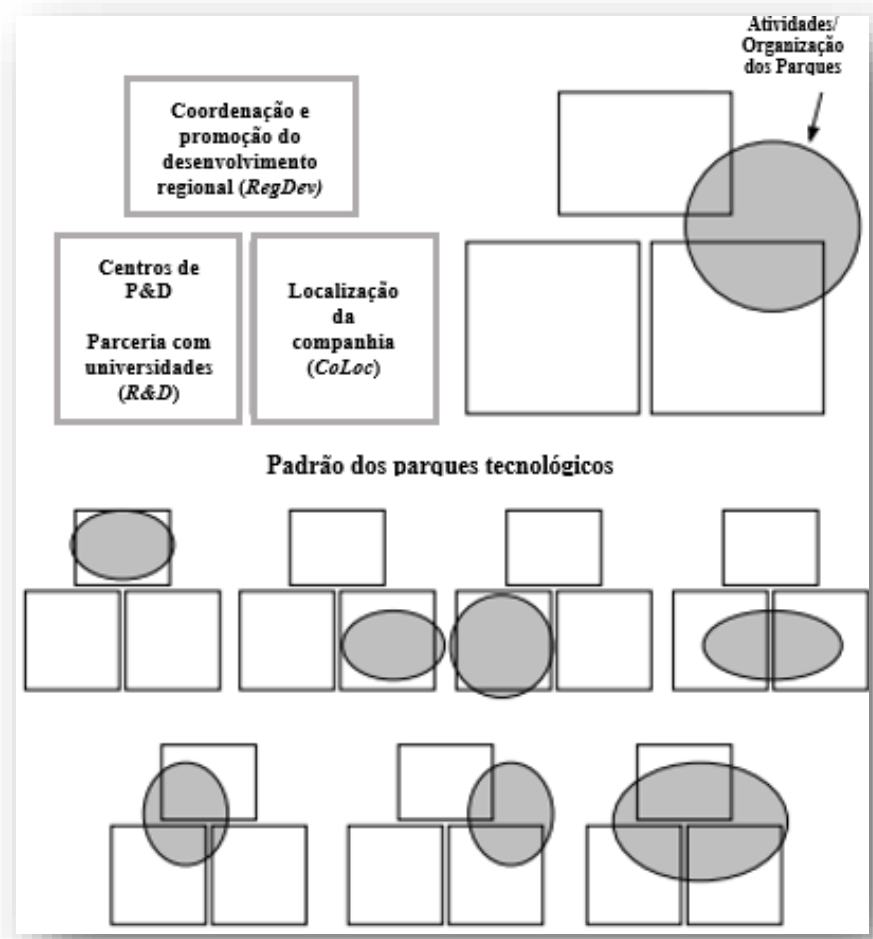

Figura 2.1 - Padrões de parques tecnológicos segundo Escorsa e Valls Fonte: Escorsa e Valls (1996). 
A seguir, apresenta-se uma breve descrição de cada um dos nove padrões:

- Padrão 1 - Coordenação e promoção do desenvolvimento regional (RegDev): os parques deste grupo atuam como agentes de desenvolvimento local. Os autores descrevem o papel desses parques como "catalisadores";

- Padrão 2 - Localização das companhias (CoLoc): os parques tecnológicos deste grupo tem como função principal atrair empresas residentes;

- Padrão 3 - Atividades de P\&D (R\&D): São parques tecnológicos geralmente constituídos de centros de pesquisa, não possuindo ou restringindo atividades de manufatura. Esses parques são frequentemente denominados parques científicos ou parques de pesquisa;

- Padrão 4 - Localização de companhias/atividades de P\&D (CoLoc R\&D): São parques que desenvolvem atividades de PD\&I e programas de atração de empresas;

- $\quad$ Padrão 5 - Desenvolvimento regional/Atividades de P\&D (RegDev R\&D): São parques com baixo, ou nenhum, interesse em empreendimentos imobiliários. Possuem centros de pesquisa fortes, que buscam o desenvolvimento regional, difundindo novas tecnologias às empresas locais;

- Padrão 6 - Desenvolvimento regional/localização de companhias (RegDev - CoLoc): são parques tecnológicos com suporte de governos locais ou regionais, tendo como foco principal a atração de empresas residentes, além de possíveis afiliações a centros de pesquisa e universidades em segundo plano;

- Padrão 7 - Desenvolvimento regional/ localização das companhias/ atividades de P\&D (RegDev - CoLoc - R\&D): Também são parques tecnológicos com suporte de governos locais ou regionais e tem como objetivo a atração de universidades, centros de pesquisa e empresas, funcionando como elementos-chave para o desenvolvimento regional.

\subsection{2.}

\section{Taxonomia de gerações de parques tecnológicos}

Caracterizam três gerações de parques, de acordo com a época em que foram predominantes e dos elementos que os tornaram singulares (Haselmayer, 2004; Annerstedt, 2006; Anprotec/ABDI, 2008).

As três gerações de parques tecnológicos apresentam níveis de resultados diferentes e concentram-se em momentos históricos distintos ao longo dos últimos 50 anos. 
A análise das características de cada uma dessas gerações permite revelar direcionamentos para uma estratégia de desenvolvimento dos Parques brasileiros, como proposto no trabalho da Anprotec/ABDI (2008).

De acordo com esse estudo, as três gerações de Parques Tecnológicos podem ser caracterizadas, conforme descrição a seguir:

- Parques de $1^{\mathrm{a}}$ geração: são os 'Parques Pioneiros', criados de forma espontânea para promover o apoio à criação de empresas de base tecnológica - EBT e a interação com universidades fortes e dinâmicas. Neste tipo de parque, é possível identificar claramente as condições favoráveis à inovação e ao desenvolvimento empresarial tais como: cultura empreendedora, disponibilidade de recursos humanos e financeiros e infraestrutura de qualidade, dentre outros. De modo geral, tiveram apoio ou investimento estatal significativo e alcançaram alto grau de relevância estratégica para o país ou região. As iniciativas dos parques pioneiros, ou de $1^{a}$ geração, permitiram que nações/regiões pudessem assumir uma posição competitiva privilegiada no desenvolvimento tecnológico mundial. Um caso clássico de Parque Pioneiro é o Stanford Research Park, do qual se originou a região inovadora conhecida como Vale do Silício (Anprotec/ABDI, 2008);

- Parques de $2^{\text {a }}$ geração: são os 'Parques Seguidores', criados de forma planejada, formal e estruturada para seguir os passos de uma tendência de sucesso estabelecida a partir dos 'Parques Pioneiros'. Quase sempre tiveram apoio e suporte sistemático estatal (nacional, regional ou local) e visavam, essencialmente, promover o processo de interação universidade-empresa e estimular um processo de "valorização" (financeira ou institucional) de áreas físicas ligadas aos campi de universidades. Criaram espaços para implantação de empresas inovadoras no contexto de uma determinada região, com pretensão de se tornar um polo tecnológico e empresarial. Em geral, os resultados desta "geração" de parques tecnológicos são modestos, restringindo-se a impactos locais ou regionais. Este tipo de parque tecnológico constituiu um verdadeiro "boom", que se espalhou por universidades e polos tecnológicos de países desenvolvidos da América do Norte e Europa, ao longo das décadas de 70 a 90 (Anprotec/ABDI, 2008); 
- Parques de $3^{\text {a }}$ geração: são os chamados 'Parques Estruturantes'. Este tipo de parque acumulou as experiências dos Parques de $1^{\mathrm{a}}$ e $2^{\mathrm{a}}$ geração e está fortemente associado ao processo de desenvolvimento econômico e tecnológico de países emergentes. Criados como fruto de uma política regional ou nacional e com orientação para promover um processo de desenvolvimento socioeconômico extremamente impactante, os Parques Estruturantes contaram com forte investimento estatal e são extremamente orientados para o mercado globalizado. Em geral, estão integrados a outras políticas e estratégias de desenvolvimento urbano, regional e ambiental. Este tipo de parque é influenciado por fatores contemporâneos, tais como: facilidade de acesso ao conhecimento, formação de clusters de inovação, ganhos de escala pela especialização, vantagens competitivas obtidas pela diversificação e necessidade de velocidade de desenvolvimento influenciada pela globalização. Exemplos de Parques Estruturantes podem ser facilmente identificados em países como Cingapura, Coréia, Taiwan (Anprotec/ABDI, 2008).

\subsection{3.}

\section{Taxonomia da Anprotec}

No Brasil, a partir de 2000, o conceito de parques tecnológicos fortaleceu-se como alternativa para promoção do desenvolvimento tecnológico, econômico e social. O levantamento realizado pelo MCTI/CDT/UnB (2014) revelou a existência de 94 iniciativas de Parques no Brasil, distribuídas nas cinco regiões brasileiras. Esses dados representam um crescimento de $27 \%$ em relação aos de 2008. Do total de 94 parques, 30 encontram-se em operação, 22 em fase de implantação e 42 em fase de projeto.

Já em 2008, diante da diversidade de objetivos, modelos de governança e gestão e estágio de desenvolvimento dos parques tecnológicos no Brasil, a Anprotec decidiu criar uma taxonomia para identificar e classificar os Parques Tecnológicos em grupos com características específicas.

Para a Anprotec, a definição da taxonomia tem como objetivos: (i) definir padrões e parâmetros de avaliação e comparação; (ii) possibilitar a definição de políticas públicas com visão sistêmica e integrada; (iii) estabelecer prioridades para aplicação de recursos e aporte de "capital político"; e (iv) permitir a 
configuração de grupos com características similares para propor políticas e instrumentos para cada grupo ou classe de Parques (Anprotec/ABDI, 2008).

Como relatado pela Associação, qualquer sistemática de classificação a ser aplicada num campo tão recente e em permanente evolução exige uma proposta extremamente simples e flexível. A definição da taxonomia resultou da análise de mais de 15 diferentes variáveis que, potencialmente, poderiam ser utilizadas como eixos principais do sistema de classificação (Anprotec/ABDI, 2008, p. 10). A taxonomia resultante desse esforço foi estruturada a partir de dois eixos básicos:

- Base de Ciência e Tecnologia (C\&T): consideram-se os parâmetros, indicadores e características do Parque Tecnológico e da região de seu entorno, no que diz respeito à base de conhecimento existente na região em universidades, instituições de C\&T, profissionais qualificados, histórico de projetos de $\mathrm{P} \& \mathrm{D}$, infraestrutura para pesquisa, sistema educacional e investimentos públicos e privados em $\mathrm{P} \& \mathrm{D}$, dentre outros.

- Base Empresarial: Consideram-se fatores relacionados à densidade de empresas inovadoras e à cultura de empreendedorismo e inovação existente na região, avaliada na forma de empresas de base tecnológica já estabelecidas, histórico e geração de startups, existência de organizações de venture capital, receitas geradas por empresas inovadoras, nível de globalização dos negócios, dentre outros.

Foram estabelecidos ainda três níveis de relevância para criar uma escala de graduação para os dois eixos básicos da taxonomia, a saber:

- Relevância nacional/mundial: aplicável àqueles Parques Tecnológicos que apresentam uma Base de C\&T ou Base Empresarial de destaque nacional e são capazes de posicionar o país de forma significativa no cenário internacional.

- Relevância regional: aplicável aos Parques Tecnológicos, cujos indicadores de C\&T e empresariais se destacam em âmbito regional;

- Relevância local: aplicável aos Parques Tecnológicos, cujos indicadores ficam restritos ao âmbito local.

A Figura 2.2 representa graficamente a taxonomia proposta pela Anprotec, em 2008. 


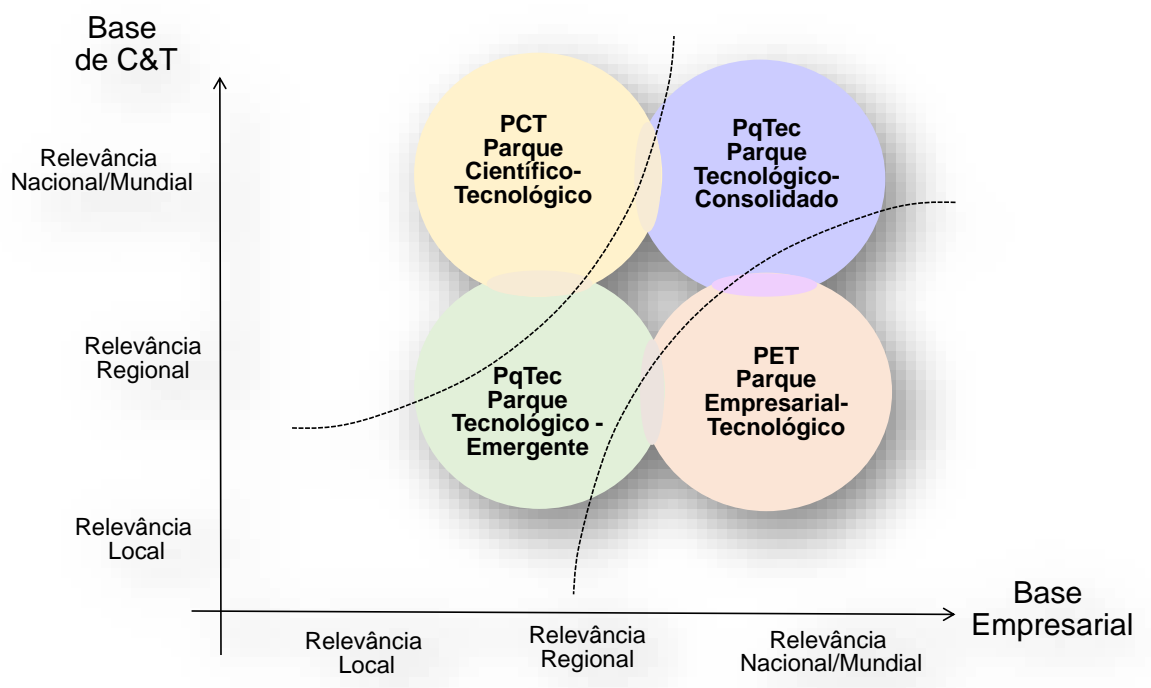

Figura 2.2 - Taxonomia Anprotec para classificação de parques tecnológicos no Brasil Fonte: Anprotec/ABDI (2008).

Como ilustrado na Figura 2.2, a taxonomia Anprotec permite classificar os Parques em quatro grandes categorias:

- Parque Tecnológico "Consolidado": contemplando os empreendimentos que possuem "base de C\&T e base Empresarial" de relevância mundial/nacional;

- Parque "Científico-tecnológico": parques tecnológicos com destaque da base de C\&T em relação à base empresarial;

- Parque "Empresarial-tecnológico": parques tecnológicos com destaque da base Empresarial em relação à base de $\mathrm{C} \& \mathrm{~T}$;

- Parque Tecnológico "Emergente": parques tecnológicos que apresentam base de C\&T e Empresarial de nível regional.

Como preconizado pela Anprotec, essa taxonomia permite, além da classificação de Parques Tecnológicos existentes, a devida orientação a projetos futuros de Parques Tecnológicos, incluindo o estabelecimento de políticas de desenvolvimento e diretrizes de investimento para esses projetos.

A ferramenta permite evidenciar elementos que definem: (i) o posicionamento estratégico do Parque Tecnológico, que pode ser atual ou futuro; (ii) a caracterização do entorno do Parque; e (iii) sua caracterização propriamente dita. 


\subsection{4.}

\section{Taxonomia de Kaczmarska e Gierulski}

Kaczmarska e Gierulski (2012) propõem uma taxonomia para classificação de ambientes de inovação, incluindo parques tecnológicos, segundo dois eixos de análise: (i) nível de tecnologia; (ii) desenvolvimento de ambientes de inovação.

A Figura 2.3 mostra a matriz de avaliação e classificação desenvolvida por Kaczmarska e Gierulski (2012) para classificação de parques tecnológicos.

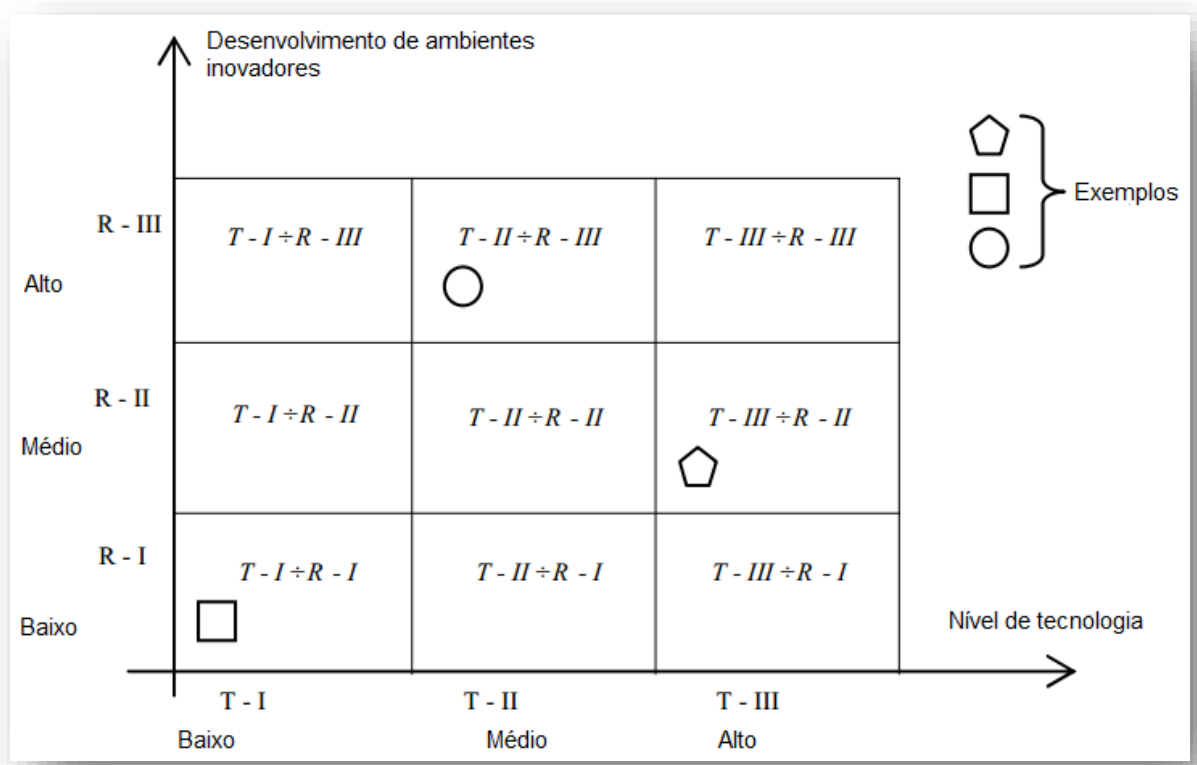

Figura 2.3 - Matriz de avaliação e classificação de parques tecnológicos segundo taxonomia Kaczmarska e Gierulski

Fonte: Kaczmarska e Gierulski (2012)

Visando posicionar os ambientes de inovação no mapa da Figura 2.3, Kaczmarska e Gierulski (2012) definiram como calcular os indicadores desses ambientes segundo essa taxonomia.

O indicador do nível tecnológico $\left(w_{T}\right)$ é representado pela razão da porcentagem de empresas de base tecnológica inovadoras com o total de empresas em funcionamento no centro.

$$
w_{T}=\frac{\% \text { empresas de base tecnlógica inovadoras }}{\mathrm{n}^{\mathrm{o}} \text { de empresas em funcionamento no centro }}
$$


O segundo indicador, desenvolvimento de ambientes inovadores $\left(\boldsymbol{w}_{\boldsymbol{R}}\right)$, é constituído pela razão da porcentagem de treinamentos inovadores com o total de cursos de treinamento.

$$
\boldsymbol{w}_{\boldsymbol{R}}=\frac{\% \text { treinamentos inovadores }}{\mathrm{n}^{\mathrm{o}} \text { de cursos de treinamento }}
$$

Com os valores obtidos pelos indicadores $\left(\boldsymbol{w}_{T}, \boldsymbol{w}_{\boldsymbol{R}}\right)$ e adicionando-se um parâmetro determinado pela quantidade de parques tecnológicos $\left(\boldsymbol{y}_{T 2}\right)$, Kaczmarska e Gierulski (2012) estabeleceram a base de cálculo para o posicionamento dos objetos de estudo na matriz de avaliação.

\section{5}

\section{Desafios atuais de gestão de parques tecnológicos}

Jiminez-Zarco, Cerdan-Chiscano e Torrent-Sellens (2013) descrevem que uma boa gestão de um parque tecnológico é estratégica para manter as relações de sinergia entre os diferentes stakeholders, sendo imperativos a disposição, o conhecimento intrínseco e o ferramental para o bom funcionamento do empreendimento, gerando os resultados e impactos esperados.

A fim de buscar a superação dos desafios que vêm sendo enfrentados atualmente pelos parques tecnológicos brasileiros, os gestores necessitam de conhecimentos e habilidades específicas para definir estratégias claras de posicionamento e de crescimento do empreendimento, de modo a estreitar essas estratégias com as prioridades regionais e nacionais junto às tendências internacionais, atrair incentivos de investidores privados, sem depender somente de recursos públicos, buscar conhecimentos referentes às áreas imobiliárias e financeiras, além de aprimorar a sinergia da academia junto aos projetos de parques tecnológicos, buscando melhores investimentos nos setores de inovação e empreendimento (Anprotec, 2008).

Destaca-se como um dos principais desafios da gestão de parques tecnológicos a criação de modelos e ferramentas de monitoramento e avaliação de desempenho, que considerem a diversidade de perfis estratégicos e de modelos de negócios desses ambientes de inovação. Na perspectiva de contribuir para o aprimoramento do processo de monitoramento e avaliação de desempenho de parques tecnológicos no Brasil e no exterior, a questão principal desta pesquisa 
emergiu dessa oportunidade. Buscou-se na abordagem de gestão adaptativa, juntamente com a disciplina de monitoramento e avaliação, a base teórica para construir um modelo que permitisse aos gestores definir indicadores e métricas em função de perfis estratégicos e modelos de negócios comuns a determinados agrupamentos de parques e adaptar-se a mudanças do ambiente externo e interno, visando cumprir a missão dos parques.

\section{6}

\section{Considerações finais sobre o capítulo}

Neste capítulo, buscou-se trazer os conceitos de parques tecnológicos, verificando que não existe uma definição única, mas sim diversas definições similares, que tendem a se adequar aos desejos e necessidades de seus stakeholders e gestores de parques tecnológicos, cujos conhecimentos, habilidades e experiências profissionais precisam estar em sinergia com os objetivos e metas desses grandes projetos, consequentemente mantendo e aprimorando a qualidade dos parques, suas empresas residentes e o capital intelectual.

Destacaram-se as experiências de sucesso dos parques internacionais e brasileiros, traduzidas em melhores práticas de gestão reportadas nas seções $2.2 \mathrm{e}$ 2.3. Descreveram-se as diferentes taxonomias de parques tecnológicos desenvolvidas por acadêmicos e especialistas em ambientes de inovação, com o objetivo de caracterizar os modelos de parques tecnológicos por agrupamentos com características comuns.

Apontam-se os desafios para a gestão de parques tecnológicos, que são empreendimentos complexos, com grande número de empregados e especialidades. Para um gestor desses ambientes de inovação, torna-se fundamental possuir conhecimentos especializados e experiência profissional para manter, de forma sinérgica, o bom funcionamento do parque, em consonância com os interesses de seus múltiplos stakeholders. 


\section{3 Monitoramento e avaliação de desempenho de parques tecnológicos}

Abordam-se as atividades de monitoramento e avaliação de desempenho de parques tecnológicos e sua importância para o ciclo de gestão desses empreendimentos, além de uma análise crítica dos principais modelos reportados nos estudos empíricos selecionados na fase exploratória da pesquisa.

Segundo Marinazzo (1996), os métodos de monitoramento e avaliação de desempenho de parques tecnológicos variam principalmente em função do estágio em que o parque se encontra (planejamento, em andamento ou em operação) e de sua configuração organizacional, incluindo modelo de negócios. É essencial ter o completo entendimento dos objetivos estratégicos e das metas julgadas mais importantes para cada parque tecnológico em diversos horizontes temporais. Em seguida, avalia-se o desempenho do parque em relação aos objetivos estratégicos e metas, utilizando-se um conjunto de indicadores específicos, definidos segundo as dimensões desejadas do processo de avaliação (Dabrowska, 2011).

\section{1 \\ Conceitos básicos de monitoramento e avaliação de desempenho}

Antes de se iniciar a discussão sobre monitoramento e avaliação de desempenho de parques tecnológicos, propriamente dita, torna-se necessário apresentar os conceitos básicos referentes à disciplina de monitoramento e avaliação de desempenho e à construção do quadro lógico de atuação dos parques tecnológicos. Essa conceituação fundamentará a modelagem pretendida.

Pode-se definir monitoramento como uma função contínua, organizada por meio de coleta sistêmica de dados e com apoio de indicadores específicos, para prover ao corpo gestor e aos principais stakeholders de um sistema em funcionamento (algo que traga resultados na forma de bens ou serviços) informações sobre o progresso durante o processo e resultados alcançados (OECD, 2002; Sera e Beaudry, 2007; UNDP, 2009). 
Já avaliação é definida como um processo sistemático para determinar o valor gerado por um sistema em relação aos objetivos estabelecidos, traduzido pela eficácia das iniciativas, impactos e sustentabilidade. As informações obtidas devem ser capazes de possibilitar a incorporação de lições aprendidas nos processos de tomadas de decisões. Uma avaliação pode ser realizada em atividades que estejam em fase de planejamento, em andamento ou concluídas (OECD, 2002; Sera e Beaudry, 2007; UNDP, 2009).

Conforme Unicef (2005), um processo de avaliação deve contemplar:

- Descobertas: declarações factuais, incluindo descrições e medidas;

- Conclusões: sínteses e análises descritivas das descobertas;

- Recomendações: o que e onde pode ser feito, no futuro, em uma determinada situação;

- Lições aprendidas: o que foi aprendido em processos anteriores e a informação adquirida poderá ser utilizado em outros casos trabalhados.

Monitoramento e avaliação destinam-se a influenciar processos de tomada de decisão em manter, aprimorar, reorientar ou descontinuar projetos, envolvendo a participação de membros da equipe gestora e representantes dos principais stakeholders (Unicef, 2005).

Focalizando-se a proposição de indicadores e métricas de monitoramento e avaliação de desempenho de parques tecnológicos, recomenda-se a elaboração do quadro lógico de atuação desses empreendimentos (Ferreira, Cassiolato e Gonzalez, 2009; Cassiolato e Gueresi, 2010). Busca-se, assim, configurar um desenho de sua operação, que possa ser realizada em determinadas circunstâncias, para atender as expectativas de seus múltiplos stakeholders.

Os elementos do quadro lógico incluem recursos, objetivos, ações, resultados intermediários e finais, impactos desses resultados, assim como as hipóteses que suportam essas relações e as influências das variáveis relevantes do contexto de um determinado parque tecnológico.

A metodologia para elaboração do quadro lógico foi concebida e divulgada por McLaughlin e Jordan (2004) e W. K. Kellogg Foundation (2004), que combinaram ainda elementos básicos de 'Planejamento de Projeto Orientado por 
Objetivos", também conhecido como $\mathrm{ZOPP}^{2}$ e de Planejamento Estratégico Situacional ${ }^{3}$.

Para a construção do quadro lógico da atuação dos parques tecnológicos, devem ser definidos três componentes: (i) explicação do problema e referências básicas da atuação do parque (direcionadores estratégicos, segmentos de clientes e stakeholders); (ii) estruturação do planejamento estratégico para alcance de resultados (resultados finais e impactos); e (iii) identificação de fatores críticos do contexto, que são variáveis relevantes que se encontram fora da governabilidade dos responsáveis pela implementação e operação do parque.

$\mathrm{Na}$ perspectiva da modelagem pretendida, o quadro lógico deve orientar também a estratégia de crescimento de um determinado parque e a definição dos indicadores e métricas para o monitoramento e avaliação de seu desempenho ao longo do tempo, focalizando-se resultados alcançados e os impactos de suas ações e iniciativas.

O processo de formulação do quadro lógico da atuação do parque tecnológico deverá contribuir para garantir as seguintes condições:

- Definição clara e plausível dos objetivos e resultados esperados do parque em horizontes temporais estabelecidos previamente;

- Identificação de indicadores relevantes de desempenho, que possam ser obtidos a um custo razoável;

- Comprometimento dos gestores do parque tecnológico, com o que está proposto no quadro lógico.

Uma vez construído o quadro lógico da atuação do parque tecnológico, torna-se possível definir os indicadores e métricas para a avaliação do desempenho das ações e iniciativas de curto, médio e longo prazos, planejadas para o alcance dos objetivos estratégicos do empreendimento.

O Quadro 3.1, a seguir, apresenta um esquema básico para construção do quadro lógico de atuação de um parque tecnológico, na perspectiva de se definir indicadores e métricas de seu desempenho em horizontes temporais previamente estabelecido.

2 A denominação ZOPP, originário do alemão (Ziel Orientierte Projekt Planung), refere-se a uma metodologia de Planejamento de Projeto Orientado por Objetivos), que foi adotada pela Agência Alemã de Cooperação Técnica (GTZ GmbH - Gesellschaft für Technische Zusammenarbeit) em 1981. Tem sido utilizada por instituições internacionais como o Banco Mundial e a Comissão Europeia.

3 Matus, Carlos. Politica, Planejamento e Governo. Brasília: IPEA. 1993. 
Quadro 3.1 - Esquema básico para construção do quadro lógico da atuação de um parque tecnológico

\begin{tabular}{|c|c|c|c|c|c|}
\hline $\begin{array}{l}\text { Hierarquia dos } \\
\text { objetivos }\end{array}$ & Objetivos & $\begin{array}{c}\text { Ações } \\
\text { (CP, MP e } \\
\text { LP) }\end{array}$ & $\begin{array}{c}\text { Resultados } \\
\text { esperados } \\
\text { (CP, MP e } \\
\text { LP) }\end{array}$ & Indicadores & Métricas \\
\hline $\begin{array}{l}\text { Objetivo } \\
\text { estratégico }\end{array}$ & \multicolumn{5}{|c|}{ [Enunciado do 1ㅇo objetivo estratégico do parque tecnológico] } \\
\hline $\begin{array}{lr}\text { Objetivos de } \\
\text { curto prazo (CP) }\end{array}$ & & & & & \\
\hline $\begin{array}{l}\text { Objetivos de } \\
\text { médio prazo } \\
\text { (MP) }\end{array}$ & & & & & \\
\hline $\begin{array}{l}\text { Objetivos de } \\
\text { longo prazo (LP) }\end{array}$ & & & & & \\
\hline $\begin{array}{l}\text { Objetivo } \\
\text { estratégico }\end{array}$ & \multicolumn{5}{|c|}{ [Enunciado do $2^{\circ}$ objetivo estratégico do parque tecnológico] } \\
\hline $\begin{array}{l}\text { Objetivos de } \\
\text { curto prazo (CP) }\end{array}$ & & & & & \\
\hline $\begin{array}{l}\text { Objetivos } \mathrm{de} \\
\text { médio prazo } \\
\text { (MP) }\end{array}$ & & & & & \\
\hline $\begin{array}{lr}\text { Objetivos } & \text { de } \\
\text { longo } & \text { prazo } \\
\text { (LP) } & \end{array}$ & & & & & \\
\hline $\begin{array}{l}\text { Objetivo } \\
\text { estratégico }\end{array}$ & \multicolumn{5}{|c|}{ [Enunciado do no objetivo estratégico do parque tecnológico] } \\
\hline $\begin{array}{l}\text { Objetivos de } \\
\text { curto prazo (CP) }\end{array}$ & & & & & \\
\hline $\begin{array}{l}\text { Objetivos de } \\
\text { médio prazo } \\
\text { (MP) }\end{array}$ & & & & & \\
\hline $\begin{array}{l}\text { Objetivos } \mathrm{de} \\
\text { longo prazo } \\
\text { (LP) }\end{array}$ & & & & & \\
\hline
\end{tabular}

Fonte: Elaboração própria.

\section{2}

Monitoramento e avaliação de desempenho como parte do ciclo de gestão de parques tecnológicos

Conforme mencionado por Sera e Beaudry (2007), monitoramento e avaliação são importantes ferramentas de gestão, que possibilitam manter o acompanhamento do progresso dos programas e empreendimentos e avaliar seus resultados e impactos. Contudo, parques tecnológicos são instituições voltadas não só para promoção de inovações e transferência de tecnologia, mas também para o desenvolvimento regional ou local (Escorsa e Valls, 1996; Matusiaka e Bakowskiego, 2008, apud Zieliński, Rogala e Takemura, 2014; Ferrara, Lamperti e Mavilia, 2015). Portanto, a aplicação adequada de ferramentas que proporcionem a identificação de pontos para melhoria para esses empreendimentos gerará benefícios não só para o corpo de gestores atuantes no 
parque tecnológico, mas também para as instituições e empresas e para o contexto mais amplo, seja em escala local, regional, nacional ou internacional.

A gestão de um parque tecnológico, conforme Pose e Hardy (2014), é responsável por diversas atividades e processos organizacionais, como seleção de funcionários, apoio administrativo e tecnológico a empresas e centros de P\&D residentes, fortalecimento do networking, transferência tecnológica, geração de receitas para assegurar a viabilidade financeira do projeto, dentre outras atribuições.

Consequentemente, o conhecimento do perfil estratégico do parque, de seu modelo de negócio, incluindo a proposição de valor para seus clientes e parceiros, torna-se crucial para se conceber um modelo de monitoramento e avaliação de desempenho que considere as especificidades de agrupamentos de parques tecnológicos com direcionadores e objetivos estratégicos comuns.

\section{3 Modelos de monitoramento e avaliação de desempenho de parques tecnológicos: métodos e ferramentas adotadas}

Identificaram-se na fase de revisão bibliográfica da presente pesquisa, modelos de monitoramento e avaliação de desempenho desenvolvidos especificamente para parques tecnológicos.

Destaca-se o trabalho de Guy (1996), que propôs um modelo de monitoramento e avaliação em quatro fases:

- Compreensão do contexto em que se encontra o parque tecnológico, abrangendo o conhecimento histórico, espacial e social;

- Desenvolvimento de uma estratégia de avaliação, considerando-se o momento em que a avaliação é aplicada, como será utilizada e o que será avaliado;

- Especificação das táticas de avaliação, que consiste da especificação cuidadosa do sistema de avaliação (indicadores e métricas), procedimentos e técnicas para a coleta, análise a apresentação dos dados e os parâmetros envolvidos (tipo e natureza do parque tecnológico, parcerias envolvidas no projeto, variáveis existentes para alcançar os objetivos pretendidos e indicadores utilizados para medir o desempenho do parque);

- Estabelecimento de uma agenda operacional, que permita planejar a condução do processo de avaliação, levando-se em consideração a 
natureza, conteúdo e precisão dos dados a serem entregues e, por fim, a utilização dos resultados, seguida da iniciação de ações de monitoramento.

A Figura 3.1 mostra as etapas propostas por Guy (1996), destacando-se o fluxo de conhecimento e os ciclos de aprendizagem que ocorrem ao longo do processo. O autor busca mostrar nesta Figura que cada etapa não se encontra em uma sequência restrita, mas sim que o conhecimento adquirido pode auxiliar na correção ou no desenvolvimento das etapas anteriores.

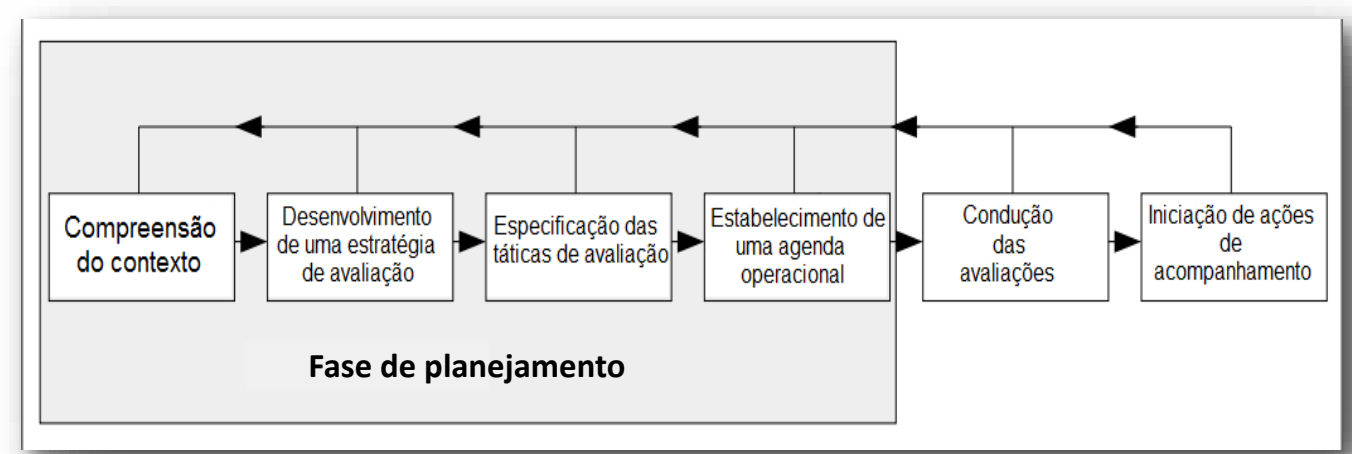

Figura 3.1 - Modelo de avaliação de parques tecnológicos segundo Guy Fonte: Guy (1996).

Em outra vertente, Hogan (1996) propõe uma metodologia de avaliação voltada para parques tecnológicos, que emprega cinco variáveis-chave, cada uma contemplando sete indicadores, em um total de trinta e cinco indicadores de avaliação.

Hogan (1996) considera 'outputs' e 'impactos' como indicadores-chave para avaliação de parques tecnológicos, chamando-os, respectivamente, de fatores intrínsecos e extrínsecos de sucesso.

Os fatores intrínsecos estão fortemente correlacionados ao nível de sinergia tecnológica adquirida, enquanto os fatores extrínsecos mensuram o nível de desenvolvimento regional proporcionado pelo parque tecnológico.

Por outro lado, Staton (1996) argumenta que a construção do quadro lógico da atuação de um parque tecnológico poderia ser benéfica nas várias fases do processo de concepção de um sistema de monitoramento e avaliação desses ambientes de inovação. Segundo o autor, a ferramenta de construção de quadro lógico pode ser aplicada com sucesso em pontos diversos do ciclo de vida do 
desenvolvimento de parques tecnológicos, permitindo o compartilhamento das informações sobre variáveis e indicadores entre todos os stakeholders.

O Quadro 3.2 apresenta as variáveis e indicadores-chave de desempenho de parques tecnológicos, segundo a visão de Hogan (1996).

Quadro 3.2 - Variáveis e indicadores- chave de desempenho de parques tecnológicos, segundo Hogan

\begin{tabular}{|c|c|c|c|c|}
\hline \multicolumn{3}{|l|}{ Variáveis } & \multicolumn{2}{|c|}{ Indicadores de desempenho } \\
\hline Inputs & Estruturas & Processos & Outputs & Impactos \\
\hline $\begin{array}{l}\text { Ambiente inicial } \\
\text { (economia, } \\
\text { indústria) }\end{array}$ & $\begin{array}{l}\text { Tipo de parque } \\
\text { tecnológico } \\
\text { (restrito / } \\
\text { aberto) }\end{array}$ & $\begin{array}{l}\text { Procedimentos } \\
\text { de governança }\end{array}$ & $\begin{array}{l}\text { № de empresas } \\
\text { residentes no } \\
\text { parque }\end{array}$ & $\begin{array}{l}\text { Empregados } \\
\text { pertencentes ao } \\
\text { parque tecnológico } \\
\text { (quantidade e } \\
\text { qualidade) }\end{array}$ \\
\hline $\begin{array}{l}\text { Qualidades e } \\
\text { forças da } \\
\text { universidade }\end{array}$ & $\begin{array}{l}\text { Tamanho do } \\
\text { parque }\end{array}$ & $\begin{array}{l}\text { Estrutura da } \\
\text { gestão }\end{array}$ & $\begin{array}{l}\text { № de fomentos } \\
\text { em novas } \\
\text { tecnologias }\end{array}$ & $\begin{array}{l}\text { Valor das aquisições } \\
\text { das firmas presentes } \\
\text { na região }\end{array}$ \\
\hline Objetivos iniciais & $\begin{array}{l}\text { Distância da } \\
\text { universidade }\end{array}$ & $\begin{array}{l}\text { Marketing do } \\
\text { parque }\end{array}$ & $\begin{array}{l}\text { Rentabilidade / } \\
\text { volume de } \\
\text { negócios no } \\
\text { parque }\end{array}$ & $\begin{array}{l}\text { Aumento na balança } \\
\text { comercial da região }\end{array}$ \\
\hline $\begin{array}{l}\text { Custo do das } \\
\text { instalações } \\
\text { (terreno, prédios, } \\
\text { entre outros) }\end{array}$ & $\begin{array}{l}\text { Seletividade } \\
\text { setorial / } \\
\text { tecnológica }\end{array}$ & $\begin{array}{l}\text { Motivação da } \\
\text { gestão do } \\
\text { parque } \\
\text { tecnológico }\end{array}$ & $\begin{array}{l}\text { Entrada de capital } \\
\text { ao parque } \\
\text { proveniente de } \\
\text { alugueis }\end{array}$ & $\begin{array}{l}\text { Aumento no PIB da } \\
\text { região }\end{array}$ \\
\hline $\begin{array}{l}\text { Custo das } \\
\text { operações } \\
\text { administrativas, } \\
\text { marketing, entre } \\
\text { outros. }\end{array}$ & $\begin{array}{l}\text { Seletividade de } \\
\text { P\&D / produçãa }\end{array}$ & $\begin{array}{l}\text { Suporte a um } \\
\text { sistema de } \\
\text { transferência } \\
\text { tecnológica }\end{array}$ & $\begin{array}{l}\text { № de patentes } \\
\text { das firmas no } \\
\text { parque }\end{array}$ & $\begin{array}{l}\text { Mudança relativa na } \\
\text { porcentagem de } \\
\text { desemprego }\end{array}$ \\
\hline $\begin{array}{l}\text { Custo de subsídios, } \\
\text { alugueis, bolsas, } \\
\text { entre outros. }\end{array}$ & $\begin{array}{l}\text { Presença de } \\
\text { incubadoras ou } \\
\text { centros de } \\
\text { inovação }\end{array}$ & $\begin{array}{l}\text { Interatividade } \\
\text { universidade - } \\
\text { empresas }\end{array}$ & $\begin{array}{l}\text { Aumento de } \\
\text { publicações e } \\
\text { patentes da } \\
\text { universidade }\end{array}$ & $\begin{array}{l}\text { Melhoria na } \\
\text { reputação da } \\
\text { universidade }\end{array}$ \\
\hline $\begin{array}{l}\text { Divisão dos custos } \\
\text { entre } \\
\text { patrocinadores }\end{array}$ & $\begin{array}{l}\text { Suporte a uma } \\
\text { gama } \\
\text { diferenciada de } \\
\text { negócios }\end{array}$ & $\begin{array}{l}\text { Interatividade } \\
\text { entre firmas }\end{array}$ & $\begin{array}{l}\text { № de publicações } \\
\text { em parcerias }\end{array}$ & $\begin{array}{l}\text { Melhoria no orgulho } \\
\text { cívico }\end{array}$ \\
\hline
\end{tabular}

Fonte: Hogan (1996).

Em consonância com os modelos de avaliação, a UKSPA encomendou uma pesquisa à Angle Technology (2003), para identificar a natureza dos benefícios que os parques tecnológicos do Reino Unido traziam para o desempenho das firmas de base de conhecimento residentes nessas organizações. Essa pesquisa propôs duas dimensões de análise:

- Desempenho econômico das empresas residentes;

- Desempenho da inovação e comercialização tecnológica das empresas residentes.

O desempenho econômico, na pesquisa de UKSPA/Angle Technology (2003), é mensurado pelos seguintes indicadores: 
- Crescimento do número de empregos e empregados nas empresas residentes;

- Volume de negócios e receitas;

- Acesso a recursos financeiros.

Já a capacidade de inovação e desempenho inovador foi avaliado segundo os indicadores abaixo:

- Novos serviços;

- Novos produtos;

- Aplicações de patentes;

- Porcentagem de cientistas e engenheiros qualificados;

- Intensidade no investimento de P\&D como porcentagem no volume de negócios.

Bigliardi et al. (2006) apresentam um estudo empírico que busca demonstrar que os parques tecnológicos adotam sistemas de avaliação de desempenho diferentes um do outro. Os resultados do estudo indicam que os critérios de avaliação de desempenho de um parque tecnológico precisam estar alinhados com a missão do parque, aos interesses dos principais stakeholders, as condições econômicas da região, configurações jurídicas, natureza das bases científicas disponíveis e com o estágio de desenvolvimento em que se encontra. É importante ressaltar que a metodologia proposta por Bligardi et al. (2006) é de natureza qualitativa.

Monck e Peters (2009) discutem inicialmente diversos modelos de avaliação de desempenho de parques tecnológicos reportados na literatura, os benefícios e os problemas associados aos processos de monitoramento e avaliação desses empreendimentos. Em seguida, propõem um modelo para medir e avaliar os impactos provocados por parques tecnológicos. Esse modelo conecta os impactos dos parques tecnológicos às análises dos desafios enfrentados pelos mesmos, além de incluir informações detalhadas sobre a avaliação dos impactos finais dos parques. Esse modelo foi utilizado no Tamar Science Park, localizado em Plymouth, Reino Unido.

Monck e Peters (2009) finalizam o artigo propondo, à comunidade internacional de parques tecnológicos, sugestões práticas para a realização de futuros passos a serem dados sobre as questões de avaliação de desempenho, 
incluindo o estabelecimento de um grupo para o desenvolvimento de uma lista de orientações para auxiliar nesse processo.

Nosratabadi, Pourdarab e Abbasian (2011), ao realizarem um levantamento das avaliações de desempenho de parques tecnológicos nos últimos anos, observaram que os estudos empíricos sobre o tema utilizam, em sua generalidade, indicadores com bases econômicas e em inovação, assim como a complexidade em medição de desempenho de parques tecnológicos, que, com o passar do tempo, tornam-se empreendimentos com objetivos, metas e missões mais amplas. Seguindo esse critério, os autores desenvolveram um método de avaliação baseado em sistema especialista de lógica fuzzy, o qual possibilita a utilização de um grande número de critérios e parques para comparação. O sistema fuzzy proposto, segundo Nosratabadi, Pourdarab e Abbasian (2011), faz uso de nove critérios para priorizar quatro parques tecnológicos. Esses critérios são:

- Maturidade dos empreendimentos;

- Capacidades tecnológicas ou de P\&D;

- Tamanho do parque;

- Interesse dos stakeholders;

- Capacidades de gestão;

- Qualidade dos profissionais;

- Grau de integração no mercado nacional ou internacional;

- Limitações (superlotação, urgência na ampliação de investimentos em inovação e pequeno porte das empresas residentes).

A exemplo dos autores anteriores, Darowska (2011) fornece uma visão geral da literatura associada a avaliações de parques tecnológicos e resume os resultados provenientes do 'Workshop sobre o desempenho de parques tecnológicos', realizado em Manchester, em 2010. Baseando-se nos resultados do Workshop, desenvolveu uma matriz de indicadores chaves de desempenho, tendo como foco parques tecnológicos de terceira geração. A matriz de desempenho, por sua vez, teve como base metodológica a ferramenta conhecida como Balanced Scorecard (Kaplan e Norton, 1996; 2004).

Hemati e Mardami (2012) também propuseram um sistema de monitoramento e avaliação de desempenho de parques tecnológicos, baseando-se na ferramenta Balanced Scorecard. A aplicabilidade do sistema foi demonstrada 
mediante um estudo empírico desenvolvido no Semnan Technology and Science Park, localizado no Irã.

A ferramenta Balanced Scorecard também foi utilizada por Andreevna (2013), considerando-se dois perfis estratégicos distintos de parques tecnológicos: (i) ambiente de inovação; e (ii) empreendimento imobiliário. Essa abordagem permitiu analisar os elementos integradores de um ambiente de inovação. Foram criadas duas listas de indicadores-chave de avaliação de desempenho, relacionadas aos dois perfis mencionados. Os indicadores, por sua vez, referiramse a quatro perspectivas de Balanced Scorecard - BSC, que foram adaptadas das originalmente propostas por Kaplan e Norton (1996; 2004).

Wang, Wan e Zhao (2014) apresentam um modelo de monitoramento e avaliação de desempenho de parques tecnológicos chineses também baseada na ferramenta Balanced Scorecard (Kaplan e Norton, 1996; 2004). Com o objetivo de aprimorar o desempenho de parques tecnológicos na China, esses autores propuseram um mapa estratégico, ressaltando as relações entre indicadores e objetivos estratégicos dos parques. O modelo foi aplicado no Zhongguancun Science Park (ZSP), servindo como protótipo para ampla difusão entre os parques chineses. Segundo os autores, a abordagem do Balance Socorecard é uma ferramenta objetiva, que permite construir mapas estratégicos para parques tecnológicos, baseando-se nas relações entre os indicadores-chave de desempenho e os objetivos estratégicos referentes às perspectivas propostas no modelo.

Kbar e Ally (2015) desenvolveram um modelo para medir o desempenho do Riyadh Techno Valley (RTV), localizado na Arábia Saudita, que consiste na utilização de um conjunto de indicadores de desempenho agrupados em quatro dimensões:

- Pesquisa e Desenvolvimento (P\&D);

- Negócios;

- Gestão;

- Infraestrutura.

Os indicadores do modelo desenvolvido por Kbar e Ally (2015) foram associados aos principais componentes ou atividades das dimensões citadas. Segundo os autores, o valor ótimo de desempenho de um parque tecnológico pode ser estimado por uma pesquisa survey encaminhada a especialistas, que determinam o peso de cada indicador. Este procedimento permite aos gestores 
comparar os resultados da pesquisa survey com o valor ótimo, auxiliando na identificação de gaps e na proposição de uma agenda de melhorias para o parque.

Ferrara, Lamperti e Mavilia (2016) exploram dados de parques tecnológicos italianos e propõem um modelo de mensuração de desempenho desses parques, levando-se em consideração as preferências endógenas de múltiplos stakeholders. Os autores aplicam a "Teoria do Valor Multiatributo" baseada na integral Choquet para eliciar as preferências dos stakeholders em diferentes dimensões de desempenho de parques tecnológicos. Como resultado principal, eles propõem um índice global que permite ranquear os parques italianos, de acordo com o modelo multicritério.

\section{4}

\section{Análise crítica dos modelos reportados nos estudos empíricos}

Após a análise dos estudos empíricos identificados na fase de revisão da literatura, concluiu-se que diversos acadêmicos e especialistas encontraram dificuldades para apresentar uma proposta apropriada para medir o desempenho de parques tecnológicos.

A criação de um método de avaliação de desempenho voltada para parques tecnológicos torna-se uma tarefa árdua, devido à complexidade desses projetos. Como abordado, os perfis estratégicos dos parques tecnológicos podem variar em função dos interesses dos múltiplos stakeholders a serem atendidos, bem como seu estágio de desenvolvimento e modelos de negócios.

A partir da análise dos estudos empíricos voltados para este tema, concluiuse que diversos acadêmicos e especialistas em gestão de ambientes de inovação e parques tecnológicos tiveram como desafio a projeção de um modelo voltado para mensuração de desempenho de parques tecnológicos.

O Quadro 3.3 apresenta uma síntese dos modelos de monitoramento e avaliação de parques tecnológicos reportados nos estudos empíricos, cobrindo o período de 1996 a 2016. 
Quadro 3.3 - Quadro-síntese dos modelos adotados nos estudos empíricos

\begin{tabular}{|c|c|c|c|}
\hline Autores & $\begin{array}{l}\text { Abordagem } \\
\text { metodológica }\end{array}$ & Método avaliativo & Dimensões/Variáveis \\
\hline Guy (1996) & $\begin{array}{l}\text { Ex-ante, } \\
\text { intercalar, ex- } \\
\text { post. }\end{array}$ & $\begin{array}{l}\text { Estudo de caso. } \\
\text { Definição de uma } \\
\text { agenda operacional } \\
\text { focada em melhoria } \\
\text { de desempenho. }\end{array}$ & $\begin{array}{l}\text { Recursos; inputs; variáveis estruturais; } \\
\text { variáveis de processo; Variáveis de } \\
\text { output; E as variáveis de impacto, as } \\
\text { quais caracterizam o efeito que os } \\
\text { outputs possuem no ambiente. }\end{array}$ \\
\hline Hogan (1996) & $\begin{array}{l}\text { Ex-ante, } \\
\text { intercalar, ex- } \\
\text { post. }\end{array}$ & $\begin{array}{l}\text { Surveys escritas e } \\
\text { entrevistas face a } \\
\text { face. Análise } \\
\text { estatística dos dados. } \\
\text { Métricas com } \\
\text { Indicadores chave de } \\
\text { desempenho. }\end{array}$ & $\begin{array}{l}\text { Dimensões: inputs; estruturas; processos; } \\
\text { outputs; impactos. } \\
\text { Conjunto de } 35 \text { indicadores (sete por } \\
\text { dimensão) considerados indicadores- } \\
\text { chave de sucesso }\end{array}$ \\
\hline Staton (1996) & & $\begin{array}{l}\text { Planejamento de } \\
\text { projetos voltados aos } \\
\text { objetivos, incluindo a } \\
\text { construção do modelo } \\
\text { lógicor avaliativo. } \\
\text { Oficina participativa. } \\
\text { Solução colaborativa } \\
\text { de problemas. }\end{array}$ & $\begin{array}{l}\text { Variáveis de inputs; atividades; outputs; e } \\
\text { impactos. Conjunto de indicadores de } \\
\text { input, output e impacto. }\end{array}$ \\
\hline $\begin{array}{l}\text { UKSPA/Angle } \\
\text { Technology } \\
\text { (2003) }\end{array}$ & & $\begin{array}{lr}\text { Survey e análise } \\
\text { estatística dos dados. } \\
\text { Métricas dos } \\
\text { indicadores. }\end{array}$ & $\begin{array}{l}\text { Desempenho econômico das empresas } \\
\text { residentes. } \\
\text { Desempenho da comercialização das } \\
\text { inovações e tecnologias provenientes das } \\
\text { empresas residentes. }\end{array}$ \\
\hline $\begin{array}{l}\text { Bigliardi et al. } \\
(2006)\end{array}$ & & $\begin{array}{l}\text { Estudo de caso, } \\
\text { indicadores métricos. }\end{array}$ & $\begin{array}{l}\text { Alinhamento com a missão do parque } \\
\text { tecnológico; Maior comprometimento } \\
\text { dos principais stakeholders; Condições } \\
\text { económicas regionais; Formas jurídicas; } \\
\text { Natureza e competência da base } \\
\text { científica disponível nos centros de } \\
\text { pesquisa; e estágios do ciclo de vida do } \\
\text { parque tecnológico. }\end{array}$ \\
\hline $\begin{array}{l}\text { Monck e } \\
\text { Peters (2009) }\end{array}$ & & $\begin{array}{lr}\text { Survey e análise } \\
\text { estatística dos dados. } \\
\text { Métricas ros } \\
\text { indicadores. }\end{array}$ & $\begin{array}{l}\text { Dois níveis na evolução dos impactos: (i) } \\
\text { efeitos diretos; (ii) efeitos de valor } \\
\text { agregado indiretos e estratégicos. } \\
\text { (i) inputs; atividades; produção bruta; } \\
\text { resultados; impactos; (ii) produção bruta; } \\
\text { resultados; impactos. }\end{array}$ \\
\hline $\begin{array}{l}\text { Dabrowska } \\
\text { (2011) }\end{array}$ & & $\begin{array}{l}\text { Métricas de } \\
\text { Indicadores chaves de } \\
\text { desempenho } \\
\text { associadas às } \\
\text { dimensões de } \\
\text { Balanced Scorecards }\end{array}$ & $\begin{array}{l}\text { Modelo para parques tecnológicos de } \\
\text { Terceira geração (3G STPS) } \\
\text { compreendendo cinco dimensões: } \\
\text { comercial; perspectiva dos shareholders; } \\
\text { perspectivas da direção; marca e } \\
\text { reputação; e processos de negócios } \\
\text { internos. }\end{array}$ \\
\hline $\begin{array}{l}\text { Nosratabadi, } \\
\text { Pourdarab e } \\
\text { Abbasian } \\
\text { (2011) }\end{array}$ & & $\begin{array}{l}\text { Survey e métodos } \\
\text { multicritério de apoio } \\
\text { a decisão combinados } \\
\text { com lógica fuzzy. }\end{array}$ & $\begin{array}{l}\text { Limitações; nível de integração com os } \\
\text { mercados nacionais e internacionais; } \\
\text { qualificações profissionais; capacidades } \\
\text { de gestão; interesse dos stakeholders; } \\
\text { tamanho; capacidade tecnológica; } \\
\text { maturidade do empreendimento; venture } \\
\text { capital. }\end{array}$ \\
\hline
\end{tabular}


Quadro 3.3 - Quadro-síntese dos modelos adotados nos estudos empíricos (cont.)

\begin{tabular}{|c|c|c|c|}
\hline Autores & $\begin{array}{l}\text { Abordagem } \\
\text { metodológica }\end{array}$ & Método avaliativo & Dimensões/Variáveis \\
\hline $\begin{array}{l}\text { Hemati e } \\
\text { Mardami } \\
(2012)\end{array}$ & & $\begin{array}{l}\text { Métricas de } \\
\text { Indicadores chaves de } \\
\text { desempenho } \\
\text { associadas às } \\
\text { dimensões de } \\
\text { Balanced Scorecard. }\end{array}$ & $\begin{array}{l}\text { Quatro perspectivas em Balanced } \\
\text { Scorecard: finanças, clientes, processos } \\
\text { internos e aprendizado e crescimento } \\
\text { dos funcionários. }\end{array}$ \\
\hline $\begin{array}{l}\text { Andreevna } \\
\text { (2013) }\end{array}$ & & $\begin{array}{l}\text { Métricas de } \\
\text { Indicadores chaves de } \\
\text { desempenho } \\
\text { associadas às } \\
\text { dimensões de } \\
\text { Balanced Scorecard }\end{array}$ & $\begin{array}{l}\text { Quatro perspectivas do Balanced } \\
\text { Scorecard foram adaptadas das } \\
\text { originalmente propostas por Kaplan e } \\
\text { Norton (1996; 2004). Indicadores foram } \\
\text { associados a essas dimensões, } \\
\text { considerando-se dois papéis distintos de } \\
\text { parques tecnológicos: (i) ambiente de } \\
\text { inovação; e (ii) empreendimento } \\
\text { imobiliário. Foram criadas duas listas de } \\
\text { indicadores: uma para cada papel. }\end{array}$ \\
\hline $\begin{array}{l}\text { Wang, Wan e } \\
\text { Zhao (2014) }\end{array}$ & $\begin{array}{l}\text { Balanced } \\
\text { Scorecard }\end{array}$ & $\begin{array}{l}\text { Estudo de caso. } \\
\text { Métricas com } \\
\text { indicadores chave de } \\
\text { sucesso associados às } \\
\text { dimensões do Balance } \\
\text { Scorecard. }\end{array}$ & $\begin{array}{l}\text { Quatro perspectivas em Balance } \\
\text { Scorecard: finanças, clientes, processos } \\
\text { internos e aprendizado e crescimento } \\
\text { dos funcionários. }\end{array}$ \\
\hline $\begin{array}{l}\text { Fernandes } \\
(2014)\end{array}$ & $\begin{array}{l}\text { Ex-ante, } \\
\text { intercalar, ex- } \\
\text { post.. }\end{array}$ & $\begin{array}{l}\text { Pesquisa survey e } \\
\text { análise estatística dos } \\
\text { dados. }\end{array}$ & $\begin{array}{l}\text { Modelo para parques tecnológicos de } \\
\text { Terceira geração ( } 3 G \quad \text { STPs) } \\
\text { compreendendo seis dimensões: itens } \\
\text { primários (infraestrutura; recursos e } \\
\text { serviços ofertados às empresas } \\
\text { residentes); desenvolvimento local e } \\
\text { humano; interligações entre } \\
\text { stakeholders; capacidade para inovação; } \\
\text { outputs em finanças; nível de integração } \\
\text { com o mercado nacional e internacional. }\end{array}$ \\
\hline $\begin{array}{l}\text { Kbar e Ally } \\
(2015)\end{array}$ & $\begin{array}{l}\text { Ex-ante, } \\
\text { intercalar, ex- } \\
\text { post. }\end{array}$ & $\begin{array}{l}\text { Pesquisa survey e } \\
\text { combinação de } \\
\text { métodos multicritério } \\
\text { de apoio a decisão. } \\
\text { Estudo de caso para } \\
\text { validação. }\end{array}$ & $\begin{array}{l}\text { Alinhamento com parques tecnológicos } \\
\text { de quarta geração. } \\
\text { Dimensões: P\&D; negócios; gestão e } \\
\text { infraestrutura. O valor ótimo de } \\
\text { desempenho dos parques tecnológico } \\
\text { pode ser estimado. }\end{array}$ \\
\hline CMI (2015) & $\begin{array}{l}\text { Business model } \\
\text { generation } \\
\text { (BMG) }\end{array}$ & $\begin{array}{l}\text { Workshop } \\
\text { participativo. } \\
\text { Métricas de } \\
\text { indicadores chaves de } \\
\text { desempenho } \\
\text { associados a blocos } \\
\text { de BMG. }\end{array}$ & $\begin{array}{l}\text { O BMG é uma gestão estratégica que } \\
\text { pode ser construída em nove blocos: } \\
\text { segmento de clientes; relacionamento } \\
\text { com clientes; parceiros chaves; recursos } \\
\text { chaves; atividades chaves; canais; fluxo } \\
\text { de receitas; custo estrutural e valor da } \\
\text { proposta. }\end{array}$ \\
\hline
\end{tabular}


Quadro 3.3 - Quadro-síntese dos modelos adotados nos estudos empíricos (cont.)

\begin{tabular}{|c|c|c|c|}
\hline Autores & $\begin{array}{l}\text { Abordagem } \\
\text { metodológica }\end{array}$ & Método avaliativo & Dimensões/Variáveis \\
\hline $\begin{array}{l}\text { Ferrara, } \\
\text { Lamperti e } \\
\text { Mavilia (2016) }\end{array}$ & $\begin{array}{l}\text { Ex ante, mid- } \\
\text { term, ex-post. }\end{array}$ & $\begin{array}{l}\text { Pesquisa survey e } \\
\text { aplicação da Teoria do } \\
\text { Valor Multiatributo } \\
\text { baseada na integral } \\
\text { Choquet para eliciar } \\
\text { as preferências dos } \\
\text { stakeholders nas em } \\
\text { diferentes dimensões } \\
\text { de desempenhos dos } \\
\text { parques tecnológicos. }\end{array}$ & $\begin{array}{l}\text { O índice agregado permite classificar os } \\
\text { parques tecnológicos. Esse índice possui } \\
\text { oito indicadores associados em duas } \\
\text { dimensões: (i) inovação; e (ii) } \\
\text { empreendedorismo. Para a primeira } \\
\text { dimensão, os indicadores referem-se a } \\
\text { centros de pesquisa; patentes; } \\
\text { networking científico; projetos. Para a } \\
\text { dimensão } \\
\text { crescimento; no de empreendedorismo: } \\
\text { geoconsistência. }\end{array}$ \\
\hline
\end{tabular}

Fonte: Lyra e Almeida (2016).

Conforme apresentado no Quadro 3.3, nos estudos empíricos foram adotadas diversas metodologias e ferramentas de monitoramento e avaliação de desempenho de parques tecnológicos. Contudo, pode-se observar uma ênfase na utilização da ferramenta Balanced Scorecard (Dabrowska, 2011; Hemati e Mardami, 2012; Andreevna,2013; e Wang, Wan e Zhao, 2014) e de pesquisas surveys (Hogan, 1996; UKSPA/Angle Technology, 2003; Monck e Peters, 2009; Nosratabadi, Pourdarab e Abbasian, 2011; Fernandes, 2014; Kbar e Ally, 2015; e Ferrara, Lamperti e Mavilia, 2016). Já a utilização de análises estatísticas e métodos multicritério de apoio à decisão foi observada nos trabalhos de Hogan (1996); UKSPA/Angle Technology (2003); Monck e Peters (2009); Nosratabadi, Pourdarab e Abbasian (2011); Fernandes (2014); Kbar e Ally (2015); e de Ferrara, Lamperti e Mavilia (2016).

A proposta de um modelo adaptativo permite a seleção de indicadores e métricas para monitoramento e avaliação de desempenho associados a agrupamentos de parques tecnológicos, levando-se em consideração as especificidades de seus ambientes complexos de atuação e de articulação institucional, seus objetivos e direcionadores estratégicos (missão, visão de futuro e valores) e interesses de seus múltiplos stakeholders.

Alvarez (1997) ressalta a importância de um modelo de avaliação baseado na gestão adaptativa, que permita que a organização gestora do parque monitore e avalie os resultados e impactos de seus processos e projetos nos horizontes de tempo considerados (curto, médio e longo prazos), identificando oportunidades de correção em tempo hábil de desvios e erros durante a execução (nível operacional), bem como a revisão de diretrizes e estratégias no nível normativo. 


\section{4 \\ Modelo conceitual adaptativo de monitoramento avaliação do desempenho de parques tecnológicos}

Propõe-se um modelo conceitual para o monitoramento e avaliação de parques tecnológicos, que foi desenvolvido segundo a abordagem de gestão adaptativa e validado empiricamente junto a 26 participantes a gestores participantes do $1^{\circ}$ Curso para Gestores de Parques Tecnológicos e Ambientes de Inovação, oferecido pela Uni-Anprotec, em parceria com o Instituto Gênesis, da PUC-Rio, em 2016.

O modelo compreende três fases, conforme o ciclo de gestão de organizações em geral, a saber: (i) fase de planejamento; (ii) fase de ação; e (iii) fase de avaliação de resultados e impactos.

\section{1}

\section{A abordagem de gestão adaptativa aplicada a parques tecnológicos}

No contexto institucional de parques tecnológicos, o processo de monitoramento e avaliação do desempenho de parques permite aos gestores modificarem ou realizarem ajustes nos processos e iniciativas em curso no parque, em função de mudanças nas condições do ambiente, tanto externo, quanto interno Além disso, possibilita a implementação de procedimentos para se alcançar os objetivos, metas e resultados desejados, buscando influenciar o ambiente, de modo que esse se torne mais favorável aos propósitos do empreendimento (Alvarez, 1997).

Outro aspecto importante a ser monitorado e avaliado é a formação de redes de inovação e consequentemente o fluxo de conhecimento e de transferência de tecnologia entre diversos atores dos parques. A gestão de parques tecnológicos, como um ambiente de inovação no qual interagem diversos atores (entidade gestora, empresas e instituições de C\&T, incubadoras, etc.), deve enfatizar a formação de redes de inovação, de forma distinta das convencionais parcerias estratégicas. Segundo Henderson (1990), essas redes caracterizam-se pela 
percepção de uma identidade compartilhada - missão, visão de futuro, perfil estratégico e modelo de negócio -, que se reflete na intensificação do fluxo de conhecimento e tecnologias nesses ambientes.

Face às lacunas identificadas nos modelos de monitoramento e avaliação de parques tecnológicos (seção 3.4), que não levam em conta os aspectos acima mencionados, discute-se inicialmente a aplicabilidade da abordagem de gestão adaptativa na modelagem pretendida, ressaltando-se as vantagens de sua utilização em relação aos mecanismos de monitoramento e avaliação de desempenho convencionais. Considerando-se as condicionantes de aplicação dessa abordagem no contexto institucional de parques tecnológicos, acredita-se que ela possa ser apropriada para responder aos desafios da gestão desses ambientes de inovação, particularmente nas fases de planejamento estratégico e de avaliação de desempenho, pelas suas propriedades associadas à administração da incerteza, da complexidade e da interdependência.

Segundo Melo e Agostinho (2007), “a gestão adaptativa é uma abordagem gerencial desenvolvida para dotar os sistemas organizacionais com maior grau de adaptabilidade, buscando oferecer meios para aumentar a velocidade de resposta às pressões ambientais e melhorar a qualidade dessa resposta”.

Para isso, as autoras argumentam que tanto o planejamento quanto a gestão de pessoas e de processos devam ser conduzidos segundo uma mesma lógica, de acordo com princípios comuns, para assegurar a coerência do empreendimento e, por conseguinte, seu desempenho superior.

A abordagem de gestão adaptativa emergiu na década de 60 e tem suas origens epistemológicas na teoria de sistemas, com adoção de métodos de ação influenciados pelas experiências da Escola Sociotécnica e por resultados de pesquisas sobre sistemas complexos adaptativos (Melo e Agostinho, 2007).

A gestão adaptativa apoia-se nos seguintes princípios: (i) questionamento normativo; (ii) autorregulação; (iii) ação reflexiva e adaptação; e (iv) cooperação e agregação (Melo e Agostinho, 2007; Strauss et al., 1963; Trist, 1981; Melo, 1985; 1986; 2002; Bauman, 2001).

Com relação ao primeiro princípio - 'Questionamento normativo'- a entidade gestora do parque tecnológico, juntamente com seus múltiplos stakeholders, deve estabelecer as direções comuns a serem seguidas pelos 
diversos atores, que se envolvem nos processos desse ambiente inovador, definindo-se, dessa forma, os fundamentos para a formação de uma verdadeira comunidade da gestão desse ambiente interorganizacional.

De acordo com Melo e Agostinho (2007), "visa-se estabelecer uma ordem negociada (Strauss, 1963), configurada em padrão de autoridade compartilhada. Essa ordem, por poder ser renegociada a cada momento, é, necessariamente, de natureza dinâmica ou, como diria Bauman (2001), constitui um acordo que precisa ser periodicamente renovado".

No que tange o segundo princípio - 'Autorregulação'- um padrão de organização (estrutura ou comportamento) deve emergir das ações das partes do sistema, ao invés de ser imposta de cima para baixo pela alta liderança do parque tecnológico. Este princípio refere-se aos princípios básicos do projeto sociotécnico de autorregulação e autonomia e liberdade de ação, identificados por Trist (1981), segundo os quais a iniciativa de cada membro é incentivada, em contraposição ao atendimento estrito de regras prescritas.

Em relação ao terceiro princípio - 'Ação reflexiva e adaptação' - a entidade gestora do parque tecnológico deve assumir uma postura de adaptação ativa, segundo a qual busca influenciar o comportamento do ambiente (externo e interno), de modo que este lhe seja favorável para o cumprimento de sua missão e objetivos estratégicos. Segundo Melo (1985), busca-se introduzir mudanças em focos geradores dessas mudanças, que se configuram como pontos de 'alavancagem', estabelecendo-se uma reação em cadeia que visa à transformação do sistema como um todo (Melo, 1985).

Finalmente, o quarto princípio - 'Cooperação e agregação' - a entidade gestora deve buscar permanentemente criar e manter vínculos comunitários, formando-se a identidade do ambiente de inovação ou rede interorganizacional, pela cooperação e agregação. A cooperação efetiva requer transparência nas decisões e ações, essenciais para o desenvolvimento da confiança, a qual só se conquista a partir da credibilidade (Melo e Agostinho, 2007).

Para a incorporação desses princípios na modelagem objeto desta dissertação, sintetizam-se, a seguir, as principais características da abordagem de gestão adaptativa (Almeida, 2006, apud Melo, 2002, p. 58): 
- Extensão do processo de planejamento para abranger o nível normativo, convertendo a discussão de valores compartilhados em base para o estabelecimento de direções comuns, a serem seguidas pelas diversas partes que se envolvem nesse processo;

- Ênfase na formulação da problemática, focalizando-se o domínio interorganizacional e buscando-se entender as interrelações entre as organizações membros e os impactos causados por essas interrelações em cada componente do domínio;

- Proposição de uma adaptação ativa, adotando-se a postura proativa, pela qual se procura influir no ambiente de modo que esse se torne mais favorável aos propósitos da organização;

- Busca de um grau ótimo de envolvimento dos membros, os quais, por uma participação ativa, tornam-se corresponsáveis pelos resultados das ações planejadas;

- Flexibilidade, com constante apreciação dos objetivos formulados e contínua avaliação das ações implementadas, permitindo a redefinição de rumos;

- Adoção da metodologia de pesquisa-ação, que possibilita o aprendizado organizacional por meio da reflexão sobre os efeitos das ações realizadas, com a consequente identificação de novos conceitos, caminhos e métodos.

Como abordado no capítulo 2, são muitos os desafios de gestão enfrentados pelos parques tecnológicos, particularmente no que se refere aos processos de monitoramento e avaliação de desempenho. A complexidade da gestão de parques tecnológicos é alta, tanto no sistema social quanto técnico. Frente aos desafios e à complexidade observada na fase exploratória desta pesquisa, a abordagem de gestão adaptativa parece ser uma alternativa viável para a proposição de um modelo conceitual voltado para o monitoramento e avaliação do desempenho de parques tecnológicos, que permita aos gestores definir indicadores e métricas em função de perfis estratégicos e modelos de negócios comuns a determinados agrupamentos de parques. Busca-se, assim, reconhecer as direções comuns a serem seguidas pelos atores de parques tecnológicos de um determinado agrupamento, assim como os padrões de organização (estrutura ou 
comportamento) que emergem das ações de cada um dos parques, classificados nesse agrupamento.

Essa escolha justifica-se pelas seguintes características (Almeida, 2006, p.81):

- Considera uma apreciação objetiva do fato e subjetiva quanto aos valores e impactos (consequências);

- Pressupõe que as organizações sejam adaptativas;

- Possui propriedades que propiciam a administração da incerteza, da complexidade e da interdependência;

- Permite uma integração ao referencial teórico de aprendizagem organizacional, como proposto por Argyris e Schon (1978; 1996).

Para fins desta dissertação, define-se aprendizagem organizacional como um processo em que as organizações percebem, interpretam e administram suas experiências, metas, rotinas, pressupostos compartilhados e valores organizacionais. Assim o conceito de aprendizagem organizacional contempla a estratégia, a estrutura e o conhecimento nas organizações, segundo uma visçao sistêmica, ou seja, não constitui processo linear separado dos outros processos organizacionais (Argyris e Schön, 1978; 1996; March, 1991, dentre outros autores).

A Figura 4.1 representa graficamente o modelo genérico de aprendizagem organizacional segundo a visão de Argyris e Schön (1978; 1996), ressaltando-se as: variáveis governantes, ações, conseqüências e os dois tipos de apreendizagem, o de 'ciclo simples' e de 'ciclo duplo'.

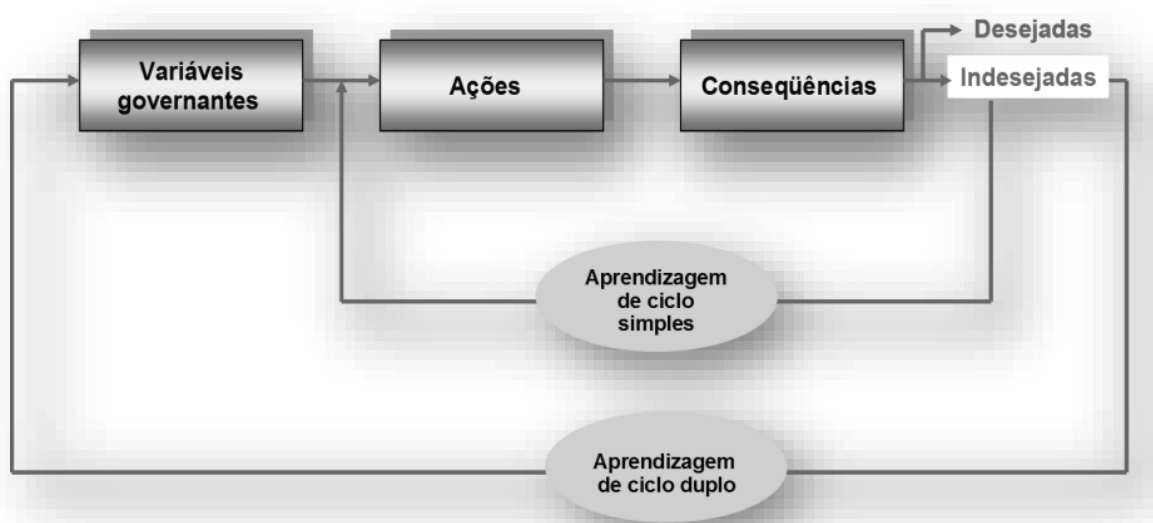

Figura 4.1 - Aprendizagem organizacional segundo Argyris e Schön

Fonte: Argyris e Schön (1978; 1996). 
De acordo com Almeida (2006), as situações de aprendizagem de 'ciclo simples' referem-se à detecção de um erro e a sua correção dentro de um certo conjunto de 'variáveis governantes', sem modificá-las. Por outro lado, os processos de aprendizagem de 'ciclo duplo' associam-se a mudanças sobre essas variáveis, qeu poderão implicar em uma mudança fundamental na direção estratégica do parque tecnológico. As entidades (indivíduos, grupos ou organizações) que integram o parque tecnológico poderão detectar e corrigir os erros, questionando e modificando os valores, premissas e políticas que balizam suas ações.

$\mathrm{Na}$ perspectiva de aplicação desse referencial na modelagem pretendida, serão considerados os dois tipos de aprendizagem (ciclo simples e duplo), como definido por Almeida (2006). A seleção de indicadores-chave deverá considerar as variáveis governantes (direcionadores estratégicos dos parques tecnológicos e interesses dos múltiplos stakeholders) e a necessidade de monitorar e avaliar as ações (atingimento de metas e progresso dos planos de ação dos parques) e suas consequências (resultados e impactos da atuação do parque tecnológico).

Com base no exposto, o modelo conceitual proposto para o monitoramento e avaliação de parques tecnológicos é representado graficamente na Figura 4.2. Descrevem-se, a seguir, os componentes do modelo conceitual adaptativo de monitoramento e avaliação de desempenho para parques tecnológicos, incluindo os ciclos de aprendizagem de ciclo simples e duplo, conforme definido por Argyris e Schon $(1978 ; 1996)$. 


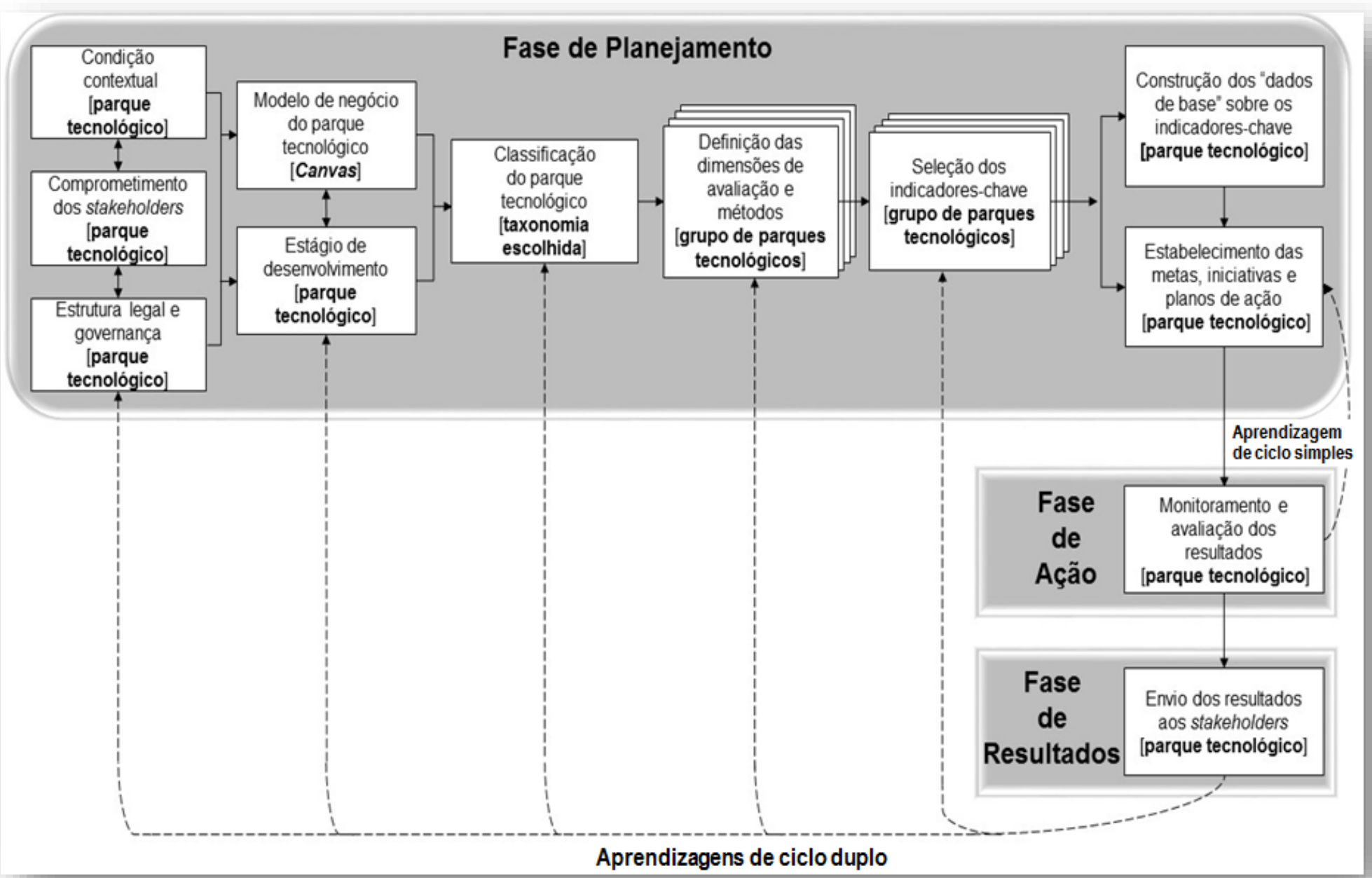

Figura 4.2 - Modelo conceitual para monitoramento e avaliação de desempenho de parques tecnológicos, segundo a abordagem de gestão adaptativa Fonte: Lyra e Almeida (2016). 


\section{2}

\section{Descrição da fase de planejamento e de suas características adaptativas}

Descrevem-se os componentes da fase de planejamento e suas características adaptativas: (i) contextualização do parque tecnológico; (ii) caracterização das partes interessadas e seus objetivos em relação ao parque tecnológico; (iii) análise do perfil estratégico do Parque Tecnológico com uso da ferramenta 'Estrategigrama' da IASP; (iv) desenho do modelo de negócio do Parque Tecnológico com uso da ferramenta Canvas; (v) análise do estágio de desenvolvimento do parque tecnológico; (vi) classificação do parque tecnológico, segundo taxonomia de escolha; (vii) definição do quadro lógico para definição de indicadores de desempenho de parques tecnológicos; e (viii) proposição de indicadores e métricas de monitoramento e avaliação de desempenho do parque tecnológico.

\subsection{1. \\ Contextualização do parque tecnológico}

Nesta etapa da fase de planejamento, é importante considerar as condições contextuais em que os parques tecnológicos estão inseridos (Guy, 1996; Staton, 1996; Bigliardi et al., 2006; Fernandes, 2014).

Segundo Guy (1996), a compreensão do contexto de um parque envolve um entendimento histórico, espacial e social em que o mesmo foi estruturado e desenvolvido. Ainda nesta mesma linha de raciocínio, Bigliardi et al. (2006) descreve que as condições contextuais de um parque tecnológico estão, geralmente, relacionadas à necessidade do desenvolvimento econômico da região em que estão localizados, da criação de novas empresas inovadoras, criadoras de novas tecnologias e fortalecimento dos empreendimentos locais através de transferências de tecnologia.

\subsection{2.}

\section{Caracterização das partes interessadas e seus objetivos em relação ao parque tecnológico}

Guy (1996), Staton (1996), Bigliardi et al. (2006), Dabrowska (2011) e Fernandes (2014) ressaltam o comprometimento das partes interessadas de parque tecnológico como um componente comum para a formulação de um modelo de 
avaliação adaptativo. Diferentes stakeholders possuem objetivos e metas diferenciados.

O Quadro 2.2, reportado no capítulo 2 desta dissertação, apresenta em detalhe tais diferenças. Segundo Bigliardi et al. (2006), os gestores de parques tecnológicos, além da administração dos processos organizacionais e atividades do parque, devem definir uma escala de prioridades, abrangendo uma série de interesses dos diferentes stakeholders envolvidos.

\subsection{3.}

\section{Análise do perfil estratégico do parque tecnológico: uso da ferramenta 'Estrategigrama' da IASP}

A ferramenta 'Estrategigrama", desenvolvida pelo diretor geral da IASP, Luiz Sanz em 2006, foi criada para melhor descrever o modelo estratégico de cada parque tecnológico (Vikström, 2006), permitindo a comparação entre os parques que utilizam da ferramenta. $\mathrm{O}$ emprego deste ferramental auxilia os tomadores de decisão e stakeholders na mensuração das características de um parque tecnológico, oferecendo suporte para os gestores analisarem as estratégias gerais do empreendimento (Mazarollo, 2010; Vikström, 2006).

O Estrategigrama tem por base sete eixos estratégicos, como descrito a seguir:

- Eixo 1 - 'Localização e ambiente externo: refere-se ao grau de urbanização do parque tecnológico. O posicionamento em cada grau da escala não depende somente da localização geográfica, dentro ou fora das cidades. Outros elementos são considerados, como a existência de áreas residenciais no parque ou adjacências, áreas comerciais e de lazer, espaços culturais e outros aspectos, que tornarão o parque atrativo;

- Eixo 2 - 'Posição no fluxo de tecnologia e conhecimento': expressa a ênfase e o posicionamento do parque em relação ao uso de fontes de conhecimento e tecnologia. As fontes de conhecimento e informação utilizadas pelo Parque, seus clientes e usuários podem ser oriundas da base de C\&T ou da base empresarial/mercado ou de ambas;

- Eixo 3 - 'Empresas-alvo': indica se a estratégia do parque é mais dirigida para empresas maduras ou para a criação de novas empresas e startups. Se o parque prefere trabalhar com empresas geradoras de novas 
tecnologias (via incubadoras) ou empresas maduras já estabelecidas no mercado. Ou se adota uma estratégia híbrida, atraindo e dirigindo esforços para ambos os tipos de empresas;

- Eixo 4 - 'Grau de especialização': neste eixo, avalia-se se o parque é especializado em um ou poucos setores tecnológicos (parque especialista) ou se admite um espectro amplo de setores tecnológicos para atuar (generalista);

- Eixo 5 - 'Mercados-alvo': refere-se a estratégias adotadas para atrair empresas locais/regionais ou empresas estrangeiras e multinacionais;

- Eixo 6 - 'Redes': verifica-se neste eixo se o parque adota diferentes abordagens para construir e manter redes de relacionamento e cooperação. Avalia-se também se o networking do parque é estratégico ou se a formação de redes não segue uma orientação estratégica;

- Eixo 7 - 'Modelo de gestão e governança': refere-se à estrutura e composição da organização gestora e à estratégia de governança do Parque. Se mais institucional ou mais empresarial.

A Figura 4.3 representa a estrutura da ferramenta 'Estrategigrama' proposta pela IASP.

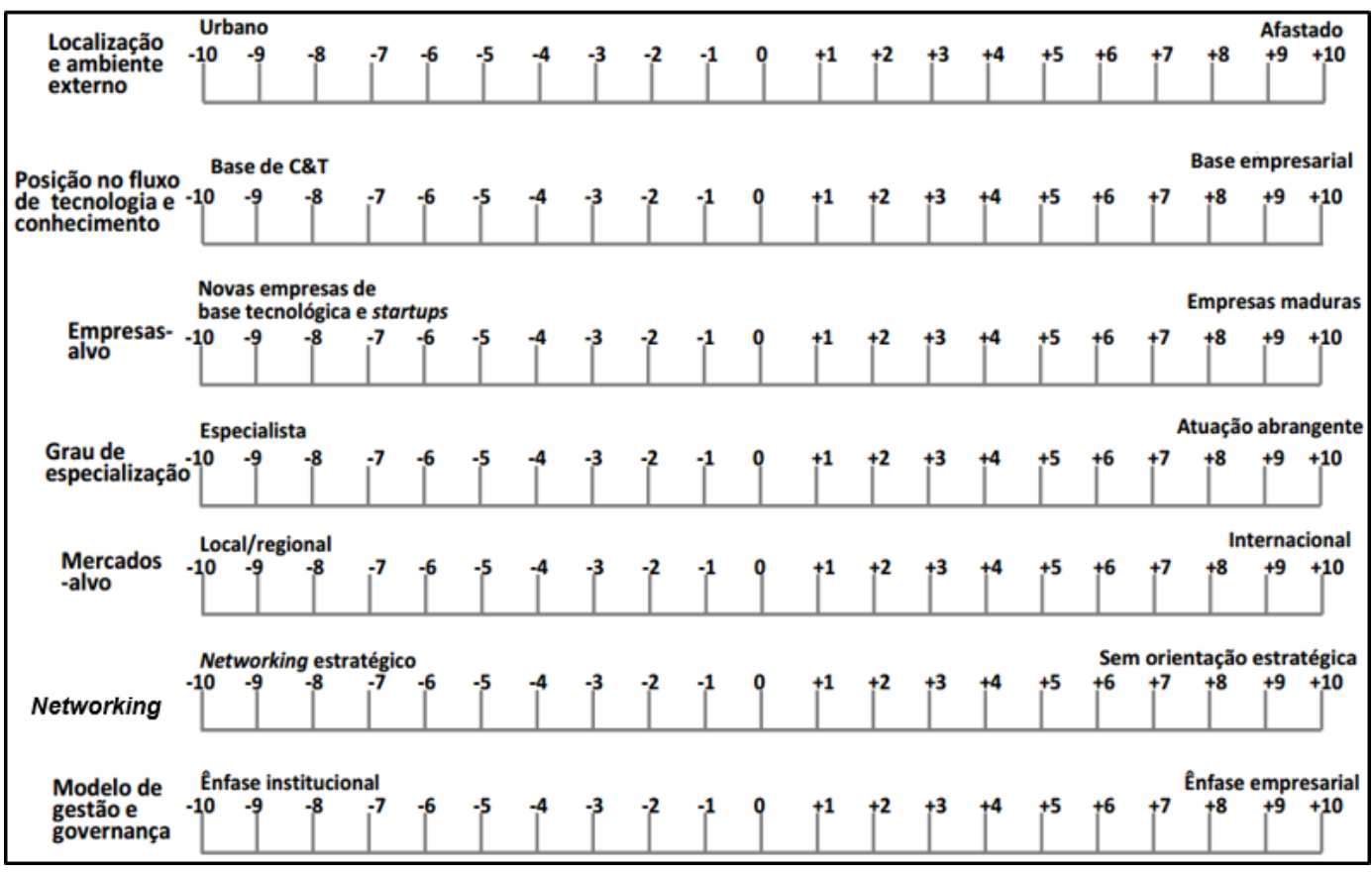

Figura 4.3 - Estrutura da ferramenta "Estrategigrama" proposta pela IASP Fonte: Adaptado de Vikström (2006); Ribeiro, Botelho e Filho (2012). 
A aplicação do 'Estrategigrama' permite gerar um índice que varia entre 10 e -10 em cada um dos sete eixos, a partir das respostas ao questionário disponibilizado pela IASP para as entidades-membro desta Associação.

Com o perfil estratégico traçado, os parques podem planejar mudanças de status e definir metas para o curto, médio e longo prazos, e até mesmo reposicionar sua forma de atuação, segundo a abordagem de gestão adaptativa discutida no item 4.1. Por exemplo, poderão evoluir de uma atuação local para internacional.

\subsection{4. \\ Modelo de negócio do parque tecnológico: uso da ferramenta Canvas}

A modelagem de negócios de parques tecnológicos baseou-se na ferramenta conhecida como Business Model Generation (BMG) ou Canvas (Osterwalder e Pigneur, 2011), que foi adaptada para o contexto de ambientes de inovação, substituindo-se o componente "Canais de distribuição" por "Fluxo de conhecimento e tecnologia". A interpretação do componente "Canais de distribuição" no contexto de Parques Tecnológicos foi baseada em um dos eixos da ferramenta "Estrategigrama para Parques Tecnológicos" (Sanz, 2005) e em conteúdos acessados nos sites de parques bemsucedidos no Brasil. Propõe-se, inicialmente, uma estrutura para a modelagem de parques tecnológicos, compreendendo nove componentes, como representado na Figura 4.4.

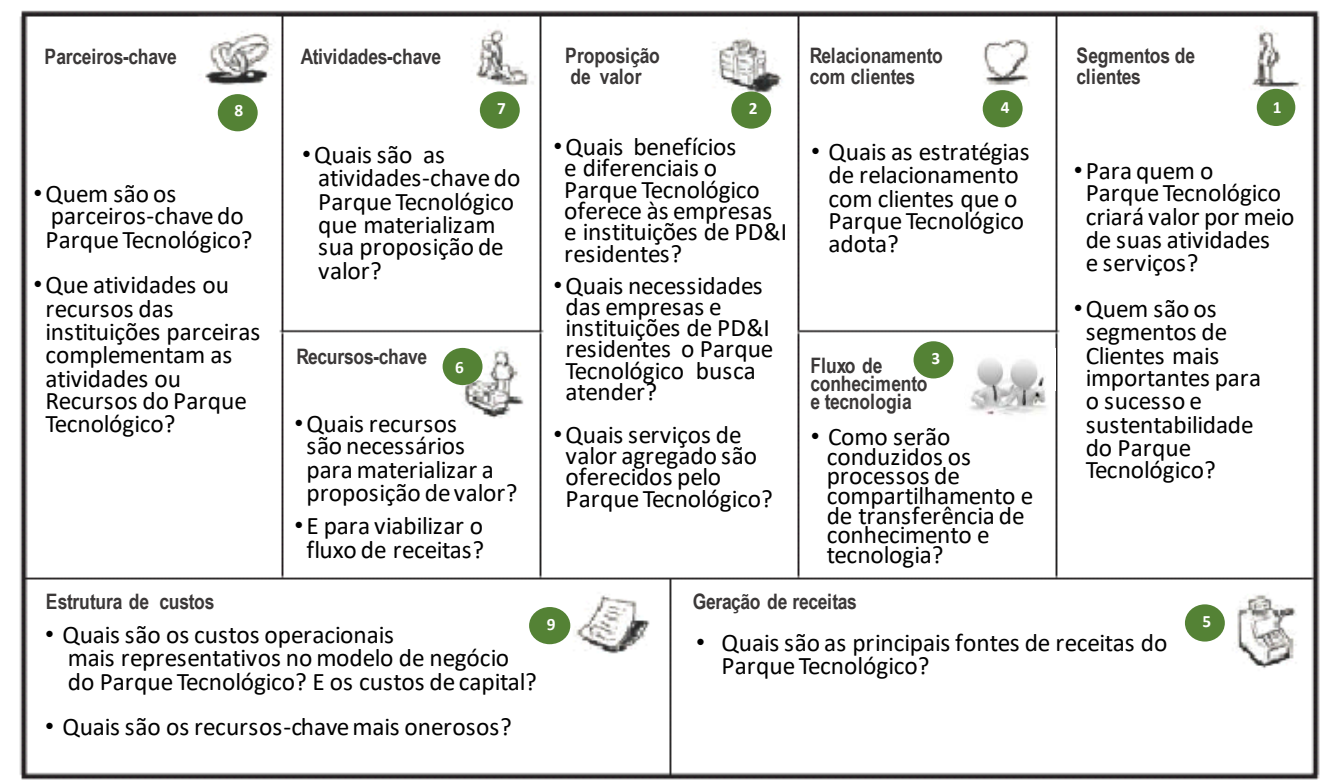

Figura 4.4 - Ferramenta Canvas customizada para a modelagem de negócios de parques tecnológicos 
Na sequência, descrevem-se no Quadro 4.1 os componentes da ferramenta Canvas, customizada para a modelagem de negócios no contexto dos parques tecnológicos, na perspectiva de se definir os modelos de negócio para os cinco Parques Tecnológicos que serão abordados na fase aplicada desta pesquisa.

Quadro 4.1 - Estrutura para a modelagem de parques tecnológicos: definição dos componentes

\begin{tabular}{|c|c|}
\hline $\begin{array}{l}\text { Componente } \\
\text { do modelo }\end{array}$ & Descrição \\
\hline Clientes & $\begin{array}{l}\text { - Empresas de base tecnológica de vários portes pertencentes aos setores foco de } \\
\text { atuação do Parque Tecnológico. A definição dos setores foco depende da } \\
\text { potencialidade empresarial e tecnológica identificada na região onde o Parque } \\
\text { Tecnológico será instalado. } \\
\text { - Instituições de PD\&l, com atuação nos setores de atuação do Parque Tecnológico. }\end{array}$ \\
\hline $\begin{array}{l}\text { Proposição de } \\
\text { valor }\end{array}$ & $\begin{array}{l}\text { - Diferenciação de infraestrutura e serviços de valor agregado a valores competitivos } \\
\text { de mercado. } \\
\text { - Ambiente propício à cooperação e à transferência de conhecimento e tecnologias } \\
\text { entre as empresas e instituições residentes e entre essas e as instituições parceiras. } \\
\text { - Serviços de valor agregado a serem prestados pela Entidade Gestora incluem } \\
\text { consultorias em gestão da inovação, prospeçãa tecnológica e de mercado, } \\
\text { marketing, captação de recursos, propriedade intelectual e transferência de } \\
\text { tecnologia, além de capacitação e treinamento em áreas demandadas pelos clientes. }\end{array}$ \\
\hline $\begin{array}{l}\text { Fluxo de } \\
\text { conhecimento e } \\
\text { tecnologia }\end{array}$ & $\begin{array}{l}\text { As fontes de conhecimento e tecnologias utilizadas pelos clientes e parceiros do Parque } \\
\text { Tecnológico podem ser oriundas da base de C\&T ou da base empresarial/mercado ou } \\
\text { de ambas. Em relação ao fluxo de conhecimento e tecnologia no âmbito do Parque } \\
\text { Tecnológico, a Entidade Gestora deverá: } \\
\text { - Promover a interação entre as empresas residentes do Parque com ICTs parceiras e } \\
\text { de outras regiões e países; } \\
\text { - Estabelecer canais diretos e contínuos para a promoção da interação ICTs-empresas; } \\
\text { - Promover a aproximação entre as empresas do Parque Tecnológico e incubadoras } \\
\text { locais, em cada um dos municípios onde se localizarão suas unidades; } \\
\text { - Realizar workshops, exposições, feiras e reuniões para fortalecimento do networking } \\
\text { para as empresas residentes, principalmente as de menor porte e em estágio inicial } \\
\text { de atuação, e instituições de PD\&I (residentes ou parceiras); } \\
\text { - Mediar contatos das empresas e instituições de PD\&I residentes com as ICTs } \\
\text { parceiras-chave para o estabelecimento de contratos referentes a projetos de PD\&I } \\
\text { colaborativo; } \\
\text { - Prestar apoio técnico à transferência de tecnologia e à propriedade intelectual para } \\
\text { seus clientes (empresas e instituições de PD\&l residentes), em parceria com os } \\
\text { Núcleos de Inovação Tecnológica das ICTs parcerias e articulação com Redes de NITs, } \\
\text { locais ou regionais. }\end{array}$ \\
\hline
\end{tabular}


Quadro 4.1 - Estrutura para a modelagem de parques tecnológicos: definição dos componentes (cont.)

\begin{tabular}{|c|c|}
\hline $\begin{array}{l}\text { Componente } \\
\text { do modelo }\end{array}$ & Descrição \\
\hline $\begin{array}{l}\text { Relacionamento } \\
\text { com clientes }\end{array}$ & $\begin{array}{l}\text { A Entidade Gestora deverá realizar a avaliação das necessidades de serviços } \\
\text { demandados pelos clientes de forma sistemática, por meio de pesquisa/censo com } \\
\text { as empresas e colaboradores do Parque Tecnológico. } \\
\text { Dentre as práticas a serem adotadas pela Entidade Gestora para se relacionar de } \\
\text { forma efetiva com seus clientes (atuais e potenciais), destacam-se: } \\
\text { - Acompanhamento da gestão de pequenas e médias empresas graduadas de } \\
\text { incubadoras e instaladas no Parque Tecnológico; } \\
\text { - Adoção de estratégias de marketing de relacionamento direcionadas para as } \\
\text { empresas e instituições de PD\&l, conforme setor e porte das organizações; } \\
\text { - Definição e implantação de política para a efetiva atração de empresas de base } \\
\text { tecnológica, também detalhada por setor de atuação e por porte das empresas; } \\
\text { - Ampla divulgação do lançamento de editais para seleção de empresas e } \\
\text { instituições de PD\&l que se instalarão no Parque Tecnológico. } \\
\text { - Melhoria contínua e excelência nos serviços de alto valor agregado prestados às } \\
\text { empresas e instituições de PD\&l residentes. } \\
\text { - Apoio na interlocução com órgãos de fomento à pesquisa e inovação, investidores } \\
\text { e demais instituições parceiras-chave. }\end{array}$ \\
\hline $\begin{array}{l}\text { Geração de } \\
\text { receitas }\end{array}$ & $\begin{array}{l}\text { - Aluguéis, em função da taxa de ocupação do Parque Tecnológico. } \\
\text { - Taxas de serviços, em função da taxa de ocupação do Parque Tecnológico. } \\
\text { - Prestação de serviços tecnológicos e realização de cooperação com empresas e } \\
\text { instituições de PD\&I residentes no desenvolvimento de projetos; } \\
\text { - Prestação de serviços gerais, como consultorias em gestão, financeira, marketing } \\
\text { e em outros pontos identificados como lacunas nas competências das empresas e } \\
\text { instituições de PD\&I residentes no Parque Tecnológico. } \\
\text { - Fator crítico para a geração de receitas: taxa de ocupação do Parque Tecnológico. } \\
\text { - Necessidade de aporte de recursos públicos para manutenção de alguns dos } \\
\text { serviços específicos oferecidos às empresas residentes. }\end{array}$ \\
\hline Recursos-chave & $\begin{array}{l}\text { - Área doada ou arrendada para implantação de edifícios próprios. } \\
\text { - Prédios próprios: sede administrativa, edifício modular para empresas nascentes } \\
\text { e edifício modular para empresas graduadas ou unidades de empresas } \\
\text { consolidadas que ocupem unidades de tamanho relativamente pequeno. } \\
\text { - Equipe dedicada e qualificada nas competências-chave da Entidade Gestora. } \\
\text { - Infraestrutura básica de suporte adequada, tais como banda larga de internet, } \\
\text { oferta de energia, água, segurança e serviços de mobilidade. }\end{array}$ \\
\hline Atividades-chave & $\begin{array}{l}\text { Atividades que devem ser realizadas pelas equipes da Entidade Gestora: } \\
\text { - Acesso, disseminação e compartilhamento do conhecimento: criação e } \\
\text { promoção de redes de relacionamento, seminários, conferências e workshops, } \\
\text { treinamentos, e demonstração tecnológica. } \\
\text { - Consultorias para elaboração de planos de Negócios (PN), propostas de } \\
\text { investimentos (PI), levantamento de fundos e melhoria da gestão do negócio. } \\
\text { - Apoio na busca de parceiros para estabelecimento de cooperação e alianças } \\
\text { - estratégicas. } \\
\text { Provisão, manutenção e controle dos serviços comuns em infraestrutura leve e } \\
\text { pesada. } \\
\text { Atividades por meio de parcerias: } \\
\text { - Incubação e aceleração de empresas; } \\
\text { - Serviços relacionados à propriedade intelectual e desenvolvimento tecnológico } \\
\text { (ensaios, testes, certificação). }\end{array}$ \\
\hline Parcerias-chave & $\begin{array}{l}\text { - Universidades e instituições de ensino e pesquisa. } \\
\text { - } \quad \text { Incubadoras de empresas e aceleradoras da região. } \\
\text { - } \quad \text { Agênciasões de classe das empresas instaladas no Parque Tecnológico. } \\
\text { - Instituições de C\&T, particularmente as localizadas no(s) município(s) do Parque } \\
\text { Tecnológico. }\end{array}$ \\
\hline
\end{tabular}


Quadro 4.1 - Estrutura para a modelagem de parques tecnológicos: definição dos componentes (cont.)

\begin{tabular}{|c|c|}
\hline $\begin{array}{l}\text { Componente } \\
\text { do modelo }\end{array}$ & Descrição \\
\hline Custos & $\begin{array}{l}\text { Na fase de implantação: } \\
\text { - Investimento na infraestrutura e construção de edificações próprios (ou cedidos } \\
\text { para exploração pela Entidade Gestora): } \\
\text { - Sede administrativa: recursos não reembolsáveis/doações de empresas } \\
\text { privadas; } \\
\text { - Edifícios com espaços compartilhados para empresas graduadas ou unidades de } \\
\text { empresas consolidadas que ocupem unidades de tamanho relativamente } \\
\text { pequeno: recursos não reembolsáveis ou recursos reembolsáveis, a taxas } \\
\text { subsidiadas. } \\
\text { - Recursos reembolsáveis: (a) taxa subsidiada, (b) carência de pelo menos } 24 \\
\text { meses; (c) garantia: fundo de aval estadual ou vinculação a receitas previstas } \\
\text { nos contratos de cessão de uso; } \\
\text { Custos operacionais: a cargo da organização proprietária da área do Parque, } \\
\text { outros stakeholders ou cobertos por Contratos de Gestão com o Poder Público. } \\
\text { - Na fase de operacionalização: } \\
\text { Enquanto não houver geração de receitas suficientes, os custos operacionais } \\
\text { deverão ser cobertos pelo proprietário da área, por outros stakeholders ou } \\
\text { mediante Contrato de Gestão com o Poder Público, nos casos em que a } \\
\text { Entidade Gestora seja uma Organização Social. } \\
\text { Paulatinamente, os custos operacionais deverão ser cobertos pelas receitas } \\
\text { geradas pelas próprias operações do Parque (cessão de uso, aluguéis e taxas de } \\
\text { serviços). }\end{array}$ \\
\hline
\end{tabular}

Fonte: Elaboração própria.

\subsection{5}

\section{Análise do estágio de desenvolvimento do parque tecnológico}

A identificação do estágio de maturidade de um parque tecnológico, em combinação com o modelo de negócios, descrito no item anterior, constituiu importante etapa a ser realizada por gestores de parques tecnológicos. A informação proveniente trará melhor compreensão do estágio de desenvolvimento das iniciativas e projetos realizados no parque (Bligliardi et al., 2006; Looey et al., 2013; Roglinger e Becker, 2012).

Para a análise do estágio de desenvolvimento de parques tecnológicos brasileiros, é importante destacar o estudo desenvolvido pela Anprotec (2008) que apresenta uma proposta de enquadramento dos parques segundo esta variável.

\subsection{6}

Classificação do parque tecnológico, segundo taxonomia de escolha

Destacam-se as taxonomias para parques tecnológicos apresentadas no item 2.5 - capítulo 2 desta dissertação. Deve-se, primeiramente, escolher a taxonomia a ser utilizada. Dentre os trabalhos realizados por Escorsa e Valls (1996); Annerstedt (2006); Anprotec (2008) e Kaczmarska e Gierulski (2012), um desses 
será selecionado para a etapa de validação empírica. Após a seleção da taxonomia, cada parque tecnológico presente na pesquisa será classificado e agrupado em acordo com as categorias propostas na taxonomia. Para fins da presente dissertação, será adotada a classificação da Anprotec (2008) no estudo empírico, cujos resultados serão reportados no capítulo 5.

\subsection{7 \\ Definição do quadro lógico para definição de indicadores de desempenho de parques tecnológicos}

Conforme citado por Fernandes (2014), a etapa de definição das dimensões de avaliação dos parques deverá considerar as perspectivas que serão consideradas no modelo de avaliação, além da proposição e seleção dos indicadores-chave. Para esta etapa deverá ser construído o quadro lógico, como definido no capítulo 2.

\subsection{8}

Proposição de indicadores e métricas de monitoramento e avaliação de desempenho do parque tecnológico

Propõem-se e selecionam-se indicadores-chave de desempenho, com a finalidade de monitorar o progresso dos inputs, ações, outputs, resultados e impactos atribuídos à atuação de um determinado parque tecnológico (Guy, 1996; Staton, 1996; Kusiek e Rist, 2004; Monk e Peters, 2009; Imas e Rist, 2009).

Os indicadores de desempenho oferecem ao modelo de gestão adaptativa feedback contínuo, além de serem importantes fontes de informação de desempenho operacional e estratégico. A criação desses indicadores deve ser realizada pela entidade gestora do parque, consultando especialistas de parques tecnológicos e representantes de seus múltiplos stakeholders, em um processo interativo, conforme preconizado na abordagem de gestão adaptativa (princípio 'Questionamento normativo').

Segundo Kusek e Rist (2004), os indicadores e métricas de desempenho estabelecem um ponto de partida para o processo de monitoramento e avaliação dos resultados alcançados.

Na próxima etapa do modelo conceitual, após proposição dos indicadores de desempenho, o parque tecnológico deverá definir os horizontes temporais associados a seus objetivos estratégicos (curto, médio e longo prazo) e as metas correspondentes em cada horizonte. Uma vez definidas as metas, a entidade 
gestora do parque tecnológico deverá implantar iniciativas e planos de ação necessários para seu alcance (Guy, 1996; Staton, 1996; Kusek e Rist, 2004; Imas e Rist, 2009).

\section{3}

\section{Fase de ação}

Este estágio do modelo conceitual refere-se à implementação das iniciativas e planos de ação definidos na fase de planejamento (Hogan, 1996: Guy, 1996; Kusek e Rist, 2004). Destaca-se nesta fase, a ênfase no terceiro princípio e no quarto princípios da gestão adaptativa, respectivamente 'Ação reflexiva e adaptação' e 'Cooperação e agregação'.

A entidade gestora do parque tecnológico deve assumir uma postura de adaptação ativa, buscando influenciar o comportamento do ambiente (externo e interno), de modo que este lhe seja favorável para o cumprimento de sua missão e objetivos estratégicos (princípio 'Ação reflexida e adaptação'). Com relação ao quarto princípio, a entidade gestora deve contribuir para a formação da entidade do ambiente de inovação ou rede interorganizacional, pela cooperação e agregação. Isso exigirá a transparência nas decisões e ações, essenciais para o desenvolvimento da confiança nesses ambientes de inovação.

\section{4}

\section{Fase de avaliação de resultados e impactos}

O parque tecnológico nesta fase deve buscar maneiras de analisar as informações adquiridas até o momento e criar relatórios para divulgação dos resultados aos stakeholders e gestores envolvidos no processo de monitoramento e avaliação do parque tecnológico.

Os indicadores-chave deverão expressar e mensurar o cumprimento dos direcionadores estratégicos dos parques tecnológicos e interesses dos múltiplos stakeholders (variáveis governantes) e o atingimento de metas e progresso dos planos de ação dos parques e suas consequências (resultados e impactos da atuação do parque tecnológico). Deverão ser considerados nesta fase os dois tipos de aprendizagem (ciclo simples e duplo), conforme abordagem conceitual de Argyris e Schön (1996).

Com essas informações geradas nesta fase, podem ser introduzidas melhorias no modelo de gestão e propostas revisões das iniciativas, políticas 
empregadas e programas em curso nos parques tecnológicos, caso essas sejam necessárias.

Aqui também, ressalta-se que a fase de avaliação de resultados e impactos deverá seguir o segundo e o terceiro princípios da gestão adaptativa, respectivamente 'Autorregulação' e ‘Ação reflexiva e adaptação'.

\section{5 \\ Considerações finais sobre o capítulo}

Neste capítulo, propôs-se um modelo conceitual adaptativo para monitoramento e avaliação de parques tecnológicos. Para tal, considerou-se a complexidade (ou até a impossibilidade) de se definir um método único e generalizado para o monitoramento e avaliação de desempenho de parques tecnológicos, buscando-se na fase de modelagem desta pesquisa contribuir para o aprimoramento deste processo no Brasil e no exterior.

Identificou-se já na fase exploratória desta pesquisa, a necessidade de se dispor de um ferramental desenvolvido segundo uma perspectiva que associasse os diferentes tipos de parque tecnológicos, gerando-se frameworks de medição personalizados para grupos de parques tecnológicos com características, objetivos estratégicos e metas similares. A abordagem de escolha foi a gestão adaptativa, integrando-se a ela diversas ferramentas aplicáveis aos contextos institucionais de parques tecnológicos, como discutido no capítulo 3.

Dentre os diferenciais do modelo baseado na abordagem de gestão adaptativa em relação aos reportados na literatura, destacam-se: (i) permite aos gestores medir e comparar o desempenho de parques tecnológicos pertencentes a um determinado agrupamento, para então priorizar ações no nível de cada parque, que venham agregar valor aos seus stakeholders; (ii) considera as diferenças de modelos de negócios de parques tecnológicos, de proposições de valor, estágios de desenvolvimento, bem como estruturas de governança; (iii) permite estabelecer um equilíbrio adequado entre o uso de métodos centrados em métricas quantitativas e aqueles que enfatizam aspectos normativos da gestão estratégica dos parques; (iv) possui propriedades que propiciam a administração da incerteza, da complexidade e da interdependência entre atribuições dos diversos atores que integram os parques; e (v) permite um alinhamento ao referencial teórico de aprendizagem organizacional, como proposto por Argyris e Schon (1978; 1996). 


\section{5 \\ Validação empírica do modelo conceitual adaptativo: foco na fase de planejamento}

Apresentam-se e discutem-se neste capítulo os resultados da validação empírica da fase de planejamento do modelo proposto, a partir de resultados gerados pelos participantes do $1^{\circ}$ Curso para Gestores de Parques Tecnológicos e Ambientes de Inovação, oferecido pela Uni-Anprotec, em parceria com o Instituto Gênesis, da PUC-Rio, em 2016.

Durante o estudo empírico, foram realizadas as seguintes etapas: (i) coleta de dados durante duas Oficinas de Trabalho, realizadas no Rio de Janeiro e no Recife, respectivamente; (ii) tutorias a distância no intervalo entre as duas Oficinas de Trabalho, conduzidas pelo pesquisador e sua orientadora; (iii) aplicação do modelo adaptativo em cinco Parques Tecnológicos, incluindo a construção de indicadores e métricas de desempenho; (iv) elaboração das conclusões do estudo empírico.

\section{1}

\section{Contexto de aplicação do modelo: Parques Tecnológicos do Brasil}

Para o contexto de aplicação do modelo conceitual para o monitoramento e avaliação de desempenho de Parques Tecnológicos deve-se, primeiramente, destacar a dificuldade encontrada por acadêmicos, profissionais do setor e gestores políticos em propor e aplicar técnicas para avaliação de desempenho de parques tecnológicos, devido às diferenças entre esses empreendimentos e a seu alto grau de complexidade. O modelo conceitual apresentado nesta dissertação utiliza a taxonomia Anprotec (2008) por apresentar parques tecnológicos brasileiros como objetos de estudo e porque o estudo conceitual da taxonomia ter sido desenvolvido para aplicação em projetos de parques tecnológicos nacionais.

Os resultados esperados da fase de planejamento do modelo de monitoramento e avaliação de desempenho são a formação de um quadro lógico, indicadores de desempenho e suas respectivas métricas customizadas para grupos 
de parques tecnológicos. As propostas aqui descritas trarão métodos distintos para auxiliar tomadores de decisão a medir e comparar o desempenho de parques tecnológicos que pertencem a um determinado grupo e, dessa maneira, priorizar ações que trarão o maior valor agregado aos negócios e projetos estabelecidos no parque.

Para o desenvolvimento deste modelo conceitual, foram levados em consideração as diferenças dos modelos de negócios de parques tecnológicos, suas proposições de valor, objetivos e metas, seu estágio de desenvolvimento, o comprometimento dos stakeholders e a estrutura da governança. É importante destacar os cuidados que precisam ser tomados para se alcançar um equilíbrio entre métodos focados em métricas quantitativas e métodos de avaliação da proposta de valor de um parque tecnológico como empreendimento capaz de prover serviços de suporte ao desenvolvimento de empresas e negócios como também promoção de desenvolvimento regional.

\section{2 Coleta de dados junto aos participantes do $1^{\circ}$ Curso para Gestores de Parques Tecnológicos e Ambientes de Inovação}

Nesta fase, realizaram-se duas oficinas de trabalho com 26 gestores de parques tecnológicos participantes do "10 Curso para Gestores de Parques Tecnológicos e Ambientes de Inovação", oferecido pela Uni-Anprotec, em parceria com o Instituto Gênesis, da PUC-Rio.

A primeira Oficina foi realizada no Rio de Janeiro e a segunda em Recife, Pernambuco. Entre as duas oficinas, conduziram-se tutorias a distância para auxiliar os participantes na elaboração dos respectivos quadros lógicos e na proposição de indicadores e métricas de desempenho.

A Figura 5.1, a seguir, apresenta a metodologia geral adotada na condução das duas Oficinas, compreendendo as atividades do Módulo 1 (Oficina do Rio de Janeiro), as atividades entre Módulos que foram realizadas a distância e a apresentação dos trabalhos de conclusão do curso no Módulo II (Oficina de Recife). 


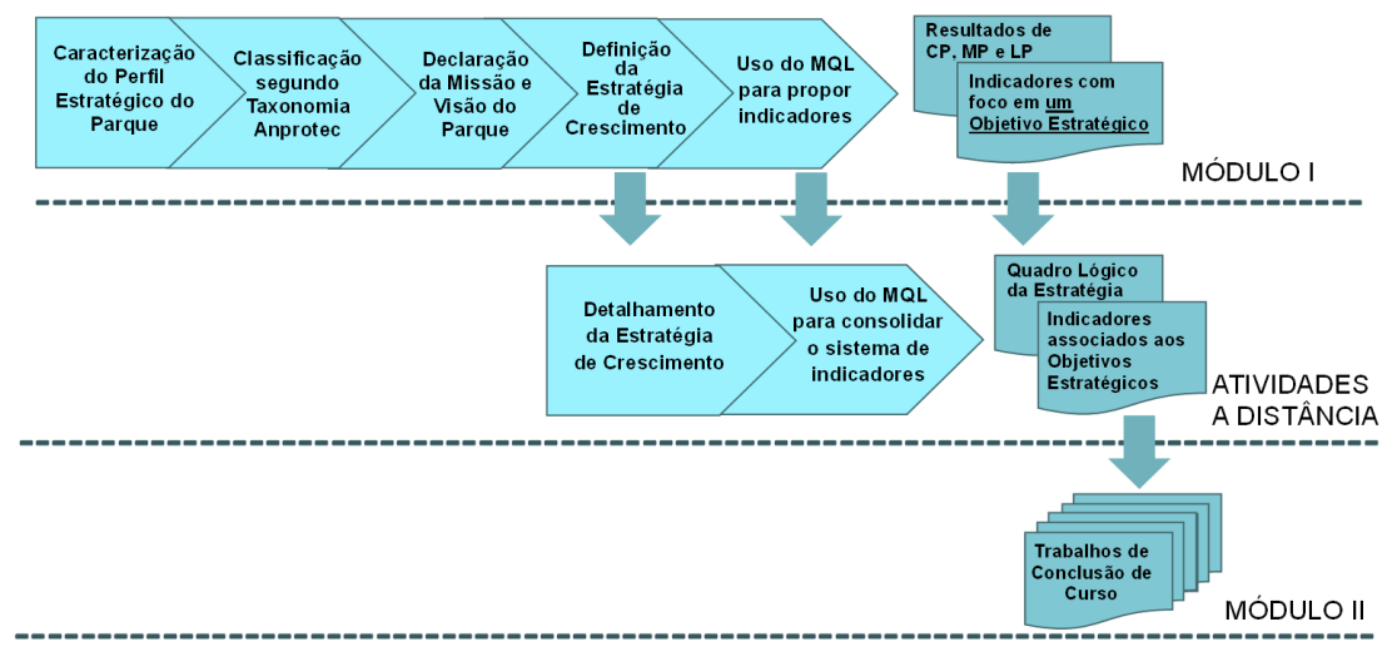

Figura 5.1 - Metodologia geral adotada na condução das Oficinas do $1^{\circ}$ Curso para Gestores de Parques Tecnológicos e Ambientes de Inovação (Uni-Anprotec/instituto Gênesis)

Fonte: Elaboração própria.

\section{2 .1}

\section{Oficina de Trabalho - Rio de Janeiro}

Durante a primeira Oficina de Trabalho, discutiu-se junto com os participantes como construir o quadro lógico para a definição de indicadores e métricas de desempenho, que atendesse às premissas enunciadas na introdução desta dissertação. Na ocasião, foi apresentada a ferramenta 'Estrategigrama', como descrita no capítulo 4.

A ferramenta 'Estrategigrama' foi exposta para o grupo de maneira que os participantes a aplicassem para a definição e caracterização dos perfis estratégicos dos parques objetos do estudo empírico. A classificação da taxonomia proposta pela Anprotec foi utilizada junto com esta ferramenta, considerando a evolução de cada parque no curto ( 2 anos), médio (5 anos) e longo prazo (10 anos).

Buscando aproveitar ao máximo a diversidade dos participantes, foram definidos os seguintes critérios para a formação dos grupos de trabalho:

- Deverão ser formados cinco grupos;

- Cada grupo deverá ter pelo menos cinco membros;

- Cada grupo deverá ter pelo menos um gestor de parque tecnológico;

- Cada grupo deverá ter pelo menos um representante do Sebrae e um representante de órgão governamental. 
Ao final desta primeira Oficina, os grupos apresentaram os parques tecnológicos escolhidos, suas missões, visões de futuro, perfis estratégicos atuais e o posicionamento atual de cada Parque em relação à taxonomia da Anprotec.

A Oficina teve duração de quatro horas e todos os grupos conseguiram atingir os objetivos propostos, tendo sido avaliados diretamente durante as apresentações.

\section{2 .2}

\section{Tutorias a distância}

Para a consecução das atividades programadas, foram disponibilizados aos grupos horários para tutorias a distância, realizadas a partir do Instituto Gênesis, no Rio de Janeiro, via Skype. Essas tutorias tiveram como finalidade auxiliar os participantes em relação a eventuais dúvidas na construção do quadro lógico, incluindo o detalhamento dos objetivos estratégicos de cada parque tecnológico em consonância com a missão e visão de futuro, definidas na primeira Oficina.

Com as orientações das tutorias, os grupos propuseram indicadores e métricas de desempenho associados aos objetivos estratégicos dos parques em foco. Foram realizadas cinco seções (uma por grupo) com duração de 30 a 40 minutos.

\section{2 .3}

\section{Oficina de Trabalho - Recife}

Com relação à segunda Oficina, os participantes utilizaram-se das informações geradas na primeira Oficina e após as tutorias a distância. Foram apresentados os quadros lógicos com os objetivos estratégicos de curto, médio e longo prazo, assim como as propostas de indicadores e métricas de monitoramento e avaliação de desempenho associados a esses objetivos e metas.

Como conclusão das atividades propostas, os integrantes dos grupos avaliaram a metodologia empregada, propuseram recomendações para o aprimoramento da mesma, suas percepções sobre as atividades e o aprendizado das ferramentas executadas. Cada grupo teve 30 minutos para apresentar suas atividades.

A título de ilustração, apresentam-se alguns depoimentos dos participantes sobre a aplicação do modelo aqui proposto ao final do $1^{\circ}$ Curso para Gestores de 
Parques Tecnológicos e Ambientes de Inovação, oferecido pela Uni-Anprotec, em parceria com o Instituto Gênesis, em 2016:

"O conhecimento sobre as ferramentas trabalhadas nas Oficinas trouxe uma visão integrada e sistêmica do empreendimento, contribuindo significativamente para a minha formação";

"A metodologia apresentada é bastante pertinente aos Parques em todas as suas fases e contribuiu para meu aprendizado e formação";

"No exercício de minhas atividades profissionais, não lido diretamente com os Parques Tecnológicos, mas a ferramenta apresentada demonstrou que tem potencialidade para direcionar este ambiente”;

"Apesar de estar dentro de uma incubadora, a minha percepção sobre as atividades trabalhadas são perfeitamente aplicáveis nas fases de planejamento, implantação e monitoramento de um Parque Tecnológico”;

"É de extrema importância o modelo proposto, pois permite a possibilidade de repensar o planejamento e valorizar a aplicação de ações de correção que estabeleceriam a sinergia necessária para o sucesso do Parque. Refletindo sobre esta perspectiva, podemos considerar a importância de ampliar o entendimento de gestores que atuam na elaboração de estratégias de sucesso em Parques Tecnológicos, assim como na condução bem planejada destas iniciativas e nas possíveis correções necessárias das mesmas";

"Quem não sabe para onde quer ir, qualquer lugar serve”. O conteúdo e o aprendizado propiciado nas Oficinas vai ajudar muito à Unochapeco e à Região do Oeste catarinense a definir com mais clareza estratégias para a construção de um sistema local de inovação, que fomente o desenvolvimento econômico e social da Região, com foco e visão de futuro";

"Vejo o quanto é importante o monitoramento e a avaliação para o dia-dia do gestor de um parque tecnológico elou ambiente de inovação. Através do monitoramento, podemos acompanhar continuamente o desenvolvimento das metas estabelecidas";

"Com a ferramenta "Estrategigrama", pode-se obter de forma clara as características de um Parque Tecnológico. Este mecanismo juntamente com os conhecimentos adquiridos nas duas Oficinas, certamente auxiliará o gestor a traçar os objetivos estratégicos e também alcançar os resultados almejados"; 
"Estas Oficinas e seus respectivos resultados contribuíram para a percepção de que a concepção de um Parque Tecnológico se sobrepõe à sua infraestrutura física e vai além do concreto e do investimento imobiliário. Trata-se de promover o engajamento de stakeholders e instituições residentes, para gerar inovação de forma acelerada e levar a mesma ao mercado";

"Sinto muita necessidade de realizar um planejamento estratégico abrangente do Parque Tecnológico da Bahia, compreendendo todos os seus atores. Pena que terei que fazê-lo com o Projeto de Publicização já encaminhado”;

O conhecimento absorvido, principalmente nos módulos presenciais, sobre as ferramentas serviram para apontar possibilidades de diagnóstico específicas para Parques Tecnológicos. Aproveitei bastante, principalmente pela oportunidade de utilizar no ambiente no qual trabalho como objeto de estudo".

\section{2 .4 \\ Coleta de dados nos sites institucionais dos parques tecnológicos}

Visando complementar as informações coletadas diretamente junto aos participantes das duas Oficinas de Trabalho, consultaram-se os sites institucionais de cada parque tecnológico objeto de estudo, assim como editais lançados para chamadas de empresas residentes e incubadoras. Essas informações foram especialmente úteis para a consolidação dos respectivos modelos de negócio dos parques abordados neste estudo empírico.

\section{3}

\section{Discussão dos resultados}

Apresentam-se e discutem-se aqui os resultados da validação empírica do modelo conceitual adaptativo proposto no capítulo 4, conduzida pelo pesquisador e sua orientadora durante o $1^{\circ}$ Curso para Gestores de Parques Tecnológicos e Ambientes de Inovação, oferecido pela Uni-Anprotec/Instituto Gênesis, em 2016.

Os Parques Tecnológicos objeto desta validação foram:

- $\quad$ Parque Tecnológico Ulbratech (Rio Grande do Sul);

- Parque Tecnológico de Santa Rita do Sapucaí (Minas Gerais);

- Órion Parque Tecnológico da Serra Catarinense (Santa Catarina);

- Parque Tecnológico da Bahia (Bahia);

- ParqTec FB (fictício). 


\subsection{1}

\section{Parque Tecnológico Ulbratech}

O modelo do Parque Tecnológico Ulbratech é multicampi e a sede da instituição gestora localiza-se nas dependências da Universidade Luterana do Brasil (Ulbra), em Canoas (RS). Suas atividades iniciaram-se em 2012 e, atualmente, possui uma área construída de $10.000 \mathrm{~m}^{2}$, abrigando 18 empresas residentes e o apoio de centros de PD\&I das áreas de energia, metalmecânica, logística, tecnologia da informação e comunicação - TIC e biotecnologia (Parque Tecnológico Ulbratech, 2016).

É importante destacar a criação da Rede Ulbra de Inovação, em 2010, cuja formação iniciou-se com a criação do Núcleo de Inovação Transferência Tecnológica (NITT), em 2004. Integra, além da sede da organização gestora do Parque Tecnológico Ulbratech, os campi do Parque Tecnológico Ulbratech localizados em Manuas (AM), Itumbiara (GO) e Manaus (AM), assim como as Incubadoras Tecnológicas da Ulbra (iUlbra's), instaladas nas cidades de Canoas, Carazinho, Gravataí, Guaíba, Porto Alegre, Santa Maria, São Jerônimo e Torres (RS), como também nas cidades de Manaus (AM), Itumbiara (GO), Jí-Paraná (RO) e Palmas (TO) (Parque Tecnológico Ulbratech, 2016).

A missão do Parque Tecnológico Ulbratech, enunciada em seu site institucional é "fomentar a cultura de inovação como vetor de competitividade empresarial, apoiado na infraestrutura de ensino, pesquisa e extensão da Ulbra, criando sinergia entre as universidades, as empresas e o governo, promovendo assim o desenvolvimento regional". O mesmo apresenta como objetivo geral "contribuir para o desenvolvimento regional através da inovação promovida pela Ulbra junto a empresas de base tecnológica" e cinco objetivos específicos. São eles (Parque Tecnológico Ulbratech, 2016):

- Oferecer ambiente favorável à inovação junto da universidade e empresas;

- Atrair investimentos para atuar em projetos de inovação junto a universidade;

- Estimular a transferência de tecnologia entre a Ulbra e as empresas do parque tecnológico;

- Promover a interação entre a Ulbra e organizações públicas e privadas; 
- Fomentar o empreendedorismo e a inovação.

Os gestores do Parque Tecnológico Ulbratech apresentam como visão de futuro "ser até 2026 referência regional em processos de pesquisa, desenvolvimento e inovação tecnológica nas áreas de concentração do parque tecnológico".

\section{Caracterização das partes interessadas e seus objetivos em relação ao empreendimento}

O Quadro 5.1 apresenta os principais stakeholders e seus objetivos em relação ao empreendimento Parque Tecnológico Ulbratech.

Quadro 5.1 - Partes interessadas e seus objetivos em relação ao Parque Tecnológico Ulbratech

\begin{tabular}{|c|c|}
\hline Partes interessadas & Objetivos em relação ao Parque Tecnológico \\
\hline $\begin{array}{l}\text { Universidade Luterana } \\
\text { do Brasil (Ulbra) }\end{array}$ & $\begin{array}{l}\text { - Ampliar a missão institucional, promovendo desenvolvimento } \\
\text { regional; } \\
\text { - Aquisição de recursos financeiros através de agências de } \\
\text { fomento, como o CNPQ, para a concessão de bolsas voltadas } \\
\text { para o desenvolvimento de projetos com base tecnológica; } \\
\text { - Integração entre o corpo docente e discente (graduados e pós- } \\
\text { graduados) junto às empresas, promovendo a transferência } \\
\text { tecnológica e desenvolvimento inovador. }\end{array}$ \\
\hline $\begin{array}{l}\text { Núcleo de Inovação } \\
\text { Transferência } \\
\text { Tecnológica (NITT) }\end{array}$ & $\begin{array}{l}\text { - Promover a cultura da proteção da propriedade intelectual; } \\
\text { - Auxiliar, junto ao corpo acadêmico, a produção e gestão da } \\
\text { inovação; } \\
\text { - Apoiar a transferência do conhecimento e tecnologia, pesquisa e } \\
\text { proteção intelectual; } \\
\text { - Prospecção de recursos em pareceria com os setores público e } \\
\text { privado; } \\
\text { - Promoção da pesquisa para as empresas afiliadas. }\end{array}$ \\
\hline $\begin{array}{l}\text { Secretaria Estadual de } \\
\text { Desenvolvimento } \\
\text { Econômico, Ciência e } \\
\text { Tecnologia (SECT) }\end{array}$ & $\begin{array}{l}\text { - Atuar, junto ao Parque Tecnológico Ulbratech, para a promoção } \\
\text { e o desenvolvimento regional. }\end{array}$ \\
\hline $\begin{array}{l}\text { Secretaria de Inovação } \\
\text { do Ministério do } \\
\text { Desenvolvimento, } \\
\text { Indústria e Comércio } \\
\text { Exterior (MDIC) }\end{array}$ & $\begin{array}{l}\text { - Promover capacitação empreendedora; } \\
\text { - Auxílio à aceleração das start-ups; } \\
\text { - Capacitar e oferecer mentoreamento e networking; } \\
\text { - Auxílio ao fomento de recursos para projetos inovadores junto } \\
\text { ao CNPq e SENAI. }\end{array}$ \\
\hline $\begin{array}{l}\text { Rede Gaúcha de } \\
\text { Incubadoras de } \\
\text { Empresas e Parques } \\
\text { Tecnológicos (Reginp) }\end{array}$ & $\begin{array}{l}\text { - Promoção do crescimento de incubadoras e parques } \\
\text { tecnológicos associados através de atividades institucionais que } \\
\text { promovam geração de renda, novos produtos e serviços, assim } \\
\text { como empregos e sustentabilidade econômica. }\end{array}$ \\
\hline
\end{tabular}

Fonte: Ulbratech (2017); Reginp (2016); Rio Grande do Sul (2017). 


\section{Perfil estratégico: uso da ferramenta 'Estrategigrama' da IASP}

A partir do levantamento de campo realizado junto aos gestores do Parque e com uso da ferramenta "Estrategigrama" da IASP, desenhou-se o perfil estratégico atual do Parque Tecnológico Ulbratech (Figura 5.2).

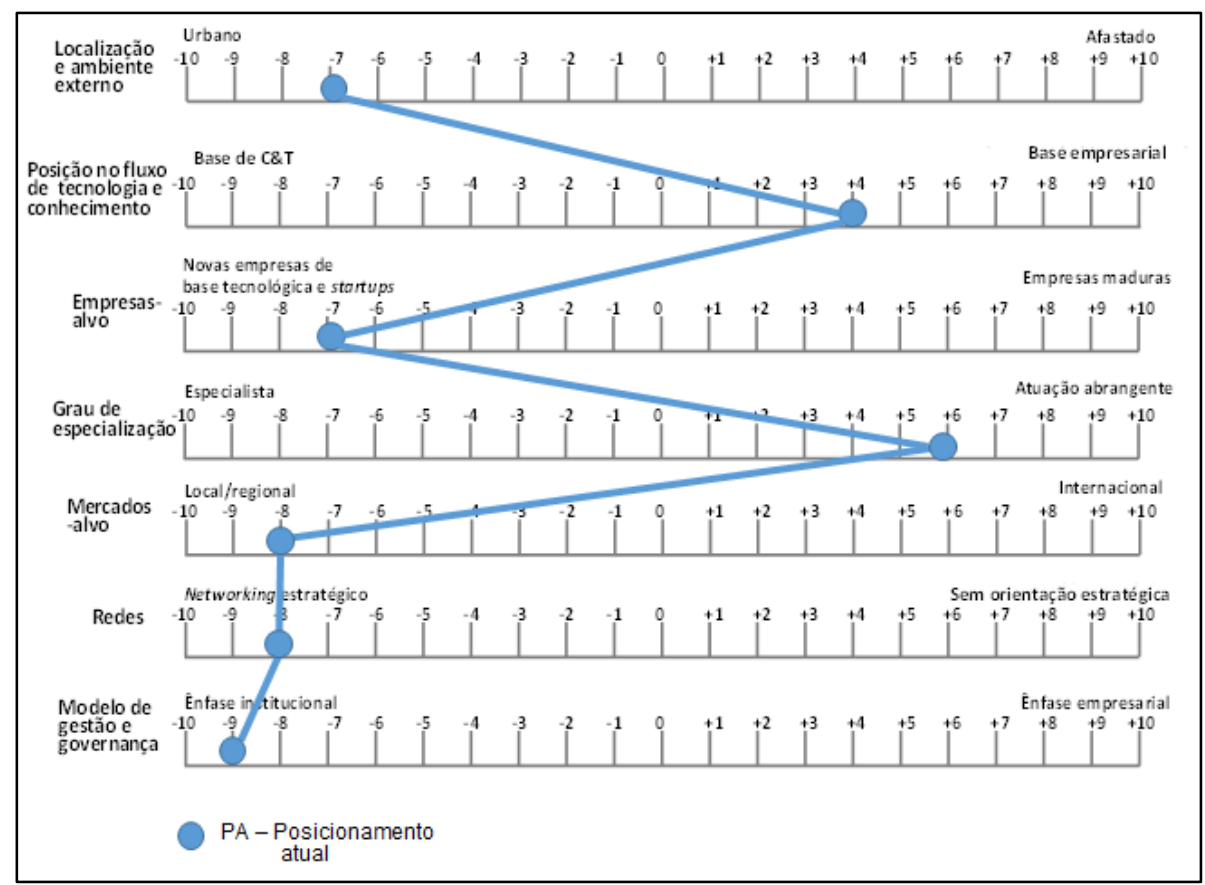

Figura 5.2 - Perfil estratégico atual do Parque Tecnológico Ultratech

Fonte: Elaboração própria a partir dos resultados das duas Oficinas realizadas durante o 1 Curso para Gestores de Parques Tecnológicos e Ambientes de Inovação, oferecido pela UniAnprotec/Instituto Gênesis em 2016.

A sede do Parque encontra-se nas dependências da Ulbra, em uma área urbana. $\mathrm{O}$ seu foco, relacionado à posição no fluxo de tecnologia e conhecimento é de base empresarial, contudo tendo espaço para a instalação de empresas de base de C\&T.

Os empreendimentos residentes são, em sua maioria, micro e pequenas empresas e start-ups incubadas. Para a definição do seu grau de especialização, o parque, apesar de possuir focos de especialidade, conforme citados anteriormente, o mesmo abriga empresas de setores de atuação diversos, tendo como restrição a capacidade da Ulbra de oferecer apoio técnico necessário. Sua atuação no mercado é concentrada na região, tendo empresas residentes locais. Devido ao modelo de redes já consolidado pelo modelo de gestão da Ulbra, possui uma estratégia sólida de networking. 
O Parque Tecnológico Ulbratech imprime grande ênfase institucional em seu modelo de gestão e governança. Como propostas para a evolução do perfil estratégico nos períodos de curto, médio e longo prazo, o Parque Tecnológico Ulbratech necessita melhorar sua infraestrutura, aprimorando a urbanização local, como também buscar atrair empresas de base C\&T com a finalidade de gerar inovação tecnológica, o qual é a missão do parque e da Ulbra. Busca-se o amadurecimento das empresas residentes durante seus períodos de estadia e a captação de empresas de médio e grande porte, que possam servir como empresas âncoras para o parque tecnológico.

Em relação ao nível de especialização do parque, tem-se como perspectiva a condensação de suas áreas de atuação (máximo de cinco), com a finalidade de adensamento de capital intelectual e para infraestrutura de PD\&I. O parque, durante esse período de evolução, tem como objetivo para seu mercado-alvo atuação tanto regional quanto internacional. A evolução do perfil estratégico do Parque Tecnológico Ulbratech encontra-se representada na Figura 5.3, a seguir.

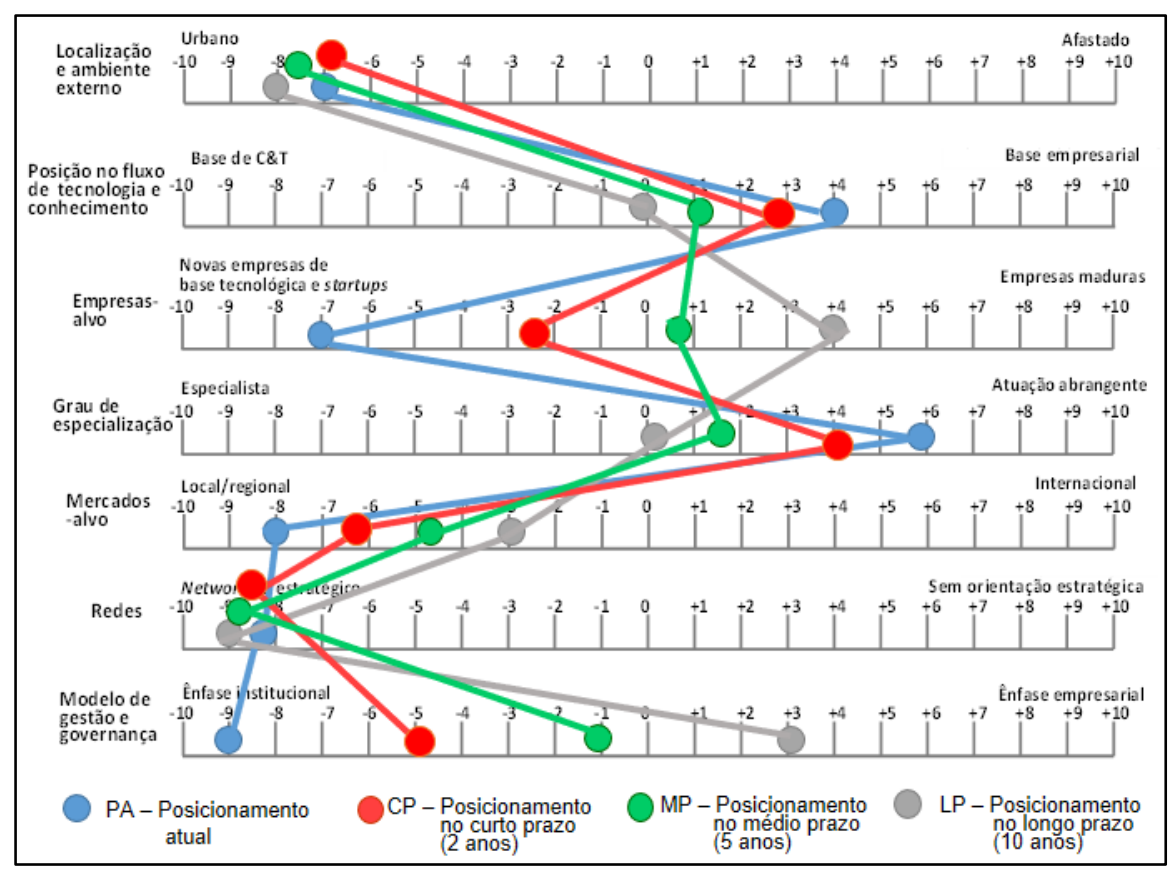

Figura 5.3 - Evolução do perfil estratégico do Parque Tecnológico Ulbratech: curto, médio e longo prazo

Fonte: Elaboração própria a partir dos resultados das duas Oficinas realizadas durante o 1 Curso para Gestores de Parques Tecnológicos e Ambientes de Inovação, oferecido pela UniAnprotec/Instituto Gênesis em 2016. 


\section{Modelo de negócio: uso da ferramenta 'Canvas'}

A partir da análise das informações acessadas no site institucional do Parque Tecnológico Ulbratech, apresenta-se o modelo de negócio segundo os componentes que integram a ferramenta "Canvas": (i) segmentos de clientes: (ii) proposição de valor; (iii) fluxo de conhecimento e tecnologia; (iv) relacionamento com clientes; (v) geração de receitas; (vi) recursos-chave; (vii) atividades-chave; (viii) parcerias-chave; e (ix) estrutura de custos.

\section{Segmentos de clientes}

De acordo com os segmentos de clientes do Parque Tecnológico Ulbratech, trata-se de um projeto de foco multissetorial, que enfatiza empresas de pequeno e médio porte e startups de base tecnológica nos seguintes setores:

- Energia: petróleo, gás e outras fontes;

- Materiais: metalmecânica;

- Logística;

- Tecnologias da informação e comunicação (TIC);

- Biotecnologia.

Também são identificados como clientes em potenciais para o Parque Tecnológico Ulbratech:

- Empresas de base tecnológica de diversos portes;

- Empresas de base em CT\&I;

- Empresas consolidadas.

O Parque Tecnológico Ulbratech é declarado aberto à comunidade, permitindo que pessoas interessadas encaminhem projetos de âmbito inovador. Não são excluídos setores de atuações diferentes dos citados, contudo é preferível que a atuação do Parque se concentre nas áreas de competência da Universidade Luterana do Brasil para que o apoio tecnológico aos novos possíveis empreendimentos seja mais efetivo (Ulbratech, 2017).

\section{Proposição de valor}

Destaca-se como proposição de valor do Parque Tecnológico Ulbratech o investimento aplicado na região de maneira a promover o desenvolvimento local por meio de inovações tecnológicas além de um conjunto diversificado de itens para o benefício dos clientes. São eles: 
- Promoção de ambientes favoráveis às empresas residentes oferecendo infraestrutura adequada para empresas de base tecnológica inovadoras;

- Facilitação para transferências de conhecimento e tecnologia entre as empresas e a universidade;

- Oferta de apoio técnico e humano qualificado;

- Promoção da inovação voltada para o mercado nacional e internacional;

- Atração de investimentos de projetos inovadores entre as empresas residentes e a Ulbra;

- Aprimoramento da interação entre a universidade e os setores público e privado.

Os serviços de valor agregado ofertados pelo Parque Tecnológico Ulbratech são:

- Concessão de espaços físicos e/ou serviços para as empresas interessadas (período de, no máximo, três anos)

- Acompanhamentos trimestrais e avaliações anuais realizadas pela incubadora às empresas e projetos aprovados pela comissão da Ulbra;

- Prestação de serviços para a definição inicial do modelo de negócios e proposta de valor do empreendimento;

- Espaços para de lazer, alimentação, conferência, confraternização entre colaboradores do parque e empresas residentes, entre outros;

- Laboratórios e estruturas tecnológicas presentes dentro da universidade;

- Ambientes co-working;

- Oferta de serviços de incentivo educacionais aos funcionários das empresas incubadas e dependentes;

- Auxílio aos discentes e docentes da Ulbra junto ao parque tecnológico (ofertas de estágio e bolsas acadêmicas).

\section{Fluxo de conhecimento e tecnologia}

Os métodos e práticas de transferência de conhecimento e tecnologia no âmbito do Parque Tecnológico Ulbratech são adotados pelos diversos membros de um sistema de networking já consolidado. Dentre essas práticas, destacam-se:

- Interação constante entre as empresas que interagem com o Parque, estejam elas residentes no Parque ou em instalações no exterior;

- Fortalecimento das relações entre as empresas incubadas e a região;

- Realização de atividades promotoras de interação e contribuição de conhecimento entre as empresas incubadas (workshops, conferências, treinamento etc.); 
- Interação, e fortalecimento, entre as empresas incubadas e o NITT, promovendo a transferência de tecnologia e conhecimento, propriedade intelectual, estímulo a pesquisa, prospecção de recursos em parceria público/privado.

\section{Relacionamento com clientes}

O relacionamento com os clientes, operacionalizado pela entidade gestora do Parque Tecnológico Ulbratech, compreende as seguintes atividades:

- Divulgação de editais para seleção de empresas e projetos inovadores a serem instalados nas incubadoras do parque;

- Implantação de políticas de atração de empreendimentos de base tecnológica de pequeno e médio porte, tendo como foco as atividades já administradas no parque, contudo possibilitando a abertura de novos setores e atração de empresas maduras.

\section{Geração de receitas}

As principais fontes de receitas geradas pelo Parque Tecnológico Ulbratech são: (i) contribuições mensais provenientes dos empreendimentos incubados, nos quais estão inclusos serviços de consultoria nas áreas de administração, marketing, relações humanas, propriedade intelectual, transferência de tecnologia e outros serviços demandados pelas empresas residentes.

Em adição, o Parque possui em seu interior diversas instalações que oferecem serviços diversos aos clientes e à comunidade (bancos, restaurantes, cafeterias, salão de beleza, salas de conferência e de reuniões compartilhadas, para citar alguns exemplos).

\section{Recursos-chave}

Para realização de suas atividades-chave e materialização da proposição de valor, o Parque Tecnológico Ulbratech considera como recursos-chave:

- Uma infraestrutura física propícia para o desenvolvimento de um ambiente para práticas inovadoras;

- Docentes, discentes, corpo gestor e funcionários especialistas e possuidores de conhecimentos para o auxílio e propagação das atividades realizadas pelo parque, incubadora e empresas incubadas;

- Centros de PD\&I e laboratórios pertencentes à Ulbra e abertas para seus clientes;

- Editais publicados pela incubadora para chamada de novas empresas e projetos. 


\section{Atividades-chave}

As atividades-chave realizadas pelo Parque Tecnológico Ulbratech são:

- Atração de empresas e projetos inovadores;

- Transferência de conhecimento e tecnológica;

- Incubação e aceleração de novos negócios;

- Promoção de desenvolvimento tecnológico para empresas incubadas, unidades de PD\&I e setores e laboratórios da universidade;

- Gestão imobiliária dos espaços físicos das unidades localizadas em diferentes municípios;

- Fortalecimento do networking entre as empresas incubadas externas (fora das dependências do Parque Tecnológico), as residentes, a entidade gestora e a Ulbra;

- Oferta de seminários, conferências, workshops, treinamentos, etc.

- Qualificação dos colaboradores, funcionários, docentes e discentes envolvidos com as atividades do Parque Tecnológico.

\section{Parceiros-chave}

São parceiros-chave do Parque Tecnológico Ulbratech:

- Rede Gaúcha de Incubadoras de Empresas e Parques Tecnológicos (Reginp);

- Secretaria Estadual de Desenvolvimento Econômico, Ciência e Tecnologia;

- Sebrae-RS;

- Associação Comercial da Indústria, Comércio e Serviços;

- Núcleo de Inovação e Transferência Tecnológica da Ulbra (NITT).

\section{Estrutura de custos}

A estrutura de custos do Parque Tecnológico compreende:

- Investimentos regulares para implantação e manutenção das unidades do Parque Tecnológico e incubadoras em escala nacional;

- Investimentos em infraestrutura para as empresas que residem no Parque;

- Investimentos nos ambientes de PD\&I (manutenção, aprimoramento e ampliação);

- Investimentos para a atração de empreendimentos maduros que virão residir no Parque Tecnológico;

- Custos de pessoal e operacionais (salários, encargos, material administrativo, empresas terceirizadas, serviços de concessionárias, dentre outros). 


\section{Estágio de desenvolvimento conforme a classificação da Anprotec}

Em operação desde 2012, o Parque Tecnológico Ulbratech está localizado na cidade de Canoas, no Rio Grande do Sul, dentro das instalações da Ulbra. Conta com uma área construída de aproximadamente $10.000 \mathrm{~m}^{2}$, abrigando 18 empresas residentes.

\section{Posicionamento do Parque Tecnológico segundo a taxonomia da Anprotec}

A Figura 5.4 apresenta o posicionamento atual do Parque Tecnológico Ulbratech segundo a taxonomia da Anprotec. Trata-se de um Parque Tecnológico emergente, cuja atuação pode ser considerada de relevância regional quanto à base de C\&T e local quanto à base empresarial.

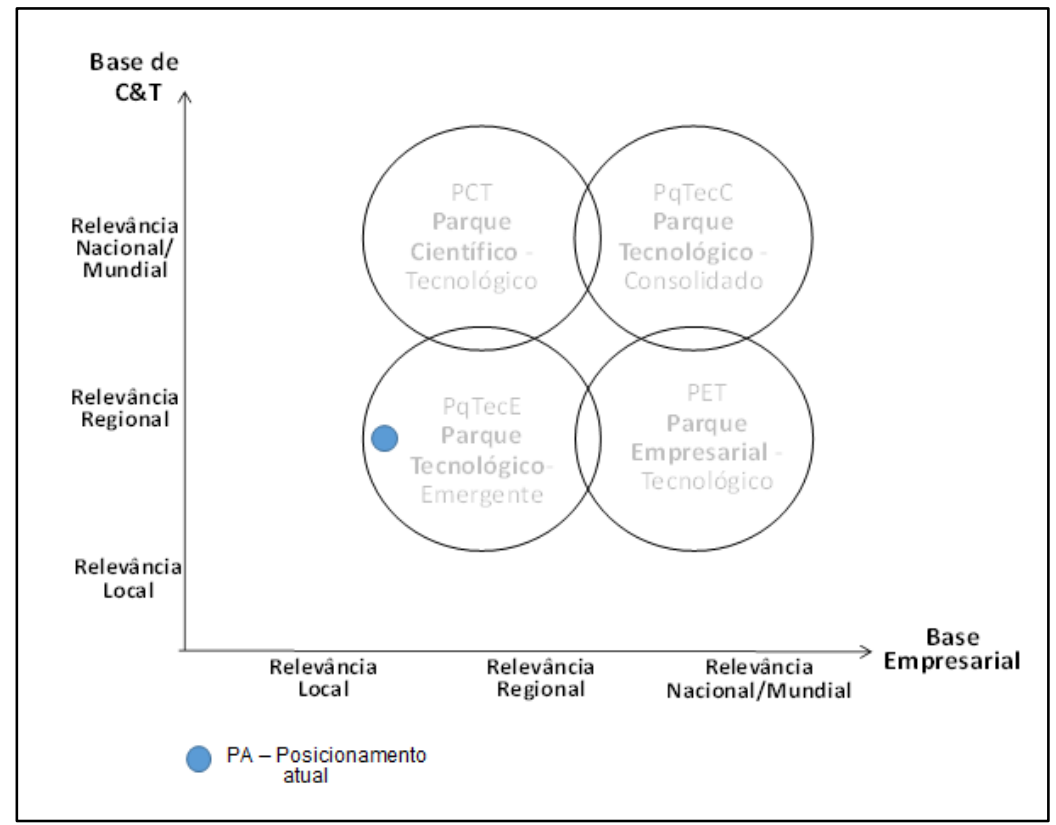

Figura 5.4 - Posicionamento atual do Parque Tecnológico Ulbratech segundo a taxonomia da Anprotec

Fonte: Elaboração própria a partir dos resultados das duas Oficinas realizadas durante o 1 Curso para Gestores de Parques Tecnológicos e Ambientes de Inovação, oferecido pela UniAnprotec/Instituto Gênesis em 2016.

O planejamento de curto prazo para o Parque Tecnológico aponta para a realização de atividades que ampliarão a relevância em escala regional das bases de C\&T e empresarial, aprimorando seu crescimento sustentável.

Já para o médio e longo prazo, tem-se como meta um Parque Tecnológico consolidado, de alta relevância nacional e mundial, quanto às bases de C\&T e empresarial. 
A Figura 5.5 apresenta graficamente a estratégia de crescimento do Parque Tecnológico Ulbratech, considerando os horizontes de curto prazo (2 anos); médio prazo (5 anos); e longo prazo (10 anos).

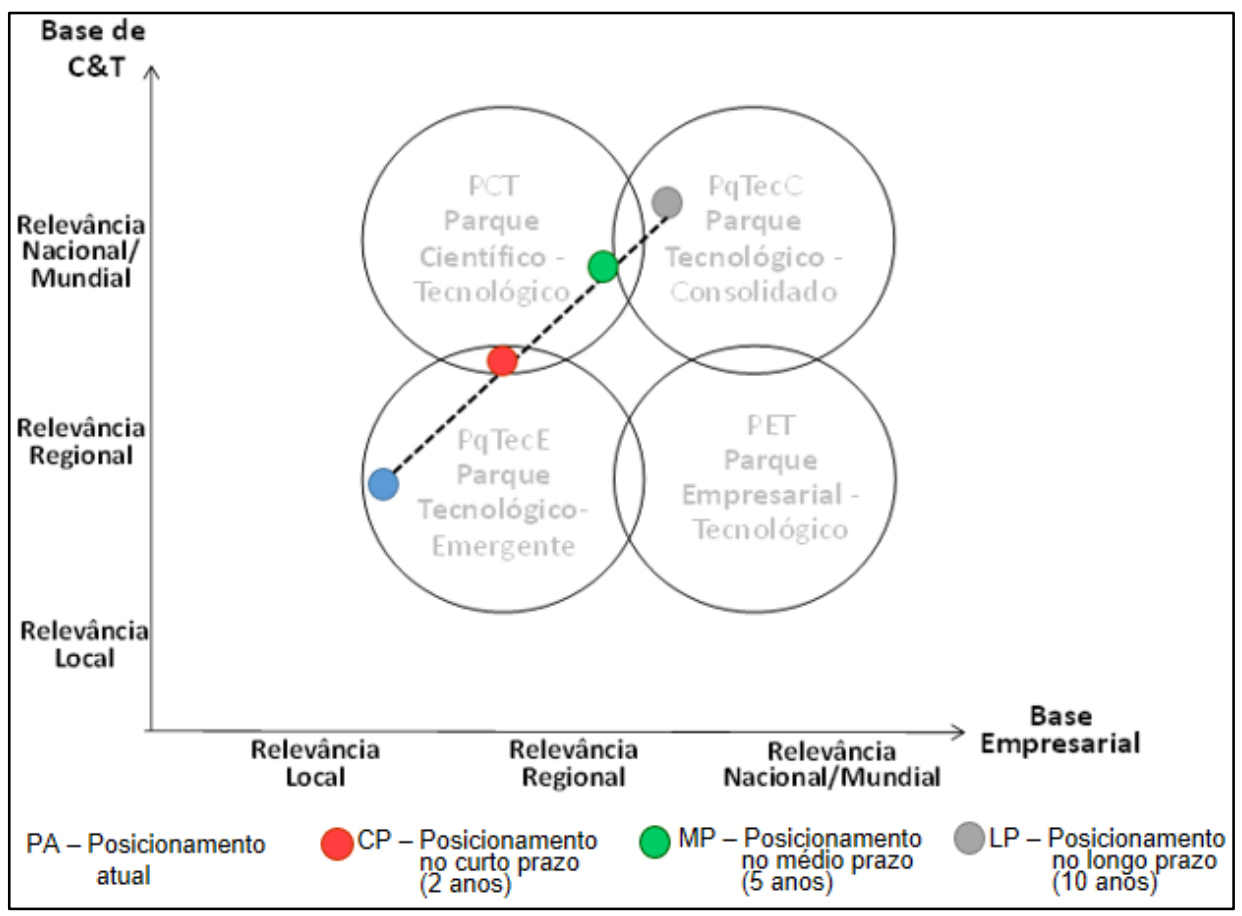

Figura 5.5 - Estratégia de crescimento do Parque Tecnológico Ulbratech: curto, médio e longo prazo

Fonte: Elaboração própria a partir dos resultados das duas Oficinas realizadas durante o 1 Curso para Gestores de Parques Tecnológicos e Ambientes de Inovação, oferecido pela UniAnprotec/Instituto Gênesis em 2016.

\section{Quadro lógico para proposição de indicadores e métricas para monitoramento e avaliação de desempenho do Parque Tecnológico}

A construção do quadro lógico para a proposição de indicadores e métricas de monitoramento e avaliação de desempenho do Parque Tecnológico Ulbratech seguiu a orientação metodológica descrita no capítulo 4 (Quadro 5.2). 
Quadro 5.2 - Quadro lógico para a proposição de indicadores e métricas de monitoramento e avaliação de desempenho do Parque Tecnológico Ulbratech

\begin{tabular}{|c|c|c|c|c|}
\hline $\begin{array}{c}\text { Hierarquia } \\
\text { dos Objetivos }\end{array}$ & Objetivos & $\begin{array}{l}\text { Resultados Esperados } \\
(\mathrm{CP}, \mathrm{MP} \text { e LP) }\end{array}$ & Indicadores & Métricas \\
\hline $\begin{array}{l}\text { Objetivo } \\
\text { Estratégico }\end{array}$ & \multicolumn{4}{|c|}{ 1. Oferecer ambiente favorável à inovação junto da Ulbra e empresas } \\
\hline \multirow{6}{*}{$\begin{array}{l}\text { Objetivos de } \\
\text { Curto Prazo } \\
\text { ( } 2 \text { anos) }\end{array}$} & \multirow{3}{*}{$\begin{array}{l}\text { 1.1. Implantar ambientes } \\
\text { criativos e colaborativos } \\
\text { para estimular o } \\
\text { empreendedorismo e a } \\
\text { inovação }\end{array}$} & $\begin{array}{l}\text { 1.1a. Criar espaço coworking de trabalho e } \\
\text { incubação }\end{array}$ & Espaço coworking implantado & $\begin{array}{l}\text { Pesquisa de satisfação dos usuários do espaço } \\
\text { coworking. }\end{array}$ \\
\hline & & $\begin{array}{l}\text { 1.1b. Ampliar a geração de novas ideias e } \\
\text { negócios }\end{array}$ & $\begin{array}{l}\text { Taxa de crescimento de novas } \\
\text { ideias e negócios }\end{array}$ & $\begin{array}{l}\text { Número de candidatos pré-incubação/ período. } \\
\text { Número de coworkers/ período. } \\
\text { Número de projetos incubados/ período. }\end{array}$ \\
\hline & & $\begin{array}{l}\text { 1.1c. Implantar oficinas constantes de ideias e } \\
\text { modelagem de negócios }\end{array}$ & Realização das oficinas & $\begin{array}{l}\text { Número de oficinas realizadas/período. } \\
\text { Número de participantes das oficinas/período }\end{array}$ \\
\hline & $\begin{array}{l}\text { 1.2. Revitalizar as áreas } \\
\text { comuns/convivência }\end{array}$ & $\begin{array}{l}\text { 1.2a. Revitalizar banheiros e copa, tornando-os } \\
\text { mais funcionais, agradáveis e criativos }\end{array}$ & $\begin{array}{l}\text { Ampliação do nível de satisfação } \\
\text { dos usuários }\end{array}$ & Pesquisa de satisfação dos usuários. \\
\hline & $\begin{array}{l}\text { 1.3. Melhorar a } \\
\text { sinalização e } \\
\text { comunicação visual do } \\
\text { prédio }\end{array}$ & $\begin{array}{l}\text { 1.3a. Implantar identidade visual e sinalização } \\
\text { no prédio, dentro do espírito criativo }\end{array}$ & $\begin{array}{l}\text { Ampliação do nível de satisfação } \\
\text { dos usuários dos espaços } \\
\text { Ulbratech }\end{array}$ & $\begin{array}{l}\text { Pesquisa de satisfação dos usuários (residentes e } \\
\text { externos). }\end{array}$ \\
\hline & $\begin{array}{l}\text { 1.4. Organizar eventos } \\
\text { culturais no prédio }\end{array}$ & $\begin{array}{l}\text { 1.4a. Ter eventos, no mínimo mensais, no } \\
\text { prédio, abertos à comunidade }\end{array}$ & $\begin{array}{l}\text { Realizar eventos culturais de } \\
\text { qualidade no prédio }\end{array}$ & $\begin{array}{l}\text { Número de eventos realizados/período. } \\
\text { Número de participantes dos eventos/período. } \\
\text { Pesquisa de satisfação dos participantes/evento. }\end{array}$ \\
\hline \multirow{6}{*}{$\begin{array}{l}\text { Objetivos de } \\
\text { Médio Prazo } \\
\text { ( } 5 \text { anos) }\end{array}$} & $\begin{array}{l}\text { 1.5. Sistematizar eventos } \\
\text { culturais no prédio }\end{array}$ & $\begin{array}{l}\text { 1.5a. Implantar uma agenda de eventos } \\
\text { recorrentes }\end{array}$ & Agenda de eventos recorrentes & Número de eventos recorrentes/período. \\
\hline & \multirow{4}{*}{$\begin{array}{l}\text { 1.6. Ampliar as áreas } \\
\text { comuns/convivência }\end{array}$} & 1.6a. Implantar uma sala de descompressão & Ter a sala estruturada & Pesquisa de satisfação dos usuários. \\
\hline & & 1.6b. Implantar uma área para fumantes & Ter a área estruturada & Pesquisa de satisfação dos usuários. \\
\hline & & 1.6c. Implantar uma área de alimentação & Ter a área estruturada & Pesquisa de satisfação dos usuários. \\
\hline & & 1.6d. Implantar um ATM & Ter o ATM implantação & Pesquisa de satisfação dos usuários. \\
\hline & $\begin{array}{l}\text { 1.7. Implantar modelo } \\
\text { colaborativo de gestão } \\
\text { predial }\end{array}$ & $\begin{array}{l}\text { 1.7a. Criar um condomínio que seja gerido por } \\
\text { um empreendedor do Parque Tecnológico } \\
\text { Ultratech. }\end{array}$ & Implantação de um condomínio & $\begin{array}{l}\text { Síndico eleito com estatuto. } \\
\text { Pesquisa de satisfação dos residentes em relação } \\
\text { ao modelo colaborativo de gestão predial. }\end{array}$ \\
\hline \multirow{2}{*}{$\begin{array}{l}\text { Objetivos de } \\
\text { Longo Prazo } \\
\text { (10 anos) }\end{array}$} & $\begin{array}{l}\text { 1.8. Colocar inteligência } \\
\text { no prédio }\end{array}$ & $\begin{array}{l}\text { 1.8a. Implantar funcionalidades que tornem o } \\
\text { prédio mais sustentável e inteligente }\end{array}$ & $\begin{array}{l}\text { Ações de sustentabilidade e } \\
\text { inteligência }\end{array}$ & $\begin{array}{l}\text { Lista de tecnologias implantadas } \\
\text { Pesquisa de satisfação. }\end{array}$ \\
\hline & $\begin{array}{l}\text { 1.9 Ampliação do parque } \\
\text { (construção) }\end{array}$ & $\begin{array}{l}\text { 1.9a. Construir um novo espaço para } \\
\text { ampliação do parque tecnológico }\end{array}$ & Novo prédio construído & Ter habite-se e PPCI do novo prédio. \\
\hline
\end{tabular}


Quadro 5.2 - Quadro lógico para a proposição de indicadores e métricas de monitoramento e avaliação de desempenho do Parque Tecnológico Ulbratech (Cont.)

\begin{tabular}{|c|c|c|c|c|}
\hline $\begin{array}{l}\text { Hierarquia } \\
\text { dos Objetivos }\end{array}$ & Objetivos & $\begin{array}{l}\text { Resultados Esperados } \\
\quad(C P, \text { MP e LP) }\end{array}$ & Indicadores & Métricas \\
\hline $\begin{array}{l}\text { Objetivo } \\
\text { Estratégico }\end{array}$ & \multicolumn{4}{|c|}{ 2. Atrair investimentos para atuar em projetos de inovação com a Ulbra } \\
\hline \multirow{11}{*}{$\begin{array}{l}\text { Objetivos de } \\
\text { Curto Prazo } \\
\text { ( } 2 \text { anos) }\end{array}$} & \multirow{2}{*}{$\begin{array}{l}\text { 2.1. Ter um portfólio } \\
\text { digital e em papel com a } \\
\text { estrutura e competências } \\
\text { da Rede }\end{array}$} & $\begin{array}{l}\text { 2.1a. Ter informações organizadas sobre a } \\
\text { Rede Ulbratech, }\end{array}$ & \multirow[t]{2}{*}{$\begin{array}{l}\text { Portfólio bilíngue impresso e } \\
\text { digital }\end{array}$} & \multirow[t]{2}{*}{$\begin{array}{l}\text { Número de exemplares impressos /período. } \\
\text { Número de downloads do portfólio digital/ período. }\end{array}$} \\
\hline & & $\begin{array}{l}\text { 2.1b. Ter material de apoio nacional e } \\
\text { internacional (bilíngue) de divulgação da Rede, }\end{array}$ & & \\
\hline & $\begin{array}{l}\text { 2.2. Ter um website } \\
\text { dinâmico que sirva como } \\
\text { referência e ferramenta } \\
\text { de consulta }\end{array}$ & $\begin{array}{l}\text { 2.2a. Ter uma fonte de notícias e contatos } \\
\text { sobre os programas de empreendedorismo e } \\
\text { inovação. }\end{array}$ & $\begin{array}{l}\text { Publicação do site } \\
\text { ulbratech.com.br } \\
\text { Aumento do número de } \\
\text { visitantes e acessos }\end{array}$ & $\begin{array}{l}\text { Número de visitas por sessão } \\
\text { Número de visitantes únicos } \\
\text { Tempo médio de visitantes }\end{array}$ \\
\hline & \multirow{2}{*}{$\begin{array}{l}\text { 2.3. Realizar ações ativas } \\
\text { de prospecção de } \\
\text { empresas para o } \\
\text { Ulbratech }\end{array}$} & $\begin{array}{l}\text { 2.3a. Ampliar a visibilidade da Ulbratech no } \\
\text { setor empresarial e governamental }\end{array}$ & \multirow{2}{*}{$\begin{array}{l}\text { Aumento de visitas realizadas } \\
\text { Evolução do número de } \\
\text { empresas candidatas no período } \\
\text { Evolução do número de } \\
\text { empresas candidatas no período }\end{array}$} & $\begin{array}{l}\text { Número de visitas realizadas/período. } \\
\text { Número de empresas candidatas/período } \\
\text { Número de empresas residentes/período }\end{array}$ \\
\hline & & $\begin{array}{l}\text { 2.3b. Ampliar a quantidade de empresas do } \\
\text { Ulbratech }\end{array}$ & & $\begin{array}{l}\text { Número de eventos realizados/período. } \\
\text { Número de participantes dos eventos/período. } \\
\text { Pesquisa de satisfação dos participantes/evento. }\end{array}$ \\
\hline & \multirow{3}{*}{$\begin{array}{l}\text { 2.4. Implementar um } \\
\text { radar de oportunidades } \\
\text { de editais para parques, } \\
\text { incubadoras e empresas }\end{array}$} & $\begin{array}{l}\text { 2.4a. Potencializar a participação do Ulbratech } \\
\text { e de suas empresas em editais }\end{array}$ & \multirow{3}{*}{$\begin{array}{l}\text { Fontes de editais monitoradas } \\
\text { Participação das empresas em } \\
\text { editais } \\
\text { Satisfação quanto aos serviços } \\
\text { oferecidos }\end{array}$} & \multirow{3}{*}{$\begin{array}{l}\text { Número de fontes de editais monitoradas/período } \\
\text { Número de projetos enviados por empresas/período } \\
\text { Pesquisa de satisfação das empresas residentes } \\
\text { quanto aos serviços oferecidos pelo Parque } \\
\text { tecnológico Ultratech }\end{array}$} \\
\hline & & $\begin{array}{l}\text { 2.4b. Ampliar as oportunidades de fontes de } \\
\text { financiamento para as empresas }\end{array}$ & & \\
\hline & & $\begin{array}{l}\text { 2.4c. Melhorar os serviços oferecidos pelo } \\
\text { Parque Tecnológico Ulbratech }\end{array}$ & & \\
\hline & \multirow{3}{*}{$\begin{array}{l}\text { 2.5. Apoiar os } \\
\text { empreendedores e } \\
\text { pesquisadores na criação } \\
\text { dos projetos para editais } \\
\text { de empreendedorismo e } \\
\text { inovação }\end{array}$} & 2.5a. Qualificar os projetos submetidos & \multirow{3}{*}{$\begin{array}{l}\text { Índice de aprovação dos projetos } \\
\text { Arquivo de projetos submetidos }\end{array}$} & \multirow{3}{*}{$\begin{array}{l}\text { Número de projetos submetidos/período } \\
\text { Número de projetos aprovados/período } \\
\text { Número de projetos submetidos/período }\end{array}$} \\
\hline & & $\begin{array}{l}2.5 b . \text { Ampliar o índice de aprovação dos } \\
\text { projetos }\end{array}$ & & \\
\hline & & $\begin{array}{l}\text { 2.5c. Estabelecer uma base de conhecimento a } \\
\text { partir dos projetos enviados }\end{array}$ & & \\
\hline
\end{tabular}


Quadro 5.2 - Quadro lógico para a proposição de indicadores e métricas de monitoramento e avaliação de desempenho do Parque Tecnológico Ulbratech (Cont.)

\begin{tabular}{|c|c|c|c|c|}
\hline $\begin{array}{l}\text { Hierarquia } \\
\text { dos Objetivos }\end{array}$ & Objetivos & $\begin{array}{l}\text { Resultados Esperados } \\
\text { (CP, MP e LP) }\end{array}$ & Indicadores & Métricas \\
\hline $\begin{array}{l}\text { Objetivo } \\
\text { Estratégico }\end{array}$ & \multicolumn{4}{|c|}{ 2. Atrair investimentos para atuar em projetos de inovação com a Ulbra (cont.) } \\
\hline \multirow{8}{*}{$\begin{array}{l}\text { Objetivos de } \\
\text { Curto Prazo } \\
(2 \text { anos }) \quad- \\
\text { cont. }\end{array}$} & \multirow{2}{*}{$\begin{array}{l}\text { 2.6. Promover eventos de } \\
\text { prospecção de novos } \\
\text { empreendimentos }\end{array}$} & $\begin{array}{l}\text { 2.6a. Ampliar a quantidade de } \\
\text { empreendedores e empresas no Ulbratech }\end{array}$ & \multirow{2}{*}{$\begin{array}{l}\text { Aumento de eventos realizados } \\
\text { Aumento de empresas } \\
\text { ingressantes }\end{array}$} & \multirow[t]{2}{*}{$\begin{array}{l}\text { Número de eventos realizados/período } \\
\text { Número de empresas ingressantes/período. }\end{array}$} \\
\hline & & $\begin{array}{l}\text { 2.6b. Divulgar institucionalmente a rede } \\
\text { Ulbratech }\end{array}$ & & \\
\hline & $\begin{array}{l}\text { 2.7. Promover eventos de } \\
\text { integração de } \\
\text { empreendedores da rede }\end{array}$ & $\begin{array}{l}\text { 2.7a. Ampliar o networking e geração de novas } \\
\text { ideias e negócios entre os clientes e } \\
\text { stakeholders do Parque Tecnológico Ulbratech }\end{array}$ & $\begin{array}{l}\text { Aumento de eventos realizados } \\
\text { Aumento de projetos em parceria } \\
\text { com empresas }\end{array}$ & $\begin{array}{l}\text { Número de eventos realizados/período } \\
\text { Número de projetos em parceria com } \\
\text { empresas/período }\end{array}$ \\
\hline & \multirow{3}{*}{$\begin{array}{l}\text { 2.8. Promover eventos de } \\
\text { integração entre } \\
\text { pesquisadores e } \\
\text { empreendedores }\end{array}$} & $\begin{array}{l}\text { 2.8a.Ampliar a quantidade de pesquisas } \\
\text { aplicadas }\end{array}$ & \multirow{3}{*}{$\begin{array}{l}\text { Realização de eventos } \\
\text { Aumento de projetos com } \\
\text { integração entre empresas e } \\
\text { pesquisas/laboratórios }\end{array}$} & \multirow{3}{*}{$\begin{array}{l}\text { Número de spinoffs de pesquisas /período } \\
\text { Número de eventos realizados/período } \\
\text { Número de projetos em parceria/período }\end{array}$} \\
\hline & & $\begin{array}{l}\text { 2.8b. Ampliar a quantidade de startups vindas } \\
\text { de spinoffs de pesquisas }\end{array}$ & & \\
\hline & & $\begin{array}{l}\text { 2.8c. Gerar oportunidades de pesquisa } \\
\text { aplicada para os pesquisadores da Ulbra }\end{array}$ & & \\
\hline & \multirow{2}{*}{$\begin{array}{l}\text { 2.9. Realizar convênios de } \\
\text { intercambio nacionais e } \\
\text { internacionais }\end{array}$} & $\begin{array}{l}\text { 2.9a. Ampliar as oportunidades de negócios } \\
\text { das empresas do Parque Tecnológico }\end{array}$ & \multirow{2}{*}{$\begin{array}{l}\text { Aumento de convênios firmados } \\
\text { Clipagem de oportunidades de } \\
\text { negócios } \\
\text { Aumento de convênios } \\
\text { executados/rodados }\end{array}$} & \multirow{2}{*}{$\begin{array}{l}\text { Número de convênios firmados } \\
\text { Número de projetos executados } \\
\text { Número de oportunidades de negócios aproveitadas } \\
\text { pelas empresas residentes/período }\end{array}$} \\
\hline & & $\begin{array}{l}\text { 2.9b. Melhorar o posicionamento do } \\
\text { Ulbratech no cenário nacional e internacional }\end{array}$ & & \\
\hline \multirow{2}{*}{$\begin{array}{l}\text { Objetivos de } \\
\text { Médio Prazo } \\
\text { (5 anos) }\end{array}$} & \multirow{2}{*}{$\begin{array}{l}\text { 2.10. Buscar convênios e } \\
\text { parcerias para } \\
\text { investimentos, com o } \\
\text { setor privado }\end{array}$} & $\begin{array}{l}\text { 2.10a. Ampliar as fontes de recursos para } \\
\text { pesquisa aplicada e inovação }\end{array}$ & \multirow{2}{*}{$\begin{array}{l}\text { Fontes de recursos para inovação } \\
\text { e P\&D } \\
\text { Diversidade de laboratórios } \\
\text { utilizados para inovação }\end{array}$} & \multirow{2}{*}{$\begin{array}{l}\text { Número de fontes de recursos } \\
\text { Número de laboratórios e serviços para PD\&I }\end{array}$} \\
\hline & & $\begin{array}{l}\text { 2.10b. Ampliar ou modernizar laboratórios de } \\
\text { pesquisa aplicada }\end{array}$ & & \\
\hline $\begin{array}{l}\text { Objetivos de } \\
\text { Longo Prazo } \\
\text { (10 anos) }\end{array}$ & $\begin{array}{l}\text { Não foram definidos pelo } \\
\text { grupo. }\end{array}$ & Não foram definidos pelo grupo. & Não foram definidos pelo grupo. & Não foram definidos pelo grupo. \\
\hline
\end{tabular}


Quadro 5.2 - Quadro lógico para a proposição de indicadores e métricas de monitoramento e avaliação de desempenho do Parque Tecnológico Ulbratech (cont.)

\begin{tabular}{|c|c|c|c|c|}
\hline $\begin{array}{l}\text { Hierarquia } \\
\text { dos Objetivos }\end{array}$ & Objetivos & $\begin{array}{l}\text { Resultados Esperados } \\
\quad(C P, \text { MP e LP) }\end{array}$ & Indicadores & Métricas \\
\hline $\begin{array}{l}\text { Objetivo } \\
\text { Estratégico }\end{array}$ & \multicolumn{4}{|c|}{ 3. Estimular a transferência de tecnologia entre a Ulbra e as empresas do Parque Tecnológico Ulbratech } \\
\hline \multirow{10}{*}{$\begin{array}{l}\text { Objetivos de } \\
\text { Curto Prazo } \\
\text { ( } 2 \text { anos) }\end{array}$} & \multirow{3}{*}{$\begin{array}{l}\text { 3.1. Ampliar a quantidade } \\
\text { de projetos em conjunto } \\
\text { com empresas e a } \\
\text { universidade }\end{array}$} & $\begin{array}{l}\text { 3.1a. Realizar mapeamento da infraestrutura } \\
\text { de pesquisa e laboratórios da Ulbra }\end{array}$ & \multirow{3}{*}{$\begin{array}{l}\text { Conhecimento sobre } \\
\text { laboratórios/ área } \\
\text { Oportunidades e demandas das } \\
\text { empresas/ área } \\
\text { Fontes de recursos disponíveis } \\
\text { recursos/área }\end{array}$} & \multirow{3}{*}{$\begin{array}{l}\text { Número de laboratórios mapeados } \\
\text { Número de oportunidades/demandas por área } \\
\text { Número de fontes de recursos disponíveis } \\
\text { recursos/área }\end{array}$} \\
\hline & & $\begin{array}{l}\text { 3.1b. Realizar mapeamento das } \\
\text { oportunidades e demandas das empresas }\end{array}$ & & \\
\hline & & $\begin{array}{l}\text { 3.1c. Implantar sistemática de identificação } \\
\text { de fontes de recursos para viabilizar os } \\
\text { projetos }\end{array}$ & & \\
\hline & \multirow{5}{*}{$\begin{array}{l}\text { 3.2. Implantar política de } \\
\text { incentivo a pesquisa } \\
\text { aplicada e inovação em } \\
\text { parceria com empresas do } \\
\text { Parque Tecnológico } \\
\text { Ulbratech }\end{array}$} & $\begin{array}{l}\text { 3.2a. Ampliação da quantidade de pesquisas } \\
\text { aplicadas }\end{array}$ & \multirow{5}{*}{$\begin{array}{l}\text { Quantidade de pesquisas } \\
\text { aplicadas no período } \\
\text { Financiamento de pesquisas } \\
\text { pelas empresas } \\
\text { Quantidade laboratórios de uso } \\
\text { compartilhado com as empresas }\end{array}$} & \multirow{5}{*}{$\begin{array}{l}\text { Número de pesquisas realizadas no período - Número } \\
\text { de pesquisas realizadas no período anterio/ Número } \\
\text { de pesquisas realizadas no período anterior } \\
\text { Recursos destinados a financiamento de pesquisas } \\
\text { (R\$)/período }\end{array}$} \\
\hline & & $\begin{array}{l}\text { 3.2b. Ampliar o financiamento de pesquisas } \\
\text { pelas empresas }\end{array}$ & & \\
\hline & & $\begin{array}{l}\text { 3.2c. Ampliar o número de laboratórios de } \\
\text { uso compartilhado com as empresas }\end{array}$ & & \\
\hline & & $\begin{array}{l}\text { 3.2d. Definição de critérios para utilização } \\
\text { dos laboratórios pelas empresas }\end{array}$ & & \\
\hline & & $\begin{array}{l}\text { 3.2e. Elaborar o regimento para uso dos } \\
\text { laboratórios de uso compartilhado }\end{array}$ & & \\
\hline & \multirow{2}{*}{$\begin{array}{l}\text { 3.3. Promover eventos de } \\
\text { sensibilização sobre } \\
\text { propriedade intelectual } \\
\text { para empreendedores e } \\
\text { pesquisadores }\end{array}$} & $\begin{array}{l}\text { 3.3a. Realizar dois eventos de sensibilização } \\
\text { por ano }\end{array}$ & $\begin{array}{l}\text { Sensibilização sobre propriedade } \\
\text { intelectual }\end{array}$ & $\begin{array}{l}\text { Número de eventos de sensibilização sobre } \\
\text { propriedade intelectual / período. }\end{array}$ \\
\hline & & $\begin{array}{l}\text { 3.3b. Realizar um evento de capacitação por } \\
\text { ano }\end{array}$ & $\begin{array}{l}\text { Capacitação sobre propriedade } \\
\text { intelectual }\end{array}$ & $\begin{array}{l}\text { Número de eventos de capacitação sobre propriedade } \\
\text { intelectual /período }\end{array}$ \\
\hline
\end{tabular}


Quadro 5.2 - Quadro lógico para a proposição de indicadores e métricas de monitoramento e avaliação de desempenho do Parque Tecnológico Ulbratech (cont.)

\begin{tabular}{|c|c|c|c|c|}
\hline $\begin{array}{l}\text { Hierarquia } \\
\text { dos Objetivos }\end{array}$ & Objetivos & $\begin{array}{l}\text { Resultados Esperados } \\
\quad(C P, \text { MP e LP) }\end{array}$ & Indicadores & Métricas \\
\hline Objetivo & \multicolumn{4}{|c|}{ 3. Estimular a transferência de tecnologia entre a Ulbra e as empresas do Parque Tecnológico Ulbratech (cont.) } \\
\hline \multirow{5}{*}{$\begin{array}{l}\text { Objetivos de } \\
\text { Curto Prazo } \\
(2 \text { anos }) \text { - } \\
\text { cont. }\end{array}$} & \multirow{3}{*}{$\begin{array}{l}\text { 3.4. Promover eventos de } \\
\text { integração entre empresas } \\
\text { e pesquisadores para } \\
\text { fomentar pesquisas } \\
\text { aplicadas }\end{array}$} & $\begin{array}{l}\text { 3.4a. Realizar um café empresarial por } \\
\text { semestre }\end{array}$ & \multirow{3}{*}{$\begin{array}{l}\text { Índice de integração entre } \\
\text { empresas e pesquisadores para } \\
\text { fomentar pesquisas aplicadas }\end{array}$} & \multirow{3}{*}{$\begin{array}{l}\text { Número de cafés empresariais/período. } \\
\text { Número de rodadas de negócios/período. } \\
\text { Número de seminários de oportunidades com } \\
\text { empreendedores e pesquisadores/período. }\end{array}$} \\
\hline & & $\begin{array}{l}\text { 3.4b. Realizar uma rodada de negócios por } \\
\text { ano }\end{array}$ & & \\
\hline & & $\begin{array}{l}\text { 3.4c. Realizar um seminário de } \\
\text { oportunidades com empreendedores e } \\
\text { pesquisadores por semestre }\end{array}$ & & \\
\hline & $\begin{array}{l}\text { 3.5. Promover maior } \\
\text { integração entre as } \\
\text { empresas do Ulbratech e os } \\
\text { cursos afins da Ulbra }\end{array}$ & $\begin{array}{l}\text { 3.5a. Realizar Bootcamp com pesquisadores } \\
\text { (alunos e professores) e empreendedores }\end{array}$ & $\begin{array}{l}\text { Índice de integração entre as } \\
\text { empresas do Ulbratech e os } \\
\text { cursos afins da Ulbra }\end{array}$ & $\begin{array}{l}\text { Número de eventos Bootcamp com pesquisadores e } \\
\text { empreendedores/período. }\end{array}$ \\
\hline & $\begin{array}{l}\text { 3.6. Apoiar a gestão de } \\
\text { propriedade intelectual das } \\
\text { empresas e da Ulbra }\end{array}$ & $\begin{array}{l}\text { 3.6a. Promover a integração do } \\
\text { NITT/Escritório de Projetos com a entidade } \\
\text { gestora do Parque Tecnológico Ulbratech }\end{array}$ & $\begin{array}{l}\text { Índice de integração do } \\
\text { NITT/Escritório de Projetos e a } \\
\text { Entidade Gestora do Parque } \\
\text { Tecnológico Ulbratech }\end{array}$ & $\begin{array}{l}\text { Número de reuniões de integração do NITT/Escritório } \\
\text { de projetos e a Entidade Gestora do Parque } \\
\text { Tecnológico / período. }\end{array}$ \\
\hline \multirow{2}{*}{$\begin{array}{l}\text { Objetivos de } \\
\text { Médio Prazo } \\
\text { (5 anos) }\end{array}$} & \multirow{2}{*}{$\begin{array}{l}\text { 3.7. Ter programas de } \\
\text { estágio entre empresas e } \\
\text { alunos da Ulbra }\end{array}$} & $\begin{array}{l}\text { 3.7a. Disponibilizar ofertas de estágios pelas } \\
\text { empresas residentes }\end{array}$ & \multirow[t]{2}{*}{$\begin{array}{l}\text { Programas de estágio entre } \\
\text { empresas e alunos da Ulbra }\end{array}$} & $\begin{array}{l}\text { Número de estágios oferecidos pelas empresas } \\
\text { residentes/período. }\end{array}$ \\
\hline & & $\begin{array}{l}\text { 3.7b. Celebrar parcerias entre as empresas } \\
\text { do Ulbratech e a Ulbra }\end{array}$ & & $\begin{array}{l}\text { Número de parcerias entre as empresas do Ulbratech } \\
\text { e a Ulbra/período. }\end{array}$ \\
\hline \multirow{2}{*}{$\begin{array}{l}\text { Objetivos de } \\
\text { Longo Prazo } \\
\text { (10 anos) }\end{array}$} & \multirow{2}{*}{$\begin{array}{l}\text { 3.8. Criar laboratórios e } \\
\text { espaços do Parque para } \\
\text { uso comum entre empresas } \\
\text { e pesquisadores }\end{array}$} & $\begin{array}{l}\text { 3.8a. Inaugurar três laboratórios de serviços } \\
\text { avançados. }\end{array}$ & $\begin{array}{l}\text { Implantação de laboratórios de } \\
\text { serviços avançados. }\end{array}$ & $\begin{array}{l}\text { Número de laboratórios de serviços } \\
\text { avançados/período. }\end{array}$ \\
\hline & & $\begin{array}{l}\text { 3.8b. Atrair pelo menos um centro de PD\&I } \\
\text { conveniado. }\end{array}$ & $\begin{array}{l}\text { Atração de centros de PD\&I } \\
\text { conveniados. }\end{array}$ & Número de centros de PD\&I conveniados/período. \\
\hline
\end{tabular}


Quadro 5.2 - Quadro lógico para a proposição de indicadores e métricas de monitoramento e avaliação de desempenho do Parque Tecnológico Ulbratech (cont.)

\begin{tabular}{|c|c|c|c|c|}
\hline $\begin{array}{c}\text { Hierarquia } \\
\text { dos Objetivos }\end{array}$ & Objetivos & $\begin{array}{l}\text { Resultados Esperados } \\
(\mathrm{CP}, \mathrm{MP} \text { e LP) }\end{array}$ & Indicadores & Métricas \\
\hline $\begin{array}{l}\text { Objetivo } \\
\text { Estratégico }\end{array}$ & \multicolumn{4}{|c|}{ 4. Promover a interação entre a ULBRA e organizações públicas e privadas } \\
\hline \multirow{3}{*}{$\begin{array}{l}\text { Objetivos de } \\
\text { Curto Prazo } \\
\text { ( } 2 \text { anos) }\end{array}$} & $\begin{array}{l}\text { 4.1. Participar ativamente } \\
\text { de entidades de classe } \\
\text { representativas }\end{array}$ & $\begin{array}{l}\text { 4.1a. Participar em conselhos de, no mínimo, } \\
\text { duas entidades representativas. }\end{array}$ & $\begin{array}{l}\text { Grau de participação em } \\
\text { conselhos de entidades de classe } \\
\text { representativas }\end{array}$ & $\begin{array}{l}\text { № de reuniões de conselhos de entidades de classe } \\
\text { representativas com participação do Parque/período. }\end{array}$ \\
\hline & \multirow[t]{2}{*}{$\begin{array}{l}\text { 4.2. Captar convênios } \\
\text { nacionais e internacionais } \\
\text { com outros parques }\end{array}$} & $\begin{array}{l}\text { 4.2a. Celebrar pelo menos dois convênios } \\
\text { nacionais. }\end{array}$ & $\begin{array}{l}\text { Índice de convênios nacionais e } \\
\text { internacionais com outros } \\
\text { Parques }\end{array}$ & $\begin{array}{l}\text { № de convênios nacionais com outros } \\
\text { parques/período. }\end{array}$ \\
\hline & & $\begin{array}{l}\text { 4.2b. Celebrar pelo menos um convênio } \\
\text { internacional. }\end{array}$ & Não definidos pelo grupo. & $\begin{array}{l}\text { № de convênios internacionais com outros } \\
\text { parques/período. }\end{array}$ \\
\hline \multirow{4}{*}{$\begin{array}{l}\text { Objetivos de } \\
\text { Médio Prazo } \\
\text { ( } 5 \text { anos) }\end{array}$} & \multirow{2}{*}{$\begin{array}{l}\text { 4.3. Apoiar a } \\
\text { internacionalização das } \\
\text { empresas do Ulbratech }\end{array}$} & $\begin{array}{l}\text { 4.3a. Celebrar parcerias com APEX e } \\
\text { entidades afins. }\end{array}$ & $\begin{array}{l}\text { Grau de internacionalização das } \\
\text { empresas do Ulbratech }\end{array}$ & № de empresas internacionalizadas /período \\
\hline & & $\begin{array}{l}\text { 4.3b. Promover missões internacionais com } \\
\text { as empresas residentes. }\end{array}$ & $\begin{array}{l}\text { Grau de realização de missões } \\
\text { internacionais com empresas } \\
\text { residentes }\end{array}$ & $\begin{array}{l}\text { № de missões internacionais com empresas } \\
\text { residentes realizadas/período. }\end{array}$ \\
\hline & \multirow[t]{2}{*}{$\begin{array}{l}\text { 4.4. Consolidar ações de } \\
\text { intercâmbio entre } \\
\text { empresas do Ulbratech } \\
\text { com outros parques }\end{array}$} & $\begin{array}{l}\text { 4.4a. Realizar matchmaking entre empresas } \\
\text { do Ulbratech e de outros parques } \\
\text { tecnológicos. }\end{array}$ & $\begin{array}{l}\text { Grau de intercâmbio entre } \\
\text { empresas residentes no Parque } \\
\text { Tecnológico Ulbratech com } \\
\text { outros Parques }\end{array}$ & $\begin{array}{l}\text { № de parcerias entre empresas do Ulbratech e de } \\
\text { outros parques tecnológicos/período }\end{array}$ \\
\hline & & $\begin{array}{l}\text { 4.4b. Executar, no mínimo, um programa } \\
\text { bilateral de softlanding }\end{array}$ & $\begin{array}{l}\text { Grau de realização de programas } \\
\text { bilaterais de softlanding. }\end{array}$ & № de programas bilaterais de softlanding/ período. \\
\hline $\begin{array}{l}\text { Objetivos de } \\
\text { Longo Prazo } \\
\text { ( } 5 \text { anos) }\end{array}$ & Não definidos pelo grupo. & Não definidos pelo grupo. & Não definidos pelo grupo. & Não definidos pelo grupo. \\
\hline
\end{tabular}

Fonte: Elaboração própria a partir dos resultados das duas Oficinas realizadas durante o 1 Curso para Gestores de Parques Tecnológicos e Ambientes de Inovação, oferecido pela Uni-Anprotec/Instituto Gênesis em 2016. 


\subsection{2}

\section{Parque Tecnológico de Santa Rita do Sapucaí}

O Parque Tecnológico de Santa Rita do Sapucaí é uma iniciativa do Sindicato das Indústrias de Aparelhos Elétricos, Eletrônicos e Similares do Vale da Eletrônica (Sindvel), em parceria com o governo do Estado de Minas Gerais e o município de Santa Rita do Sapucaí. Atualmente está em fase de projeto, sendo prevista sua entrada em operação no segundo semestre de 2017. Contudo, o ambiente de inovação no município de Santa Rita do Sapucaí já constituiu um ecossistema tecnológico, empresarial e inovador consolidado.

O município de Santa Rita do Sapucaí (MG), também conhecido como o "vale da eletrônica", é considerado uma dos dez municípios brasileiros com grande potencial para inovação, conforme Ewers, Gomes e Octaviano (2015).

O projeto do Parque Tecnológico de Santa Rita do Sapucaí é o de um parque aberto, em que os limites do empreendimento estão determinados pelas fronteiras do município de Santa Rita do Sapucaí e não havendo, necessariamente, a concessão e restrição de um espaço físico para a instalação de empresas. Segundo informações fornecidas durante as Oficinas, a cidade é sede do Arranjo Produtivo Eletroeletrônico de Santa Rita do Sapucaí (APL), constituído por mais de 150 empresas dos setores de eletroeletrônica, telecomunicações, segurança, eletrônica, informática, radiodifusão e equipamentos eletromédicos, assim como 153 indústrias tecnológicas e três incubadoras. Inclui ainda um polo educacional, formado por instituições de ensino técnico, superior e pós graduação, a exemplo da Escola Técnica de Eletrônica "Francisco Moreira da Costa" (ETE), o Instituto Nacional de Telecomunicações (INATEL) e o Centro de Ensino Superior em Gestão, Tecnologia e Educação (FAI).

O Parque Tecnológico de Santa Rita do Sapucaí já tem um edifício central, compartilhado entre todas as empresas e instituições parceiras e adequado estrutural e ambientalmente para as necessidades dos afiliados e do corpo gestor.

A missão do Parque é enunciada como "promover o desenvolvimento de Santa Rita do Sapucaí e da Região por meio de inovação, conhecimento e geração de novos negócios de base tecnológica" e visão até 2016, "ser o melhor ambiente de empreendedorismo, inovação e negócios de base tecnológica do país". Para 
atingir sua missão e prospecção de futuro, o parque possui os objetivos específicos:

- Desenvolver a cultura de inovação e competitividade das empresas e instituições intensivas em conhecimento associadas ao parque tecnológico de Santa Rita do Sapucaí;

- Gerar novos negócios de base tecnológica para o município de Santa Rita do Sapucaí;

- Promover a cultura empreendedora voltada para a geração de emprego, trabalho e renda;

- Instituir uma estrutura de pessoa jurídica de direito privado, adotando o modelo de "associação", com a possibilidade de que, futuramente, o Parque Tecnológico possa tornar-se uma Organização Social (OS).

\section{Caracterização das partes interessadas e seus objetivos em relação ao empreendimento}

O Quadro 5.3 apresenta os principais stakeholders e seus objetivos em relação ao empreendimento Parque Tecnológico de Santa Rita do Sapucaí.

Quadro 5.3 - Partes interessadas e seus objetivos em relação ao Parque Tecnológico Aberto de Santa Rita do Sapucaí

\begin{tabular}{|c|c|}
\hline $\begin{array}{l}\text { Partes } \\
\text { interessadas }\end{array}$ & Objetivos em relação ao empreendimento \\
\hline $\begin{array}{l}\text { Instituições de } \\
\text { ensino superior e } \\
\text { pesquisa (ETE, } \\
\text { INATEL e FAI) }\end{array}$ & $\begin{array}{l}\text { - Ampliar a missão institucional, promovendo desenvolvimento } \\
\text { regional; } \\
\text { - Aquisição de recursos financeiros através de agências de fomento, } \\
\text { como o CNPq, para a concessão de bolsas voltadas para o } \\
\text { desenvolvimento de projetos com base tecnológica; } \\
\text { - Integração entre o corpo docente e discente (graduados e pós- } \\
\text { graduados) junto às empresas, promovendo a transferência } \\
\text { tecnológica e desenvolvimento inovador. }\end{array}$ \\
\hline $\begin{array}{lr}\text { Sindicato } & \text { das } \\
\text { Indústrias } & \text { de } \\
\text { Aparelhos Elétricos, } \\
\text { Eletrônicos } \\
\text { Similares do Vale da } \\
\text { Eletrônica (Sindvel), }\end{array}$ & $\begin{array}{l}\text { - Promover a cultura da proteção da propriedade intelectual; } \\
\text { - Auxiliar, junto ao corpo acadêmico, a produção e gestão da } \\
\text { inovação; } \\
\text { - Apoiar a transferência do conhecimento e tecnologia, pesquisa e } \\
\text { proteção intelectual; } \\
\text { - Prospecção de recursos em pareceria com os setores público e } \\
\text { privado; } \\
\text { - Promoção da pesquisa para as empresas afiliadas. }\end{array}$ \\
\hline $\begin{array}{l}\text { - Arranjo Produtivo } \\
\text { Eletroeletrônico } \\
\text { (APL) }\end{array}$ & $\begin{array}{l}\text { - Produzir produtos e serviços inovadores e pioneiros através das } \\
\text { contribuições dos programas exercidos pelo parque tecnológico } \\
\text { (consultorias especializadas, pesquisas, assistência técnica e } \\
\text { tecnológica de ponta, entre outros). }\end{array}$ \\
\hline
\end{tabular}

Fontes: Sindvel, (2017), Estado de Minas Gerais (2015). 


\section{Perfil estratégico: uso da ferramenta 'Estrategigrama' da IASP}

A Figura 5.6 mostra o perfil estratégico atual do Parque Tecnológico de Santa Rita do Sapucaí.

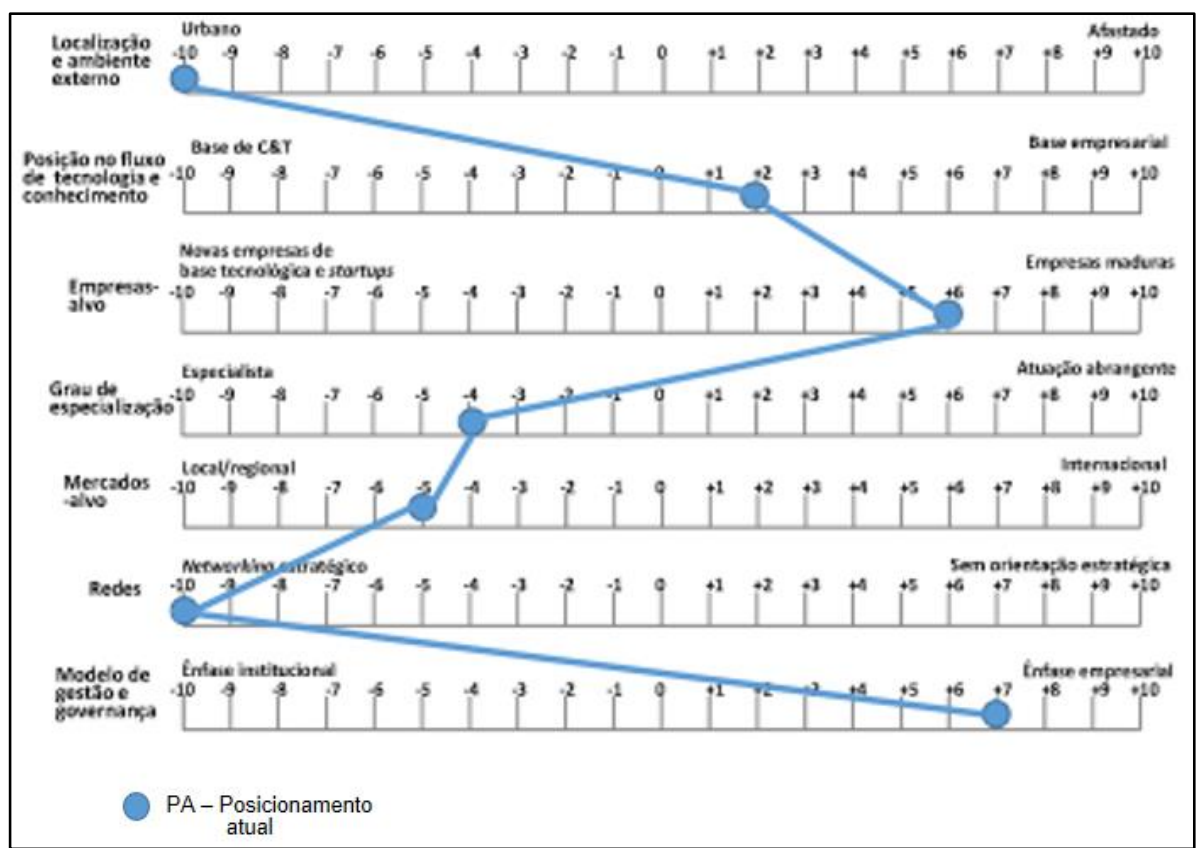

Figura 5.6 - Perfil estratégico atual do Parque Tecnológico de Santa Rita do Sapucaí

Fonte: Elaboração própria a partir dos resultados das duas Oficinas realizadas durante o 1 Curso para Gestores de Parques Tecnológicos e Ambientes de Inovação, oferecido pela UniAnprotec/Instituto Gênesis em 2016.

Pela definição de parque aberto, considerou-se toda a extensão do município de Santa Rita do Sapucaí para a análise do Parque em relação ao eixo 'localização e ambiente externo'. O fluxo de tecnologia e conhecimento é voltado para base empresarial, contudo existe um forte desempenho de base de C\&T. Na cidade existe um número considerável de empresas maduras (período de atividades superior a 10 anos) de pequeno, médio e grande porte, assim como esses empreendimentos estão, em sua maioria, voltados para o setor de eletroeletrônico e telecomunicações.

O mercado-alvo do Parque Tecnológico de Santa Rita do Sapucaí é voltado para as regiões de Minas Gerais e São Paulo, sendo que existem iniciativas internacionais. É válido ressaltar o networking estratégico consolidado entre as instituições de ensino, indústrias, empresas e setores governamentais locais. O 
modelo de gestão e governança do parque, atualmente é impulsionado pelo Sindvel, portanto grande ênfase empresarial.

Em relação à evolução do perfil estratégico do Parque Tecnológico de Santa Rita do Sapucaí, a estratégia é aumentar e fortalecer os laboratórios e instituições de PD\&I para aprimorar a base de C\&T do empreendimento, e atingir um equilíbrio com a base empresarial (Figura 5.7).

Com relação ao grau de especialização, tem-se como objetivo aumentar as áreas de atuação do parque, tornando-o mais abrangente e aumentando sua posição diante do mercado internacional. Ao modelo de gestão, entende-se que o parque tecnológico necessita ser desvinculado do modelo atual, tornando-se, no longo prazo, uma organização independente.

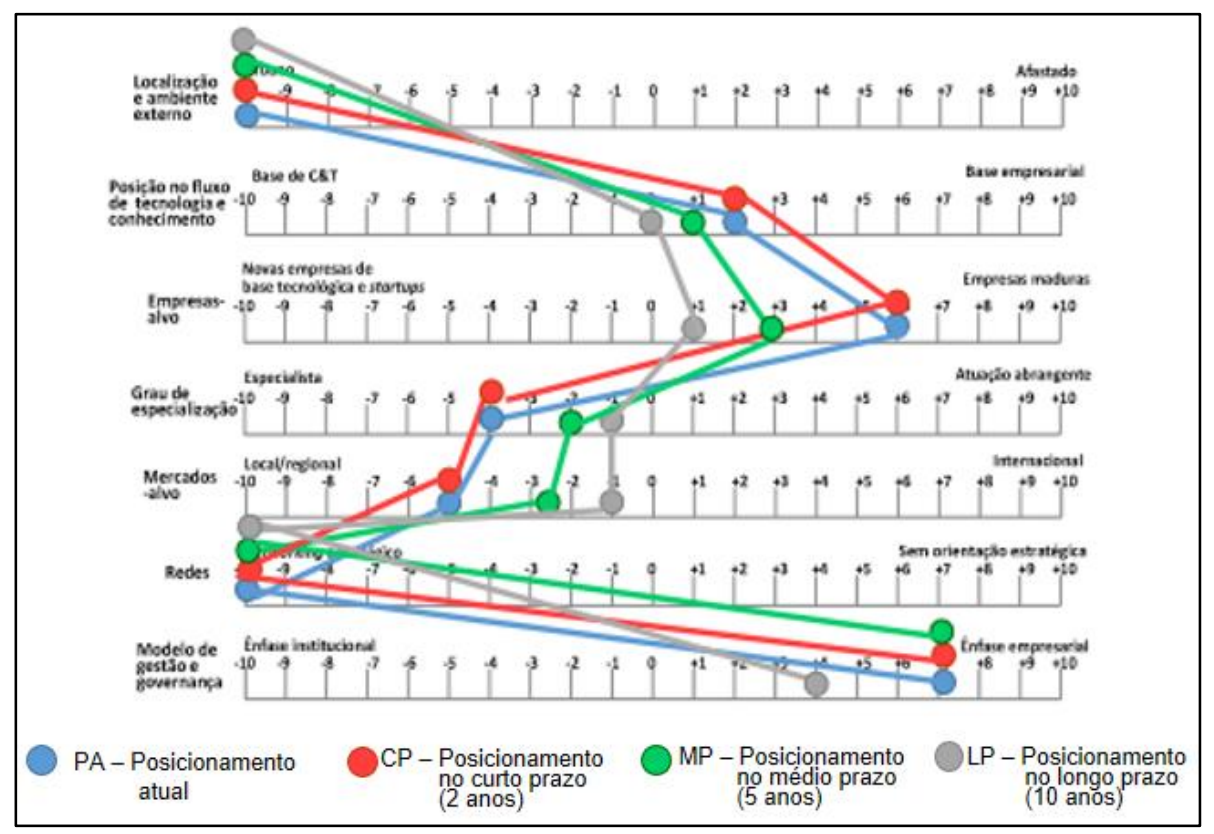

Figura 5.7 - Evolução do perfil estratégico do Parque Tecnológico de Santa Rita do Sapucaí: curto, médio e longo prazo

Fonte: Elaboração própria a partir dos resultados das duas Oficinas realizadas durante o 1ำ Curso para Gestores de Parques Tecnológicos e Ambientes de Inovação, oferecido pela UniAnprotec/Instituto Gênesis em 2016.

\section{Modelo de negócio: uso da ferramenta 'Canvas'}

Para a formulação do modelo de negócios do parque tecnológico de Santa Rita do Sapucaí utilizou-se das informações transmitidas por gestores do parque em elaboração das atividades das oficinas e pesquisa em websites de divulgação tecnológica e de inovações. O Parque Tecnológico não apresenta um site 
institucional. As informações contidas nesses meios de comunicação deram os dados necessários para completar os blocos pertinentes à ferramenta Canvas.

\section{Segmentos de clientes}

O município de Santa Rita do Sapucaí, antes da implementação do projeto de criação do Parque Tecnológico, já era considerado um importante polo brasileiro de eletroeletrônicos, sendo base para empresas nacionais e internacionais do setor. Entre essas empresas citam-se a Panasonic, Ericsson, Qualcomm, Intelbras e Grupo Giga. O foco de atuação do Parque são as seguintes áreas:

- Eletroeletrônicos

- Telecomunicações;

- Segurança digital;

- Eletrônico;

- Informática;

- Radiodifusão;

- Eletromédicos.

Atualmente, o município consta com 153 indústrias e 3 incubadoras, sendo o parque tecnológico capaz de abrigar, em média, 25 empresas para o seu primeiro ano de funcionamento.

\section{Proposição de valor}

Por se tratar de um ambiente já consolidado no setor de eletroeletrônicos, o Parque Tecnológico de Santa Rita do Sapucaí busca, em sua proposição de valor, o fortalecimento das atividades dos ICTs, empresas e da sociedade, como também melhor interatividade entre esses três elementos. As atividades propostas para se atingir essa visão de valor são:

- Incentivo a pesquisa tecnológica;

- Fomentos para laboratórios e criação de bolsas acadêmicas;

- Criação de novas tecnologias;

- Maior atratividade para estudantes e professores;

- Aumento da competitividade empresarial;

- Maior acesso a recursos financeiros para as empresas;

- Incentivo ao alinhamento entre o ensino local e o mercado-alvo do parque; 
- Desenvolvimento social através da geração de novos empregos, e aumento da renda per capta, assim como maior disseminação e promoção da cultura de inovação e empreendedorismo.

\section{Fluxo de conhecimento e tecnologia}

Por já possuir um networking estratégico e maduro para implementação ao Parque Tecnológico de Santa Rita do Sapucaí, existe um sistema em rede que conecta os institutos de educação, as indústrias parceiras do parque, ICTs e laboratórios. As atividades desenvolvidas para o fluxo de conhecimento e tecnologia do parque são:

- Fortalecer a interação entre as empresas clientes, atuais e futuras, com os ICTs, as instituições de ensino superior e as incubadoras;

- Oferecer apoio especializado à transferência tecnológica e a propriedade intelectual para as empresas e instituições de ensino, PD\&I e ICTs clientes do parque.

- Mediar o contato entre as empresas e as instituições parceiras para a formulação de projetos colaborativos de PD\&I para o mercado interno e externo.

\section{Relacionamento com clientes}

O Sindvel, responsável pela governança do parque tecnológico, já estabilizou um sistema de relacionamento com seus clientes existentes. Para a proposição do Parque Tecnológico, é recomendado que sejam adotadas as seguintes práticas:

- Melhoria contínua e de excelência nos serviços de alto valor agregado prestado às empresas, às instituições de ensino e de PD\&I;

- Divulgação de editais e estruturas de marketing para a atração de startups e empresas de pequeno e médio porte;

- Implantação de uma política de atração para empresas de base de ciência e tecnologia.

\section{Geração de receitas}

Para a geração de receitas do parque tecnológico, foram estabelecidas as seguintes atividades:

- Programas para a utilização dos módulos dos edifícios a serem instalados na cidade para as empresas residentes;

- Fomento proveniente de recursos governamentais;

- Produção de novos produtos e serviços inovadores especializados no setor de eletroeletrônicos para o mercado nacional e internacional;

- Serviços de consultorias especializadas. 


\section{Recursos-chave}

Como recursos-chave para o parque tecnológico, são considerados essenciais recursos físicos, a exemplo das estruturas construídas como os edifícios compartilhados para as empresas residentes e o corpo gestor do parque. As áreas que serão atribuídas aos institutos de PD\&I e os investimentos direcionados aos laboratórios técnicos e especializados (localizados nas instituições de ensinos parceiras).

Também são concedidos ao Parque Tecnológico recursos públicos e privados para manutenção e desenvolvimento das estruturas e atividades do parque, com a finalidade de crescimento e contratos de novas empresas e projetos inovadores. A qualificação e especialização do corpo discente e docente dos institutos de pesquisa também são importantes geradores de receita, e para tanto.

\section{Atividades-chave}

As atividades-chave realizadas pelo parque tecnológico são:

- Realização de projetos e pesquisas para a formação de alianças empresariais e institucionais em nível local, regional, nacional e internacional;

- Promover a especialização acadêmica de alunos e professores das instituições de ensino superior afiliadas;

- Promover cultura empreendedora para a geração de novos empregos e desenvolvimento econômico e social;

- Atração de empresas e projetos inovadores;

- Transferência de tecnologia e conhecimento;

- Gestão imobiliária dos espaços físicos destinados as empresas clientes e institutos parceiros;

- Manutenção do forte sistema de networking.

\section{Parceiros-chave}

Os parceiros-chave do Parque Tecnológico Santa Rida do Sapucaí são:

- Instituições de ensino superior e pesquisa (ETE, INATEL e FAI);

- Sindvel;

- APL.

\section{Estrutura de custos}

Os seguintes itens integram a estrutura de custos do Parque Tecnológico de Santa Rita do Sapucaí: 
- Investimentos regulares para manutenção dos edifícios do Parque Tecnológico;

- Custo de pessoal e operacional (salários, encargos, material administrativo, empresas terceirizadas, etc.);

- Investimentos em infraestruturas para as empresas que residem no parque;

- Investimentos nos ambientes de PD\&I (manutenção, aprimoramento e ampliação).

\section{Estágio de desenvolvimento do Parque Tecnológico conforme classificação da Anprotec}

O projeto do Parque Tecnológico para o município de Santa Rita do Sapucaí encontra-se atualmente no estágio de planejamento, no entanto o ecossistema consolidado do município como um polo eletroeletrônico torna o ambiente local ideal para a implantação do parque, criando grande potencial para o desenvolvimento de novas empresas, geração de conhecimento, desenvolvimento de novos processos e produtos de base tecnológica.

Para o ano de 2017, segundo gestores do parque, estão registradas 25 empresas associadas, com o planejamento de aumentar até 178 para o ano de 2026. Para tanto, o parque contará com investimentos públicos e privados, totalizando 20,7 milhões de reais, para financiar suas atividades durante o horizonte de 10 anos de atividade.

\section{Posicionamento do Parque Tecnológico segundo a taxonomia da Anprotec}

De acordo com a taxonomia da Anprotec (2008), os gestores responsáveis pela classificação do Parque Tecnológico de Santa Rita do Sapucaí o descreveram como um ecossistema consolidado, apresentando um ambiente de inovação tecnológica maduro para a implementação do Parque (Figura 5.8).

O empreendimento possui potencial para a aceleração e desenvolvimento de novos negócios, geração de conhecimento e desenvolvimento de novos processos e produtos de base tecnológica. O município já é apresentado como um polo reconhecido nacionalmente por suas atividades tecnológicas e inovativas. 


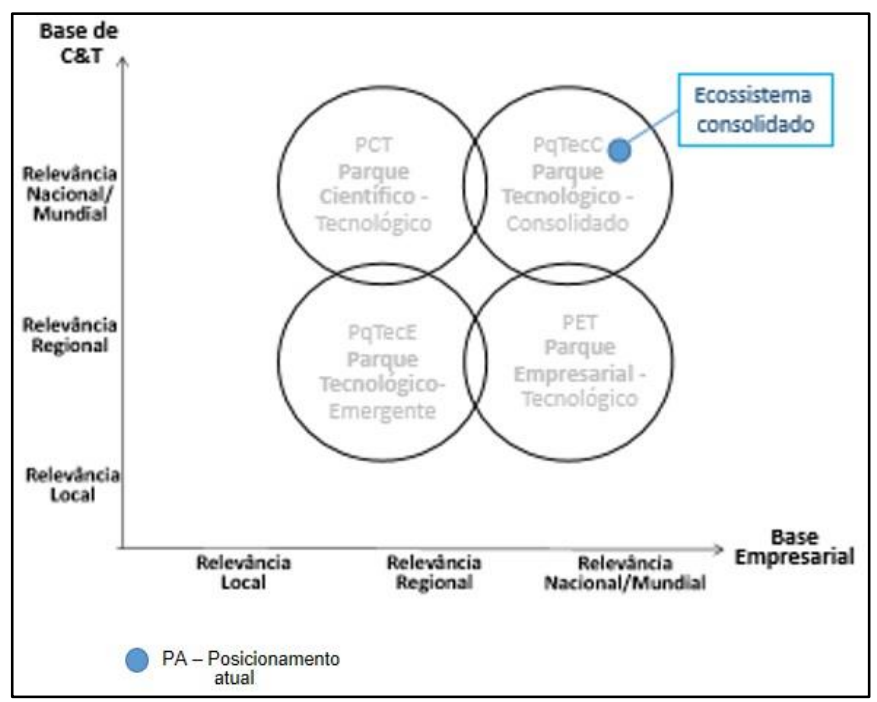

Figura 5.8 - Posicionamento atual do Parque Tecnológico Santa Rita do Sapucaí

Fonte: Elaboração própria a partir dos resultados das duas Oficinas realizadas durante o $1^{\circ}$ Curso para Gestores de Parques Tecnológicos e Ambientes de Inovação, oferecido pela UniAnprotec/Instituto Gênesis em 2016.

Ao término da estruturação física do Parque Tecnológico de Santa Rita do Sapucaí, será considerado um parque tecnológico emergente. O Parque, tendo relevância regional devido ao ecossistema já consolidado, atuará com ênfase no desenvolvimento no curto prazo na relevância em base de C\&T e para o médio e longo prazo no seu posicionamento em escala internacional para a base empresarial e C\&T (Figura 5.9).

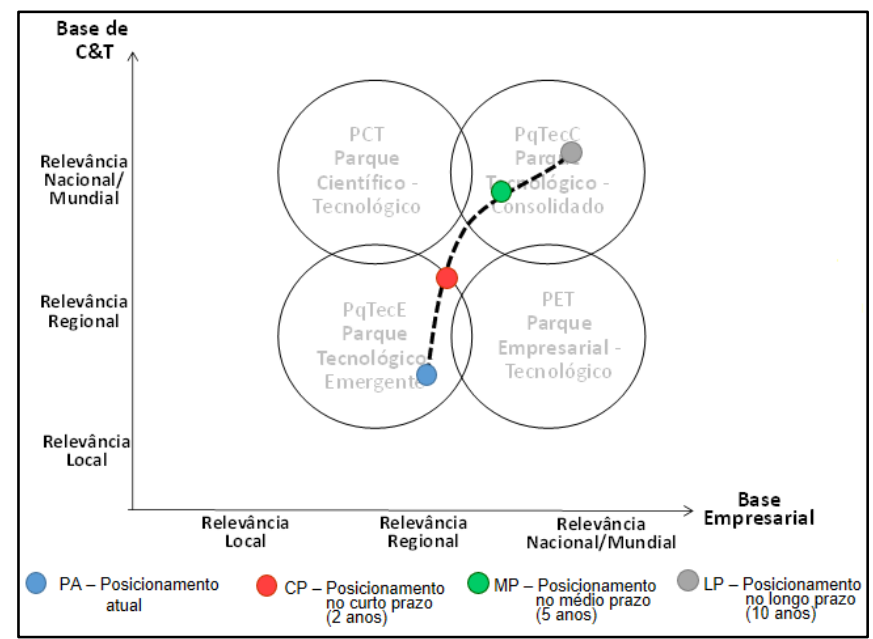

Figura 5.9 - Estratégia de crescimento do Parque Tecnológico de Santa Rita do Sapucaí: curto, médio e longo prazo

Fonte: Elaboração própria a partir dos resultados das duas Oficinas realizadas durante o $1^{\circ}$ Curso para Gestores de Parques Tecnológicos e Ambientes de Inovação, oferecido pela UniAnprotec/Instituto Gênesis em 2016. 
Quadro lógico e proposição de indicadores e métricas para monitoramento e avaliação de desempenho do Parque Tecnológico

A construção do quadro lógico para a proposição de indicadores e métricas de monitoramento e avaliação de desempenho do Parque Tecnológico de Santa Rita do Sapucaí: seguiu a orientação metodológica descrita no capítulo 4 (Quadro $5.4)$. 
Quadro 5.4 - Quadro lógico para a proposição de indicadores e métricas de monitoramento e avaliação de desempenho do Parque Tecnológico de Santa Rita do Sapucaí

\begin{tabular}{|c|c|c|c|c|}
\hline $\begin{array}{c}\text { Hierarquia } \\
\text { dos Objetivos }\end{array}$ & Objetivos & $\begin{array}{l}\text { Resultados Esperados } \\
\quad(\mathrm{CP}, \mathrm{MP} \text { e LP) }\end{array}$ & Indicadores & Métricas \\
\hline $\begin{array}{l}\text { Objetivo } \\
\text { Estratégico }\end{array}$ & \multicolumn{4}{|c|}{ 1. Desenvolver a cultura da inovação e competitividade das empresas e instituições intensivas em conhecimento associadas ao parque de Santa Rita do Sapucaí } \\
\hline $\begin{array}{l}\text { Objetivos de } \\
\text { Curto Prazo } \\
\text { ( } 2 \text { anos) }\end{array}$ & $\begin{array}{l}\text { 1.1. Incentivar a criação } \\
\text { de alianças estratégicas } \\
\text { em nível regional, } \\
\text { nacional e internacional }\end{array}$ & $\begin{array}{l}\text { 1.1a. Formar novas empresas de base } \\
\text { tecnológica }\end{array}$ & $\begin{array}{l}\text { Aumento empresas de base } \\
\text { tecnológica criadas e incubadas. } \\
\text { Novos projetos e pesquisas } \\
\text { realizados através de alianças } \\
\text { estratégicas. }\end{array}$ & $\begin{array}{l}\text { Número de empresas de base tecnológica criadas e } \\
\text { incubadas. } \\
\text { Número de projetos e pesquisas realizados através de } \\
\text { alianças estratégicas. }\end{array}$ \\
\hline \multirow{4}{*}{$\begin{array}{l}\text { Objetivos de } \\
\text { Médio Prazo } \\
\text { ( } 5 \text { anos) }\end{array}$} & \multirow{3}{*}{$\begin{array}{l}\text { 1.2. Facilitar a } \\
\text { transferência de } \\
\text { tecnologia entre } \\
\text { instituições acadêmicas e } \\
\text { empresas localizadas no } \\
\text { Parque Tecnológico. }\end{array}$} & $\begin{array}{l}\text { 1.2a. Desenvolver empreendedorismo } \\
\text { universitário. }\end{array}$ & \multirow{4}{*}{$\begin{array}{l}\text { Interação dos stakeholders do } \\
\text { parque com os centros de } \\
\text { tecnologia da comunidade } \\
\text { científica. } \\
\text { Transferências de tecnologia e } \\
\text { conhecimento entre academia e } \\
\text { empresa. } \\
\text { Número de avanços e } \\
\text { desenvolvimentos tecnológicos } \\
\text { que foram aplicados } \\
\text { internamente nas empresas e } \\
\text { academia }\end{array}$} & \multirow{4}{*}{$\begin{array}{l}\text { Número de resultados obtidos através da interação } \\
\text { dos stakeholders do parque com os centros de } \\
\text { tecnologia da comunidade científica. } \\
\text { Número de transferências de tecnologia e } \\
\text { conhecimento entre academia e empresa. }\end{array}$} \\
\hline & & 1.2b. Depositar novas patentes. & & \\
\hline & & 1.2c. Introduzir novos produtos no mercado & & \\
\hline & $\begin{array}{l}\text { 1.3. Estimular a } \\
\text { cooperação entre as } \\
\text { empresas associadas ao } \\
\text { Parque }\end{array}$ & $\begin{array}{l}\text { 1.3a. Aumentar a competitividade dos } \\
\text { produtos e serviços das empresas do Parque. }\end{array}$ & & \\
\hline \multirow{4}{*}{$\begin{array}{l}\text { Objetivos de } \\
\text { Longo Prazo } \\
\text { (10 anos) }\end{array}$} & \multirow{4}{*}{$\begin{array}{l}\text { 1.4. Desenvolver e } \\
\text { aperfeiçoar novos } \\
\text { produtos e serviços } \\
\text { inovadores por meio dos } \\
\text { recursos disponibilizados } \\
\text { no Parque Tecnológico. }\end{array}$} & 1.4a. Gerar novos negócios & \multirow{4}{*}{$\begin{array}{l}\text { Empreendimentos referentes a } \\
\text { novos negócios. } \\
\text { Novas patentes depositadas. }\end{array}$} & \multirow{4}{*}{$\begin{array}{l}\text { Número de empreendimentos referentes a novos } \\
\text { negócios } \\
\text { Número de resultados de pesquisas comercializados e } \\
\text { divulgados. } \\
\text { Número de participações em eventos científico- } \\
\text { tecnológicos. } \\
\text { Número de novas patentes/ano }\end{array}$} \\
\hline & & 1.4b. Gerar maiores impostos & & \\
\hline & & $\begin{array}{l}\text { 1.4c. Aumentar o faturamento das empresas } \\
\text { associadas. }\end{array}$ & & \\
\hline & & $\begin{array}{l}\text { 1.4d. Aumentar a competitividade dos } \\
\text { produtos e serviços das empresas associadas }\end{array}$ & & \\
\hline
\end{tabular}


Quadro 5.4 - Quadro lógico para a proposição de indicadores e métricas de monitoramento e avaliação de desempenho do Parque Tecnológico de Santa Rita do Sapucaí (cont.)

\begin{tabular}{|c|c|c|c|c|}
\hline $\begin{array}{c}\text { Hierarquia } \\
\text { dos Objetivos }\end{array}$ & Objetivos & $\begin{array}{l}\text { Resultados Esperados } \\
\text { (CP, MP e LP) }\end{array}$ & Indicadores & Métricas \\
\hline Objetivo & \multicolumn{4}{|c|}{ 2. Gerar novos negócios de base tecnológica para o município de Santa Rita do Sapucaí } \\
\hline $\begin{array}{l}\text { Objetivos de } \\
\text { Curto Prazo } \\
\text { ( } 2 \text { anos) }\end{array}$ & $\begin{array}{l}\text { 2.1. Promover ações para } \\
\text { a atração das empresas } \\
\text { de base tecnológica para } \\
\text { dinamização das } \\
\text { atividades produtivas da } \\
\text { Região de Santa Rita do } \\
\text { Sapucaí }\end{array}$ & $\begin{array}{l}\text { 2.1b. Dinamizar as atividades produtivas da } \\
\text { Região. }\end{array}$ & $\begin{array}{l}\text { Taxa de crescimento de } \\
\text { pequenas empresas de BT } \\
\text { residentes no período } \\
\text { Aumento do PIB da Região de } \\
\text { Santa Rita do Sapucaí no período } \\
\text { Faturamento das empresas } \\
\text { instaladas no Parque de Santa } \\
\text { Rita do Sapucaí no período }\end{array}$ & $\begin{array}{l}\text { Número de novas empresas residentes /ano } 1 \\
\text { Projeção: } 25 \text { empresas associadas } \\
\text { Número de novas empresas residentes /ano } 2 \\
\text { Projeção 2018: } 33 \text { empresas associadas } \\
\text { PIB ano2 - PIB ano1/PIB ano1 } \\
\text { Faturamento das empresas instaladas no Parque no } \\
\text { período }\end{array}$ \\
\hline $\begin{array}{l}\text { Objetivos de } \\
\text { Médio Prazo } \\
\text { (5 anos) }\end{array}$ & $\begin{array}{l}\text { 2.2. Encorajar o } \\
\text { surgimento de empresas } \\
\text { spin-off iniciadas por } \\
\text { acadêmicos, prestando } \\
\text { serviços para a } \\
\text { Universidade e outras } \\
\text { empresas localizadas no } \\
\text { Parque Tecnológico }\end{array}$ & $\begin{array}{l}\text { 2.2b. Criar novos negócios voltados para o } \\
\text { mercado. }\end{array}$ & $\begin{array}{l}\text { Aumento de empresas incubadas } \\
\text { recém-ingressas no mercado. } \\
\text { Aumento de novas spin-offs no } \\
\text { mercado }\end{array}$ & $\begin{array}{l}\text { Número de empresas incubadas recém-ingressas no } \\
\text { mercado. } \\
\text { Número de novas spin-offs no mercado. }\end{array}$ \\
\hline \multirow{2}{*}{$\begin{array}{l}\text { Objetivos de } \\
\text { Longo Prazo } \\
\text { (10 anos) }\end{array}$} & \multirow{2}{*}{$\begin{array}{l}\text { 2.3. Desenvolver um } \\
\text { modelo de fundo de } \\
\text { investimentos para } \\
\text { geração de novos } \\
\text { negócios }\end{array}$} & 2.3a. Gerar novos negócios & \multirow{2}{*}{$\begin{array}{l}\text { Aumento do faturamento das } \\
\text { empresas associadas } \\
\text { Aumento de novos modelos de } \\
\text { produtos e serviços de base } \\
\text { tecnológica }\end{array}$} & \multirow{2}{*}{$\begin{array}{l}\text { EBITDA em percentagem do volume de novos negócios } \\
\text { (\%) /ano } \\
\text { Taxa de crescimento das empresas instaladas } \\
\text { Faturamento das empresas instaladas no Parque. }\end{array}$} \\
\hline & & $\begin{array}{l}\text { 2.3c. Aumentar o faturamento das empresas } \\
\text { associadas. }\end{array}$ & & \\
\hline
\end{tabular}


Quadro 5.4 - Quadro lógico para a proposição de indicadores e métricas de monitoramento e avaliação de desempenho do Parque Tecnológico de Santa Rita do Sapucaí (cont.)

\begin{tabular}{|c|c|c|c|c|}
\hline $\begin{array}{l}\text { Hierarquia } \\
\text { dos Objetivos }\end{array}$ & Objetivos & $\begin{array}{l}\text { Resultados Esperados } \\
\text { (CP, MP e LP) }\end{array}$ & Indicadores & Métricas \\
\hline Objetivo & \multicolumn{4}{|c|}{ 3. Promover a cultura empreendedora voltada à geração de emprego, trabalho e renda. } \\
\hline \multirow{3}{*}{$\begin{array}{l}\text { Objetivos de } \\
\text { Curto Prazo } \\
\text { ( } 2 \text { anos) }\end{array}$} & \multirow{3}{*}{$\begin{array}{l}\text { 3.1. Promover ações para } \\
\text { a atração das empresas } \\
\text { de base tecnológica para } \\
\text { dinamização das } \\
\text { atividades produtivas da } \\
\text { Região de Santa Rita do } \\
\text { Sapucaí }\end{array}$} & $\begin{array}{l}\text { 3.1a. Aumentar o número de pequenas } \\
\text { empresas de base tecnológica residentes. }\end{array}$ & \multirow{3}{*}{$\begin{array}{l}\text { Grau de impacto na renda da } \\
\text { comunidade local. } \\
\text { Quantidade de mão de obra } \\
\text { qualificada e treinada. } \\
\text { Número de postos de trabalho } \\
\text { formal e informais gerados. }\end{array}$} & \multirow{3}{*}{$\begin{array}{l}\text { Novos postos de trabalho gerados / ano } \\
\text { PIB ano2 - PIB ano1/PIB ano1 } \\
\text { Faturamento (\$) das empresas instaladas no Parque no } \\
\text { período }\end{array}$} \\
\hline & & $\begin{array}{l}\text { 3.1b. Dinamizar as atividades produtivas da } \\
\text { Região. }\end{array}$ & & \\
\hline & & 3.1c. Criar novos postos de trabalho & & \\
\hline \multirow{2}{*}{$\begin{array}{l}\text { Objetivos de } \\
\text { Médio Prazo } \\
\text { ( } 5 \text { anos) }\end{array}$} & \multirow[t]{2}{*}{$\begin{array}{l}\text { 3.2. Gerar novos postos } \\
\text { de trabalho na região. }\end{array}$} & $\begin{array}{l}\text { 3.2a. Melhorar o desempenho da economia } \\
\text { local }\end{array}$ & \multirow{2}{*}{$\begin{array}{l}\text { Novos empregos gerados pelos } \\
\text { empreendimentos } \\
\text { Aumento de renda da população }\end{array}$} & \multirow{2}{*}{$\begin{array}{l}\text { Número de postos de trabalho gerados no período } \\
\text { Empresas por número de funcionários. } \\
\text { Aparição em mídia e número de eventos. } \\
\text { PIB do período }\end{array}$} \\
\hline & & 3.2b. Aumentar o PIB local. & & \\
\hline \multirow{3}{*}{$\begin{array}{l}\text { Objetivos de } \\
\text { Longo Prazo } \\
\text { (10 anos) }\end{array}$} & \multirow{3}{*}{$\begin{array}{l}\text { 3.3. Desenvolver um } \\
\text { modelo de fundo de } \\
\text { investimentos para } \\
\text { geração de novos } \\
\text { negócios, prospecção de } \\
\text { novas parcerias e atração } \\
\text { de empresas âncoras. }\end{array}$} & 3.3a. Gerar novos negócios & \multirow{3}{*}{$\begin{array}{l}\text { Número de empreendimentos } \\
\text { referentes a novos negócios } \\
\text { Taxa de atração de empresas de } \\
\text { médio e grande porte. } \\
\text { Taxa de crescimento das } \\
\text { empresas instaladas. }\end{array}$} & \multirow{3}{*}{$\begin{array}{l}\text { EBITDA em percentagem do volume de novos negócios } \\
\text { (\%) /ano } \\
\text { Número de empresas de médio e grande porte } \\
\text { (âncoras). } \\
\text { Faturamento das empresas instaladas no Parque. }\end{array}$} \\
\hline & & 3.3b. Gerar maiores impostos & & \\
\hline & & $\begin{array}{l}\text { 3.3c. Aumentar o faturamento das empresas } \\
\text { associadas. }\end{array}$ & & \\
\hline
\end{tabular}


Quadro 5.4 - Quadro lógico para a proposição de indicadores e métricas de monitoramento e avaliação de desempenho do Parque Tecnológico de Santa Rita do Sapucaí (cont.)

\begin{tabular}{|c|c|c|c|c|}
\hline $\begin{array}{l}\text { Hierarquia } \\
\text { dos Objetivos }\end{array}$ & Objetivos & $\begin{array}{l}\text { Resultados Esperados } \\
\quad(C P, \text { MP e LP) }\end{array}$ & Indicadores & Métricas \\
\hline $\begin{array}{l}\text { Objetivo } \\
\text { Estratégico }\end{array}$ & \multicolumn{4}{|c|}{$\begin{array}{l}\text { 4. Instituir uma estrutura de pessoa jurídica de direito privado, adotando o modelo de Associação, com a possibilidade de que futuramente, o Parque Tecnológico de } \\
\text { Santa Rita do Sapucaí possa tornar-se uma Organização Social. }\end{array}$} \\
\hline $\begin{array}{l}\text { Objetivos de } \\
\text { Curto Prazo } \\
\text { (2 anos) }\end{array}$ & $\begin{array}{l}\text { 4.1. Instituir um modelo } \\
\text { de gestão organizacional } \\
\text { no formato de Associação }\end{array}$ & $\begin{array}{l}\text { 4.1a. Permitir a participação de órgãos } \\
\text { públicos em associações de direito privado. }\end{array}$ & & \\
\hline $\begin{array}{l}\text { Objetivos de } \\
\text { Médio Prazo } \\
\text { ( } 5 \text { anos) }\end{array}$ & $\begin{array}{l}\text { 4.2. Trabalhar na } \\
\text { evolução do modelo } \\
\text { organizacional } \\
\text { politicamente para } \\
\text { alcançar o modelo de } \\
\text { Organização Social. }\end{array}$ & $\begin{array}{l}\text { 4.2a. Estabelecer estratégias junto com a } \\
\text { administração do parque e poder público para } \\
\text { a futura aquisição do título de Organização } \\
\text { Social. }\end{array}$ & & \\
\hline $\begin{array}{l}\text { Objetivos de } \\
\text { Longo Prazo } \\
\text { (10 anos) }\end{array}$ & $\begin{array}{l}\text { 4.3. Instituir o modelo de } \\
\text { governança } \\
\text { organizacional no } \\
\text { formato de Organização } \\
\text { Social. }\end{array}$ & $\begin{array}{l}\text { 4.3a. Recebimento de determinados benefícios } \\
\text { do Poder Público (dotações orçamentárias, } \\
\text { isenções fiscais etc.), para a realização de } \\
\text { estratégias de interesse da comunidade. }\end{array}$ & & \\
\hline
\end{tabular}

Fonte: Elaboração própria a partir dos resultados das duas Oficinas realizadas durante o 1 Curso para Gestores de Parques Tecnológicos e Ambientes de Inovação, oferecido pela Uni-Anprotec/Instituto Gênesis em 2016. 


\subsection{3}

\section{Órion Parque Tecnológico da Serra Catarinense}

O Órion Parque Tecnológico, projeto concebido por empresários do setor de tecnologia, integrantes da Associação Empresarial de Lages, em 2007, encontra-se atualmente em fase de implantação, porém existem expectativas para o funcionamento do mesmo para 2017. Como suporte ao desenvolvimento do projeto do Parque tecnológico, formou-se o Núcleo de Tecnologia da Informação da Associação Comercial e Industrial de Lages, presentemente chamado de Núcleo de Tecnologia e Inovação de Lages - SC (Órion Parque Tecnológico, 2017; Associação Empresarial de Lages, 2014). A instalação estrutural do Parque é constituída por um edifício central, o Centro de Inovação, cedido pelo governo do Estado de Santa Catarina, o qual está instalado o corpo administrativo, a incubadora, espaço co-working, ambientes desenvolvidos para PD\&I e programas voltados ao incentivo à inovação e empreendedorismo.

O conselho administrativo do Órion Parque Tecnológico, gerido pelo Instituto Órion, uma associação privada, é formado seguindo o conceito triple Helix, o qual seus representantes são das instituições de ensino superior presentes na região, como o Instituto Federal de Santa Catarina (IFSC), a Universidade do Estado de Santa Catarina, Centro de Ciências Agroveterinárias (UDESC - Lages), a Universidade do Planalto Catarinense (Uniplac), gestores públicos providos pela prefeitura do município de Lages, do Núcleo de Tecnologia e Inovação, representantes de empresas residentes e da Associação de Micro e Pequenas Empresas (AMPE) (Órion Parque Tecnológico, 2017).

Os setores proeminentes o qual o Parque abrigará são os de TI, biotecnologia e demais serviços e/ou produtos cuja finalidade seja agregar novas tecnologias e inovação. Também serão desenvolvidas pesquisas avançadas no setor tecnológico. De acordo com a apresentação do grupo de trabalho na $1^{\text {a }}$ Oficina (Rio de Janeiro), o Parque tem como missão "criar uma cultura inovadora e empreendedora, articulando ações para ativar o ecossistema de inovação e viabilizar negócios inovadores com alto potencial de crescimento para transformar a economia da região". Como visão de futuro, planeja "estar consolidado como um centro de inovação acelerador de desenvolvimento regional sustentável em um horizonte de 10 anos". 
O objetivo geral, apresentado no site institucional do Órion Parque Tecnológico (2017), é “incrementar a riqueza de sua comunidade promovendo a cultura da inovação e da competitividade das empresas e instituições geradores de conhecimento" e como objetivos específicos:

- Gerar e fortalecer novos negócios de base tecnológica e startups na região da cidade de Lages;

- Fomentar a criação de redes de colaboração e networking.

\section{Caracterização das partes interessadas e seus objetivos em relação ao empreendimento}

O Quadro 5.5 apresenta os principais stakeholders e seus objetivos em relação ao empreendimento Órion Parque Tecnológico.

Quadro 5.5 - Partes interessadas do Órion Parque Tecnológico e seus interesses individuais

\begin{tabular}{|c|c|}
\hline $\begin{array}{l}\text { Partes } \\
\text { interessadas }\end{array}$ & Objetivos em relação ao empreendimento \\
\hline $\begin{array}{l}\text { Instituições de } \\
\text { ensino superior e } \\
\text { pesquisa (IFSC, } \\
\text { SENAC, SENAI, UDESC } \\
\text { CAV e UNIPLAC) }\end{array}$ & $\begin{array}{l}\text { - Integração entre o corpo docente e discente (graduados e pós- } \\
\text { graduados) junto às empresas, promovendo a transferência } \\
\text { tecnológica e desenvolvimento inovador; } \\
\text { - Publicação e chamada de editais para projetos inovadores, } \\
\text { empresas residentes de pequeno, médio e grande porte, institutos } \\
\text { de PD\&I, empresas virtuais e avaliadores ad-hocs. }\end{array}$ \\
\hline $\begin{array}{l}\text { Setor público } \\
\text { (Governo do Estado e } \\
\text { Prefeitura do } \\
\text { Município de Lages) }\end{array}$ & $\begin{array}{l}\text { - Fomento e concessão de terrenos e edifícios para a instalação de } \\
\text { empresas residentes, incubadas e instituições de PD\&I; } \\
\text { - Desenvolvimento local e regional de forma sustentável. }\end{array}$ \\
\hline Instituto Órion & $\begin{array}{l}\text { - Promover a gestão administrativa e financeira do Parque } \\
\text { tecnológico; } \\
\text { - Realizar planejamentos estratégicos junto aos clientes e instituições } \\
\text { parceiras para desenvolvimento das atividades do Parque; } \\
\text { - Interatividade e canal aberto de comunicação entre os setores } \\
\text { públicos, privados, a sociedade e as universidades. }\end{array}$ \\
\hline
\end{tabular}

Fonte: Órion Parque Tecnológico (2017).

\section{Perfil estratégico: uso da ferramenta 'Estrategigrama' da IASP}

Presentemente, o perfil estratégico do Órion Parque Tecnológico, conforme descrito pelos gestores, é de um parque em fase de implantação, onde sua localização dar-se-á no centro da cidade de Lages e próximo ao IFSC, porém é imperativo que exista investimento para um desenvolvimento urbano local. As parcerias estabelecidas entre os institutos de ensino superior e o fomento à 
pesquisa para as empresas clientes demonstra o incentivo do projeto as bases empresarial e de C\&T.

As atividades do Órion Parque Tecnológico, neste primeiro momento, estão formalizadas com a instalação de espaços para empresas maduras e firmadas no mercado, e pertencentes a seis áreas de atuação, foco do parque tecnológico. Neste primeiro momento, o mercado-alvo está concentrado localmente, devido a dificuldades de atração de empresas renomadas, que possam competir diretamente com demais parques tecnológicos e ambientes de inovação no Estado de Santa Catarina, ou até mesmo na região Sul.

O sistema de redes já estabelecido é declarado como suficientes para atender um alcance regional, contudo não é adequado para atender uma projeção em maior escala. O modelo de gestão do Órion Parque Tecnológico, apesar de não estar completamente definido, possui caráter institucional. No entanto, pesquisamse maneiras de modificar o sistema de governança do parque para o futuro (Figura $5.10)$.

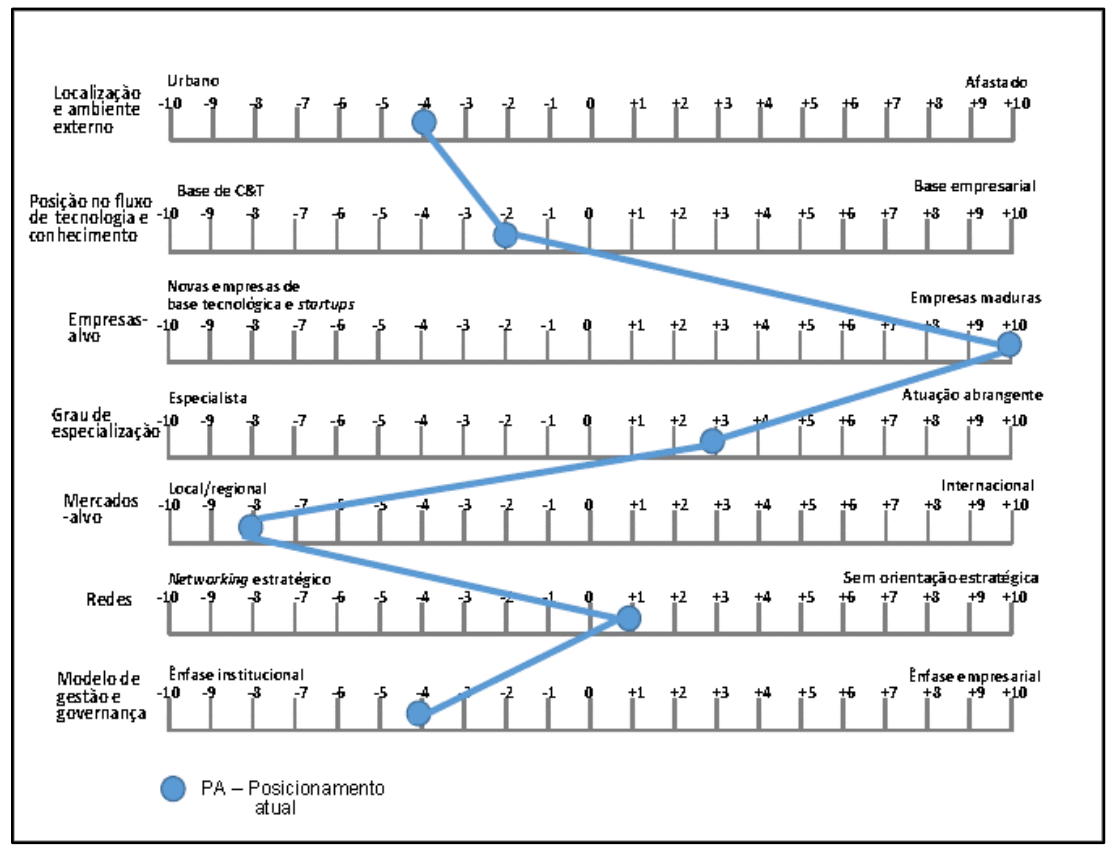

Figura 5.10 - Perfil estratégico atual do Órion Parque Tecnológico

Fonte: Elaboração própria a partir dos resultados das duas Oficinas realizadas durante o 1ํ Curso para Gestores de Parques Tecnológicos e Ambientes de Inovação, oferecido pela UniAnprotec/Instituto Gênesis em 2016. 
Traçando-se o perfil estratégico do Órion Parque Tecnológico, pode-se desenhar a evolução do mesmo em acordo com os objetivos do projeto, a exemplo do plano de urbanização da área de entorno do parque tecnológico.

Com relação ao posicionamento no fluxo de tecnologia e conhecimento, tem-se um planejamento de equilibrar o ambiente em relação à base de C\&T e empresarial, contudo é nevrálgico delimitar o fomento de novos negócios como uma das atividades essenciais futuras para quando o Órion Parque Tecnológico atingir um nível de maturidade maior diante do ecossistema inovador

Seguindo a tendência de evolução do projeto, o Órion Parque Tecnológico, em parceria com a Rede de Centros de Inovação do Estado de Santa Catarina, procurará fortalecer um networking estratégico, assim como o fortalecimento da instituição gestora do parque através de atividades de desenvolvimento adotadas pela instituição (Figura 5.11).

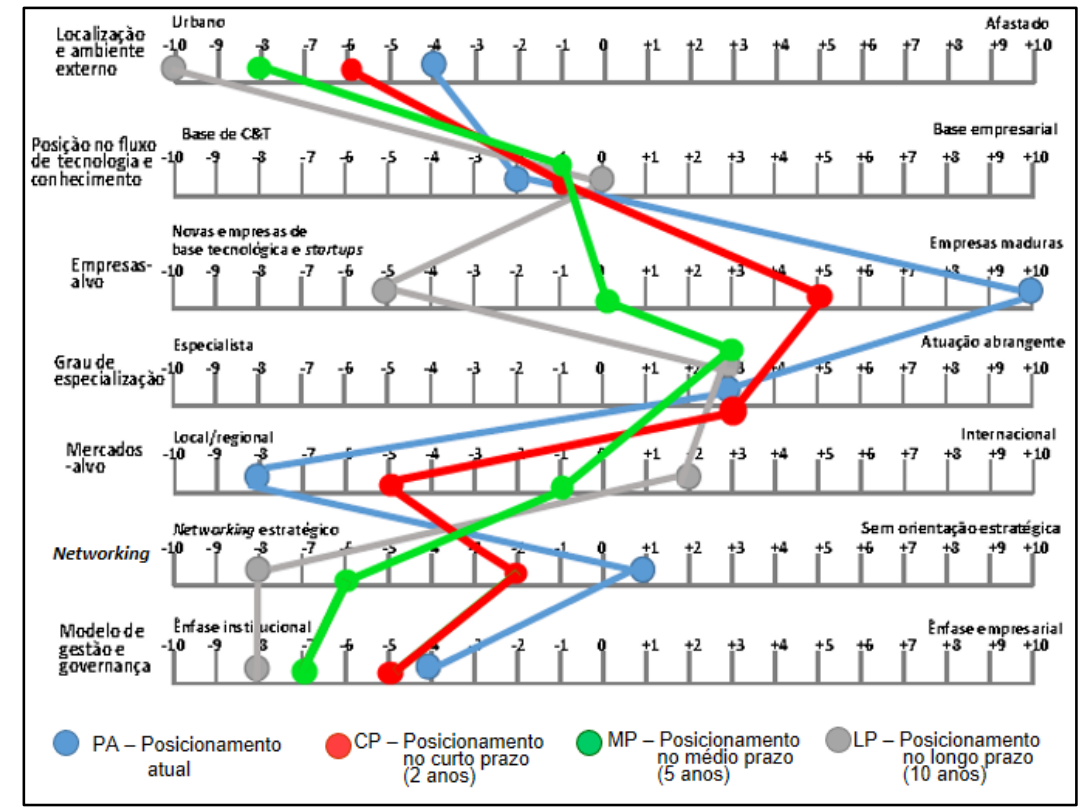

Figura 5.11 - Evolução do perfil estratégico do Órion Parque Tecnológico: curto, médio e longo prazo

Fonte: Elaboração própria a partir dos resultados das duas Oficinas realizadas durante o 1 Curso para Gestores de Parques Tecnológicos e Ambientes de Inovação, oferecido pela UniAnprotec/Instituto Gênesis em 2016.

O Órion Parque Tecnológico tem como característica o desenvolvimento e fomento da inovação e empreendedorismo local, porém tem-se a idealização no curto, médio e longo prazo, de desenvolver as atividades do parque para competir 
no mercado internacional, além da atração de empresas estrangeiras como residentes.

\section{Modelo de negócio: uso da ferramenta 'Canvas'}

O modelo de negócio para o Órion Parque Tecnológico foi desenhado para esta dissertação através de pesquisa documental e informações adquiridas no website do parque. As informações adquiridas foram suficientes para preencher os nove blocos pertences a ferramenta Canvas. A seguir estão apresentados os principais itens para cada bloco.

\section{Segmento de clientes}

Segundo os gestores participantes das oficinas e o site institucional, o Órion Parque Tecnológico apresenta empresas incubadas das seguintes áreas (Órion Parque Tecnológico, 2017):

- Tecnologias da informação e comunicação (TIC);

- Biotecnologia;

- Automação;

- Metalmecânica;

- Economia verde;

- Tecnologia da madeira.

O Órion Parque Tecnológico atrai em sua maioria empresas já consolidadas no mercado. Conforme o projeto do Órion Parque Tecnológico torna-se maduro, existe o planejamento de atração de novas empresas de base tecnológica, start ups e projetos inovadores (em consonância com as áreas de atuação do parque). Empresas de consultoria nas áreas jurídicas, gestão, economia e marketing também estão presentes nas dependências do parque;

\section{Proposição de valor}

Foram identificados como benefícios ofertados pelo Órion Parque Tecnológico os seguintes itens:

- Incentivo à inovação e cultura de empreendedorismo na região;

- Interface e networking fortes entre as universidades, empresas públicas e privadas e agências de fomento buscando o desenvolvimento e aprimoramento das empresas residentes e regionais perante o mercado;

- Incentivos fiscais e suporte ao acesso dos incentivos para instalação de empresas e unidades de instituições de PD\&I. 
Os serviços de valor agregado presentes no Parque são:

- Concessão de espaços físicos e/ou serviços para as empresas interessadas (período de, no máximo, quatro anos);

- Ecossistema sinérgico e com capital humano qualificado;

- Disponibilização de salas de conferência, centros de eventos e espaços de relacionamento

- Ambientes de Pesquisa, Desenvolvimento e Inovação (PD\&I) (em parceria);

- Ambientes co-working;

- Incubadoras de empresas (em parceria);

- Transferência de tecnologia.

\section{Fluxo de conhecimento e tecnologia}

O Parque Tecnológico possui um networking com foco de atuação regional. Contudo, a proximidade física com as instituições de ensino superior parceiras, os centros de inovação e PD\&I atendem as necessidades locais das empresas residentes e afiliadas.

\section{Relacionamento com clientes}

O Órion Parque Tecnológico possui como estratégias, em destaque, para o relacionamento com seus clientes:

- Divulgação de editais para seleção de empresas, projetos inovadores, centros de PD\&I a serem instalados nas incubadoras do parque;

- Divulgação ampla das políticas de atração de empreendimentos de base tecnológica, tendo como foco as atividades já administradas no parque.

\section{Geração de receitas}

As fontes para geração de receitas do Órion Parque Tecnológico estão concentradas nos serviços imobiliários cedidos às empresas incubadas, fomentos governamentais, serviços de consultoria nas áreas de gestão empresarial e econômica, marketing, TIC e TI (Órion Parque Tecnológico, 2016; 2017).

\section{Recursos-chave}

Dentre os recursos-chave utilizados pelo Órion Parque Tecnológico são destacados os investimentos provenientes do governo do estado de Santa Catarina para o desenvolvimento das atividades do parque, a infraestrutura física e os 
centros de PD\&I disponíveis aos clientes. Os docentes, discentes e especialistas fornecem o conhecimento, trabalho qualificado na forma de estágios e consultorias para as empresas residentes. Da mesma forma, são publicados e divulgados editais pelos centros de inovação para chamada de novas empresas e projetos.

\section{Atividades-chave}

Como atividades-chave realizadas pelo Órion Parque Tecnológico são:

- Transferência de conhecimento e tecnológica;

- Incubação e aceleração de novos negócios;

- Promoção de desenvolvimento tecnológico para empresas incubadas, unidades de PD\&I e setores e laboratórios da universidade;

- Gestão imobiliária dos espaços físicos das unidades dentro do parque;

- Gestão das parecerias com as empresas clientes fora das mediações do parque;

- Realização de seminários, conferências, workshops e treinamentos, etc.

- Consultorias e avaliações dos projetos inovadores por meio de especialistas chamados por editais.

\section{Parceiros-chave}

São identificadas as seguintes parcerias junto ao Órion Parque Tecnológico:

- Instituto Federal de Santa Catarina (IFSC);

- Serviço Nacional de Aprendizagem Comercial (SENAC);

- Serviço Nacional de Aprendizagem Industrial (SENAI);

- Universidade do Estado de Santa Catarina, Centro de Ciências Agroveterinárias (UDESC CAV);

- Universidade do Planalto Catarinense (UNIPLAC), a qual também se encontra a Incubadora Micro Distrito de Base Tecnológica de Lages;

- Câmara dos Dirigentes Lojistas de Lages (CDL).

\section{Estrutura de custos}

Os custos operacionais mais representativos para o Órion parque tecnológico estão destacados a seguir:

- Investimentos regulares para o parque tecnológico e incubadora;

- Custo de pessoal e operacional (salários, encargos, material administrativo, empresas terceirizadas, etc.); 
- Investimentos em infraestruturas para as empresas que residem no parque;

- Investimentos nos ambientes de PD\&I e centros de inovação.

\section{Estágio de desenvolvimento do Parque Tecnológico conforme classificação da Anprotec}

O Órion Parque Tecnológico encontra-se em fase de implantação, composto atualmente por um edifício-sede, o Centro de Inovação, em que estão instalados a incubadora, um espaço co-working, ambientes de PD\&I e o centro administrativo do Parque.

\section{Posicionamento do Parque Tecnológico segundo a taxonomia da Anprotec}

Caracterizado atualmente como um parque de relevância apenas local, o empreendimento possui um desafio para a identificação e implantação de um ecossistema inovador na região tanto para base de C\&T quanto empresarial (Figura 5.12).

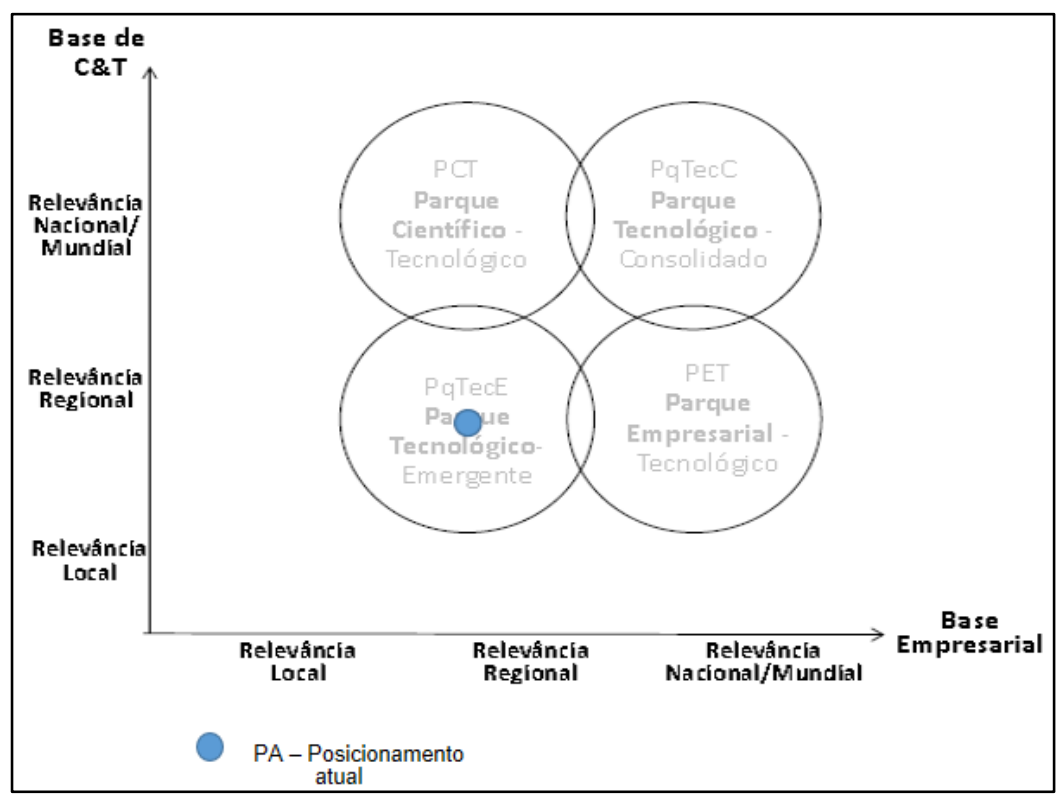

Figura 5.12- Posicionamento atual do Órion Parque Tecnológico

Fonte: Elaboração própria a partir dos resultados das duas Oficinas realizadas durante 0 1 Curso para Gestores de Parques Tecnológicos e Ambientes de Inovação, oferecido pela UniAnprotec/Instituto Gênesis em 2016.

Planeja-se para o Órion Parque Tecnológico maior investimento regional no que se refere à base empresarial, para então aplicar recursos no médio e longo 
prazo em atividades que possam aprimorar a relevância da base de $C \& T$, ao nível de relevância nacional e internacional (Figura 5.13).

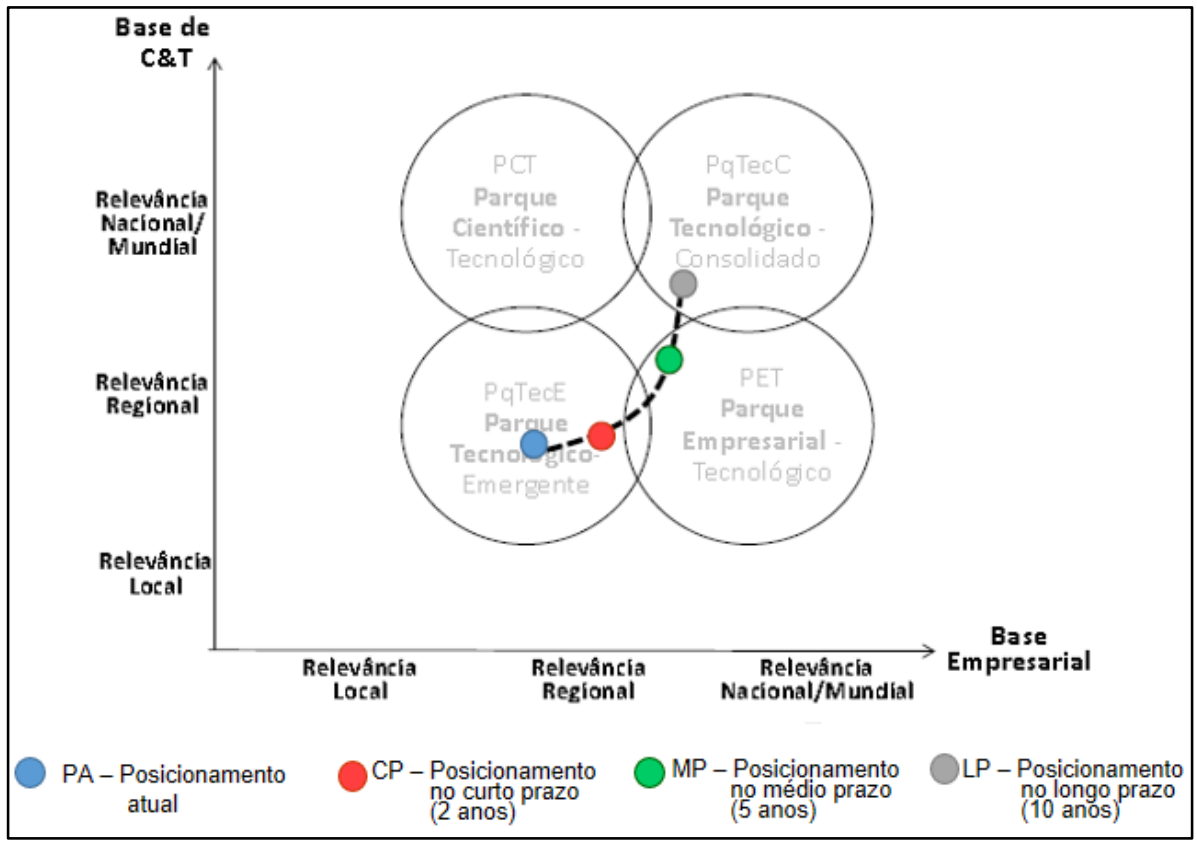

Figura 5.13 - Estratégia de crescimento do Órion Parque Tecnológico: curto, médio e longo prazo

Fonte: Elaboração própria a partir dos resultados das duas Oficinas realizadas durante 0 1ํ Curso para Gestores de Parques Tecnológicos e Ambientes de Inovação, oferecido pela UniAnprotec/Instituto Gênesis em 2016.

\section{Quadro lógico e proposição de indicadores e métricas para monitoramento e avaliação de desempenho do Parque Tecnológico}

A construção do quadro lógico para a proposição de indicadores e métricas de monitoramento e avaliação de desempenho do Órion Parque Tecnológico seguiu a orientação metodológica descrita no capítulo 4 (Quadro 5.6). 


\begin{tabular}{|c|c|c|c|c|}
\hline $\begin{array}{l}\text { Hierarquia } \\
\text { dos Objetivos }\end{array}$ & Objetivos & $\begin{array}{l}\text { Resultados Esperados } \\
\quad(\mathrm{CP}, \mathrm{MP} \text { e LP) }\end{array}$ & Indicadores & Métricas \\
\hline $\begin{array}{l}\text { Objetivo } \\
\text { Estratégico }\end{array}$ & $\begin{array}{l}\text { 1. Gerar e fortalecer } \\
\text { novos negócios de base } \\
\text { tecnológica e startups na } \\
\text { região da cidade de Lages }\end{array}$ & $\begin{array}{l}\text { Fortalecimento da incubadora do Parque } \\
\text { Tecnológico, e geração de novos negócios. } \\
\text { Criação de programas de aceleração. }\end{array}$ & $\begin{array}{l}\text { Número de empresas pequenas } \\
\text { de base tecnológica e startups no } \\
\text { período }\end{array}$ & Número de incubadas por ano \\
\hline $\begin{array}{l}\text { Objetivos de } \\
\text { Curto Prazo } \\
\text { ( } 2 \text { anos) }\end{array}$ & $\begin{array}{l}\text { 1.1. Promover ações para } \\
\text { a atração de pequenas } \\
\text { empresas de base } \\
\text { tecnológica e startups }\end{array}$ & $\begin{array}{l}\text { 1.1a. -Aumentar o número de pequenas } \\
\text { empresas de base tecnológica e startups } \\
\text { residentes }\end{array}$ & $\begin{array}{l}\text { Número de empresas pequenas } \\
\text { de base tecnológica e startups no } \\
\text { período } \\
\text { Taxa de crescimento de } \\
\text { pequenas empresas de base } \\
\text { tecnológica e startups no período } \\
\text { Área construída do Parque } \\
\text { Faturamento das empresas } \\
\text { instaladas no Órion Parque no } \\
\text { período }\end{array}$ & $\begin{array}{l}\text { Número de novas empresas residentes por ano. } \\
\text { Percentual de crescimento de empresas por ano. } \\
\text { Área construída em } \mathrm{m}^{2} \text { por ano. } \\
\text { Faturamento das empresas instaladas no Parque Orion } \\
\text { no período. }\end{array}$ \\
\hline $\begin{array}{l}\text { Objetivos de } \\
\text { Médio Prazo } \\
\text { (5 anos) }\end{array}$ & $\begin{array}{l}\text { 1.2. Gerar emprego e } \\
\text { renda }\end{array}$ & $\begin{array}{l}\text { 1.2a. Aumentar do número de profissionais } \\
\text { trabalhando em empresas do Parque }\end{array}$ & $\begin{array}{l}\text { Empregos gerados pelos } \\
\text { empreendimentos }\end{array}$ & $\begin{array}{l}\text { Número de novas empresas residentes por ano } \\
\text { Número de postos de trabalho gerados no período }\end{array}$ \\
\hline $\begin{array}{l}\text { Objetivos de } \\
\text { Longo Prazo } \\
\text { (10 anos) }\end{array}$ & $\begin{array}{l}\text { 1.3. Desenvolver um } \\
\text { modelo de fundo de } \\
\text { investimentos para } \\
\text { geração de novos } \\
\text { negócios. }\end{array}$ & 1.3a. Gerar novos negócios & $\begin{array}{l}\text { Número de empreendimentos } \\
\text { referentes a novos negócios }\end{array}$ & $\begin{array}{l}\text { EBITDA em percentagem do volume de novos } \\
\text { negócios (\%) /ano }\end{array}$ \\
\hline
\end{tabular}


Quadro 5.6 - Quadro lógico para a proposição de indicadores e métricas de monitoramento e avaliação de desempenho do Órion Parque Tecnológico (cont.)

\begin{tabular}{|c|c|c|c|c|}
\hline $\begin{array}{l}\text { Hierarquia } \\
\text { dos Objetivos }\end{array}$ & Objetivos & $\begin{array}{l}\text { Resultados Esperados } \\
\quad(\mathrm{CP}, \mathrm{MP} \text { e LP) }\end{array}$ & Indicadores & Métricas \\
\hline $\begin{array}{l}\text { Objetivo } \\
\text { Estratégico }\end{array}$ & \multicolumn{4}{|c|}{ 2. Fomentar a criação de redes de colaboração e networking } \\
\hline $\begin{array}{l}\text { Objetivos de } \\
\text { Curto Prazo } \\
\text { ( } 2 \text { anos) }\end{array}$ & $\begin{array}{l}\text { 2.1. Atrair entidades } \\
\text { associativas de áreas } \\
\text { estratégicas para a } \\
\text { operação do parque }\end{array}$ & 2.1a. - Instalar entidades associativas & Entidades instaladas & $\begin{array}{l}\text { Número de novas entidades associativas instaladas por } \\
\text { ano }\end{array}$ \\
\hline $\begin{array}{l}\text { Objetivos de } \\
\text { Médio Prazo } \\
\text { (5 anos) }\end{array}$ & $\begin{array}{l}\text { 2.2. Atrair empresas } \\
\text { vinculadas às entidades } \\
\text { associativas }\end{array}$ & $\begin{array}{l}\text { 2.2a. Aumentar o número de empresas } \\
\text { vinculadas a entidades associativas }\end{array}$ & $\begin{array}{l}\text { Empresas instaladas vinculadas a } \\
\text { entidades associativas }\end{array}$ & $\begin{array}{l}\text { Número de empresas vinculadas a entidades } \\
\text { associativas }\end{array}$ \\
\hline $\begin{array}{l}\text { Objetivos de } \\
\text { Longo Prazo } \\
\text { (10 anos) }\end{array}$ & $\begin{array}{l}\text { 2.3. Desenvolver } \\
\text { mecanismos de interação } \\
\text { e colaboração interna e } \\
\text { externa }\end{array}$ & $\begin{array}{l}\text { 2.3a. Proposta de um programa de } \\
\text { colaboração entre os residentes e parceiros }\end{array}$ & $\begin{array}{l}\text { Interações e negócios gerados } \\
\text { por meio do programa }\end{array}$ & $\begin{array}{l}\text { Número de interações e negócios gerados por meio do } \\
\text { programa de estímulo a colaboração e interação }\end{array}$ \\
\hline
\end{tabular}

Fonte: Elaboração própria a partir dos resultados das duas Oficinas realizadas durante o 1 Curso para Gestores de Parques Tecnológicos e Ambientes de Inovação, oferecido pela Uni-Anprotec/Instituto Gênesis em 2016. 


\subsection{4}

\section{Parque Tecnológico da Bahia}

Apresentando-se em fase de implantação, o Parque Tecnológico da Bahia atuará como um ambiente convergente entre a academia, o setor empresarial e a esfera pública.

O projeto deste Parque foi dividido em três partes, sendo elas a (i) urbanização da área pertinente ao parque tecnológico e inauguração do edifíciosede Tecnocentro; (ii) construção e implantação da infraestrutura pertinente a PD\&I como laboratórios especializados e compartilhados, a escola de iniciação científica, espaços interativos para divulgação da ciência e tecnológica e espaços voltados para entretenimento; e (iii) a ocupação dos lotes destinados as empresas residentes (Parque Tecnológico da Bahia, 2017).

O projeto do Parque Tecnológico da Bahia é uma iniciativa da Secretaria da Ciência, Tecnologia e Inovação do Estado da Bahia (SECTI - BA), que é responsável pela coordenação do empreendimento. O projeto integra instituições de ensino superior parceiras como a Universidade Federal da Bahia (UFBA), a Universidade Estadual da Feira de Santana (UEFS) e a Universidade Federal do Recôncavo Baiano (UFRB). No Tecnocentro, encontra-se a Áity Incubadora de Empresas, com 21 empresas incubadas, selecionadas por meio de editais, e trabalha em parceria com a Fundação Centros de Referência em Tecnologia Inovadoras, uma instituição independente e sem fins lucrativos, especializada em PD\&I e serviços tecnológicos especializados (Parque Tecnológico da Bahia, 2017; Fundação Certi, 2017).

Tratando-se de um projeto voltado para o desenvolvimento empresarial, urbano, tecnológico e inovador do Estado da Bahia, o Parque Tecnológico tem como missão "estimular o empreendedorismo e o desenvolvimento científico, tecnológico e inovador no Estado da Bahia, através da interação e do compartilhamento de conhecimento entre os agentes de CT\&I, num ambiente colaborativo e sustentável”, e apresenta para sua visão de futuro até 2026 ser “o elemento central do sistema de parques tecnológicos do Estado, representando o principal vetor de desenvolvimento científico, tecnológico e da inovação da Bahia, atuando de forma sustentável. Deverá ser reconhecido, nacional e 
internacionalmente, por seu trabalho no desenvolvimento econômico do Estado e na popularização da ciência”. Os objetivos específicos são:

- Implantar novo modelo de governança, com foco em resultados e na busca pela sustentabilidade financeira;

- Disseminar as culturas empreendedoras, da colaboração e da inovação;

- Ocupar os espaços do parque com empreendimentos de CT\&I;

- Fomentar o empreendedorismo inovador.

\section{Caracterização das partes interessadas e seus objetivos em relação ao parque tecnológico da Bahia}

O Quadro 5.7 apresenta os principais stakeholders e seus objetivos em relação ao empreendimento Parque Tecnológico da Bahia.

Quadro 5.7 - Partes interessadas e seus objetivos em relação ao Parque Tecnológico da Bahia

\begin{tabular}{|c|c|}
\hline $\begin{array}{l}\text { Partes } \\
\text { interessadas }\end{array}$ & Objetivos em relação ao empreendimento \\
\hline $\begin{array}{lr}\text { Instituições } & \text { de } \\
\text { ensino } & \text { superior } \\
\text { parceiras } & \text { (UFBA, } \\
\text { UEFS e UFRB). }\end{array}$ & $\begin{array}{l}\text { - Ampliar a missão institucional, promovendo desenvolvimento } \\
\text { regional; } \\
\text { - Aquisição de recursos financeiros através de agências de fomento } \\
\text { para a concessão de bolsas voltadas para o desenvolvimento de } \\
\text { projetos com base tecnológica; } \\
\text { - Fornecer serviços especializados, manutenção e aprimoramento } \\
\text { (junto ao parque) de laboratórios de PD\&l; } \\
\text { - Integração entre o corpo docente e discente (graduados e pós- } \\
\text { graduados) junto às empresas, promovendo a transferência } \\
\text { tecnológica e desenvolvimento inovador. }\end{array}$ \\
\hline $\begin{array}{l}\text { Instituições de } \\
\text { pesquisa (Fundação } \\
\text { CERTI) }\end{array}$ & $\begin{array}{l}\text { - Serviços de assessoramento, consultoria e pesquisa, realizações de } \\
\text { medições para o setor público e privado; } \\
\text { - Promover a inovação tecnológica e pesquisa em nível nacional. }\end{array}$ \\
\hline $\begin{array}{l}\text { Setor público (SECTI, } \\
\text { Governo Estadual e } \\
\text { municipal) }\end{array}$ & $\begin{array}{l}\text { - Concessão de lotes para instalação de empresas e instituições } \\
\text { residentes; } \\
\text { - Implantação do parque tecnológico, promovendo o } \\
\text { desenvolvimento social e econômico regional; } \\
\text { - Retenção e atração de pessoal qualificado para atuação no parque } \\
\text { tecnológico; } \\
\text { - Atuação como corpo gestor do parque tecnológico da Bahia. }\end{array}$ \\
\hline
\end{tabular}

Fonte: Parque Tecnológico da Bahia (2017).

\section{Perfil estratégico: uso da ferramenta 'Estrategigrama' da IASP}

O edifício-sede, Tecnocentro, do Parque Tecnológico da Bahia, encontra-se instalado dentro do município de Salvador, contudo localizado em uma região em processo de urbanização. Possuidor de uma base empresarial substancial, o parque 
também é detentor de um grande potencial para maior participação de institutos de ciência e tecnologia.

O Parque concentra suas atividades em três áreas de atuação, possuindo maior presença em start-ups, na incubadora e menor representatividade por empresas maduras.

Os mercados-alvo referem-se tanto ao mercado regional e local quanto ao internacional, devido à existência de projetos e instituições estrangeiras participantes junto ao Parque Tecnológico da Bahia.

O sistema de redes é voltado para a realização de um networking estratégico, contudo atualmente existe pouco planejamento para a atração de novas empresas. A administração do parque é feita diretamente pelo Governo do Estado da Bahia, utilizando de equipes e recursos estatais (Figura 5.14).

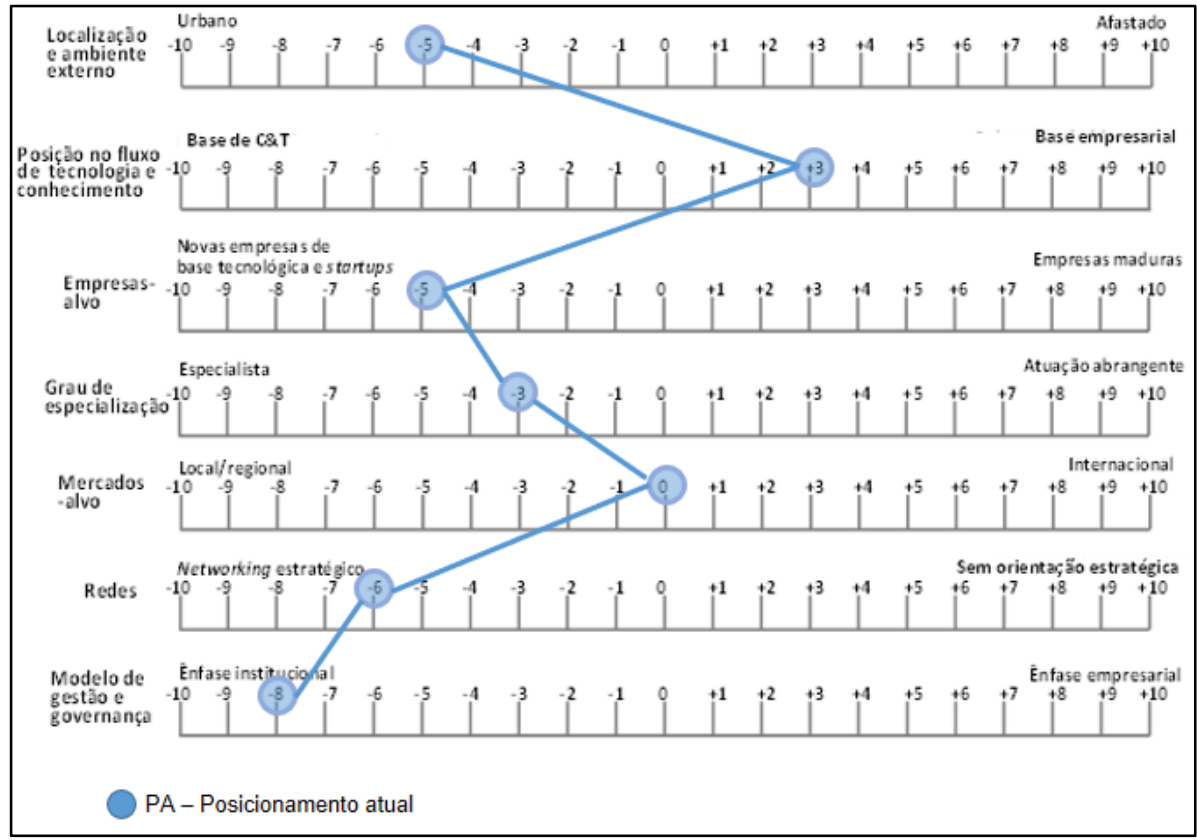

Figura 5.14 - Perfil estratégico atual do Parque Tecnológico da Bahia

Fonte: Elaboração própria a partir dos resultados das duas Oficinas realizadas durante o 1 Curso para Gestores de Parques Tecnológicos e Ambientes de Inovação, oferecido pela UniAnprotec/Instituto Gênesis em 2016.

De acordo com o processo de evolução estabelecido, em acordo com a oficina com os gestores de parques tecnológicos, programa-se um processo de urbanização local ao médio e longo prazo das atividades do parque, assim como a introdução de novas instituições de ciência e tecnologia com a participação de institutos de ensino superior públicos e privados (Figura 5.15). 
Para a atração de empresas maduras, planeja-se melhorar a atratividade para a ocupação dos lotes voltados para empresas e instituições de maior porte.

Ao eixo de mercados-alvo, uma programação no médio e longo prazo para aprimorar o foco internacional do parque tecnológico produzindo produtos serviços ao mercado global.

Estabelecendo uma premissa com foco em resultados, adequar-se-á o planejamento das estratégias do Parque Tecnológico através de um network robusto e adequado para a nova governança.

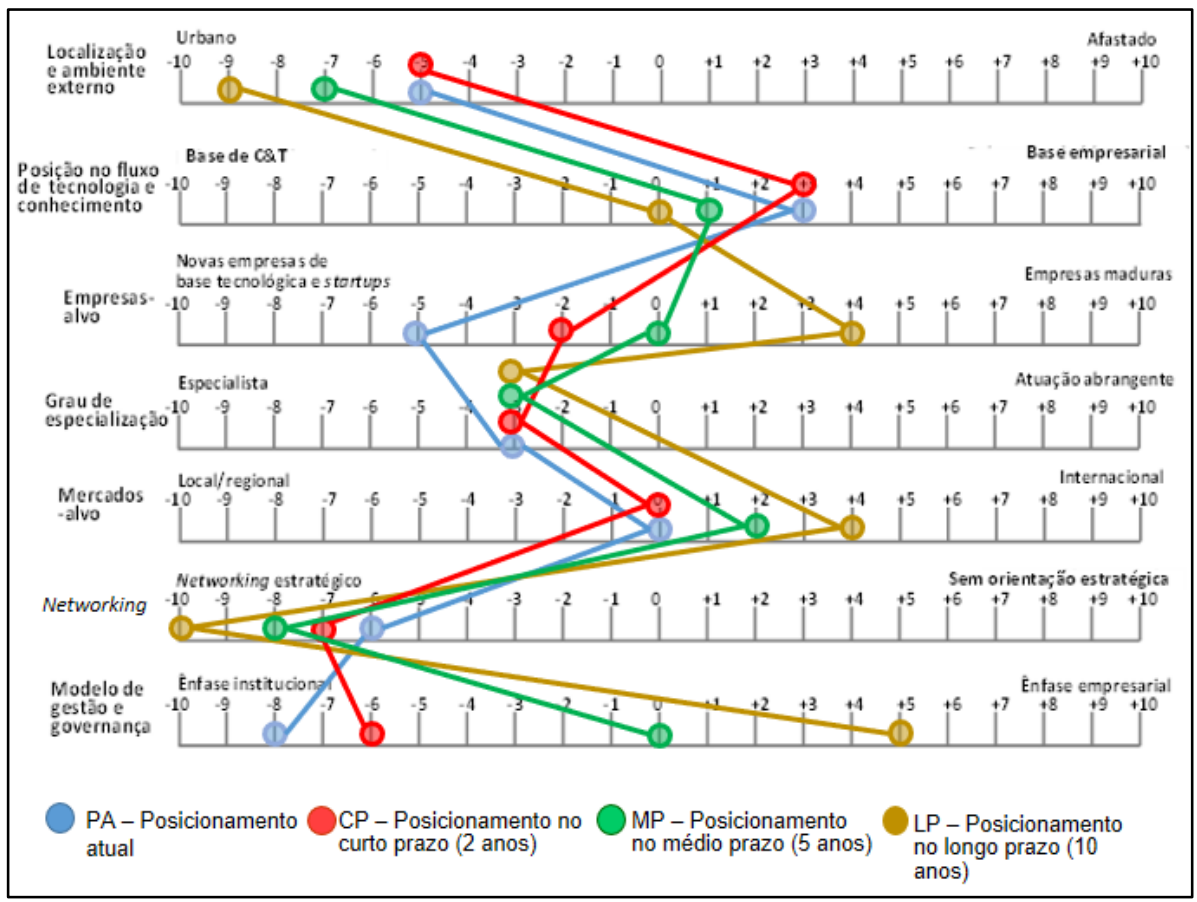

Figura 5.15 - Evolução do perfil estratégico do Parque Tecnológico da Bahia: curto, médio e longo prazo

Fonte: Elaboração própria a partir dos resultados das duas Oficinas realizadas durante o 1 Curso para Gestores de Parques Tecnológicos e Ambientes de Inovação, oferecido pela UniAnprotec/Instituto Gênesis em 2016.

\section{Modelo de negócio: uso da ferramenta 'Canvas'}

A seguir estão descritos os as informações pertinentes a cada bloco da ferramenta Canvas para o modelo de negócios do Parque Tecnológico da Bahia.

\section{Segmentos de clientes}

Segundo os gestores e o site institucional do parque tecnológico da Bahia, existe uma concentração de empresas atuando em três campos distintos. São eles:

- Biotecnologia e saúde; 
- TIC;

- Engenharia e Energias renováveis.

O Parque Tecnológico da Bahia atualmente possui como maioria dos empreendimentos residentes start ups e novas empresas de base tecnológica. Contudo, realiza investimentos e promoção de atratividades para o aumento de empresas maduras que possam residir no Parque.

\section{Proposição de valor}

O Parque Tecnológico da Bahia destaca como seu diferencial ser um centro que une os atores responsáveis pelo estímulo à inovação e empreendedorismo no Estado da Bahia.

De acordo com seu gestor, o Parque atua junto ao setor público, as universidades e o setor empresarial de maneira coesa, tendo como objetivo principal o desenvolvimento regional e competitividade das empresas em escala global em um ambiente inovador e sustentável.

Como estrutura das suas atividades, o parque promove a atração de empresas de pequeno, médio e grande porte, a comunicação permanente entre os empreendimentos residentes e as universidades parceiras, além de estratégias claras de fortalecimento da produção científica. A forte presença de profissionais qualificados e possuidores de títulos de pós-graduação nas áreas em que o parque atua funciona como atratividade para as empresas, além de elevação do potencial educacional do Estado da Bahia (Parque Tecnológico da Bahia, 2017).

\section{Fluxo de conhecimento e tecnologia}

As fontes de conhecimento e tecnologia do parque tecnológico da Bahia é procedente da base empresarial e C\&T local e internacional. Dentre os métodos de fluxo de conhecimento e tecnologia presente no parque tecnológico da Bahia destacam-se:

- Interação permanente entre as empresas residentes e os ICTs afiliados/parceiros de nível nacional e internacional;

- Prestação de serviço de qualidade pela incubadora para as empresas residentes;

- Canais diretos entre as empresas e ICTs com os laboratórios de PD\&I nos edifícios compartilhados e lotes na região; 
- Realização de atividades promotoras de interação e contribuição de conhecimento entre as empresas incubadas (workshops, conferências, treinamento etc.);

- Interação, e fortalecimento, entre as empresas incubadas, promovendo a transferência de tecnologia e conhecimento, propriedade intelectual, estímulo à pesquisa, prospecção de recursos em parceria público/privado.

\section{Relacionamento com clientes}

As práticas para o relacionamento com as empresas e instituições clientes do parque tecnológico são:

- Divulgação de editais para seleção de empresas e projetos inovadores a serem instalados na Áity Incubadora de empresas;

- Implantação de políticas de atração de empreendimentos de base tecnológica de pequeno, médio e grande porte, tendo como foco as atividades já administradas no parque, tendo como foco as áreas de atuação já presentes no projeto do parque tecnológico;

- Apresentação das atividades do parque através de palestras e divulgação em feiras científicas e tecnológicas (em geral pertencentes as áreas de atuação do parque);

- Investimento realização de marketing das atividades já desenvolvidas pelas empresas incubadas.

\section{Geração de receitas}

O Parque Tecnológico da Bahia possui como principais fontes de receitas:

- Contribuições das empresas e institutos de pesquisa, ciência e tecnologia residentes pelo uso dos espaços compartilhados e lotes destinados a suas instalações;

- Taxas de serviço de valor agregado no formato de consultorias em gestão da inovação, prospecção tecnológica e mercado, marketing, propriedade intelectual, transferência tecnológica e gestão financeira;

- Taxas de serviços para as empresas e instituições de PD\&I afiliadas e usuárias dos lotes cedidos pelo parque tecnológico da Bahia.

\section{Recursos-chave}

Como recursos-chave para o Parque Tecnológico, são considerados:

- A infraestrutura construída para atender e comportar empresas de base tecnológica de qualidade e propícia para o desenvolvimento de um ambiente para práticas inovadoras; 
- Docentes, discentes, corpo gestor e funcionários especialistas e possuidores de conhecimentos para o auxílio e propagação das atividades realizadas pelo Parque, incubadora e empresas incubadas;

- Fomento proveniente do Governo do Estado da Bahia, através do Programa Estadual de Incentivos à Inovação Tecnológica (Inovatec), contendo fundo anual de 15 milhões de Reais voltados para aquisição de equipamentos visando o fortalecimento dos projetos de PD\&I;

- Fomento em forma de bolsas designadas para atração de doutores, mestres e/ou graduados possuidores de conhecimento interligados com as atividades foco do parque tecnológico;

- Incentivos fiscais desenhados para atração de empresas industriais ou agroindústrias e manutenção daqueles já instalados no parque; empresas voltadas a produção de biodiesel, álcool etílico hidratado e anidro combustível, petroquímicas, termoelétricas, de TI, informática, produtos elétricos e eletrônicos (Parque Tecnológico da Bahia, 2016).

\section{Atividades-chave}

As atividades-chave realizadas pelo Parque Tecnológico da Bahia são:

- Atração de empresas e projetos inovadores;

- Transferência de conhecimento e tecnológica;

- Estímulo ao desenvolvimento de serviços sustentáveis (econômico e ambiental);

- Desenvolvimento urbano da região;

- Concessão de área física em espaços estabelecidos para empresas afiliadas e instituições de base tecnológica;

- Promoção de desenvolvimento tecnológico para empresas incubadas, unidades de PD\&I e setores e laboratórios da universidade;

- Gestão imobiliária dos espaços físicos cedidos para as empresas clientes dos setores público e privado;

- Oferta de seminários, conferências, workshops e treinamentos para a equipe de funcionários ligados ao Parque.

\section{Parceiros-chave}

São parceiros-chave do Parque Tecnológico da Bahia:

- O governo do Estado da Bahia;

- Secretaria de Ciência, Tecnologia e Inovação do Estado da Bahia (responsável pela coordenação do empreendimento);

- Instituto Federal da Bahia (IFBA);

- Fundação Osvaldo Cruz (Fiocruz); 
- Áity Incubadora de Empresas.

\section{Estrutura de custos}

Os custos relacionados ao Parque Tecnológico da Bahia estão apresentados em seu site institucional como custos para manutenção da infraestrutura do Parque.

- Investimentos no processo de urbanização da região (parceria com o governo municipal);

- Custo de pessoal e operacional (salários, encargos, material administrativo, empresas terceirizadas, etc.);

- Investimentos em infraestruturas para as empresas que residem no parque;

- Investimentos nos ambientes de PD\&I (manutenção, aprimoramento e ampliação).

\section{Estágio de desenvolvimento conforme a classificação da Anprotec}

O Parque Tecnológico da Bahia encontra-se em fase de implantação. Para atingir, de forma ótima, a fase operacional do projeto, foi-se dividido em três etapas para a conclusão da fase atual. São elas:

- Urbanização e inauguração do edifício-sede Tecnocentro (concluída em 2012);

- Construção e implantação de equipamentos pertencentes a infraestrutura laboratorial (laboratórios especializados, compartilhados, centros educacionais de iniciação científica, espaços interativos e área de lazer;

- Ocupação dos lotes destinados à instalação das empresas e instituições afiliadas.

\section{Posicionamento do Parque Tecnológico segundo a taxonomia da Anprotec}

O Parque Tecnológico da Bahia encontra-se instalado em Salvador (BA), contudo numa região a qual está em processo de urbanização. As empresas e instituições de PD\&I afiliadas são, em sua maioria, empresas locais e regionais, contudo tem-se destaque aos polos de pesquisa e desenvolvimento das empresas Ericsson e Accenture, como também a presença da Fiocruz e Instituto Fraunhofer (Alemanha) como representantes das instituições de pesquisa.

O Parque Tecnológico pode ser considerado como parque em transição da classificação como tecnológico-emergente para empresarial-tecnológico de acordo com a taxonomia Anprotec, possuindo grande relevância regional (Figura 5.16). 


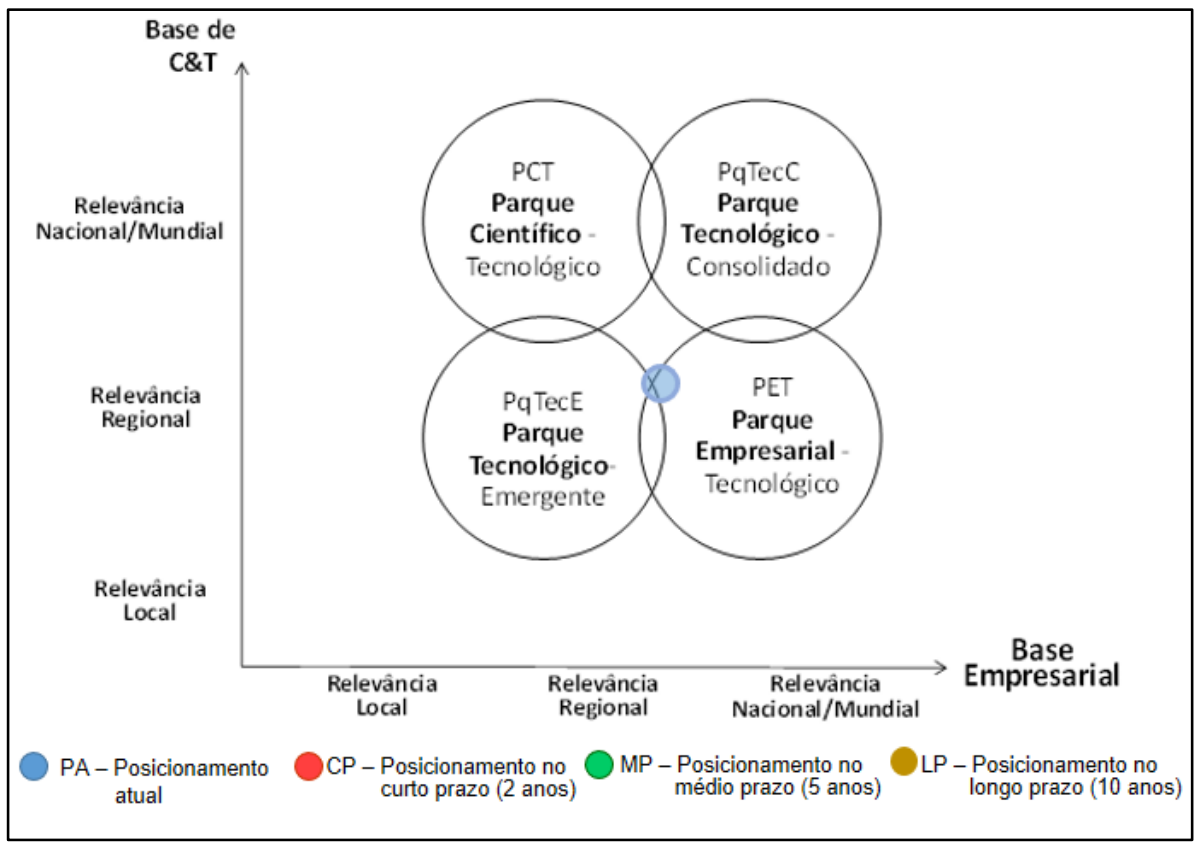

Figura 5.16 - Posicionamento atual do Parque Tecnológico da Bahia segundo a taxonomia da Anprotec

Fonte: Elaboração própria a partir dos resultados das duas Oficinas realizadas durante o 1 Curso para Gestores de Parques Tecnológicos e Ambientes de Inovação, oferecido pela UniAnprotec/Instituto Gênesis em 2016.

O objetivo para a promoção do desenvolvimento da estratégia do Parque Tecnológico da Bahia é aprimorar no curto, médio e longo prazo a relevância nacional e internacional do projeto, através de programas de atração de novos centros de C\&T e parcerias com novas instituições de ensino superior, intensificação das ações integradoras das empresas e instituições já cadastradas, aquisição de novos equipamentos auxiliadores e aceleradores de empresas incubadas e a instalação e aquisição, junto ao Governo do Estado, de novos edifícios e lotes para futuras empresas clientes e projetos inovadores (Figura 5.17). 


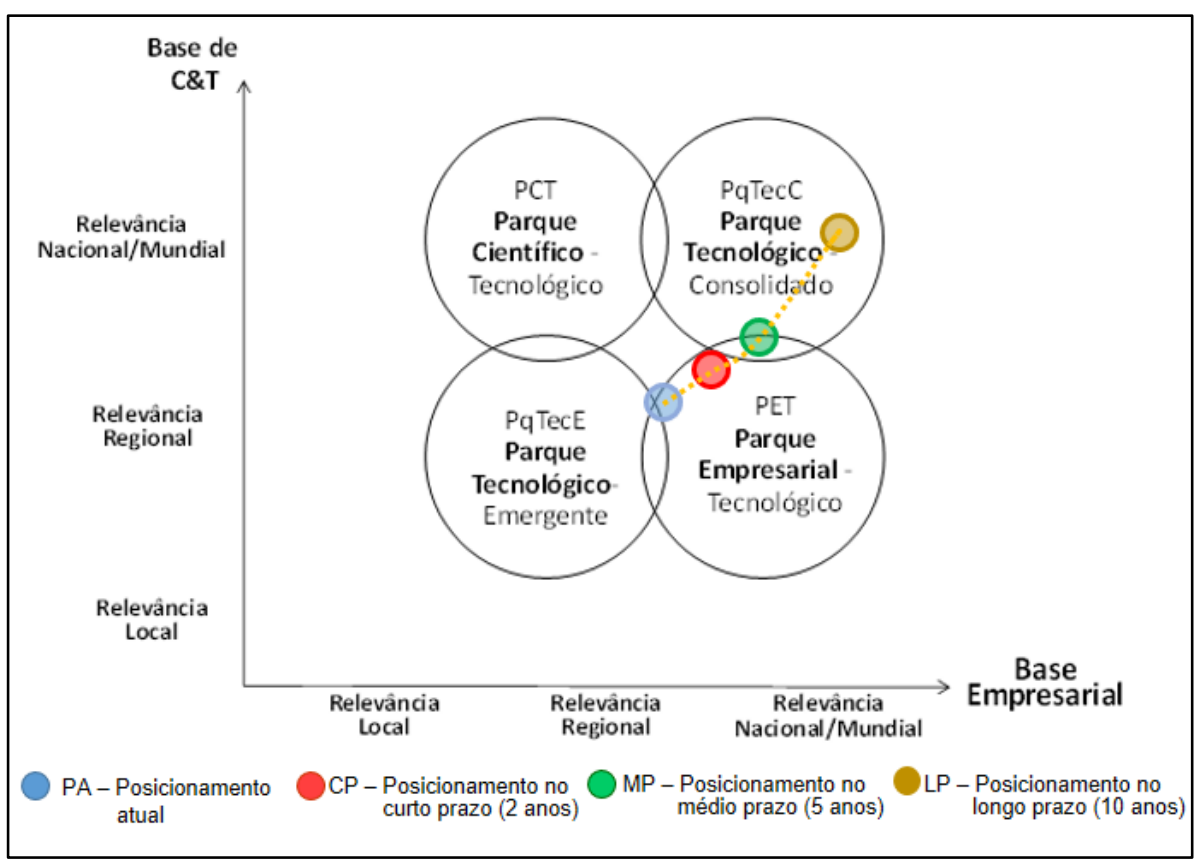

Figura 5.17 -. Estratégia de crescimento do Parque Tecnológico da Bahia: curto, médio e longo prazo

Fonte: Elaboração própria a partir dos resultados das duas Oficinas realizadas durante o 1 Curso para Gestores de Parques Tecnológicos e Ambientes de Inovação, oferecido pela UniAnprotec/Instituto Gênesis em 2016.

\section{Quadro lógico para proposição de indicadores e métricas para monitoramento e avaliação de desempenho do Parque Tecnológico}

A construção do quadro lógico para a proposição de indicadores e métricas de monitoramento e avaliação de desempenho do Parque Tecnológico da Bahia seguiu a orientação metodológica descrita no capítulo 4 (Quadro 5.8). 


\begin{tabular}{|c|c|c|c|c|}
\hline $\begin{array}{c}\text { Hierarquia } \\
\text { dos Objetivos }\end{array}$ & Objetivos & $\begin{array}{l}\text { Resultados Esperados } \\
\quad(\mathrm{CP}, \mathrm{MP} \text { e LP) }\end{array}$ & Indicadores & Métricas \\
\hline $\begin{array}{l}\text { Objetivo } \\
\text { Estratégico }\end{array}$ & \multicolumn{4}{|c|}{ 1. Implantar novo modelo de governança, com foco em resultados e na busca pela sustentabilidade financeira. } \\
\hline $\begin{array}{l}\text { Objetivos de } \\
\text { Curto Prazo } \\
(2 \text { anos) }\end{array}$ & $\begin{array}{l}\text { 1.1. Dinamizar a Gestão } \\
\text { do Parque. }\end{array}$ & $\begin{array}{l}\text { 1.1a. Implantar o novo modelo de Governança } \\
\text { em Organização Social }\end{array}$ & $\begin{array}{l}\text { Contrato de Gestão assinado e } \\
\text { em operação. }\end{array}$ & Indicadores de desempenho do Contrato de Gestão. \\
\hline \multirow{2}{*}{$\begin{array}{l}\text { Objetivos de } \\
\text { Médio Prazo } \\
\text { ( } 5 \text { anos) }\end{array}$} & \multirow{2}{*}{$\begin{array}{l}\text { 1.2. Reduzir a } \\
\text { dependência dos } \\
\text { repasses do Estado no } \\
\text { custeio da operação. }\end{array}$} & $\begin{array}{l}\text { 1.2a. Crescimento no volume de recursos } \\
\text { arrecadados diretamente pela Organização } \\
\text { Social }\end{array}$ & \multirow[t]{2}{*}{$\begin{array}{l}\text { Arrecadação direta } \\
\text { Captação de recursos } \\
\text { extracontratuais }\end{array}$} & \multirow[t]{2}{*}{$\begin{array}{l}\text { Valor total arrecadado. } \\
\text { Valor total captado. }\end{array}$} \\
\hline & & $\begin{array}{l}\text { 1.2b. Crescimento no volume de recursos } \\
\text { externos extracontratuais }\end{array}$ & & \\
\hline $\begin{array}{l}\text { Objetivos de } \\
\text { Longo Prazo } \\
\text { (10 anos) }\end{array}$ & $\begin{array}{l}\text { 1.3. Atingir a auto } \\
\text { sustentabilidade } \\
\text { financeira. }\end{array}$ & $\begin{array}{l}\text { 1.3a. Montante arrecadado diretamente ou } \\
\text { por recursos extracontratuais seja suficiente } \\
\text { para o custeio da operação. }\end{array}$ & $\begin{array}{l}\text { Taxa de contribuição da } \\
\text { arrecadação no custeio }\end{array}$ & $\begin{array}{l}\text { Custo operacional total. } \\
\text { Valor total arrecadado. } \\
\text { Valor total captado. }\end{array}$ \\
\hline
\end{tabular}




\begin{tabular}{|c|c|c|c|c|}
\hline $\begin{array}{c}\text { Hierarquia } \\
\text { dos Objetivos }\end{array}$ & Objetivos & $\begin{array}{l}\text { Resultados Esperados } \\
\text { (CP, MP e LP) }\end{array}$ & Indicadores & Métricas \\
\hline $\begin{array}{l}\text { Objetivo } \\
\text { Estratégico }\end{array}$ & \multicolumn{4}{|c|}{ 2. Disseminar as culturas empreendedora, da colaboração e da inovação } \\
\hline \multirow{2}{*}{$\begin{array}{l}\text { Objetivos de } \\
\text { Curto Prazo } \\
\text { ( } 2 \text { anos) }\end{array}$} & \multirow{2}{*}{$\begin{array}{l}\text { 2.1. Desenvolver uma } \\
\text { agenda contínua e } \\
\text { integrada de eventos. }\end{array}$} & $\begin{array}{l}\text { 2.1a. Estabelecer um calendário programado } \\
\text { de eventos. }\end{array}$ & \multirow{2}{*}{$\begin{array}{l}\text { Quantidade de Eventos } \\
\text { realizados. } \\
\text { Taxa de participação nos eventos } \\
\text { realizados. }\end{array}$} & \multirow[t]{2}{*}{$\begin{array}{l}\text { Quantidade de eventos realizados por tipo. } \\
\text { Quantidade de participantes por evento. }\end{array}$} \\
\hline & & $\begin{array}{l}\text { 2.1b. Aumentar a quantidade de participantes } \\
\text { (organizações e indivíduos) nos eventos } \\
\text { realizados. }\end{array}$ & & \\
\hline \multirow{3}{*}{$\begin{array}{l}\text { Objetivos de } \\
\text { Médio Prazo } \\
\text { ( } 5 \text { anos) }\end{array}$} & \multirow{3}{*}{$\begin{array}{l}\text { 2.2. Ampliar a integração } \\
\text { da comunidade do } \\
\text { Parque em níveis regional } \\
\text { e nacional. }\end{array}$} & $\begin{array}{l}\text { 2.2a. Aumentar a participação ativa em } \\
\text { eventos externos. }\end{array}$ & \multirow{3}{*}{$\begin{array}{l}\text { Taxa de Participação em Eventos } \\
\text { Externos. } \\
\text { Taxa de Participantes externos } \\
\text { nos Eventos Realizados. } \\
\text { Número de parcerias } \\
\text { estabelecidas. }\end{array}$} & \multirow{3}{*}{$\begin{array}{l}\text { Quantidade de participações em eventos. } \\
\text { Quantidade de participantes externos nos eventos } \\
\text { realizados. }\end{array}$} \\
\hline & & $\begin{array}{l}2.2 \mathrm{~b} \text {. Aumentar a presença de participantes } \\
\text { regionais e nacionais nas atividades realizadas } \\
\text { pelo Parque. }\end{array}$ & & \\
\hline & & $\begin{array}{l}\text { 2.2c. Estabelecer parcerias no } \\
\text { desenvolvimento de projetos }\end{array}$ & & \\
\hline \multirow{2}{*}{$\begin{array}{l}\text { Objetivos de } \\
\text { Longo Prazo } \\
\text { (10 anos) }\end{array}$} & \multirow{2}{*}{$\begin{array}{l}\text { 2.3. Consolidar o Parque } \\
\text { como um ambiente } \\
\text { empreendedor e de } \\
\text { colaboração para } \\
\text { inovação. }\end{array}$} & $\begin{array}{l}\text { 2.3a. Adquirir reconhecimento nacional e } \\
\text { internacional }\end{array}$ & $\begin{array}{l}\text { Taxa de Participação em Eventos } \\
\text { Internacionais. }\end{array}$ & $\begin{array}{l}\text { Quantidade de Participações em Eventos } \\
\text { Internacionais. }\end{array}$ \\
\hline & & 2.3b. Popularizar a ciência & $\begin{array}{l}\text { Taxa de Participantes } \\
\text { internacionais nos Eventos } \\
\text { Realizados. }\end{array}$ & $\begin{array}{l}\text { Quantidade de Participantes internacionais nos } \\
\text { eventos realizados. }\end{array}$ \\
\hline
\end{tabular}




\begin{tabular}{|c|c|c|c|c|}
\hline $\begin{array}{c}\text { Hierarquia } \\
\text { dos Objetivos }\end{array}$ & Objetivos & $\begin{array}{l}\text { Resultados Esperados } \\
(\mathrm{CP}, \mathrm{MP} \text { e LP) }\end{array}$ & Indicadores & Métricas \\
\hline $\begin{array}{l}\text { Objetivo } \\
\text { Estratégico }\end{array}$ & \multicolumn{4}{|c|}{ 3. Ocupar os espaços do parque com empreendimentos de CT\&I. } \\
\hline \multirow{2}{*}{$\begin{array}{l}\text { Objetivos de } \\
\text { Curto Prazo } \\
\text { ( } 2 \text { anos) }\end{array}$} & \multirow{2}{*}{$\begin{array}{l}\text { 3.1. Ampliar o número de } \\
\text { colaboradores e } \\
\text { visitantes do } \\
\text { Tecnocentro. }\end{array}$} & 3.1a. Ocupar plenamente o Tecnocentro. & \multirow{2}{*}{$\begin{array}{l}\text { Quantidade de Eventos } \\
\text { realizados. } \\
\text { Taxa de participação nos eventos } \\
\text { realizados. }\end{array}$} & \multirow{2}{*}{$\begin{array}{l}\text { Quantidade de eventos realizados por tipo. } \\
\text { Quantidade de participantes por evento. }\end{array}$} \\
\hline & & $\begin{array}{l}\text { 3.1b. Implantar os novos equipamentos } \\
\text { previstos no Tecnocentro. }\end{array}$ & & \\
\hline \multirow{2}{*}{$\begin{array}{l}\text { Objetivos de } \\
\text { Médio Prazo } \\
\text { ( } 5 \text { anos) }\end{array}$} & \multirow{2}{*}{$\begin{array}{l}\text { 3.2. Ampliar o número de } \\
\text { colaboradores e } \\
\text { visitantes do Parque. }\end{array}$} & $\begin{array}{l}\text { 3.2a. Atrair a iniciativa privada para os lotes } \\
\text { públicos. }\end{array}$ & \multirow[t]{2}{*}{ Taxa de ocupação dos lotes } & \multirow[t]{2}{*}{ Área total ocupada no Parque. } \\
\hline & & 3.2b. Iniciar a ocupação dos lotes privados. & & \\
\hline $\begin{array}{l}\text { Objetivos de } \\
\text { Longo Prazo } \\
\text { (10 anos) }\end{array}$ & $\begin{array}{l}\text { 3.3. Estabelecer o Parque } \\
\text { como uma região ativa e } \\
\text { reconhecida. }\end{array}$ & $\begin{array}{l}\text { 3.3a. Ocupar plenamente os lotes e } \\
\text { empreendimentos públicos }\end{array}$ & Taxa de ocupação dos lotes & Área total ocupada no Parque. \\
\hline
\end{tabular}




\begin{tabular}{|c|c|c|c|c|}
\hline $\begin{array}{c}\text { Hierarquia } \\
\text { dos Objetivos }\end{array}$ & Objetivos & $\begin{array}{l}\text { Resultados Esperados } \\
(\mathrm{CP}, \mathrm{MP} \text { e LP) }\end{array}$ & Indicadores & Métricas \\
\hline $\begin{array}{l}\text { Objetivo } \\
\text { Estratégico }\end{array}$ & \multicolumn{4}{|c|}{ 4. Fomentar o empreendedorismo inovador. } \\
\hline \multirow{3}{*}{$\begin{array}{l}\text { Objetivos de } \\
\text { Curto Prazo } \\
\text { ( } 2 \text { anos) }\end{array}$} & \multirow{3}{*}{$\begin{array}{l}\text { 4.1. Fomentar o } \\
\text { empreendedorismo } \\
\text { inovador. }\end{array}$} & 4.1a. Ocupar plenamente a Incubadora. & \multirow{3}{*}{$\begin{array}{l}\text { Taxa de Ocupação da Incubadora; } \\
\text { Catálogo de Serviços da } \\
\text { Incubadora. } \\
\text { Certificação da Incubadora }\end{array}$} & \multirow{3}{*}{$\begin{array}{l}\text { Área Total Ocupada na Incubadora; } \\
\text { Certificação da Incubadora. }\end{array}$} \\
\hline & & 4.1b. Adquirir primeira certificação CERNE & & \\
\hline & & $\begin{array}{l}\text { 4.1c. Ampliar a oferta de serviços da } \\
\text { incubadora. }\end{array}$ & & \\
\hline \multirow{3}{*}{$\begin{array}{l}\text { Objetivos de } \\
\text { Médio Prazo } \\
\text { ( } 5 \text { anos) }\end{array}$} & \multirow{3}{*}{$\begin{array}{l}\text { 4.2. Ampliar a maturidade } \\
\text { e a atuação da } \\
\text { Incubadora. }\end{array}$} & $\begin{array}{l}\text { 4.2a. Expandir a oferta de serviços para além } \\
\text { da incubadora;. }\end{array}$ & \multirow{3}{*}{$\begin{array}{l}\text { Catálogo de Serviços da } \\
\text { Incubadora; } \\
\text { Certificação da Incubadora }\end{array}$} & \multirow[t]{3}{*}{$\begin{array}{l}\text { Quantidade de Intercâmbios realizados; } \\
\text { Certificação da Incubadora. }\end{array}$} \\
\hline & & 4.2b. Realizar intercâmbios internacionais; & & \\
\hline & & 4.2c. Obter certificação CERNE estágio 2; & & \\
\hline \multirow{2}{*}{$\begin{array}{l}\text { Objetivos de } \\
\text { Longo Prazo } \\
\text { (10 anos) }\end{array}$} & \multirow[t]{2}{*}{$\begin{array}{l}\text { 4.3. Ampliar a atuação } \\
\text { Nacional e Internacional } \\
\text { da Incubadora. }\end{array}$} & 4.3a. Obter certificação CERNE estágio 4; & \multirow[t]{2}{*}{$\begin{array}{l}\text { Catálogo de serviços da } \\
\text { Incubadora } \\
\text { Certificação da Incubadora. }\end{array}$} & \multirow[t]{2}{*}{$\begin{array}{l}\text { Quantidade de parcerias realizados; } \\
\text { Certificação da Incubadora }\end{array}$} \\
\hline & & 4.3b. Atuar como Aceleradora de empresas & & \\
\hline
\end{tabular}

Fonte: Elaboração própria a partir dos resultados das duas Oficinas realizadas durante o 1 Curso para Gestores de Parques Tecnológicos e Ambientes de Inovação, oferecido pela Uni-Anprotec/Instituto Gênesis em 2016. 


\subsection{5.}

\section{ParqTec FB}

O Parque Tecnológico FB (ParqTec FB) é uma proposta de parque fictício, elaborado por um grupo de gestores participantes das oficinas. O estágio do empreendimento apresenta-se na fase de planejamento. O projeto está localizado na região fictícia de Novo Horizonte, constituída por cidades de porte médio.

As construções das estruturas necessárias para o funcionamento do parque, assim como espaços de lazer, alimentação e setores voltados para convivência e colaboração entre os residentes do parque tecnológico, serão feitas dentro e no entorno da Universidade Federal de Novo Horizonte. O empreendimento conterá empresas de portes diversificados, instituições de ciência e tecnologia (ICTs), módulos especializados em transferências tecnológicas e laboratórios.

Planejam-se seguintes atividades iniciais do Parque: a instalação de dez startups e cinco Pequenas e Médias Empresas (PMEs) e atualmente as partes encarregadas pela captação de renda buscam parcerias para o fornecimento de fundos de capital semente e venture capital. O parque estará voltado, inicialmente, para atuação no mercado regional e possui como direcionamento para as empresas residentes as áreas listadas a seguir:

- TIC;

- Biotecnologia;

- Jogos eletrônicos;

- Engenharia.

Em uma primeira etapa, a equipe dedicada à gestão do Parque está construindo uma rede formal com a IASP, Anprotec, Associação Nacional de Pesquisa e Desenvolvimento das Empresas Inovadoras (Anpei), Rede de Incubadoras, Centro de Estratégias em Recursos Naturais e Energia (Cerne) e o Serviço Brasileiro de Apoio às Micro e Pequenas Empresas (Sebrae). É válido citar também o planejamento na formulação no médio prazo de um networking entre as empresas afiliadas, assim como o corpo jurídico e gestor do parque tecnológico, o qual será formado por membros representantes das universidades afiliadas, dos investidores, representantes empresariais, do governo do Estado e municipal.

O planejamento para o projeto do ParqTec FB já possui como missão "contribuir para o desenvolvimento regional, de maneira sustentável, por meio da 
ciência, tecnologia, inovação e empreendedorismo" e prospecção de futuro "ser reconhecida, até 2026, como referência na promoção do desenvolvimento regional sustentável, mobilizando parceiros e a população do Estado". Para tanto, os objetivos específicos são:

- Humanizar o parque tecnológico, tornando um ambiente de convívio agradável;

- Fortalecer o ecossistema de inovação aberta na região;

- Gerar e fortalecer negócios de base tecnológica de diferentes portes, de modo a balancear o ecossistema;

- $\quad$ Liderar ações de empreendedorismo e inovação.

\section{Caracterização das partes interessadas e seus objetivos em relação ao ParqTec FB}

O Quadro 5.9 apresenta os principais stakeholders e seus objetivos em relação ao empreendimento ParqTec FB.

Quadro 5.9 - Partes interessadas e seus objetivos em relação ao ParqTec FB

\begin{tabular}{|c|c|}
\hline $\begin{array}{l}\text { Partes } \\
\text { interessadas }\end{array}$ & Objetivos em relação ao Parque Tecnológico \\
\hline $\begin{array}{lr}\text { Instituições } & \text { de } \\
\text { ensino superior } \\
\text { públicas e privadas } \\
\text { locais (Universidade } \\
\text { Federal de Novo } \\
\text { Horizonte) }\end{array}$ & $\begin{array}{l}\text { - Ampliar a missão institucional, promovendo desenvolvimento } \\
\text { regional e o entorno da universidade; } \\
\text { - Aquisição de recursos financeiros através de agências de fomento, } \\
\text { como o CNPq, para a concessão de bolsas voltadas para o } \\
\text { desenvolvimento de projetos com base tecnológica; } \\
\text { - Integração entre o corpo docente e discente (graduados e pós- } \\
\text { graduados) junto às empresas, promovendo a transferência } \\
\text { tecnológica e desenvolvimento inovador; } \\
\text { - Qualificação de especialistas e promoção de consultorias de } \\
\text { qualidade aos clientes; } \\
\text { A Universidade Federal de Novo Horizonte atuará como líder } \\
\text { institucional, responsável pela gestão e contratação de serviços } \\
\text { diversos ao ParqTec FB. }\end{array}$ \\
\hline $\begin{array}{l}\text { Órgãos } \\
\text { governamentais } \\
\text { locais (Estado e } \\
\text { Município onde está } \\
\text { localizado o Parque). }\end{array}$ & $\begin{array}{l}\text { - Desenvolvimento regional e social do entorno do parque } \\
\text { tecnológico; } \\
\text { - Aumento da renda per capta pela promoção de empregos de } \\
\text { qualidade para a região; } \\
\text { - Desenvolvimento e geração de novas tecnologias para o benefício } \\
\text { social e empresarial; } \\
\text { - Promoção e disseminação da cultura de inovação e } \\
\text { empreendedorismo. }\end{array}$ \\
\hline
\end{tabular}

Fonte: Elaboração própria a partir dos resultados das duas Oficinas realizadas durante o 1 Curso para Gestores de Parques Tecnológicos e Ambientes de Inovação, oferecido pela UniAnprotec/Instituto Gênesis em 2016. 


\section{Perfil estratégico: uso da ferramenta 'Estrategigrama' da IASP}

O ParqTec FB terá sua localização em ambiente urbano, proporcionando uma variada de serviços de entretenimento. $\mathrm{O}$ Parque será vinculado à Universidade Federal de Novo Horizonte e contará com uma incubadora e um escritório de transferência de tecnologia. As instalações do parque conterão 15 empresas nos prédios compartilhados, sendo 10 delas incubadas, e aproximadamente 100 pessoas em circulação pelo parque tecnológico (Figura $5.18)$.

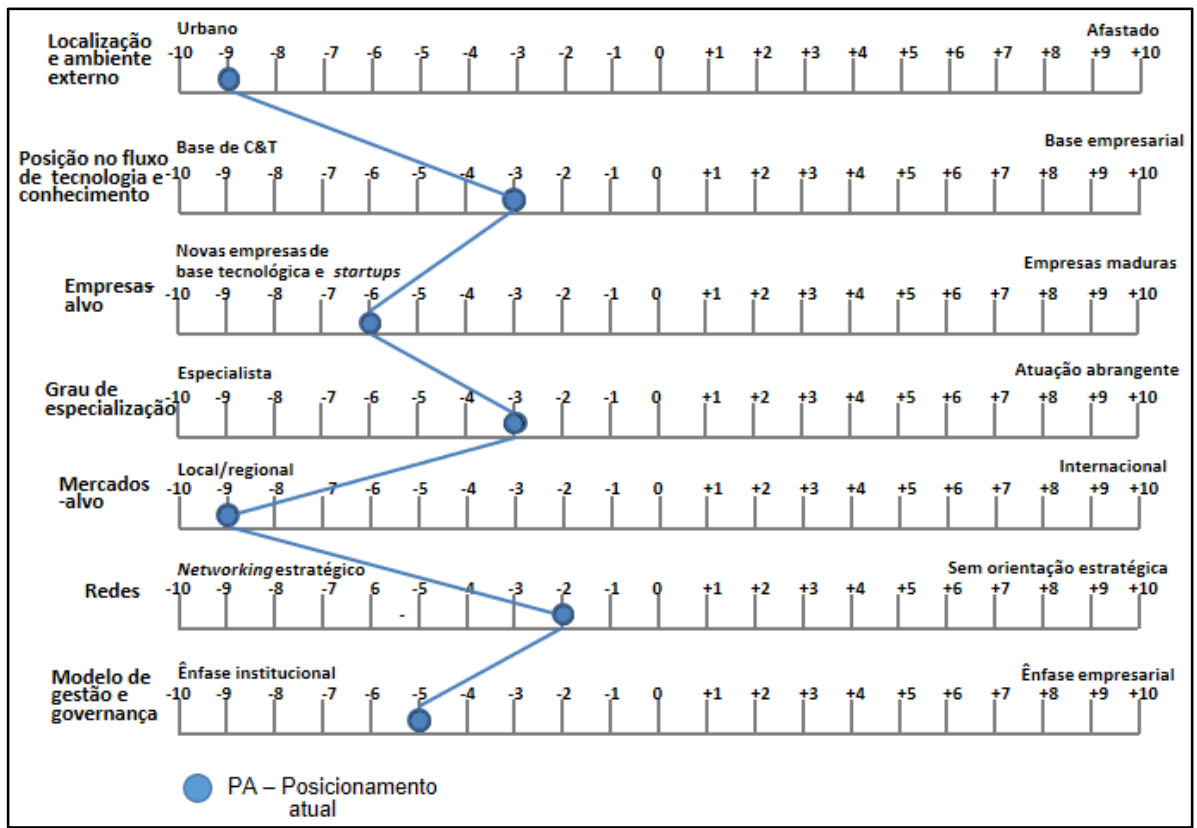

Figura 5.18 - Perfil estratégico atual do ParqTec FB

Fonte: Elaboração própria a partir dos resultados das duas Oficinas realizadas durante o 1ำ Curso para Gestores de Parques Tecnológicos e Ambientes de Inovação, oferecido pela UniAnprotec/Instituto Gênesis em 2016.

A incubadora do ParqTec FB terá capacidade inicial para 20 empresas. O direcionamento para a incubadora é de atrair um percentual mais elevado de startups e buscar ativamente ICTs.

As áreas de atuação serão selecionadas de acordo com as competências da Universidade e das empresas do entorno.

O mercado-alvo do Parqtec FB será regional e os esforços de marketing serão divididos em $75 \%$ para a região e $25 \%$ a nível nacional e internacional. 
Dentre os mecanismos utilizados desde o início de operação do parque tecnológico, haverá uma organização de eventos mensais para empreendedores com enfoque nas necessidades das empresas incubadas. O Parque participará de, no mínimo, 12 eventos por ano para construir e fortalecer o networking e inserirse cada vez mais nos ambientes de inovação.

A Universidade atuará como instituição administrativa e de governança, tendo uma fundação pública sem fins lucrativos para operacionalizar a gestão e contratação de serviços dentro do ParqTec FB.

Como planejamento estratégico futuro, projeta-se a implantação de espaços de convivência, a começar por um centro esportivo com academia e piscina. No médio prazo, os serviços serão expandidos com a construção de creches e de centros de saúde. No longo prazo, a partir de parcerias com o Governo do Estado e municipal e instituições privadas, será implantada uma nova escola.

Para o objetivo de longo prazo, planeja-se a vinda de 70 empresas clientes, das quais serão incubadas, 20 PMEs, 10 de grande porte e 3 ICTs. Para isso, se fará necessária a expansão dos prédios compartilhados e até mesmo a destinação de novas áreas para construção de laboratórios próprios.

Para alcançar os objetivos propostos, o corpo gestor do ParqTec FB concentrará seus esforços para atrair, no médio prazo, 40 empresas, sendo que 30 serão incubadas, 10 PMEs e 1 ICT.

O projeto do parque tecnológico está dividido nas áreas de atuação em: 10\% jogos; 35\% TICs; 35\% engenharia; e 20\% biotecnologia. O ParqTec FB terá uma incubadora em funcionamento, contudo adotará modelos específicos para cada área. Para a proposta no médio prazo, espera-se que as aplicações de marketing terão proporções de: $45 \%$ local; 30\% regional; e 25\% nacional. Já para o longo prazo, serão adotadas novas proporções, incluindo atividades internacionais. A atuação será de: $40 \%$ local; 35\% regional; 20\% nacional; e 5\% estrangeira.

A respeito das interações, o Parque se pautará na organização de eventos para residentes e públicos de interesse; na participação de encontros, cursos, treinamentos, fóruns que fortaleçam a rede; na formação de alianças estratégicas e; na utilização de ferramentas que facilitem a atração e consolidação de networking. 
No curto prazo, eventos serão realizados em uma base mensal e a participação do Parque será em no mínimo 12 eventos por ano. O Sistema S será o primeiro parceiro no estabelecimento de alianças estratégicas.

No médio prazo, eventos serão realizados em uma base mensal e a participação do Parque será em no mínimo 15 eventos por ano. As parcerias serão realizadas com outros ambientes de inovação e nos aproximaremos de fundos de investimento, inclusive estrangeiros. Algumas ferramentas de prospecção e networking serão introduzidas na rotina do Parque (ex: Inovall).

No longo prazo, eventos serão realizados quinzenalmente e a participação do Parque será em no mínimo 20 eventos por ano. As parcerias serão estimuladas a nível internacional com ambientes de inovação globais. Planeja-se ter um sistema de networking consolidado a partir da adesão de instrumentos ao longo do tempo que fortaleçam as atividades e agreguem as necessidades.

O modelo de gestão e governança não deverá sofrer alterações ao longo da implantação e operação do Parque (Figura 5.19).

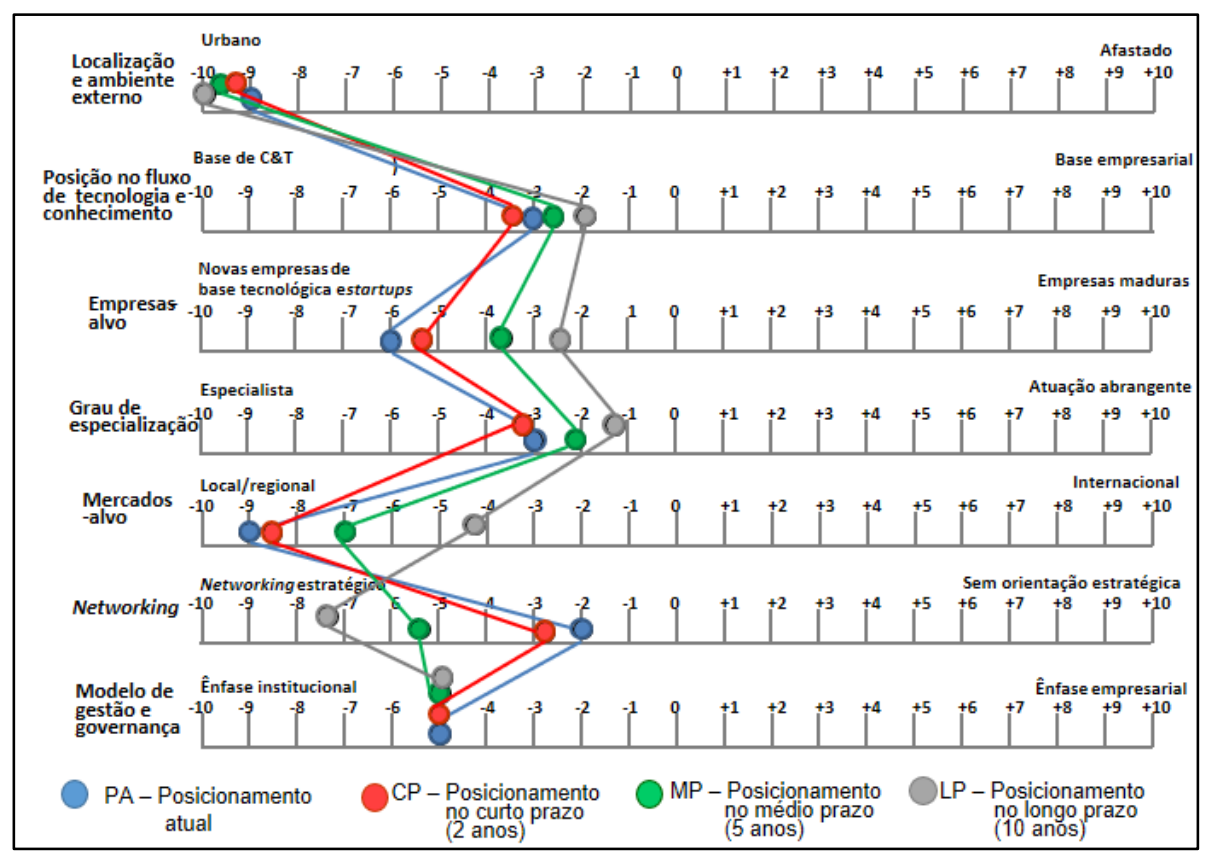

Figura 5.19 - Evolução do perfil estratégico do ParqTec FB: curto, médio e longo prazo

Fonte: Elaboração própria a partir dos resultados das duas Oficinas realizadas durante 0 1 Curso para Gestores de Parques Tecnológicos e Ambientes de Inovação, oferecido pela UniAnprotec/Instituto Gênesis em 2016. 


\section{Modelo de negócio: uso da ferramenta 'Canvas'}

Apresenta-se, a seguir, a proposta do modelo de negócio para o ParqTec FB.

\section{Segmentos de clientes}

A partir da análise das potencialidades empresariais e competências científicas e tecnológicas identificadas na região de Novo Horizonte, o ParqTec FB será multissetorial e orientará a implantação de sua infraestrutura e serviços especializados, de forma a atender empresas de base tecnológica de diversos portes e instituições de PD\&I com atuação nos seguintes setores:

- Agroindústria;

- Saúde: desenvolvimento de produtos farmoquímicos e farmacêuticos; cosméticos, perfumaria e produtos de higiene pessoal; aparelhos eletromédicos e instrumentos, utensílios e materiais para uso médico-cirúrgico, odontológico e de laboratório;

- Tecnologias da informação e comunicação (TIC);

- Energia: geração de energia por fontes renováveis; extração e beneficiamento de petróleo e gás; e produção de biocombustíveis;

- Materiais: novos materiais; siderurgia; metalmecânica; e cerâmica;

- Meio ambiente: água; gestão de resíduos; e tecnologias limpas.

Seguindo a tendência da maioria dos parques tecnológicos bem-sucedidos no Brasil, foram identificados como potenciais clientes do ParqTec FB:

- Empresas de base tecnológica de diversos portes;

- Empresas consolidadas que investem em PD\&I;

- Empresas de serviços tecnológicos especializados;

- Instituições de PD\&I.

Cabe ressaltar, no entanto, que o Parque não deverá excluir empresas de base tecnológica e instituições de PD\&I de outros setores, caso queiram usufruir dos benefícios desse ambiente de inovação e dos serviços de valor agregado oferecidos pela Entidade Gestora do Parque Tecnológico.

\section{Proposição de valor}

A Entidade Gestora deverá oferecer um conjunto de benefícios que coloque o ParqTec FB como um ambiente de inovação, com infraestrutura e serviços diferenciados e que, ao mesmo tempo, ofereça preços competitivos frente a iniciativas congêneres.

Dentre esses benefícios, destacam-se como proposição de valor do ParqTec FB: 
- Diferenciação de infraestrutura e serviços a valores competitivos de mercado;

- Ecossistema sinérgico e com capital humano qualificado;

- Rede estratégica de inovação e poder de articulação;

- Incentivos fiscais e suporte ao acesso dos incentivos para instalação de empresas e unidades de instituições de PD\&I no Parque Tecnológico.

Os principais serviços de valor agregado a serem prestados pelo Parque às empresas e instituições de PD\&I residentes são:

- Concessão, em caráter temporário e/ou provisório, de direito de uso das áreas edificadas ou dos lotes;

- Incubadoras de empresas (em parceria);

- Aceleradoras de empresas (em parceria);

- Centros de Inovação (em parceria);

- Laboratórios: multiusuários e de referência (os últimos, em parceira);

- Ambientes co-working;

- Escritório de negócios: consultoria em gestão da inovação; inteligência competitiva; prospecção de mercado; valoração de tecnologias; modelagem de negócios; mobilização de capitais e de investimentos, dentre outros serviços de valor agregado;

- Aluguel e disponibilização de minicentros de conferências, salas para eventos e outros espaços;

- Centro de convivência: galerias para exposições; serviços de reprografia; cafeterias; academias de ginástica, etc.

- Serviços de logística para mobilização dos diversos atores de CT\&I.

Cabe destacar que os serviços relacionados à propriedade intelectual, à transferência de tecnologia e ao desenvolvimento tecnológico deverão ser articulados junto aos Núcleos de Inovação Tecnológica (NIT), que integram a Rede de Núcleos de Inovação Tecnológica de Novo Horizonte (RedeNIT- NH), especialmente aqueles das Universidades e de Instituições de PD\&I localizadas na região.

\section{Fluxo de conhecimento e tecnologia}

As fontes de conhecimento e tecnologias utilizadas pelos clientes e parceiros do ParqTec FB podem ser oriundas da base de C\&T ou da base empresarial local ou de ambas. Dentre as práticas a serem adotadas pela Entidade Gestora para intensificar o fluxo de conhecimento e tecnologia no âmbito do ParqTec FB, destacam-se: 
- Promover a interação entre as empresas residentes do Parque com ICTs parceiras e de outras regiões e países;

- Estabelecer canais diretos e contínuos para a promoção da interação ICTsempresas;

- Promover a aproximação entre as empresas do Parque Tecnológico e incubadoras locais, em cada um dos municípios onde se localizarão suas unidades;

- Realizar workshops, exposições, feiras e reuniões para fortalecimento do networking para as empresas residentes, principalmente as de menor porte e em estágio inicial de atuação, e instituições de PD\&I (residentes ou parceiras);

- Mediar contatos das empresas e instituições de PD\&I residentes com as ICTs parceiras-chave para o estabelecimento de contratos referentes a projetos de PD\&I colaborativo;

- Prestar apoio técnico à transferência de tecnologia e à propriedade intelectual para seus clientes (empresas e instituições de PD\&I residentes), em parceria com os Núcleos de Inovação Tecnológica das ICTs parcerias e articulação com a RedeNIT- NH.

\section{Relacionamento com clientes}

A Entidade Gestora deverá realizar a avaliação das necessidades de serviços demandados pelos clientes sistematicamente, por meio de pesquisa/censo com os clientes do ParqTec FB. Dentre as práticas a serem adotadas pelo Parque para relacionamento com seus clientes, destacam-se:

- Melhoria contínua e excelência nos serviços de alto valor agregado prestados às empresas e instituições de PD\&I residentes;

- Adoção de estratégias de marketing de relacionamento consagradas;

- Definição e implantação de política para a efetiva atração de empresas de base tecnológica, detalhada por setor e por porte;

- Ampla divulgação do lançamento de editais para seleção de empresas e instituições de PD\&I que se instalarão no Parque Tecnológico.

\section{Geração de receitas}

As principais fontes de receitas geradas pelo ParqTec FB serão:

- Cessão de uso das áreas dos edifícios compartilhados;

- Taxas de serviços de valor agregado, como consultorias em gestão da inovação, prospecção tecnológica e de mercado, gestão financeira, marketing, captação de recursos, propriedade intelectual e transferência de 
tecnologia, além de outras áreas demandadas pelas empresas residentes no parque tecnológico;

- Taxas de serviços para as empresas e instituições de PD\&I que se instalarão em lotes do Parque, em suas diversas localidades;

- Outras receitas incluem aluguéis de minicentros de conferências e de instalações para cafeterias, academias, serviço de reprografia etc.

\section{Recursos-chave}

Partindo-se do pressuposto que a Entidade Gestora não será a proprietária das áreas do ParqTec FB, ela deverá receber como doação ou arrendamento sem remuneração (pelo período considerado como de depreciação total dos imóveis implantados) áreas suficientes para implantar as unidades da Entidade Gestora e edifícios compartilhados nas diversas localidades onde atuará. Consideram-se também recursos físicos as áreas que serão oferecidas a empresas e instituições de PD\&I, para que venham a construir seus edifícios e instalações no Parque.

No caso de áreas públicas, investimentos diretos por parte do poder público ou das instituições de ensino e pesquisa (parceiras) podem ser realizados para promover a implantação da infraestrutura física do Parque. Nesses casos, deve-se considerar que universidades públicas têm acesso a editais de fortalecimento da estrutura de ciência e tecnologia, que podem ser direcionados para implantação de âncoras voltadas à prestação de serviços tecnológicos no parque, tais como laboratórios de ensaios e calibração e também organismos acreditados pelo Inmetro para certificação de produtos.

Além da infraestrutura física, considera-se que os recursos considerados como os mais importantes para operacionalizar o parque tecnológico são os recursos humanos, quais sejam: (i) Diretores que detenham expertise na gestão de ambientes de inovação, em formação de networking estratégico e com poder de negociação; (ii) especialistas em captação de recursos financeiros; (iii) especialistas certificados em gerenciamento de projetos, junto com o suporte administrativo financeiro e jurídico; (iv) especialistas em comunicação institucional e gerenciamento estratégico de stakeholders.

\section{Atividades-chave}

A Entidade Gestora será uma organização com forte articulação institucional para geração de inovações em rede, além de realizar a gestão imobiliária dos espaços físicos de suas unidades. Suas atividades-chave serão: 
- Fomento ao desenvolvimento empresarial e qualificação de capital humano;

- Acesso, disseminação e compartilhamento do conhecimento: criação e promoção de redes de relacionamento, seminários, conferências e workshops, treinamentos, e demonstração tecnológica;

- Incubação e aceleração de novos negócios (inclusive em parceria);

- Atração de empresas inovadoras;

- Mobilização de capitais e de investimentos;

- Estímulo à prática de responsabilidade social empresarial (RSE);

- Aperfeiçoamento contínuo da equipe técnica e dos processos de gestão da Entidade Gestora;

- Atração de projetos de pesquisa e desenvolvimento tecnológico por empresas e unidades de instituições de PD\&I a serem instaladas no Parque Tecnológico;

- Gestão imobiliária dos espaços físicos das unidades localizadas em diversos municípios.

É estratégico que a Entidade Gestora do ParqTec FB venha a oferecer às empresas e às instituições de PD\&I a serem instaladas (segundo o conceito multicampi) uma série de serviços que contribuam de forma significativa para o sucesso das atividades dessas organizações e sirvam de elemento de atração de novas empresas de base tecnológica.

Considera-se que, além de oferecer áreas ou locações a preços competitivos e isenção de impostos como elementos de atração e de sucesso das atividades desenvolvidas no Parque, a Entidade Gestora deve ter capacidade de facilitar o acesso das empresas de base tecnológica a instrumentos adequados de financiamento de suas atividades, sobretudo aqueles voltados às pequenas e médias empresas.

\section{Parceiros-chave}

Serão parceiros-chave do ParqTec FB:

- Secretaria da Ciência, Tecnologia e Educação Superior do Estado da Região de Novo Horizonte;

- Fundação de Apoio ao Desenvolvimento Científico e Tecnológico do Estado da Região de Novo Horizonte;

- Secretaria de Desenvolvimento Econômico do Estado da Região de Novo Horizonte; 
- Secretaria do Planejamento, Gestão e Orçamento do Estado da Região de Novo Horizonte;

- Associação dos Municípios e Prefeitos do Estado da Região de Novo Horizonte;

- Instituições de Ensino Superior públicas e privadas locais;

- Instituições de PD\&I, como Embrapa, Fiocruz; INPE;

- Rede de Incubadoras de Empresas de Novo Horizonte

- Rede de Núcleos de Inovação Tecnológica de Novo Horizonte (RedeNIT$\mathrm{NH})$

- Federação das Indústrias do Estado de Novo Horizonte;

- Federação da Agricultura e Pecuária do Estado de Novo Horizonte;

- Serviço Brasileiro de Apoio às Micro e Pequenas Empresas (Sebrae);

- Banco de Novo Horizonte (BNH);

- Ministério da Ciência, Tecnologia, Inovações e Comunicações (Programa Nacional de Apoio a Incubadoras de Empresas - PNI).

Com relação às parcerias do parque com organismos públicos, cabe destacar os avanços no Marco Legal da Ciência, Tecnologia e Inovação, no nível federal, e a criação de marcos regulatórios que vêm beneficiando a expansão e a consolidação institucional do Sistema de CT\&I da região de Novo Horizonte. Destacam-se, a seguir, as Leis que integram o Marco Legal da Ciência, Tecnologia e Inovação, no nível federal:

- Lei $n^{\circ} 13.243$, de 11 de janeiro de 2016, que ainda não foi regulamentada, dispõe sobre estímulos ao desenvolvimento científico, à pesquisa, à capacitação científica e tecnológica e à inovação e altera nove leis, inclusive a Lei $\mathrm{n}^{\mathrm{o}}$ 10.973, de 2 de dezembro de 2004. Para fins deste estudo, destacam-se os incisos V e VI do Art. $1^{\circ}$, parágrafo único:

- V - promoção da cooperação e interação entre os entes públicos, entre os setores público e privado e entre empresas;

- VI - estímulo à atividade de inovação nas Instituições Científicas, Tecnológicas e de Inovação (ICTs) e nas empresas, inclusive para a atração, a constituição e a instalação de centros de pesquisa, desenvolvimento e inovação e de parques e polos tecnológicos no País.

- Regulamentação da Lei Federal de Inovação no 10.973, de 3 de dezembro de 2004, através do Decreto $n^{\circ} 5.563$, de 11 de outubro de 2005, que estabelece medidas de incentivo à inovação e à pesquisa científica e tecnológica no ambiente produtivo, com vistas à capacitação e ao alcance da autonomia tecnológica e ao desenvolvimento industrial do País. 


\section{Estrutura de custos}

Uma vez instituída como Organização Social, a entidade gestora do ParqTec FB poderá ser dotada de recursos orçamentários e bens públicos necessários ao cumprimento do contrato de gestão estabelecido junto ao poder público. A ela, deverão ser assegurados os créditos previstos no orçamento e as respectivas liberações financeiras, de acordo com o cronograma de desembolso previsto no Contrato de Gestão.

A exemplo da maioria dos casos bem-sucedidos de Parques Tecnológicos no Brasil, o ParqTec FB deverá contar com o aporte de recursos não reembolsáveis, especialmente para apoio à infraestrutura e à construção dos edifícios da Entidade Gestora, entre outros. O apoio financeiro e institucional público será importante também para o fortalecimento do ParqTec FB na fase de operacionalização, especialmente nos primeiros anos, dando mais segurança às empresas e instituições de PD\&I interessadas no empreendimento.

Os recursos financeiros não reembolsáveis para a fase de implantação referem-se aos seguintes itens:

- Investimento em infraestrutura básica de suporte nas localidades onde o parque implantará módulos para as empresas residentes e instituições de PD\&I parceiras;

- Investimento em edifícios próprios ou cedidos para exploração pelo corpo gestor;

- Investimento em edifícios com espaços compartilhados para empresas graduadas ou unidades de empresas consolidadas que ocupem unidades de tamanho relativamente pequeno;

- Custos operacionais durante o estágio de implantação do projeto.

Os principais itens de custos operacionais são: (i) pessoal (salários e encargos); (ii) serviços de terceiros; (iii) serviços de concessionárias; (iv) e despesas administrativas. No caso da equipe de gestão do parque, considera-se que a mesma deva ser enxuta, com terceirização das atividades que não são relacionadas com as atividade-fim, tais como limpeza, paisagismo, manutenção predial, segurança, dentre outras.

Para a fase de operacionalização, os recursos financeiros referem-se aos custos operacionais. Enquanto não houver geração de receitas suficientes, esses custos deverão ser cobertos por recursos não reembolsáveis via Contrato de Gestão com o Poder Público. Nesse sentido, deve-se ressaltar que: 
- Os editais de fomento para apoio à implantação de Parques Tecnológicos no Brasil, lançados no âmbito do Programa Nacional de Apoio a Incubadoras de Empresas (PNI), do Ministério da Ciência, Tecnologia, Inovações e Comunicações (MCTIC), têm como entidades proponentes instituições públicas ou privadas sem fins lucrativos. A Entidade Gestora instituída como uma Organização Social é elegível para submissão de propostas para os referidos editais de fomento;

- Os Programas Estaduais de Apoio a Parques Tecnológicos têm apoiado iniciativas, cujas Entidades Gestoras sejam sem fins lucrativos. Os incentivos fiscais, ou de outra natureza, deles decorrentes somente são possíveis de utilização se as empresas residentes estiverem abrigadas em Parques, que se enquadrem nesta modalidade.

Recomenda-se, para o caso do ParqTec FB, que os financiamentos reembolsáveis tenham maiores prazos de carência e total, devido ao tempo de maturação do empreendimento e ao seu papel como ambiente de inovação, transformador de conhecimento me riqueza para a região.

No caso de empresas de maior porte, em geral empresas âncoras, que poderão se instalar no Parque, é possível que o financiamento seja realizado diretamente, para que construam seus próprios edifícios nos terrenos no Parque. Nesses casos, o apoio financeiro pode ser mediante instrumentos de apoio à inovação das instituições financeiras, a exemplo do BNDES. Outras alternativas poderão ser avaliadas, como o Project Finance, caso o parque venha dispor de contratos firmes com empresas-âncora e um fluxo de receitas previsíveis de longo prazo. Nessa modalidade, a análise da operação deverá considerar a previsibilidade e estabilidade dos fluxos de caixa do projeto, os riscos de implantação do projeto e os respectivos mitigadores, entre outros aspectos.

\section{Estágio de desenvolvimento do Parque Tecnológico conforme classificação da Anprotec}

O ParqTec FB é apresentado como em estágio de planejamento, sendo os esforços iniciais do empreendimento a atração de empresas que possuam relevância regional. Nesta fase do projeto, há 6 pessoas, pertencentes a equipe do parque tecnológico, realizando os trabalhos até a próxima etapa de execução do planejamento. 


\section{Posicionamento do Parque Tecnológico segundo a taxonomia da Anprotec}

Ao término da fase de projeto do ParqTec FB, serão concentrados esforços para a atração de base empresarial de relevância regional, já possuindo uma base de C\&T de relevância regional e nacional.

A posição do parque tecnológico dentro da taxonomia Anprotec para a base de ciência e tecnologia é representada pela parceria com a Universidade Federal de Novo Horizonte, assim como a proximidade de instituições de C\&T, a presença de profissionais qualificados na região, um histórico incipiente, contudo crescente, de projetos de $\mathrm{P} \& \mathrm{D}$ a partir da interação academia-indústria e infraestrutura básica para pesquisa com impacto regional e nacional (Figura 5.20).

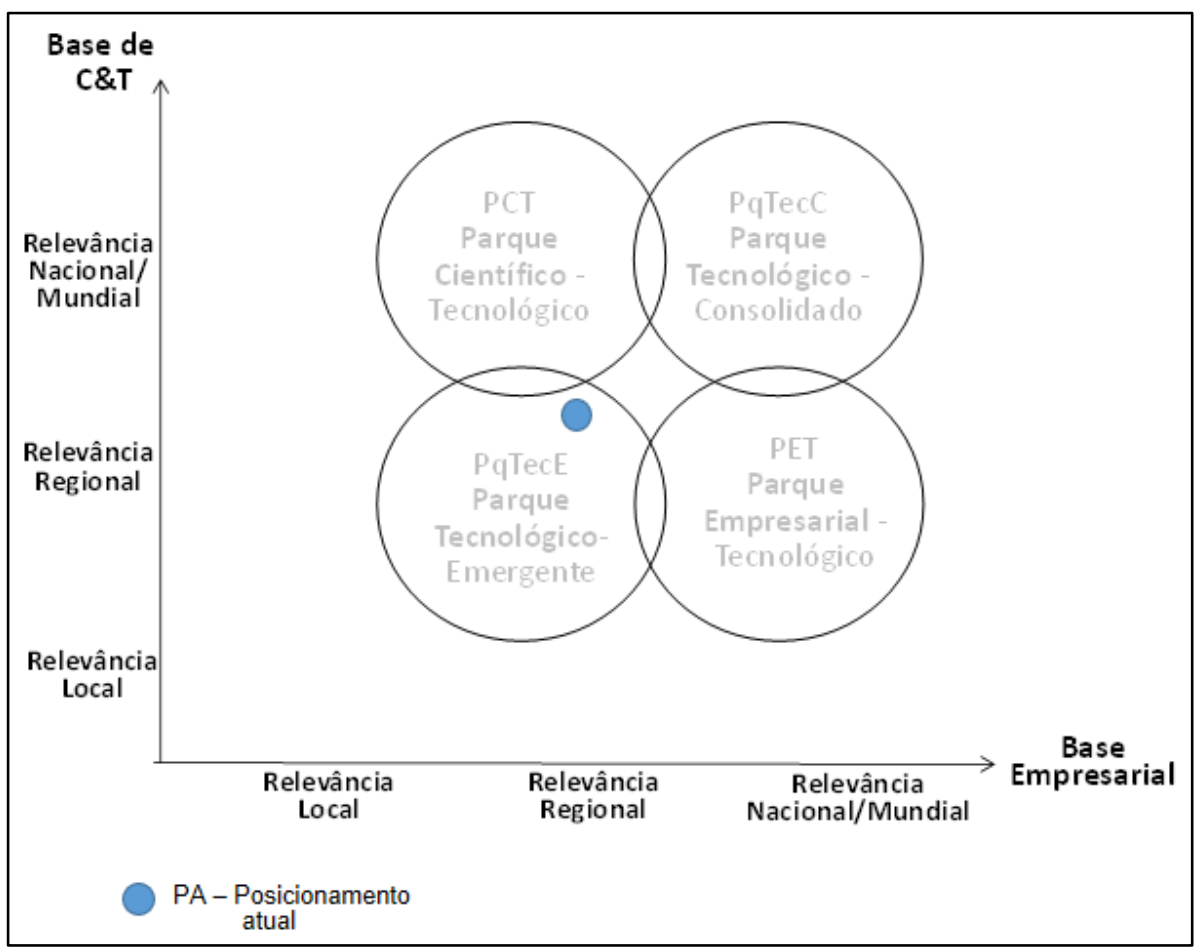

Figura 5.20 - Posicionamento atual do ParqTec FB na taxonomia Anprotec

Fonte: Elaboração própria a partir dos resultados das duas Oficinas realizadas durante o 1 Curso para Gestores de Parques Tecnológicos e Ambientes de Inovação, oferecido pela UniAnprotec/Instituto Gênesis em 2016.

Para a base empresarial, são consideradas as: start-ups de base tecnológica, sobretudo as spin-offs dos laboratórios da universidade, os quais possuem atuação local e regional e a afiliação de pequenas e médias empresas de impacto regional.

Para a estratégia de crescimento do parque tecnológico no curto, médio e longo prazo, planeja-se para a base de C\&T instalação de instituições de C\&T no 
ecossistema do Parque, aumento do número de profissionais qualificados da região e migração de profissionais para o ambiente, portfólio crescente de interações academia-indústria e uma infraestrutura mais robusta para pesquisa com impacto global. Para uma evolução na base empresarial, atração expressiva de start-ups e PMEs de base tecnológica com atuação nacional e internacional (Figura 5.21).

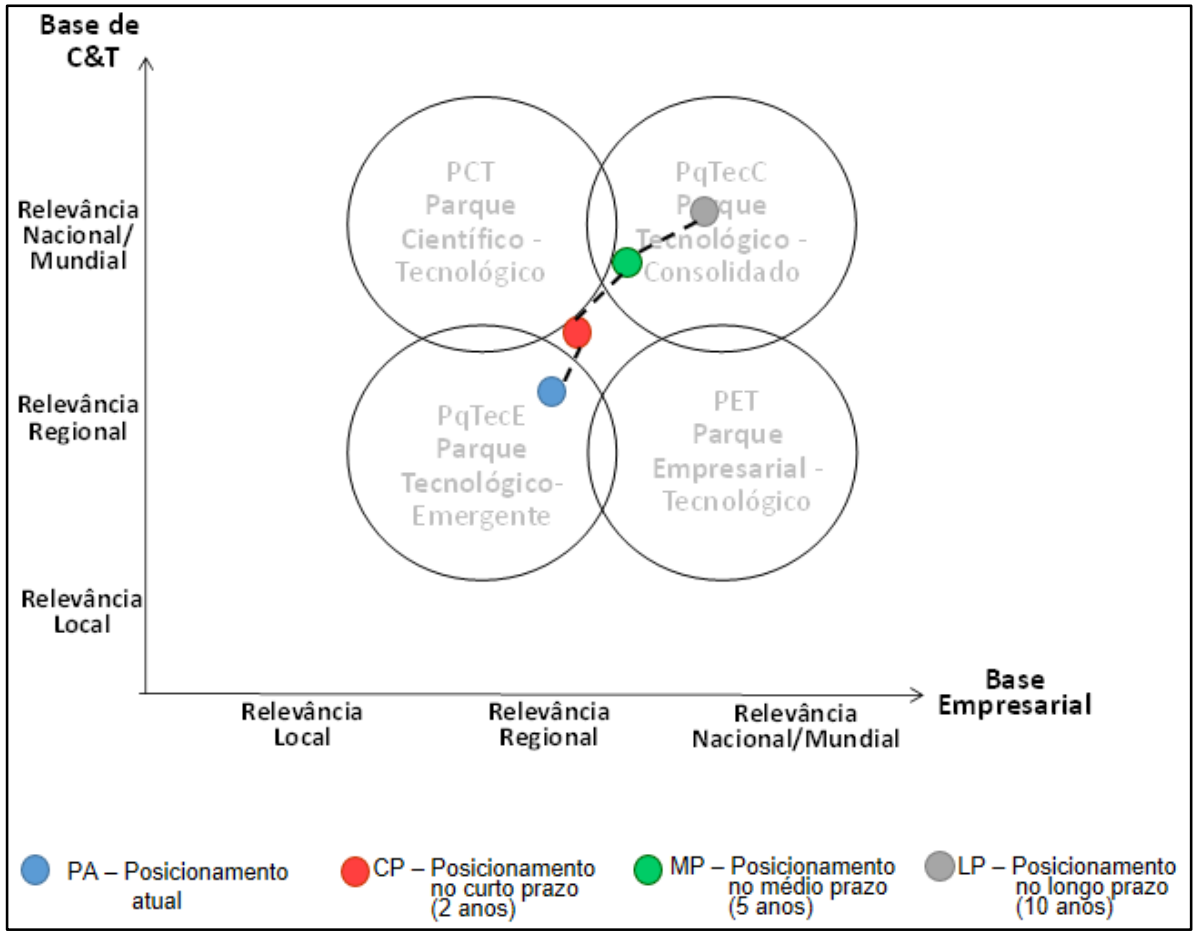

Figura 5.21 - Estratégia de crescimento do ParqTec FB: curto, médio e longo prazo

Fonte: Elaboração própria a partir dos resultados das duas Oficinas realizadas durante o $1^{\circ}$ Curso para Gestores de Parques Tecnológicos e Ambientes de Inovação, oferecido pela UniAnprotec/Instituto Gênesis em 2016.

\section{Quadro lógico e proposição de indicadores e métricas para monitoramento e avaliação de desempenho do Parque Tecnológico}

A construção do quadro lógico para a proposição de indicadores e métricas de monitoramento e avaliação de desempenho do ParqTec FB seguiu a orientação metodológica descrita no capítulo 4 (Quadro 5.10). 


\begin{tabular}{|c|c|c|c|c|}
\hline $\begin{array}{c}\text { Hierarquia } \\
\text { dos Objetivos }\end{array}$ & Objetivos & $\begin{array}{l}\text { Resultados Esperados } \\
\quad(C P, \text { MP e LP) }\end{array}$ & Indicadores & Métricas \\
\hline $\begin{array}{l}\text { Objetivo } \\
\text { Estratégico }\end{array}$ & $\begin{array}{l}\text { 1. Humanizar o Parque } \\
\text { Tecnológico, tornando } \\
\text { um ambiente de convívio } \\
\text { agradável }\end{array}$ & $\begin{array}{l}\text { Atração e retenção de talentos e recursos no } \\
\text { ambiente }\end{array}$ & & \\
\hline \multirow{3}{*}{$\begin{array}{l}\text { Objetivos de } \\
\text { Curto Prazo } \\
\text { ( } 2 \text { anos) }\end{array}$} & \multirow{3}{*}{$\begin{array}{l}\text { 1.1. Criar um espaço de } \\
\text { convívio com áreas } \\
\text { verdes, com opções de } \\
\text { alimentação e happy } \\
\text { hours }\end{array}$} & $\begin{array}{l}\text { 1.1a. Instalar restaurantes, bares e } \\
\text { lanchonetes }\end{array}$ & \multirow{3}{*}{$\begin{array}{l}\text { Aumento de empresas do ramo } \\
\text { alimentício instaladas no Parque; } \\
\text { Aumento das interações entre os } \\
\text { residentes; } \\
\text { Taxa de crescimento da } \\
\text { circulação de pessoas no Parque. }\end{array}$} & \multirow{3}{*}{$\begin{array}{l}\text { Número de estabelecimentos de alimentação } \\
\text { instalados anualmente. } \\
\text { Número de happy hours realizados pelo Parque no } \\
\text { ambiente informal de convívio; } \\
\text { Número de usuários do espaço informal por mês. }\end{array}$} \\
\hline & & $\begin{array}{l}\text { 1.1b. Destinar de uma área informal para } \\
\text { convívio dos residentes; }\end{array}$ & & \\
\hline & & $\begin{array}{l}\text { 1.1c. Aumentar a circulação de pessoas no } \\
\text { Parque. }\end{array}$ & & \\
\hline \multirow{2}{*}{$\begin{array}{l}\text { Objetivos de } \\
\text { Médio Prazo } \\
\text { ( } 5 \text { anos) }\end{array}$} & $\begin{array}{l}\text { 1.2. Promover ações } \\
\text { sustentáveis junto à } \\
\text { comunidade acadêmica e } \\
\text { às empresas; }\end{array}$ & $\begin{array}{l}\text { 1.2a. Implementar ações sustentáveis no } \\
\text { entorno com base no levantamento de ações } \\
\text { em andamento pela universidade e empresas; }\end{array}$ & \multirow[t]{2}{*}{$\begin{array}{l}\text { Taxa de implementação de boas } \\
\text { práticas; } \\
\text { Taxa de crescimento do convívio } \\
\text { social dentro do Parque. }\end{array}$} & \multirow{2}{*}{$\begin{array}{l}\text { Número de boas práticas mapeadas; } \\
\text { Número de boas práticas implementadas; } \\
\text { Número de atividades sociais promovidas pelo Parque; } \\
\text { Número de participantes em atividades organizadas } \\
\text { dentro do Parque. }\end{array}$} \\
\hline & $\begin{array}{l}\text { 1.3. Estabelecer } \\
\text { atividades de } \\
\text { entretenimento. }\end{array}$ & 1.3a. Realizar atividades de entretenimento. & & \\
\hline \multirow{3}{*}{$\begin{array}{l}\text { Objetivos de } \\
\text { Longo Prazo } \\
\text { (10 anos) }\end{array}$} & \multirow{3}{*}{$\begin{array}{l}\text { 1.4. Elaborar em conjunto } \\
\text { com residentes um plano } \\
\text { de sustentabilidade para } \\
\text { o ecossistema }\end{array}$} & $\begin{array}{l}\text { 1.4a. Criar de um ecossistema que favoreça a } \\
\text { sustentabilidade dos residentes e do entorno; }\end{array}$ & \multirow{3}{*}{$\begin{array}{l}\text { Taxa de sucesso na formação de } \\
\text { parcerias com universidade e } \\
\text { empresas na vertente da } \\
\text { sustentabilidade; } \\
\text { Percentual do impacto negativo } \\
\text { causado ao meio-ambiente; } \\
\text { Taxa de crescimento de empresas } \\
\text { certificadas no sistema B.. }\end{array}$} & \multirow{3}{*}{$\begin{array}{l}\text { Número de conversas, negociações em andamento e } \\
\text { parcerias formadas na esfera ambiental com } \\
\text { diferentes atores ( } 3 \text { métricas); } \\
\text { Número de ações adequadas e inadequadas segundo } \\
\text { regulamentação ambiental ( } 2 \text { métricas); } \\
\text { Número de empresas certificadas no sistema B; } \\
\text { Número de empresas sem certificação no sistema B. }\end{array}$} \\
\hline & & $\begin{array}{l}\text { 1.4b. Reduzir o impacto negativo causado } \\
\text { pelas empresas e pelo Parque ao meio } \\
\text { ambiente; }\end{array}$ & & \\
\hline & & $\begin{array}{l}\text { 1.4c. Estabelecer uma política de estímulo à } \\
\text { certificação das empresas no sistema B. }\end{array}$ & & \\
\hline
\end{tabular}




\begin{tabular}{|c|c|c|c|c|}
\hline $\begin{array}{l}\text { Hierarquia } \\
\text { dos Objetivos }\end{array}$ & Objetivos & $\begin{array}{c}\text { Resultados Esperados } \\
(\mathrm{CP}, \mathrm{MP} \text { e LP) }\end{array}$ & Indicadores & Métricas \\
\hline $\begin{array}{l}\text { Objetivo } \\
\text { Estratégico }\end{array}$ & $\begin{array}{l}\text { 2. Fortalecer o } \\
\text { ecossistema de inovação } \\
\text { aberta na região }\end{array}$ & $\begin{array}{l}\text { Atrair investimentos para inovação } \\
\text { tecnológica, visando a geração de riqueza e } \\
\text { bem-estar social }\end{array}$ & & \\
\hline \multirow[b]{2}{*}{$\begin{array}{l}\text { Objetivos de } \\
\text { Curto Prazo } \\
\text { ( } 2 \text { anos) }\end{array}$} & \multirow[t]{2}{*}{$\begin{array}{l}\text { 2.1. Estimular a inovação } \\
\text { dentro das empresas e do } \\
\text { Parque }\end{array}$} & $\begin{array}{l}\text { 2.1a. Aproximar com formação de parcerias } \\
\text { entre diferentes atores (residentes, } \\
\text { universidade e sistema S); }\end{array}$ & \multirow{2}{*}{$\begin{array}{l}\text { Taxa de crescimento de } \\
\text { negociações e parcerias } \\
\text { realizadas entre residentes; } \\
\text { Quantidade de projetos de } \\
\text { inovação implantados; } \\
\text { Quantidade de experimentos } \\
\text { atraídos para teste no Parque. }\end{array}$} & \multirow{2}{*}{$\begin{array}{l}\text { Número de negociações realizadas entre residentes; } \\
\text { Número de parcerias firmadas entre residentes; } \\
\text { Número de experimentos inovadores implementados } \\
\text { no Parque. }\end{array}$} \\
\hline & & $\begin{array}{l}\text { 2.1b. Atrair novos experimentos para teste no } \\
\text { Parque - living lab }\end{array}$ & & \\
\hline \multirow{2}{*}{$\begin{array}{l}\text { Objetivos de } \\
\text { Médio Prazo } \\
\text { ( } 5 \text { anos) }\end{array}$} & \multirow{2}{*}{$\begin{array}{l}\text { 2.2. Estabelecer parcerias } \\
\text { com outras } \\
\text { universidades, ICTs, } \\
\text { fundos de VC e outras } \\
\text { empresas de base } \\
\text { tecnológica e/ou } \\
\text { interessadas na atividade } \\
\text { de PD\&I }\end{array}$} & $\begin{array}{l}\text { 2.2a. -Aumentar as parcerias com atores } \\
\text { relevantes no ecossistema de inovação; }\end{array}$ & \multirow{2}{*}{$\begin{array}{l}\text { Taxa de formação de novas } \\
\text { parcerias com stakeholders; } \\
\text { Taxa de sucesso da cooperação } \\
\text { entre residentes e universidades; } \\
\text { Taxa de crescimento dos } \\
\text { investimentos em projetos de } \\
\text { PD\&I. }\end{array}$} & $\begin{array}{l}\text { Número de convênios/acordos com outras } \\
\text { instituições; } \\
\text { Número de conversas com stakeholders; } \\
\text { Número de projetos em fase de execução na área de } \\
\text { PD\&l; }\end{array}$ \\
\hline & & $\begin{array}{l}\text { 2.2b. Aumentar as práticas de inovação aberta } \\
\text { entre empresas residentes e universidades }\end{array}$ & & $\begin{array}{l}\text { Numero de projetos de cooperaçao realizados entre } \\
\text { residentes e universidades; } \\
\text { Número de projetos de cooperação realizados } \\
\text { satisfatoriamente em parceria; } \\
\text { Quantidade de recursos alocados em projetos de } \\
\text { P,D\&l por ano. }\end{array}$ \\
\hline $\begin{array}{l}\text { Objetivos de } \\
\text { Longo Prazo } \\
\text { (10 anos) }\end{array}$ & $\begin{array}{l}\text { 1.4. Fortalecer a inovação } \\
\text { aberta na região, nas } \\
\text { empresas e no Parque }\end{array}$ & $\begin{array}{l}\text { 1.4a. - Prática de inovação aberta } \\
\text { estruturada, consistente e sistemática que } \\
\text { acolha as soluções da população, dos } \\
\text { colaboradores e de agentes externos }\end{array}$ & $\begin{array}{l}\text { Taxa de execução de ações de } \\
\text { inovação aberta sistematizadas }\end{array}$ & $\begin{array}{l}\text { Número de soluções levantadas sistematizadas; } \\
\text { Número de soluções sistematizadas convertidas em } \\
\text { ações dentro do ecossistema do Parque. }\end{array}$ \\
\hline
\end{tabular}




\begin{tabular}{|c|c|c|c|c|}
\hline $\begin{array}{l}\text { Hierarquia } \\
\text { dos Objetivos }\end{array}$ & Objetivos & $\begin{array}{l}\text { Resultados Esperados } \\
\text { (CP, MP e LP) }\end{array}$ & Indicadores & Métricas \\
\hline $\begin{array}{l}\text { Objetivo } \\
\text { Estratégico }\end{array}$ & $\begin{array}{l}\text { 3. Gerar e fortalecer } \\
\text { negócios de base } \\
\text { tecnológica de diferentes } \\
\text { portes de modo a } \\
\text { balancear o ecossistema }\end{array}$ & $\begin{array}{l}\text { Ecossistema equilibrado com diversidade de } \\
\text { negócios de diferentes portes }\end{array}$ & & \\
\hline $\begin{array}{l}\text { Objetivos de } \\
\text { Curto Prazo } \\
\text { ( } 2 \text { anos) }\end{array}$ & $\begin{array}{l}\text { 3.1. Fortalecer a } \\
\text { Incubadora }\end{array}$ & $\begin{array}{l}\text { 3.1a. Aumento da quantidade de empresas na } \\
\text { Incubadora e estruturação do modelo de } \\
\text { gestão da Incubadora }\end{array}$ & $\begin{array}{l}\text { Número de novos negócios } \\
\text { gerados a partir da Incubadora; } \\
\text { Faturamento das empresas } \\
\text { incubadas instaladas. }\end{array}$ & $\begin{array}{l}\text { Número de empresas incubadas; } \\
\text { Número de empresas graduadas } \\
\text { Número de projetos em fase de execução na área de } \\
\text { PD\&l; } \\
\text { Número de empresas inscritas no processo seletivo } \\
\text { para incubação; } \\
\text { Número de seleções para incubação; } \\
\text { Número de instrumentos normativos. }\end{array}$ \\
\hline \multirow{3}{*}{$\begin{array}{l}\text { Objetivos de } \\
\text { Médio Prazo } \\
\text { (5 anos) }\end{array}$} & $\begin{array}{l}\text { 3.2. Atrair empresas } \\
\text { multinacionais/âncoras; }\end{array}$ & 3.2a. Instalação de empresas multinacionais; & \multirow{3}{*}{$\begin{array}{l}\text { Faturamento das empresas } \\
\text { instaladas no Parque; } \\
\text { Taxa de ocupação do Parque; } \\
\text { Quantidade de pesquisadores e } \\
\text { laboratórios que desenvolvem } \\
\text { P\&D. }\end{array}$} & \multirow{3}{*}{$\begin{array}{l}\text { Percentual de ocupação de residentes; } \\
\text { Percentual de ocupação por pequenas e médias } \\
\text { empresas; } \\
\text { Percentual de ocupação por Grandes empresas; } \\
\text { Percentual de ocupação por ICTs; } \\
\text { Número de empregos altamente qualificados gerados } \\
\text { no Parque. }\end{array}$} \\
\hline & $\begin{array}{l}\text { 3.3. Atrair Centros de } \\
\text { Pesquisa (ICTs); }\end{array}$ & 3.3a. Instalação de e ICTs no Parque & & \\
\hline & $\begin{array}{l}\text { 3.4. Criar regras que } \\
\text { estimulem pesquisadores } \\
\text { a desenvolver } P \& D\end{array}$ & $\begin{array}{l}\text { 3.4a Criação de instrumentos reguladores e de } \\
\text { estímulo para inserção de pesquisadores das } \\
\text { empresas. }\end{array}$ & & \\
\hline \multirow{2}{*}{$\begin{array}{l}\text { Objetivos de } \\
\text { Longo Prazo } \\
\text { (10 anos) }\end{array}$} & \multirow[t]{2}{*}{$\begin{array}{l}\text { 3.5. Estimular P,D\&I e } \\
\text { transferência de } \\
\text { tecnologia (TT) }\end{array}$} & \multirow{2}{*}{$\begin{array}{l}\text { 3.5a. Aumento do número de empresas } \\
\text { nascentes e maduras, de ICTs, spin-offs e de } \\
\text { laboratórios no Parque; } \\
\text { 3.5b. Fortalecimento das ações do escritório } \\
\text { de transferência de tecnologia junto aos } \\
\text { residentes e às universidades parceiras }\end{array}$} & \multirow{2}{*}{$\begin{array}{l}\text { Taxa de licenciamento de } \\
\text { patentes; } \\
\text { Taxa de projetos de pesquisa que } \\
\text { são de Inovação (especialmente } \\
\text { os de cooperação com indústria); } \\
\text { Taxa de crescimento do } \\
\text { atendimento do escritório de } \\
\text { transferência tecnológica }\end{array}$} & $\begin{array}{l}\text { Número de depósitos de Pl; } \\
\text { Número de licenças concedidas; } \\
\text { Número de projetos de cooperação entre empresas e } \\
\text { universidade; }\end{array}$ \\
\hline & & & & $\begin{array}{l}\text { Número de consultas ao escritório de TT por } \\
\text { residentes e universidade por ano. }\end{array}$ \\
\hline
\end{tabular}




\begin{tabular}{|c|c|c|c|c|}
\hline $\begin{array}{l}\text { Hierarquia } \\
\text { dos Objetivos }\end{array}$ & Objetivos & $\begin{array}{l}\text { Resultados Esperados } \\
\text { (CP, MP e LP) }\end{array}$ & Indicadores & Métricas \\
\hline $\begin{array}{l}\text { Objetivo } \\
\text { Estratégico }\end{array}$ & $\begin{array}{l}\text { 4. Liderar ações de } \\
\text { empreendedorismo e } \\
\text { inovação }\end{array}$ & $\begin{array}{l}\text { Protagonismo em iniciativas de } \\
\text { empreendedorismo e inovação na região }\end{array}$ & & \\
\hline $\begin{array}{l}\text { Objetivos de } \\
\text { Curto Prazo } \\
\text { (2 anos) }\end{array}$ & $\begin{array}{l}\text { 4.1. Desenvolver e apoiar } \\
\text { ações de } \\
\text { empreendedorismo e } \\
\text { inovação com parceiros } \\
\text { chave }\end{array}$ & $\begin{array}{l}\text { 4.1a. Estruturação e implementação de ações } \\
\text { de sensibilização }\end{array}$ & $\begin{array}{l}\text { Taxa de pessoas sensibilizadas } \\
\text { que entraram no ambiente do } \\
\text { Parque }\end{array}$ & $\begin{array}{l}\text { Número de pessoas sensibilizadas } \\
\text { Número de empreendedores incubados }\end{array}$ \\
\hline \multirow{4}{*}{$\begin{array}{l}\text { Objetivos de } \\
\text { Médio Prazo } \\
\text { ( } 5 \text { anos) }\end{array}$} & \multirow{2}{*}{$\begin{array}{l}\text { 4.2. Estimular a cultura } \\
\text { empreendedora dentro } \\
\text { da Universidade } \\
\text { (disciplinas, concursos, } \\
\text { hackatons); }\end{array}$} & $\begin{array}{l}\text { 4.2a. Elaboração e implementação de uma } \\
\text { estrutura curricular transversal de educação } \\
\text { empreendedora na Universidade; }\end{array}$ & \multirow{4}{*}{$\begin{array}{l}\text { Quantidade de disciplinas de } \\
\text { empreendedorismo e inovação } \\
\text { na Universidade; } \\
\text { Quantidade de eventos de } \\
\text { aproximação discentes- } \\
\text { empresas; } \\
\text { Quantidade de problemas } \\
\text { resolvidos das grandes empresas; } \\
\text { Taxa de adesão de residentes aos } \\
\text { desafios }\end{array}$} & \multirow{4}{*}{$\begin{array}{l}\text { Número de matrículas nas disciplinas; } \\
\text { Número de participantes (residentes) nos desafios; } \\
\text { Número de desafios lançados para resolução de } \\
\text { problemas de grandes empresas }\end{array}$} \\
\hline & & $\begin{array}{l}\text { 4.2b. Aproximação do corpo discente com } \\
\text { residentes }\end{array}$ & & \\
\hline & \multirow{2}{*}{$\begin{array}{l}\text { 4.3. Promover desafios } \\
\text { com o objetivo de } \\
\text { expandir a prática de } \\
\text { inovação aberta }\end{array}$} & $\begin{array}{l}\text { 4.3a. Aproximação do parque com empresas } \\
\text { de grande porte }\end{array}$ & & \\
\hline & & $\begin{array}{l}\text { 4.3b. Interação entre PMEs e grandes } \\
\text { empresas }\end{array}$ & & \\
\hline \multirow[t]{2}{*}{$\begin{array}{l}\text { Objetivos de } \\
\text { Longo Prazo } \\
\text { (10 anos) }\end{array}$} & \multirow{2}{*}{$\begin{array}{l}\text { 4.4. Articular com } \\
\text { stakeholders que estejam } \\
\text { interessados em liderar } \\
\text { junto ao parque ações de } \\
\text { empreendedorismo e } \\
\text { inovação }\end{array}$} & $\begin{array}{l}\text { 4.4a. Desenvolvimento e execução de ações } \\
\text { conjuntas com stakeholders; }\end{array}$ & \multirow[t]{2}{*}{$\begin{array}{l}\text { Quantidade de ações conjuntas } \\
\text { de empreendedorismo e } \\
\text { inovação } \\
\text { Taxa de crescimento dos } \\
\text { negócios entre as empresas }\end{array}$} & \multirow[t]{2}{*}{ Número de negócios efetivados } \\
\hline & & $\begin{array}{l}\text { 4.4b. Geração de negócios entre empresas de } \\
\text { diferentes portes }\end{array}$ & & \\
\hline
\end{tabular}

Fonte: Elaboração própria a partir dos resultados das duas Oficinas realizadas durante o 1 Curso para Gestores de Parques Tecnológicos e Ambientes de Inovação, oferecido pela Uni-Anprotec/Instituto Gênesis em 2016. 


\section{4 \\ Discussão integrada dos resultados e conclusões do estudo empírico}

A Figura 5.22 mostra as análises dos perfis estratégicos atuais dos Parques Tecnológicos abordados no estudo empírico, utilizando-se a ferramenta 'Estrategigrama'.

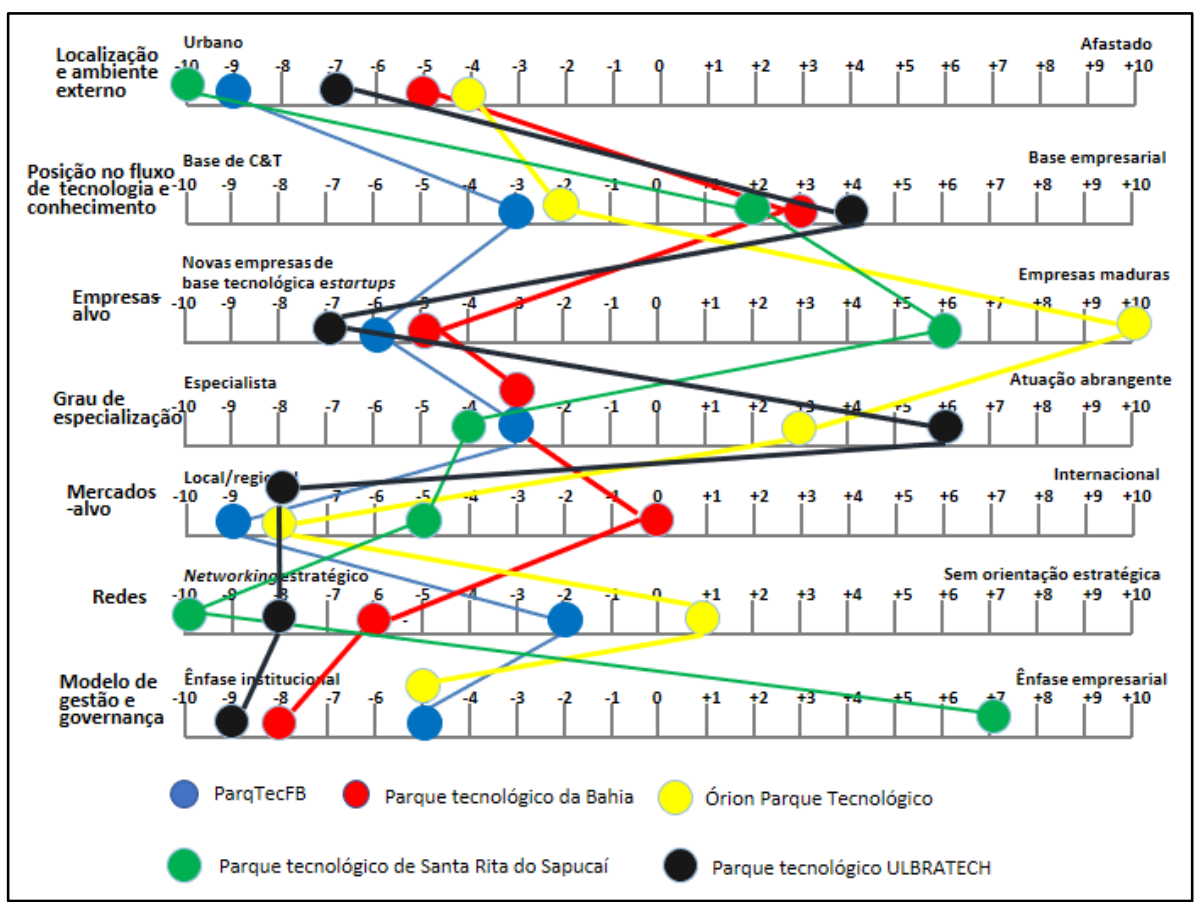

Figura 5.22 - Perfis estratégicos atuais dos Parques Tecnológicos: visão comparativa

Fonte: Elaboração própria a partir dos resultados das duas Oficinas realizadas durante o 1 Curso para Gestores de Parques Tecnológicos e Ambientes de Inovação, oferecido pela UniAnprotec/Instituto Gênesis em 2016.

Conforme descrito no tópico 2.1, os parques tecnológicos brasileiros estão geralmente localizados em centros urbanos ou em suas proximidades (Fernandes, 2014). Os parques tecnológicos objetos deste estudo não são exceção, tendo como fator nevrálgico do empreendimento o desenvolvimento local.

O Parques Tecnológico Ulbratech, apresenta um posicionamento atual no fluxo de tecnologia e conhecimento de base empresarial, porém os parques Bahia, Santa Rita do Sapucaí, Órion e ParqTec FB apresentam focos iniciais um pouco mais equilibrados entre base empresarial e C\&T. No entanto, os 5 parques tecnológicos apresentam projetos de incentivos para um equilíbrio quase total em seu posicionamento no fluxo de tecnologia e conhecimento. 
A cidade de Santa Rita do Sapucaí, MG, conforme mencionado anteriormente, é um polo eletroeletrônico estabelecido no Brasil, possuindo empresas maduras dessa área de atuação. O Órion Parque Tecnológico, em sua fase de implantação, também possui empresas maduras afiliadas ao empreendimento, sendo o ParqTec FB, Bahia e Ulbratech estabeleceram maior presença de start-ups e novas empresas inovadoras de pequeno porte.

Com relação ao grau de especialização das atividades das empresas residentes dos parques tecnológicos, Ulbratech e Órion apresentam uma atuação mais abrangente em suas áreas de atuação no mercado, porém planejam reduzir seu nível de atuação, concentrando seus esforços em um número mais reduzido de 'setores do mercado, buscando grau de excelência nos mesmos.

Dentro do eixo mercado alvo, atualmente, o Parque Tecnológico da Bahia é o único dos projetos aqui apresentados que atua em ambientes nacionais e internacionais. Os demais parques concentram suas atividades no mercado local e/ou regional.

O parque tecnológico de Santa Rita do Sapucaí destaca-se pelo seu sistema de redes já estabelecido, sendo estratégico para o networking entre os stakeholders, clientes, empresas e laboratórios pesquisa afiliados. Os demais parques estabeleceram programas de fortalecimento do networking, destacando-se o parque Órion, em que apresenta como um dos seus objetivos específicos a criação de redes de colaboração entre as empresas residentes e afiliados.

Por tratar-se de um parque, cujo projeto iniciou-se a partir de uma iniciativa de um sindicato local, Santa Rita de Sapucaí possui maior ênfase empresarial entre os demais parques do estudo empírico, sendo o modelo de gestão destes preferencialmente ênfase institucional.

Apesar de várias similaridades entre os parques tecnológicos dos estudos de caso, podem-se verificar divergências em atuação de mercado, governança, formação de rede, estratégias de operação e stakeholders, o que pode dificultar a utilização de um dos modelos de monitoramento e avaliação de desempenho apresentados na revisão da literatura, os quais não consideram a identidade do parque como parte nevrálgica para sua gestão (missão, visão de futuro, modelo de negócios e perfil estratégico). Utilizando a abordagem da gestão adaptativa, a 
equipe gestora do parque tecnológico pode dispor de um modelo que considere essas diferenças, possibilitando a revisão das suas estratégias ao longo do tempo.

A Figura 5.23 mostra as estratégias de crescimento dos Parques Tecnológicos abordados no estudo empírico, considerando-se horizontes de curto, médio e longo prazo. Pode-se observar a existência de aproximações nas estratégias de crescimento dos Parques Tecnológicos em foco, em função das estratégias adotadas pelos mesmos para alcançar relevância nacional e/ou mundial em suas bases de C\&T e Empresarial, melhorando assim sua competitividade dentro do mercado (Parque tecnológico Consolidado).

Os parques tecnológicos apresentados nesta dissertação atuam como fortes promotores de desenvolvimento socioeconômico, sendo os planejamentos desses parques associados a um processo de desenvolvimento e fortalecimento econômico e tecnológico regional. Uma característica de parques tecnológicos de terceira geração (Anprotec, 2008a). Esse fator justifica a tendência de internacionalização dos parques objetos de estudo. 


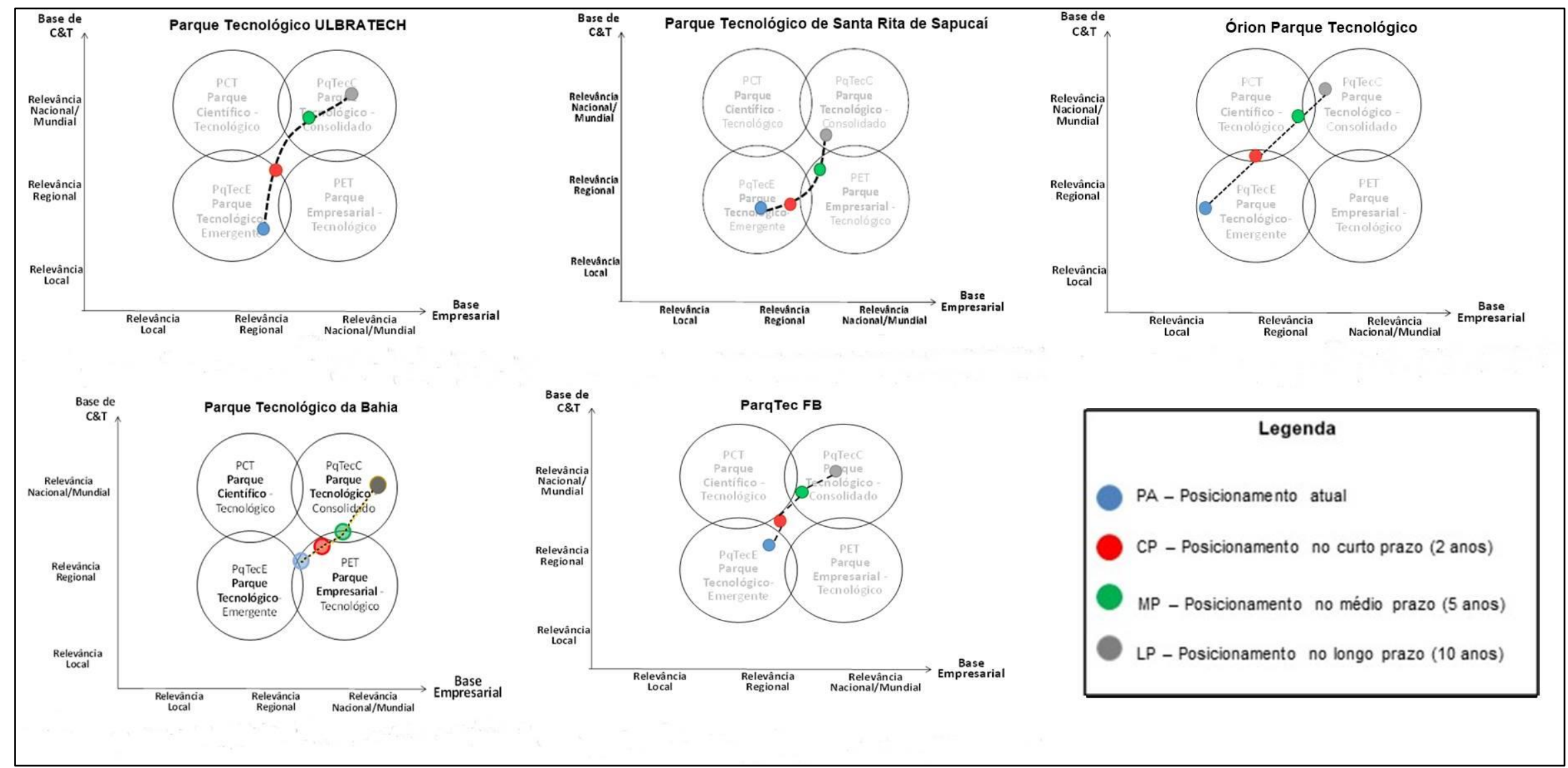

Figura 5.23 - Estratégias de crescimento dos Parques Tecnológicos: curto, médio e longo prazo

Fonte: Elaboração própria a partir dos resultados das duas Oficinas realizadas durante o 1ํ Curso para Gestores de Parques Tecnológicos e Ambientes de Inovação, oferecido pela Uni-Anprotec/Instituto Gênesis em 2016. 
O Quadro 5.11 compara os estágios de desenvolvimento de cada parque estudado, segundo a classificação Anprotec.

Quadro 5.11 - Estágio de desenvolvimento dos parques tecnológicos

\begin{tabular}{|l|l|}
\hline \multicolumn{1}{|c|}{ Parque Tecnológico } & \multicolumn{1}{c|}{ Estágio de Desenvolvimento } \\
\hline ULBRATECH & Em operação \\
\hline Santa Rita do Sapucaí & Em planejamento \\
\hline Órion & Em implantação \\
\hline Bahia & Em implantação \\
\hline ParqTec FB (fictício) & Em planejamento \\
\hline
\end{tabular}

Fonte: Elaboração própria.

Considerando-se os diferentes estágios de desenvolvimento (somente um Parque encontra-se em operação) e os objetivos estratégicos definidos para cada horizonte temporal (curto, médio e longo prazo), observou-se uma certa homogeneidade de articulação das entidades gestoras dos Parques, de maneira que os empreendimentos estejam preparados para formarem parcerias em nível internacional, assim como desenvolverem estratégias de crescimento alinhadas às expectativas de seus stakeholders.

Tendo as direções para promoção do crescimento dos parques tecnológicos do presente estudo empírico traçadas dentro dos horizontes de tempo do CP, MP e LP, a escolha de um modelo de monitoramento e avaliação de desempenho seguindo a abordagem da gestão adaptativa segue-se viável. Os empreendimentos em estágios de desenvolvimento distintos apresentam propriedades apresentadas no capítulo 4, em que os atores diretamente relacionados aos parques tecnológicos estão envolvidos no monitoramento e avaliação de desempenho, seguindo uma metodologia de aprendizado e autorregulação do processo, sendo o mesmo flexível o suficiente para atender a todos os modelos de parques tecnológicos.

A Figura 5.21 mostra os perfis estratégicos dos Parques Tecnológicos, no longo prazo (10 anos), definido com o uso da ferramenta 'Estrategigrama', da IASP. 


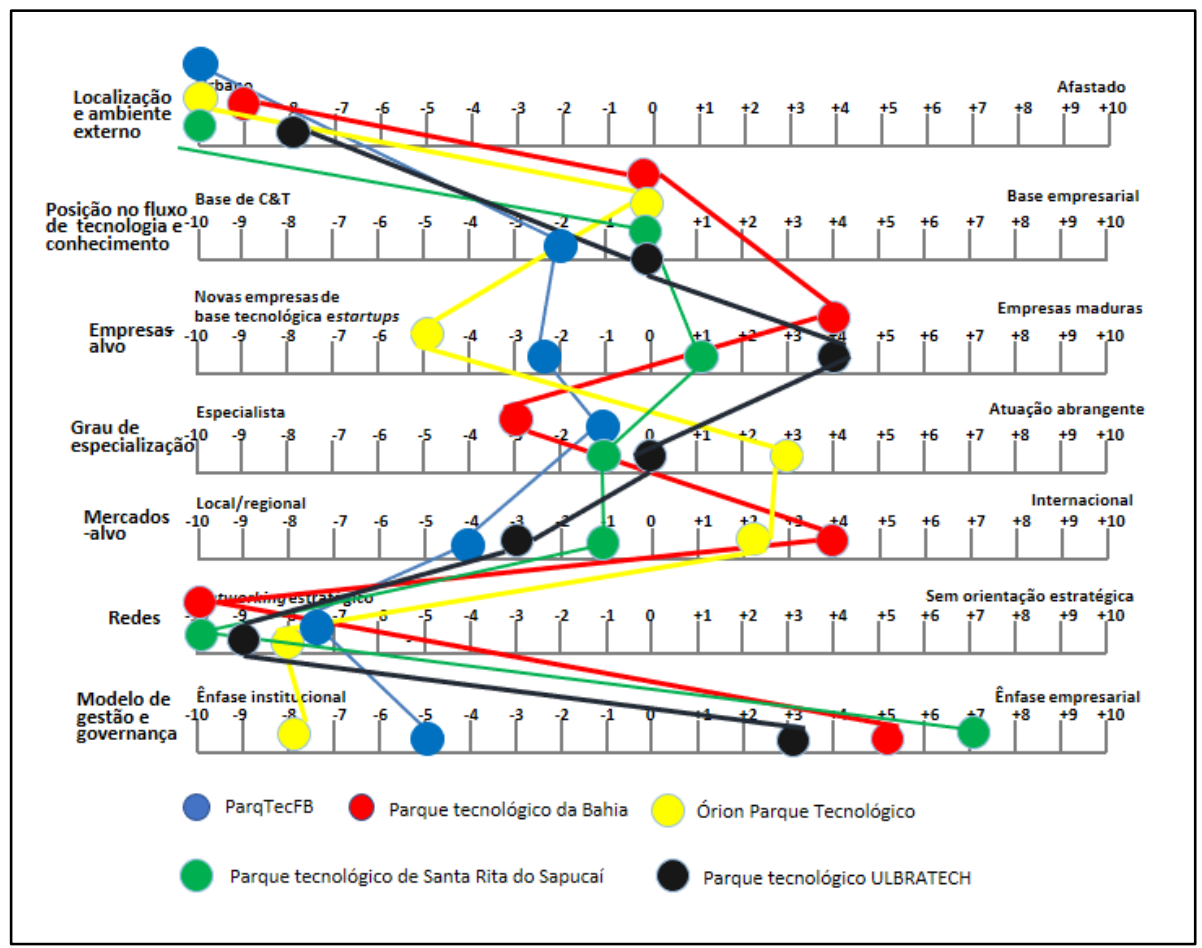

Figura 5.24 - Perfis estratégicos dos Parques Tecnológicos no longo prazo (10 anos)

Fonte: Elaboração própria a partir dos resultados das duas Oficinas realizadas durante o $1^{\circ}$ Curso para Gestores de Parques Tecnológicos e Ambientes de Inovação, oferecido pela UniAnprotec/Instituto Gênesis em 2016.

É possível visualizar a homogeneidade do perfil estratégico dos parques tecnológicos através da figura 5.21. Seguindo o planejamento estratégico de longo prazo (horizonte de 10 anos), os parques tecnológicos possuem como foco a melhoria e desenvolvimento urbano, equilíbrio entre o fluxo de transferência de tecnologia e conhecimento nas bases de C\&T e Empresarial, limite nas quantidades de área de atuação, com foco na excelência das mesmas em suas instituições de ensino e laboratórios de PD\&I e CT\&I, maior internacionalização do mercado alvo e a presença de um forte networking estratégico.

Conforme comentado anteriormente, muitos parques tecnológicos nacionais têm como missão a promoção do desenvolvimento local ou regional pelo estímulo à geração de inovações em determinados contexto socioprodutivos. Esse aspecto pode explicar a tendência da convergência observada nos perfis estratégicos dos parques abordados no longo prazo.

A classificação dos Parques em agrupamentos, segundo a taxonomia Anprotec, e a construção dos respectivos quadros lógicos permitiram aos gestores dos Parques propor e selecionar indicadores e métricas de desempenho adequados 
para monitorar os planos de ação e avaliar os resultados e impactos dos processos e inciativas dos respectivos empreendimentos, como mostrado nos Quadros 5.2, 5.4. 5.6, 5.8 e 5.10 .

Ao analisar os quadros lógicos dos cinco parques tecnológicos, observam-se indicadores comuns, como ilustrado a seguir:

- Indicadores que mostrem o nível de atração de clientes com a intenção de ocupar o parque tecnológico de maneira plena;

- Indicadores que representem o número e/ou taxa de crescimento de empresas de base tecnológica e startups;

- Indicadores para o número de novos empreendimentos, projetos e negócios;

- Indicadores para o faturamento das empresas residentes e/ou clientes;

- Indicadores para quantidade de patentes e pesquisas;

- Indicadores para a quantidade de projetos integrados com empresas, indústrias, universidades ou laboratórios de pesquisa;

- Indicadores que representem a quantidade de transferência de tecnologia e conhecimento entre as organizações afiliadas;

- Indicadores demonstrando o número de empregos gerados pelo parque. 


\section{6 \\ Conclusões e recomendações}

A presente pesquisa contribuiu para o avanço do conhecimento sobre gestão de parques tecnológicos, mais especificamente sobre o tema monitoramento e avaliação do desempenho de parques tecnológicos, de modo a permitir aos gestores definir indicadores e métricas de desempenho, em função de perfis estratégicos e modelos de negócios comuns a determinados agrupamentos de parques, e adaptar-se a possíveis mudanças do ambiente externo e interno desses empreendimentos.

Nesse sentido, um modelo conceitual foi desenvolvido, tendo como principal abordagem metodológica a gestão adaptativa, integrada a ferramentas de gestão aplicáveis aos contextos institucionais dos parques tecnológicos, como o 'Estrategigrama' proposto pela IASP, o Business Model Generation, também conhecido como Canvas; a taxonomia da Anprotec para classificação dos parques tecnológicos brasileiros (Anprotec, 2008); e a construção do quadro lógico para a definição de indicadores e métricas do desempenho dos parques a serem avaliados. Essas características metodológicas conferiram ao modelo diferenciais em relação às práticas e modelos de monitoramento e avaliação de desempenho de parques reportados na literatura.

Os resultados obtidos ao longo da pesquisa aqui relatada permitiram que o objetivo geral da dissertação fosse alcançado. Foi possível, com o uso do modelo proposto, definir na prática diferentes conjuntos de indicadores e métricas associados a objetivos estratégicos de curto, médio e longo prazos de cinco parques tecnológicos selecionados pelos participantes do $1^{\circ}$ Curso para Gestores de Parques Tecnológicos e Ambientes de Inovação, oferecido pela Uni-Anprotec/Instituto Gênesis em 2016.

Os marcos conceituais e metodológicos discutidos nos capítulos 2 e 3 fundamentaram o desenvolvimento do modelo de monitoramento e avaliação do desempenho de parques tecnológicos, contribuindo de forma significativa para que os objetivos específicos da dissertação fossem alcançados. Particularmente, a partir da pesquisa bibliográfica e documental, foi possível identificar modelos e ferramentas de 
monitoramento e avaliação de desempenho de parques tecnológicos, reportados em estudos empíricos, tendo sido observada uma tendência no uso de determinadas ferramentas, como o Balanced Scorecard adaptado para o contexto organizacional de parques tecnológicos. Esta revisão permitiu identificar lacunas na literatura, que apontaram para a oportunidade de se adotar na modelagem objeto desta dissertação a abordagem de gestão adaptativa, juntamente com ferramentas de gestão aplicáveis em ambientes interorganizacionais, que caracterizam os parques tecnológicos.

Pelos aspectos descritos e resultados gerados na fase aplicada da pesquisa, considera-se que eles propiciaram, em um primeiro nível, o ferramental adequado para que os gestores de parques que participaram do $1^{\circ}$ Curso para Gestores de Parques Tecnológicos e Ambientes de Inovação, possam monitorar e avaliar o desempenho de seus parques efetivamente, revisando de forma sistemática as metas e indicadores, conforme as características da abordagem de gestão adaptativa, apesentadas no início do capítulo 4.

O estudo empírico desenvolvido durante a realização do $1^{\circ}$ Curso para Gestores de Parques Tecnológicos e Ambientes de Inovação permitiu demonstrar a aplicabilidade do modelo proposto, com resultados relevantes para cada um dos cinco parques selecionados pelos grupos, que se formaram durante as duas Oficinas de Trabalho.

Destacam-se os aspectos inovadores do modelo baseado na abordagem de gestão adaptativa, a saber: (i) permite aos gestores medir e comparar o desempenho de parques tecnológicos pertencentes a um determinado agrupamento, para então priorizar ações no nível de cada parque, que venham agregar valor aos seus stakeholders; (ii) considera as diferenças de modelos de negócios de parques tecnológicos, distintas proposições de valor, objetivos e metas, estágios de desenvolvimento, bem como estruturas de governança; (iii) permite estabelecer um equilíbrio adequado entre o uso de métodos centrados em métricas quantitativas e aqueles que enfatizam aspectos normativos da gestão estratégica dos parques; (iv) possui propriedades que propiciam a administração da incerteza, da complexidade e da interdependência entre atribuições dos diversos atores que integram os parques; e (v) permite um alinhamento ao referencial teórico de aprendizagem organizacional, como proposto por Argyris e Schon $(1978 ; 1996)$. 
Para trabalhos futuros de desdobramento da pesquisa e aprofundamento dos resultados, propõem-se:

- Explorar o uso de métodos multicritério de apoio à decisão na fase de proposição e escolha de indicadores e métricas de desempenho de parques tecnológicos;

- Desenvolver novas taxonomias de parques tecnológicos alternativamente às reportadas nesta dissertação, considerando as especificidades de países em desenvolvimento, economias emergentes e países desenvolvidos;

- Realizar novos estudos empíricos para aplicação do modelo proposto em outros parques do Brasil, buscando sua difusão e aperfeiçoamento contínuo;

- Divulgar os resultados desta pesquisa junto à International Association of Science Parks and Areas of Innovation (IASP) para a realização de estudos empíricos em parques tecnológicos membros desta Associação, na perspectiva de ampla difusão e aperfeiçoamento contínuo do modelo;

- Realizar projetos de pesquisa-ação, a partir dos resultados desta pesquisa, para analisar os ciclos de aprendizagem de ciclo simples e duplo e a implementação das fases subsequentes à de planejamento dos Parques abordados no estudo empírico. Esses projetos deveriam ser conduzidos no âmbito dos quatro casos reais de Parques Tecnológicos brasileiros, abordados no estudo empírico desta pesquisa. 


\section{Referências bibliográficas}

Allen, J. Third Generation Science Parks. Manchester Science Parks Ltd. 2007.

Almeida, M.F.L. Sustentabilidade corporativa, inovação tecnológica e planejamento adaptativo: dos princípios à ação. 2006. 225 p. Tese (Doutorado). Departamento de Engenharia Industrial. Pontifícia Universidade Católica do Rio de Janeiro. Rio de Janeiro, 2006.

Andreevna, M. A. The Balanced Scorecard for Estimation of Science and Technology Parks. World Applied Sciences Journal, v. 25, n. 5, p. 720-727, 2013.

Angle Technology Limited. Evaluation of the past \& future economic contribution of the UK Science Park Movement. UKSPA, Executive Summary, 2003.

Annerstedt, J. Science Parks and High Tech Clustering. In: International Handbook on Industrial Policy. Bianchi, P.; Labory, S. (Eds.), Edward Elgar Publishing, 2006.

Argyris, C.; Schön, D. A. Organizational Learning II: Theory, Method, and Practice. MA: Addison-Wesley, 1978.

Argyris, C.; Schön, D. A. Organizational Learning: A Theory of Action Perspective. MA: Addison-Wesley, 1996.

Associação Nacional de Entidades Promotoras de Empreendimentos de Tecnologias Avançadas. Anprotec. Parques Tecnológicos no Brasil - Estudo, Análise e Proposições. Brasília: Anprotec, 2008a. 24p.

Associação Nacional de Entidades Promotoras de Empreendimentos de Tecnologias Avançadas. Anprotec. Portfólio de parques tecnológicos do Brasil. Brasília: Anprotec, 2008b. 78p.

Associação Nacional de Entidades Promotoras de Empreendimentos de Tecnologias Avançadas. Anprotec. Definição de parques tecnológicos. 2016. Disponível em: <http://anprotec.org.br/site/menu/incubadoras-e-parques/>. Acesso em: 12 dez. 2016.

Bauman, Z. Comunidade: a busca por segurança no mundo atual. Rio de Janeiro: Jorge Zahar Editor, 2001. 
Bigliardi, B. et al. Assessing Science Parks' Performances: Directions from Selected Italian Case Studies. Technovation. v. 26, n. 4, p 489-505, 2006.

Brasil. Lei n. 13.243, de 11 de janeiro de 2016. Diário Oficial da União República Federativa do Brasil: Poder Executivo. Brasília, DF, 11/01/2016.

Cassiolato, M.; Gueresi, S. Como elaborar modelo lógico de programas: roteiro para formular programas e organizar avaliação. Nota Técnica, n.6. Brasília: IPEA, 2010.

Center for Mediterranean Integration (CMI). Developing Key Performance Indicators for STP's in the MENA Region. Summary report, Regional Workshop. Tunis, Tunisia. 2015.

Centro de Apoio ao Desenvolvimento Tecnológico. Ministério da Ciência, Tecnologia e Inovação (CDT/UnB). Estudo de projetos de alta complexidade: indicadores de parques tecnológicos. Brasília: CDT/UnB, 2014

Collarino, R. L. X. O papel dos parques tecnológicos no estímulo e criação de spin-offs acadêmicos. São Paulo, 2014. Dissertação de Mestrado - Centro de Ciência Exatas e de Tecnologia, Universidade Federal de São Carlos, 2014.

Dabrowska, J. Measuring the Success of Science Parks: Performance Monitoring and Evaluation. In: Proceedings of XXVIII IASP Conference on Science and Technology Parks, Kopenhagen, Denmark, 2011.

Escorsa, P.; Valls, J. A proposal for a Typology of Science parks, In: GUY, K. (Ed.) The Science Park Evaluation Handbook. Technopolis Group. European Innovation Monitoring System (EIMS), v. 61, p. 65-80, 1996.

Etzkowitz, H.; Leydesdorff, L. The dynamics of innovation: from national systems and "mode 2" to a triple helix of university-industry-government relations. Research Policy, n. 29, p. 109-123, 2000.

Etzkowitz, H.; Leydesdorff, L. The Triple helix university-industry-government relations: a laboratory for knowledge-based economic development. EASST Review, v. 14, n. 1, p. 14-19, 1995.

European Commission. The role of science parks in smart specialisation strategies. Brussels: European Commission, 2014.

Fernandes, S. C. R. F. Avaliação de parques tecnológicos: uma proposta de modelo para parques de $3^{\text {a }}$ geração. 2014. 154 p. Dissertação (Mestrado). Universidade Federal do Rio de janeiro. Rio de Janeiro, 2014.

Ferrara, M.; Lamperti, F.; Mavilia, R. Looking for the Best Performers: A Pilot Study Towards the Evaluation of Science Parks. Scientometrics, v. 106, n. 2, p 717-750, 2016. 
Ferreira, H.; Cassiolato, M.; Gonzalez, R. Uma experiência de desenvolvimento metodológico para avaliação de programas: o modelo lógico do Programa Segundo Tempo. Texto para discussão no 1.369. Brasília: Ipea, 2009.

Fundação Centros de Referência em Tecnologias Inovadoras. Fundação Certi. Inovação para competitividade da indústria. Disponível em: <http://www.certi.org.br/ > . Acesso em: 10 abr. 2017.

Alvarez, Miguel Domingo González. Processos de planejamento nos pólos tecnológicos: um enfoque adaptativo. 1997. 307 p. Tese (Doutorado). Departamento de Engenharia Industrial. Pontifícia Universidade Católica do Rio de Janeiro. Rio de Janeiro, 1997.

Governo do Estado de Minas Gerais. Tecnologia: Entenda por que Santa Rita do Sapucaí é uma potência tecnológica em Minas, 2015. Disponível em: < http://www.em.com.br/app/noticia/tecnologia/2015/06/22/interna_tecnologia,6605 61/potencia-tecnologica.shtml>. Acesso em: 10 abr. 2017.

Governo do Estado do Rio Grande do Sul. Secretaria Estadual de Desenvolvimento Econômico, Ciência e Tecnologia (SECT). Disponível em: < http://www.sdect.rs.gov.br/inicial >. Acesso em: 10 abr. 2017.

Guy, K. Designing a Science Park Evaluation, In: Guy, K. (Ed.) The Science Park Evaluation Handbook. Technopolis Group. European Innovation Monitoring System (EIMS), v. 61, p. 8-28, 1996.

Hemati, M.; Mardami, M. Designing a Performance Appraisal system based on Balanced Scorecard for Improving Productivity: Case Study in Semnan Technology and Science Park. Management Science Letters, v. 2, p. 1619-1630, 2012.

Hogan, B. Evaluation of Science and Technology Parks: The Measurement of 'Success', In: GUY, K. (Ed.) The Science Park Evaluation Handbook. Technopolis Group. European Innovation Monitoring System (EIMS), v. 61, p. 85-95, 1996.

Hu, A. G. Technology parks and regional economic growth in China. Research Policy, v. 36, n. August 2004, p. 76-87, 2007.

Imas, L. G. M.; Rist, R. C. The Road to Results: Designing and Conducting Effective Development Evaluations. World Bank, Washington, DC, 2009.

International Association of Science Parks and Areas of Innovation. IASP. 2016. IASP official definition for science parks. Disponível em: <http://www.iasp.ws/knowledge-bites>. Acesso em: 01 set. 2016

Jimenez-Zarco, A. I.; Cerdan-Chiscano, M. C.; Torrent-Sellens, J. Challenges and Opportunities in Science Parks' Management: design of a tool based on the 
analysis of resident companies. Rbgn-Revista Brasileira De Gestão De Negócios, v. 15, n. 48, p. 362-389, 2013.

Kaczmarska, B.; Gierulski, W. Technological Parks as an Element of Innovation Systems Infrastructure, In: Innovations in Management and Production Engineering, Oficyna Wydawnicza Polskiego Towarzystwa Zaradzania Produkja, p. 81-93, 2012.

Kaplan, R. S.; Norton, D. P. Strategy Maps: Converting Intangible Assets into Tangible Outcomes. Harvard Business School Press, 2004.

Kaplan, R. S.; Norton, D. P. The Balanced Scorecard: Translating Strategy into Action. Harvard Business School Press, 1996.

Kbar, G; Aly, S. Goal-based Key Performance Indicators of Science Parks' Effectiveness: A Case Study at Riyadh Techno-Valley. British Journal of Economics, Management \& Trade, v. 8, n. 3, p. 237-257, 2015.

Kusek, J. Z.; Rist, R. C. Ten Steps to a Results-Based Monitoring and Evaluation System. World Bank, Washington, DC, 2004.

Looy, A. V. et al. Choosing the right business process maturity model. Information and Management, v. 50, n. 7, p. 466-488, 2013.

Luger, M. I.; Goldstein, H. A. Technology in the Garden. Chapel Hill, UNC Press, 1991.

Lyra, R. M.; Almeida, M. F. L. Monitoring and evaluating the performance of science and technology parks: an action-research project. In: Proceedings of the $18^{\text {th }}$ International Conference of the Global Business and Technology Association, p. 248-260. Dubai: GBATA, 2016.

Magalhães, A. B. V. B.; Zouain, D. M. Serviços do conhecimento em Parques Científicos e Tecnológicos - incrementando a relação empresa-universidadecentros de pesquisa. In: Anais do Seminário Nacional de Parques Tecnológicos e Incubadoras de Empresas da Anprotec. 2009.

March, J. G. Exploration, and exploitation in organizational learning. Organizational Science, v.2, n.1, February 1991.

Marinazzo, M. Science Park Evaluation and Organizational Analysis, In: GUY, K. (Ed.) The Science Park Evaluation Handbook. Technopolis Group. European Innovation Monitoring System (EIMS), v. 61, p. 81-84, 1996.

Mazzarolo, C. F. Estratégia de apoio à inovação em tecnologias da informação no parque tecnológico Capital Digital. 2010, Dissertação (Mestrado em Engenharia Elétrica) - Universidade de Brasília, Brasília, 2010. 
McLaughlin, J.; Jordan, G. Using logic models. In: Wholley, J. Hatry, H. P. Newcomer, K. E. (Orgs.). Handbook of Practical Program Evaluation, 2ed. São Francisco: John Wiley \& Sons, 2004.

Melo, M. A. C. A pesquisa-ação e o processo de planejamento: uma perspectiva de aprendizado. In: Anais do Encontro Nacional de Engenharia de Produção, Florianópolis, SC, Brasil, 1985.

Melo, M. A. C. A dimensão interorganizacional do planejamento de C\&T: elementos para uma metodologia. In: Anais XI Simpósio Nacional de Pesquisa de Administração em Ciência e Tecnologia. PACTo- FEA/USP, p. 697-702. São Paulo. 1986.

Melo, M. A. C. Inovação e modernização tecnológica e organizacional nas MPME: o domínio interorganizacional. Setembro de 2002. Disponível em: <http:// www.ie.ufrj./redesist.>. Acesso em: 10 abr. 2017.

Melo, M.A.C.; Agostinho, M.C.E. Gestão adaptativa: uma proposta para o gerenciamento de redes de inovação. RAC, v. 11, n. 2, p. 93-111, 2007.

Ministério da Ciência, Tecnologia e Inovação. MCTI. Parques \& Incubadoras para o desenvolvimento do Brasil: estudo de práticas de parques tecnológicos e incubadoras de empresas. Brasília: MCTI, 2015.

Miranda, F. B. Da classificação de obras lexicográficas e seus problemas: proposta de uma taxonomia. Alfa: Revista de Linguística, v. 58, n. 1, p. 215-231, 2014.

Monck, C.; Peters, K. Science Parks as an Instrument of Regional Competitiveness: Measuring Success and Impact. In: Proceedings of XXVI IASP Conference on Science and Technology Parks, North Carolina, USA, 2009.

Nauwelaers, C.; Kleibrink, A.; Stancova, K. The role of science parks in smart specialisation strategies. S3 Policy Brief Series, No. 08/2014. European Commission, Joint Research Centre, Institute for prospective Technological Studies, Spain, 2014.

Nosratabadi, H. E.; Pourdarab, S.; Abbasian, M. Evaluation of science and technology parks by using fuzzy expert system. The Journal of Mathematics and Computer Science. v. 2, n. 4, p. 594-606, 2011.

Organisation for Economic Co-operation and Development (OECD). Glossary of Key Terms in Evaluation and Results Based Management. Disponível em: <https://www.oecd.org/dac/evaluation/2754804.pdf>. Acesso em: 10 abr. 2017.

Órion Parque Tecnológico. Tecnologia e Inovação na Serra Catarinense. Perfil institucional. Disponível em < http://www.orionparque.com/orion>. Acesso em: 10 abr. 2017. 
Ostewalder, A.; Pigneur, Y. Business Model Genearation - Inovação em Modelos de Negócios. Rio de Janeiro: Alta Books, 2011.

Parque Tecnológico da Bahia. Perfil institucional. Disponível em: < http://www.secti.ba.gov.br/parque/institucional/parque-tecnologico-da-bahia/ >. Acesso em: 10 abr. 2017.

Parque Tecnológico Ulbratech. Rede ULBRA de Inovação. Disponível em < http://ulbratech.com.br/v1/ >. Acesso em: 10 abr. 2017.

Phan, P.; Siegel, D.; Wright, M. Science parks and incubators: observations, synthesis, and future research. Journal of Business Venturing, v. 20, n.2, p. 165$182,2005$.

Ratinho, T.; Henriques, E. The role of science parks and business incubators in converging countries: Evidence from Portugal. Technovation, v. 30, p. 278-290, 2010 .

Rede Gaúcha de Incubadoras de Empresas e Parques Tecnológicos (Reginp). O que é?. Disponível em: < http://www.reginp.org.br/?page_id=3 >. Acesso em: 10 abr. 2017.

Ribeiro, L. M.; Botelho, S. S.C.; Filho, N. D. Avaliando a Estratégia do Parque Tecnológico OCEANTEC a Partir da Utilização da Ferramenta Estrategigrama. In: IX Simpósio de Excelência em Gestão e Tecnologia, 2012.

Rodrígues-Pose, A.; Hardy, D. Technology and Industrial Parks in Emerging Countries: Panacea or Pipedream? 1.ed. London: Springer International Publishing, 2014, 115p.

Roglinger, M. J.; Becker, P.J. Maturity models in business process management. Business Process Management Journal, v. 18, p. 328-346, 2012.

Sera, Y.; Beaudry, S. Monitoring \& Evaluation. Social Development Department, The World Bank, 2007.

Sindicato das Indústrias de Aparelhos Elétricos, Eletrônicos e Similares do Vale da Eletrônica (Sindvel). Sul de Minas vai ganhar parque tecnológico com 50 empresas. Disponível em: < http://www.sindvel.com.br/sala-deimprensa/noticias/520/sul-de-minas-vai-ganhar-parque-tecnologico-com-50empresas>. Acesso em: 10 abr. 2017.

Sindicato das Indústrias de Aparelhos Elétricos, Eletrônicos e Similares do Vale da Eletrônica (Sindvel). APL Eletrônica de Santa Rita do Sapucaí. Disponível em: <http://www.sindvel.com.br/o-vale-da-eletronica/apl-eletroeletronico>. Acesso em: 10 abr. 2017. 
Staton, M. Science park evaluation and goal oriented project planning, In: GUY, K. (Ed.) The Science Park Evaluation Handbook. Technopolis Group. European Innovation Monitoring System (EIMS), v. 61, p. 29-41, 1996.

Steiner, J. E.; Cassim, M. B.; Robazzi, A. C. Parques tecnológicos: ambientes de inovação. Instituto de Estudos Avançados da Universidade de São Paulo, 2008.

Strauss, A., Schatzman, L., Ehrlich, D., Bucher, R.; Sabshin, M. (1963). The hospital and its negotiated order. In E. Friedson (Org.). The hospital in modern society (pp. 147-169). Londres: The Free Press of Glencoe, 1963.

Telechea, P. S. A contribuição das empresas instaladas para as competências organizacionais de um parque tecnológico: o caso do TECNOPUC. Porto Alegre, 2011, Dissertação de Mestrado - Faculdade de Administração, Contabilidade e Economia, 2011.

Trist, E. L. The evolution of socio-technical systems: a conceptual framework and an action research program. Occasional Paper (2). Ontario Quality of Working Life Centre, Toronto, Ontario, 1981.

United Nations Children's Fund. Unicef. Monitoring and Evaluation, In: Unicef (Eds.) Programme Policy and Procedure Manual. New York: Unicef, 2005.

United Nations Development Programme. UNDP. Handbook on Planning, Monitoring and Evaluating for Development Results. New York: UNDP, 2009.

United Nations Educational, Scientific and Cultural Organization. Unesco. Science parks around the world. 2016. Disponível em: $<$ http://www.unesco.org/new/en/natural-sciences/science-technology/universityindustry-partnerships/science-parks-around-the-world/> . Acesso em: 10 abr. 2017.

Vedovello, C. A. Aspectos relevantes de parques tecnológicos e incubadoras de empresas. Revista do BNDES, v. 7, n. 14, p. 273-300, 2000.

Vedovello, C. A.; Judice, V. M. M.; Maculan, A.-M. D. Revisão crítica às abordagens a parques tecnológicos: alternativas interpretativas às experiências brasileiras recentes. RAI: Revista de Administração e Inovação, v. 3, n. 2, p. 103-118, 2006.

Vikström, M. The Strategigram - development and critical analysis. Lahti University of Applied Sciences, 2006.

W. K. Kellogg Foundation. Logic model development guide: using logic models to bring together planning, evaluation, and action. Michigan: W. K. Kellog Foundation, 2004. 
Wang, G.; Wan, J.; Zhao, L. Strategy map for chinese science parks with KPIs of BSC, Journal of Science and Technology Policy Management, v. 5 n. 2, p. 82$105,2014$.

Zieliński, M.; Rogala, A.; Takemura, M. Business model of science and technology parks: Comparison of European Best Practice. The Bulletin of the Faculty of Commerce Meiji University, Meiji: Meiji University Press, n.1, p. 15-28, 2014.

Zouain, D. M. Parques tecnológicos: propondo um modelo conceitual para regiões urbanas - o Parque Tecnológico de São Paulo. 2003, 261 p. Tese (Doutorado). Instituto de Pesquisas Energéticas e Nucleares, Universidade de São Paulo. São Paulo, 2003. 